\title{
Imagens de Tomografia por Potencial Aplicado em Tempo Real
}

Roberto Masaishi Santos Yoshikawa

DISSERTAÇÃO APRESENTADA

AO

INSTITUTO DE MATEMÁTICA E ESTATÍSTICA

DA

UNIVERSIDADE DE SÃO PAULO

PARA

OBTENÇÃO DO GRAU DE MESTRE

$\mathrm{EM}$

MATEMÁTICA APLICADA

Área de Concentração: Análise Numérica

Orientador: Profa. Dra. Joyce da Silva Bevilacqua

-São Paulo, maio de 2005 - 
Aos meus pais Ana e Geraldo e aos meus irmãos Alfredo, Alessandro, Mitiko e Chimaso 


\section{Agradecimentos}

De todos os professores que tive ao longo da vida, dois deles merecem toda a minha gratidão: Prof. Alexandre Megiorin Roma e Profa. Joyce da Silva Bevilacqua.

Prof. Roma foi meu primeiro orientador na vida acadêmica e, desde o começo, demonstrou acreditar e confiar em mim. Sua opinião foi muito importante para que eu começasse minha vida na pós-graduação.

Profa. Joyce acompanhou meus primeiros passos com o Prof. Roma e também sempre me incentivou a continuar meu trabalho na vida acadêmica, levando-me a conhecer não só a visão científica dos matemáticos como o ponto de vista de outras áreas como a Engenharia e a Medicina. Além de tudo, foi uma ótima conselheira profissional e pessoal.

Graças a professores como eles, os alunos de hoje e de amanhã da Matemática Aplicada podem explorar campos além daqueles encontrados nos livros e teoremas.

Gostaria de agradecer também a outras pessoas que foram importantes para o desenvolvimento desta dissertação:

Ao Prof. Dr. Marcelo Britto Passos Amato e sua equipe do Laboratório de Pneumologia da Faculdade de Medicina da USP, que forneceu uma aplicação clínica para o trabalho apresentado aqui e forneceu dados experimentis importantes para os testes realizados aqui.

Ao Prof. Dr. Raul Gonzalez Lima e sua equipe do Departamento de Engenharia Mecânica da Escola Politécnica da USP por fornecer o programa simulador de voltagens utilizado na validação do programa.

Ao amigo e colega Guilherme Molina Benites que, nos momentos finais, ajudou na revisão do texto.

À empresa RiskOffice, especialmente para Fernando Lovisotto, que me deram condições de terminar este trabalho.

Finalmente, a amigos e professores da Universidade de São Paulo que, de uma forma ou de outra, compartilharam o desenvolvimento deste trabalho: Prof. Dr. Nelson Mugayar Kuhl, Alexandre Lymberopoulos, Prof. Dr. Daniel Victor Tausk, Profa. Dra. Mary Lillian Lourenço, Prof. Dr. Plínio Amarante Quirino Simões, Prof. Dr. Takeshi Sato, Prof. Dr. Elói Medina Galego, Saul Sebastian Orozco Gallegos, Edward Mitsuo Iwanaga Iamamoto, Henry Kiyoshi Oyagawa, Sérgio Augusto Malacrida Jr., Rodnei Roberto da Silva, Silvio Rodrigues de Faria Jr., Janaína de Azevedo Perez, Claudia de Lello Courtouké Guedes, Rudimar Luiz Nos, Olga Harumi Saito entre outros aos quais peço perdão por não ter mencionado. 


\section{Resumo}

A Tomografia por Potencial Aplicado representa uma alternativa para o diagnóstico médico de pacientes à beira do leito. A partir de leituras de voltagens medidas na superfície de uma secção transversal do corpo humano, o perfil de condutividades do interior da seç̧ão é reconstruído e, consequentemente, uma imagem dos tecidos humanos presentes é obtida. Neste trabalho, apresentamos um algoritmo de reconstrução, chamado de BackProjection, partindo de um modelo eletrostático, passando por sua implementação numérica e analisando alternativas como filtros de dados e imagem final para melhorar a qualidade dos resultados. Durante o desenvolvimento, serão levantadas questões conflitantes sobre precisão e velocidade, relacionadas ao uso prático do algoritmo em aplicações do mundo real, como aplicações médicas.

\section{Abstract}

The Applied Potential Tomography represents a choice for bedside medical diagnosis of patients. From boundary voltage measures taken on a transversal section of a human body, the condutivity profile of the interior of the section is reconstructed and, consequently, an image of the actual human tissues is obtained. In this work, we present a reconstruction algorithm, called BackProjection, starting from an electrostatic model, passing through its numerical implementation and analyzing alternatives like data and image filters to improve the quality of the results. During the algorithm development, it will be raised conflicting questions involving precision and speed, related to the practical use of the algorithm in real world application, as medical applications. 


\section{Introdução}

Quando Allan Cormack, sul-africano, bacharel e mestre em Física pela Universidade de Cape Town (África do Sul) e professor da Tufts University (Massachusetts, EUA), e Godfrey Hounsfield, inglês, engenheiro elétrico da EMI Ltd. (Inglaterra), receberam o Prêmio Nobel de Medicina em 1979 pela inveção da tomografia computadorizada, o mundo reconhecia ali uma revolução no diagnóstico médico. A possibilidade de se obter uma "foto" interna de uma seção do corpo de um ser humano com uma excelente qualidade, sem se aplicar um corte sequer na superfície do corpo, trouxe novas perspectivas a médicos e pacientes no mundo todo.

A nova técnica era uma sucessora do já então conhecido Raio X, através do qual uma imagem dos ossos de uma pessoa e objetos estranhos no corpo já era possível. Faltava, porém, a possibilidade de visualização de tecidos como os músculos, pulmões e outros órgãos internos.

Descontente com os resultados fornecidos pelo Raio X, Cormack empenhou-se em estudar o problema de reconstrução. Ele intuiu que, a partir das medidas de variação de energia vinda da emissão dos raios através do corpo, poder-se-ia melhorar o diagnóstico feito até então através de impressões em chapas. Tal variação seria a soma de pequenas variações ocorridas em toda a trajetória do raio. No começo dos anos 60, Cormack conseguiu desenvolver modelos matemáticos que permitiriam a reconstrução de uma seção transversal do corpo a partir de medidas da superfície. A reconstrução ainda era baseada na técnica de Raio X, mas não havia até então nenhum equipamento nos moldes idealizados por Cormack que pudesse ser utilizado para transformar seu método em um processo prático e industrial. Seu modelo requeria um massa considerável de dados, tomados de diversos ângulos de um paciente. Cormack também sugeriu que fossem utilizados prótons ao invés de Raios X, pois permitiam detectar variações de energia menores, o que facilitaria a visualização de tecidos humanos além dos ossos.

Foi quando, no início dos anos 70, surgiu o primeiro sistema de tomografia prático, feito por Hounsfield. O sistema havia sido idealizado para diagnósticos do crânio e do cérebro, e era composto por um tubo de emissão de raios $\mathrm{X}$ e de um conjunto de detectores colocados 
de forma diametralmente oposta ao tubo em relação à cabeça do paciente, ambos apoiados em uma roda que os permitia girar ao redor da cabeça. O equipamento de Hounsfield foi desenvolvido de forma totalmente independente dos trabalhos de Cormack, mas permitia uma implementação completa do trabalho do sul-africano.

Nascia, assim, a tomografia computadorizada. Como disse Torgny Greitz, professor da Karolina Medico-Chirurgical Institute (Suécia) no discurso de apresentação do prêmio Nobel de 1979, "Até aquele momento, observações normais por Raio X da cabeça mostravam os ossos do crânio, mas o cérebro permanecia uma névoa cinza, indiferenciável. Agora, repentinamente, a névoa clareou".

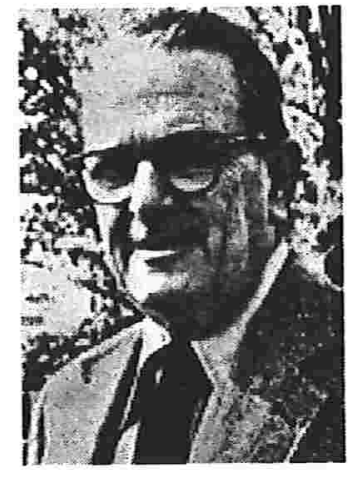

Allan Cormack

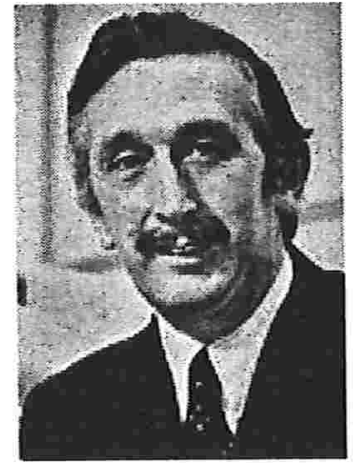

Godfrey Hounsfield

$\star 1919-\dagger 2004$

Em termos de precisão de imagens, a tomografia computadorizada permanece entre as técnicas que fornecem as imagens mais nítidas no mercado. Entretanto, a pouca mobilidade e a não aplicabilidade para o monitoramento contínuo ou acompanhamento de outras situações como, por exemplo, o crescimento de fetos, levou ao desenvolvimento de outros métodos que, apesar de serem inspirados no princípio da tomografia, fornecem imagens através de outros meios como ultra-som e eletromagnetismo. Equipamentos como o Ultra-som tiveram um ganho significativo de qualidade nos últimos anos, mas ainda estão longe da qualidade da tomografia.

Quando levamos em consideração acompanhamento de pacientes na UTI, surgem outras preocupações. Há a necessidade do monitoramento contínuo do estado do paciente. Além disso, o paciente, por estar em situação grave, não pode ser deslocado de seu leito sem correr riscos de piorar sua situação, pois ele depende de outros equipamentos e medicação para estabilizar seu quadro médico. A maioria dos métodos citados não permite um monitoramento contínuo, seja pelo tempo e forma como o diagnóstico é feito, seja pelos danos que possam ser causados ao paciente pela exposição contínua aos materiais usados. 
Um método alternativo, que vem sendo amplamente pesquisado e que será o objeto de nosso estudo, é a Tomografia por Potencial Aplicado. Nela, a emissão de raios será substituída pela injeção de corrente elétrica, muito menos nociva ao corpo humano e muito mais acessível como meio de diagnóstico, tanto por questões financeiras quanto por meios práticos de utilização. O princípio de reconstrução é semelhante ao da tomografia computadorizada, tanto na geometria quanto na álgebra do processo.

Atualmente, há poucos protótipos com relativo sucesso e apenas um caso de equipamento disponível para uso médico, implementado pela Universidade de Sheffield (Inglaterra). Porém, por fornecer imagens de qualidade muito inferior às de qualquer equipamento médico e por apenas indicar onde ocorreu variação de condutividade, sua aplicabilidade fica reduzida.

Uma das técnicas médicas a ser beneficiada por esse equipamento seria a ventilação mecânica. Para o controle do volume de ar no pulmão de um paciente, o médico utiliza medidas globais, como resistência e complacência, para adequar o volume necessário para o tratamento do paciente. Com um equipamento que permitisse visualizar o interior do tórax, seria possível observar a distribuição de ar.

O equipamento para Tomografia por Potencial Aplicado consiste em uma cinta que possui eletrodos igualmente espaçados em sua superfície interior. A cinta é colocada em uma seção tranversal do paciente, por exemplo, no tórax, e a injeção é feita sempre através de um par de eletrodos, um injetando efetivamente corrente elétrica e o outro aterrado, gerando um campo elétrico no interior do corpo do paciente. A leitura do potencial feita nos outros eletrodos são a base para a reconstrução da imagem interior.

Há dificuldades tanto na construção da máquina quanto do algoritmo de reconstrução de imagens. A medição do potencial elétrico precisa ser muito bem trabalhada em função do ruído que se espera obter nesse experimento: tanto o próprio corpo humano quanto o ambiente em que o paciente se encontra possuem campos eletro-magnéticos que podem gerar erros nas medidas, que serão invariavelmente propagados pelo algoritmo.

Em termos do algoritmo, há dificuldades naturais do processo. O domínio e o meio são variáveis e dependem do paciente. Mesmo assumindo que trabalharemos apenas em determinada seç̧ão transversal do corpo humano, essa região terá formas diferentes para pessoas diferentes. Os tecidos também poderão variar de condutividade, dependendo do estado em que se encontram. Para tanto, precisaremos assumir hipóteses restritivas sobre o problema, que nos ajudarão a implementar a solução sem perda de informação necessária a um diagnóstico médico primário.

A proposta deste trabalho é estudar uma implementação viável do algoritmo de recons- 
trução da imagem de tomografia. Por implentação viável, entende-se um algoritmo que concilie uma reconstrução rápida, que permite o monitoramento contínuo do paciente e a visualização dos tecidos encontrados na secção transversal analisada, suas variações de volume e o valor de sua condutividade. 


\section{Sumário}

1 Diagnóstico Médico por Imagens 25

1.1 Raios X . . . . . . . . . . . . . . . . . . . 26

1.2 Tomografia Computadorizada . . . . . . . . . . . . . . . . 28

1.3 Princípio do BackProjection . . . . . . . . . . . . . . . . . . . . . . 32

1.4 BackProjection e a Tomografia por Potencial Aplicado . . . . . . . . . . . . 39

1.5 Ventilação Mecânica . . . . . . . . . . . . . . . . . . . . . . 45

2 Eletrostática aplicada à obtenção de imagens $\quad 48$

2.1 Aplicação das Equações de Maxwell . . . . . . . . . . . . . . . . . . . . . . . . 48

2.2 Condições de Compatibilidade . . . . . . . . . . . . . . . . . . . . 51

2.3 Linearização do Problema Eletrostático . . . . . . . . . . . . . . . . . . . 52

2.4 Potencial de uma carga puntiforme no espaço . . . . . . . . . . . . . . . 54

2.5 Potencial bidimensional . . . . . . . . . . . . . . . . . . . 55

2.5 .1 Lei de Gauss . . . . . . . . . . . . . . . . . . . . 55

2.5.2 Potencial de uma linha infinita de cargas . . . . . . . . . . . . 56

2.6 Dipolo Elétrico . . . . . . . . . . . . . . . . . . . . . . . . . . . . . . . 58

2.6.1 Aproximação para o potencial do dipolo . . . . . . . . . . . . . . 59

2.6 .2 Dipolo na bola unitária . . . . . . . . . . . . . . . . . 61

2.7 Cálculo do BackProjection . . . . . . . . . . . . . . . . . . . . 63

3 Implementação Numérica $\quad 68$

3.1 Discretização da Integral do BackProjection . . . . . . . . . . . . . . . . . 70

3.2 Cálculo da grandeza $W \ldots \ldots \ldots \ldots \ldots$

3.3 Algoritmo Preliminar . . . . . . . . . . . . . . . . . . . 75

3.4 Pré-filtro dos dados de entrada . . . . . . . . . . . . . . . . . 80

3.5 Interpolação de Dipolos e Eletrodos . . . . . . . . . . . . . . . . . . 88

3.6 Um Filtro Pós-Processamento: Média da Vizinhança . . . . . . . . . . . . . 92 


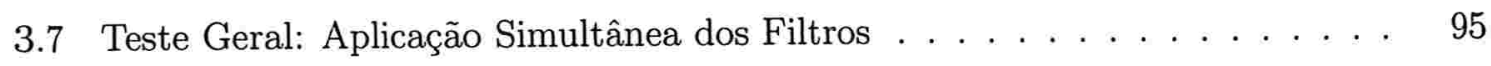

3.8 Algoritmo Completo . . . . . . . . . . . . . . . . . 96

4 Resultados 100

4.1 Tempos de Processamento . . . . . . . . . . . . . . . . . . . . . 100

4.2 Variação de Condutividade para um Único Objeto . . . . . . . . . . . . . . . 102

4.2.1 Condutividade $(1.003 \mathrm{Ohm}-\mathrm{m})^{-1} \ldots \ldots \ldots \ldots$

4.2 .2 Condutividade $(1.016 \mathrm{Ohm}-\mathrm{m})^{-1} \ldots \ldots \ldots \ldots$

4.2 .3 Condutividade $(1.16 \mathrm{Ohm}-\mathrm{m})^{-1} \ldots \ldots \ldots \ldots$

4.2 .4 Condutividade $(1.32 \mathrm{Ohm}-\mathrm{m})^{-1} \ldots \ldots \ldots$. . . . . . . . . 109

4.3 Variação de Condutividade para um Par de Objetos . . . . . . . . . . . . . . 112

4.3 .1 Condutividade $(1.003 \mathrm{Ohm}-\mathrm{m})^{-1} \ldots \ldots \ldots \ldots$

4.3 .2 Condutividade $(1.016 \mathrm{Ohm}-\mathrm{m})^{-1} \ldots \ldots \ldots \ldots \ldots$

4.3 .3 Condutividade $(1.16 \mathrm{Ohm}-\mathrm{m})^{-1} \ldots \ldots \ldots \ldots \ldots$

4.3 .4 Condutividade $(1.32 \mathrm{Ohm}-\mathrm{m})^{-1} \ldots \ldots \ldots \ldots$

4.4 Par de Objetos com Condutividades Diferentes . . . . . . . . . . . . . . 123

4.4.1 Condutividades $(1.003 \mathrm{Ohm}-\mathrm{m})^{-1}$ e $1.003(\mathrm{Ohm}-\mathrm{m})^{-1} \ldots \ldots . . . \quad 124$

4.4.2 Condutividades $(1.016 \mathrm{Ohm}-\mathrm{m})^{-1}$ e $1.016(\mathrm{Ohm}-\mathrm{m})^{-1} \ldots \ldots . . . .126$

4.4.3 Condutividades $(1.16 \mathrm{Ohm}-\mathrm{m})^{-1}$ e $1.16(\mathrm{Ohm}-\mathrm{m})^{-1} \ldots \ldots . . . .128$

4.4.4 Condutividades $(1.32 \mathrm{Ohm}-\mathrm{m})^{-1}$ e $1.32(\mathrm{Ohm}-\mathrm{m})^{-1} \ldots \ldots . . . . .130$

4.5 Reconstrução de acordo com a posição do objeto . . . . . . . . . . . . . . . . 134

4.6 Teste: Geometria do Pulmão . . . . . . . . . . . . . . . . . . . . . . . . 140

4.7 Dados Experimentais: Tanque com Solução Salina . . . . . . . . . . . . . . 143

4.7.1 Deslocamento do cilindro de $1 \mathrm{~cm}$ de raio . . . . . . . . . . . . . . 146

4.7 .2 Deslocamento do cilindro de $3 \mathrm{~cm}$ de raio . . . . . . . . . . . . . . 149

4.7 .3 Deslocamento do cilindro de $6 \mathrm{~cm}$ de raio . . . . . . . . . . . . . 152

4.8 Dados Experimentais: Sr. Porco . . . . . . . . . . . . . . . 156

$\begin{array}{ll}\text { Conclusão e Trabalhos Futuros } & 161\end{array}$

A Determinação do ponto de fronteira 165 


\section{Lista de Tabelas}

3.1 Valores de $\mathrm{x}^{f}$ para diferentes posições do dipolo . . . . . . . . . . . . . . 71

3.2 Valores de voltagens esperados pela equação $2.53 \ldots \ldots$. . . . . . . . . . 82

3.3 Comparação dos filtros aplicados aos dados de entrada (valores multiplicados

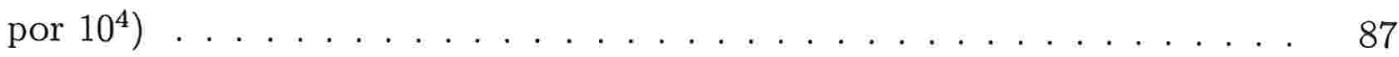

3.4 Comparação da Interpolação de Dipolos (valores multiplicados por $10^{4}$ ) . . . 92

3.5 Comparação da Aplicação do Filtro da Vizinhança 5x5 (valores multiplicados

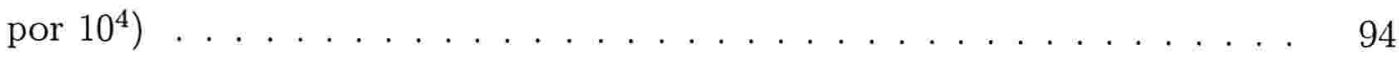

4.1 Reconstrução de Imagens $64 x 64$ pixels - tempos em segundos . . . . . . . . . 101

4.2 Reconstrução de Imagens 128x128 pixels - tempos em segundos . . . . . . . 101

4.3 Teste -1 Objeto de Condutividade $(1.003 \mathrm{Ohm}-\mathrm{m})^{-1}$. . . . . . . . . . . 111

4.4 Teste -1 Objeto de Condutividade $(1.016 \mathrm{Ohm}-\mathrm{m})^{-1} \ldots \ldots \ldots 111$

4.5 Teste -1 Objeto de Condutividade $(1.16 \mathrm{Ohm}-\mathrm{m})^{-1} \ldots \ldots \ldots . \ldots 111$

4.6 Teste - 1 Objeto de Condutividade $(1.32 \mathrm{Ohm}-\mathrm{m})^{-1} \ldots \ldots \ldots 111$

4.7 Comparativos do Valor Esperado com o Reconstruído . . . . . . . . . . . . . 112

4.8 Teste - Par de Objetos de Condutividade $(1.003 \mathrm{Ohm}-\mathrm{m})^{-1}$ - . . . . . . . 121

4.9 Teste - Par de Objetos de Condutividade $(1.016 \mathrm{Ohm}-\mathrm{m})^{-1} \ldots \ldots$. . . . . 121

4.10 Teste - Par de Objetos de Condutividade $(1.16 \mathrm{Ohm}-\mathrm{m})^{-1} \ldots \ldots$. . . . . . 121

4.11 Teste - Par de Objetos de Condutividade $(1.32 \mathrm{Ohm}-\mathrm{m})^{-1} \ldots \ldots . . . . .2121$

4.12 Comparativos do Valor do Vale com os Picos . . . . . . . . . . . . . . . . . 122

4.13 Valores esperados de reconstrução . . . . . . . . . . . . . . . . . . . . . . . 123

4.14 Teste - Par de Objetos de Condutividade (1.003 Ohm-m) $)^{-1}$ e $1.003(\mathrm{Ohm}-\mathrm{m})^{-1} 132$

4.15 Teste - Par de Objetos de Condutividade (1.016 Ohm-m) $)^{-1}$ e $1.016(\mathrm{Ohm}-\mathrm{m})^{-1} 132$

4.16 Teste - Par de Objetos de Condutividade (1.16 Ohm-m) $)^{-1}$ e $1.16(\mathrm{Ohm}-\mathrm{m})^{-1} 132$

4.17 Teste - Par de Objetos de Condutividade (1.32 Ohm-m) $)^{-1}$ e $1.32(\mathrm{Ohm}-\mathrm{m})^{-1} 132$

4.18 Comparativos dos Valores Esperados com os Reconstruídos . . . . . . . . . 133

4.19 Resultados - Deslocamento de objeto de $(1.016 \mathrm{Ohm}-\mathrm{m})^{-1}$ pelo domínio . . . 138 
4.20 Condutividades dos tecidos . . . . . . . . . . . . . . . . . . . 140

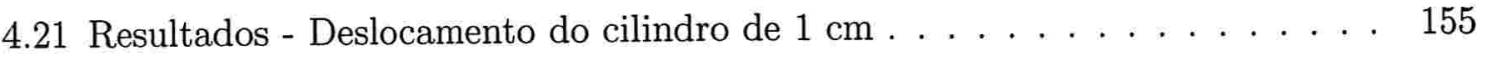

4.22 Resultados - Deslocamento do cilindro de $3 \mathrm{~cm} \ldots \ldots \ldots \ldots$

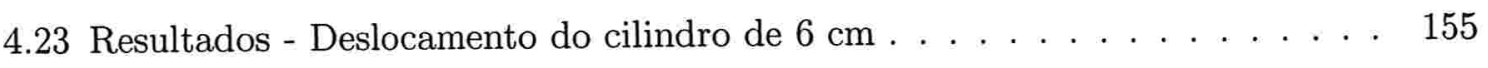

4.24 Resultados - Coleta de Dados no Porco . . . . . . . . . . . . . . . . . . 159 


\section{Lista de Figuras}

1.1 Objeto teste colocado entre um tubo de emissão e uma placa de detectores. . 28

1.2 Esquema da emissão de raios através do objeto teste. . . . . . . . . . . . . 29

1.3 Objeto teste colocado mais próximo ou mais afastado do tubo de emissão. . 29

1.4 Objetos teste de formas diferentes produzem a mesma imagem. . . . . . . . 30

1.5 Objeto teste fotografado a partir de nova posição do tubo. . . . . . . . . . . 30

1.6 Melhoria na determinação da forma do objeto teste. . . . . . . . . . . . . . . 31

1.7 Esquema de tomada de dados na Tomografia Computadorizada. . . . . . . . 31

1.8 Domínio de teste no exemplo do BackProjection. . . . . . . . . . . . . 33

1.9 Domínio Teste - Posição $90^{0}$ dos emissores . . . . . . . . . . . . . . . 33

1.10 Domínio Teste - Posição $135^{0}$ dos emissores . . . . . . . . . . . . . . . . . . . 34

1.11 Domínio Teste - Posição $180^{0}$ dos emissores . . . . . . . . . . . . . . . . . . 34

1.12 Domínio Teste - Posição $225^{0}$ dos emissores . . . . . . . . . . . . . . . . 35

1.13 Domínio Teste - Posição $270^{0}$ dos emissores . . . . . . . . . . . . . . . 35

1.14 Domínio Teste - Posição $315^{0}$ dos emissores . . . . . . . . . . . . . . 36

1.15 Domínio Teste - Posição $0^{0}$ dos emissores . . . . . . . . . . . . . . 36

1.16 Domínio Teste - Posição $45^{0}$ dos emissores . . . . . . . . . . . . . . . . 37

1.17 Visão final do algoritmo sobre o domínio teste. . . . . . . . . . . . . . . . 37

1.18 Superfície representando o domínio original. . . . . . . . . . . . . . . . . . . 38

1.19 Superfície representando o domínio reconstruído. . . . . . . . . . . . . . . 38

1.20 Trajetória dos elétrons . . . . . . . . . . . . . . . . . . 40

1.21 Linhas equipotenciais devidas ao potencial gerado por duas cargas opostas . 40

1.22 Posição do Dipolo em relação às duas cargas . . . . . . . . . . . . . . . . . . 40

1.23 Linhas equipotenciais e linhas de trajetória no modelo de dipolo. . . . . . . . 41

1.24 Esquema do Experimento. . . . . . . . . . . . . . . . . . . 41

1.25 Linhas de trajetória no domínio de interesse . . . . . . . . . . . . . . . 42

1.26 Equipotenciais no domínio de interesse. . . . . . . . . . . . . . . . . . . 42 
1.27 Eletrodos colocados ao redor do domínio para medição do potencial. . . . . . 42

1.28 Princípio do BackProjection aplicado à TPA . . . . . . . . . . . . . . . . . . . . 44

1.29 Curva Pressão-Volume de um rato. . . . . . . . . . . . . . . . . . 46

2.1 Superposição de campos . . . . . . . . . . . . . . . . . . . 56

2.2 Superfície auxiliar para o uso da Lei de Gauss . . . . . . . . . . . . . . 57

2.3 Transformação conforme entre o domínio $\Omega$ e o semi-plano $\left\{v_{\omega}>1 / 2\right\} \ldots 63$

3.1 Linha equipotencial utilizada no cálculo de $W(\mathbf{s}, \omega) \ldots \ldots \ldots$

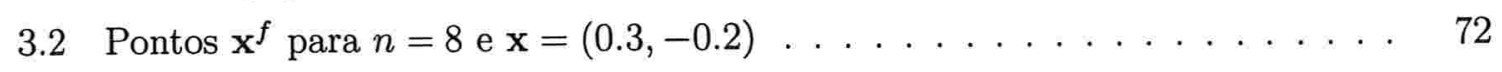

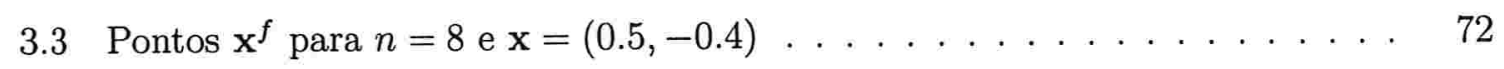

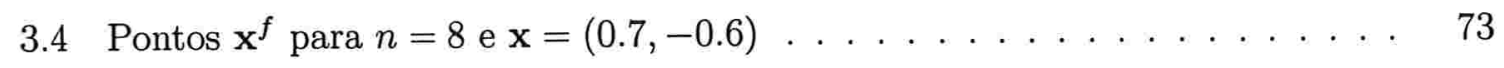

3.5 Disposição dos eletrodos para $n=8$ e $\omega_{0}=0 \ldots \ldots \ldots \ldots$

3.6 Tela do Programa Simulador de Voltagens . . . . . . . . . . . . . . 78

3.7 Problema Teste para o Algoritmo $1 \ldots \ldots$. . . . . . . . 78

3.8 Visão Tridimensional dos Resultados do Teste Inicial - Algoritmo 1 . . . . . 79

3.9 Visão Bidimensional dos Resultados do Teste Inicial - Algoritmo 1 . . . . . 79

3.10 Comparação do Resultado do Teste Inicial com a Posição Real do Objeto Algoritmo $1 \ldots \ldots \ldots \ldots$. . . . . . . . . . . . . . . . . . . . . . . . 80

3.11 Perfil das Voltagens Esperadas Reescalonadas . . . . . . . . . . . . . 83

3.12 Valores do perfil de voltagens a serem estimados . . . . . . . . . . . . . 83

3.13 Extrapolação dos Valores de Voltagens . . . . . . . . . . . . . . . . 84

3.14 Reconstrução a partir de dados com ruído gaussiano $O\left(10^{-4}\right) \ldots \ldots$. . . . 85

3.15 Reconstrução a partir de dados com ruído gaussiano $O\left(10^{-4}\right)(2) \ldots \ldots$

3.16 Reconstrução a partir de dados com ruído gaussiano $O\left(10^{-4}\right)$ - Apenas com a suavização polinomial dos extremos . . . . . . . . . . . 86

3.17 Reconstrução a partir de dados com ruído gaussiano $O\left(10^{-4}\right)$ - Apenas com a suavização polinomial dos extremos $(2) \ldots \ldots \ldots$. . . . . . . 86

3.18 Reconstrução a partir de dados com ruído gaussiano $O\left(10^{-4}\right)$ - Aplicação dos Filtros . . . . . . . . . . . . . . . . 86

3.19 Reconstrução a partir de dados com ruído gaussiano $O\left(10^{-4}\right)$ - Aplicação dos Filtros $(2) \ldots \ldots \ldots \ldots \ldots$. . . . . . . . . . . . . . . . . . . 87

3.20 Interpolação de Dipolos - Passos na Expansão da matriz $\left[W_{k, i}\right] \ldots \ldots$. . . . 89

3.21 Interpolação de Dipolos - Expansão da matriz $\left[W_{k, i}\right]$ para $64 \times 64 \ldots \ldots$

3.22 Interpolação de Dipolos - Expansão da matriz $\left[W_{k, i}\right]$ para $64 x 64(2) \ldots \ldots$ 
3.23 Interpolação de Dipolos - Expansão da matriz $\left[W_{k, i}\right]$ para $128 \times 128 \ldots$. . . . . 91

3.24 Interpolação de Dipolos - Expansão da matriz $\left[W_{k, i}\right]$ para $128 \times 128(2)$. . . . 91

3.25 Filtro da Vizinhança - Passos da Implementação . . . . . . . . . . . . . . . . 93

3.26 Aplicação do Filtro da Vizinhança $5 \times 5$. . . . . . . . . . . . . . . . . . . . 94

3.27 Aplicação do Filtro da Vizinhança $5 \times 5$ (2) . . . . . . . . . . . . . . . . . . 94

3.28 Aplicação Simultânea dos Filtros . . . . . . . . . . . . . . . . . . . 95

3.29 Aplicação Simultânea dos Filtros (2) . . . . . . . . . . . . . . . 96

4.1 Visão Tridimensional - Objeto com $(1.003 \mathrm{Ohm}-\mathrm{m})^{-1}-32$ Eletrodos . . . . . 103

4.2 Perfil - Objeto com (1.003 Ohm-m) $)^{-1}-32$ Eletrodos . . . . . . . . . . . . 103

4.3 Visão Bidimensional - Objeto com $(1.003 \mathrm{Ohm}-\mathrm{m})^{-1}-32$ Eletrodos . . . . . 103

4.4 Visão Tridimensional - Objeto com $(1.003 \mathrm{Ohm}-\mathrm{m})^{-1}-128$ Eletrodos . . . . 104

4.5 Perfil - Objeto com $(1.003 \text { Ohm-m })^{-1}-128$ Eletrodos . . . . . . . . . . . . . 104

4.6 Visão Bidimensional - Objeto com (1.003 Ohm-m) $)^{-1}-128$ Eletrodos . . . . . 104

4.7 Visão Tridimensional - Objeto com $(1.016 \mathrm{Ohm}-\mathrm{m})^{-1}-32$ Eletrodos . . . . . 105

4.8 Perfil - Objeto com $(1.016 \text { Ohm-m) })^{-1}-32$ Eletrodos . . . . . . . . . . . . . 105

4.9 Visão Bidimensional - Objeto com $(1.016 \mathrm{Ohm}-\mathrm{m})^{-1}-32$ Eletrodos . . . . . 105

4.10 Visão Tridimensional - Objeto com $(1.016 \mathrm{Ohm}-\mathrm{m})^{-1}-128$ Eletrodos . . . . 106

4.11 Perfil - Objeto com (1.016 Ohm-m) $)^{-1}-128$ Eletrodos . . . . . . . . . . . 106

4.12 Visão Bidimensional - Objeto com $(1.016 \mathrm{Ohm}-\mathrm{m})^{-1}-128$ Eletrodos . . . . . 106

4.13 Visão Tridimensional - Objeto com $(1.16 \mathrm{Ohm}-\mathrm{m})^{-1}-32$ Eletrodos . . . . . 107

4.14 Perfil - Objeto com $(1.16 \text { Ohm-m })^{-1}-32$ Eletrodos . . . . . . . . . . . . 107

4.15 Visão Bidimensional - Objeto com (1.16 Ohm-m) $)^{-1}-32$ Eletrodos . . . . . . 107

4.16 Visão Tridimensional - Objeto com $(1.16 \mathrm{Ohm}-\mathrm{m})^{-1}-128$ Eletrodos . . . . . 108

4.17 Perfil - Objeto com $(1.16 \mathrm{Ohm}-\mathrm{m})^{-1}-128$ Eletrodos . . . . . . . . . . . . . 108

4.18 Visão Bidimensional - Objeto com $(1.16 \mathrm{Ohm}-\mathrm{m})^{-1}-128$ Eletrodos . . . . . 108

4.19 Visão Tridimensional - Objeto com $(1.32 \mathrm{Ohm}-\mathrm{m})^{-1}-32$ Eletrodos . . . . . 109

4.20 Perfil - Objeto com $(1.32 \text { Ohm-m) })^{-1}-32$ Eletrodos . . . . . . . . . . . . . 109

4.21 Visão Bidimensional - Objeto com $(1.32 \mathrm{Ohm}-\mathrm{m})^{-1}-32$ Eletrodos . . . . . . 109

4.22 Visão Tridimensional - Objeto com $(1.32 \mathrm{Ohm}-\mathrm{m})^{-1}-128$ Eletrodos . . . . . 110

4.23 Perfil - Objeto com $(1.32 \text { Ohm-m) })^{-1}-128$ Eletrodos . . . . . . . . . . . . . . 110

4.24 Visão Bidimensional - Objeto com $(1.32 \text { Ohm-m) })^{-1}-128$ Eletrodos . . . . . 110

4.25 Teste: Par de objetos diametralmente opostos . . . . . . . . . . . . . . . . 112

4.26 Visão Tridimensional - Par de Objetos com (1.003 Ohm-m $)^{-1}-32$ Eletrodos 113

4.27 Perfil - Par de Objetos com $(1.003 \text { Ohm-m) })^{-1}-32$ Eletrodos . . . . . . . . . 113 
4.28 Visão Bidimensional - Par de Objetos com (1.003 Ohm-m $)^{-1}-32$ Eletrodos . 113

4.29 Visão Tridimensional - Par de Objetos com $(1.003 \text { Ohm-m })^{-1}-128$ Eletrodos 114

4.30 Perfil - Par de Objetos com (1.003 Ohm-m) $)^{-1}-128$ Eletrodos . . . . . . . 114

4.31 Visão Bidimensional - Par de Objetos com $(1.003 \text { Ohm-m })^{-1}-128$ Eletrodos 114

4.32 Visão Tridimensional - Par de Objetos com $(1.016 \mathrm{Ohm}-\mathrm{m})^{-1}-32$ Eletrodos 115

4.33 Perfil - Par de Objetos com (1.016 Ohm-m) $)^{-1}-32$ Eletrodos . . . . . . . . 115

4.34 Visão Bidimensional - Par de Objetos com (1.016 Ohm-m $)^{-1}-32$ Eletrodos . 115

4.35 Visão Tridimensional - Par de Objetos com (1.016 Ohm-m) $)^{-1}-128$ Eletrodos 116

4.36 Perfil - Par de Objetos com (1.016 Ohm-m) $)^{-1}-128$ Eletrodos . . . . . . . 116

4.37 Visão Bidimensional - Par de Objetos com $(1.016 \mathrm{Ohm}-\mathrm{m})^{-1}-128$ Eletrodos 116

4.38 Visão Tridimensional - Par de Objetos com $(1.16 \mathrm{Ohm}-\mathrm{m})^{-1}-32$ Eletrodos . 117

4.39 Perfil - Par de Objetos com $(1.16 \text { Ohm-m) })^{-1}-32$ Eletrodos . . . . . . . . . 117

4.40 Visão Bidimensional - Par de Objetos com $(1.16 \mathrm{Ohm}-\mathrm{m})^{-1}-32$ Eletrodos . 117

4.41 Visão Tridimensional - Par de Objetos com $(1.16 \text { Ohm-m })^{-1}-128$ Eletrodos 118

4.42 Perfil - Par de Objetos com $(1.16 \text { Ohm-m) })^{-1}-128$ Eletrodos . . . . . . . . 118

4.43 Visão Bidimensional - Par de Objetos com $(1.16 \mathrm{Ohm}-\mathrm{m})^{-1}-128$ Eletrodos . 118

4.44 Visão Tridimensional - Par de Objetos com $(1.32 \text { Ohm-m })^{-1}-32$ Eletrodos . 119

4.45 Perfil - Par de Objetos com (1.32 Ohm-m) $)^{-1}-32$ Eletrodos . . . . . . . . . 119

4.46 Visão Bidimensional - Par de Objetos com $(1.32 \mathrm{Ohm}-\mathrm{m})^{-1}-32$ Eletrodos . 119

4.47 Visão Tridimensional - Par de Objetos com $(1.32 \mathrm{Ohm}-\mathrm{m})^{-1}-128$ Eletrodos 120

4.48 Perfil - Par de Objetos com $(1.32 \mathrm{Ohm}-\mathrm{m})^{-1}-128$ Eletrodos . . . . . . . 120

4.49 Visão Bidimensional - Par de Objetos com $(1.32 \text { Ohm-m })^{-1}-128$ Eletrodos . 120

4.50 Teste: Par de objetos diametralmente opostos com condutividades diferentes 123

4.51 Visão Tridimensional - Par de Objetos com $(1.003 \mathrm{Ohm}-\mathrm{m})^{-1}$ e 1.003 (Ohm$\mathrm{m})^{-1}-32$ Eletrodos . . . . . . . . . . . . . . . . . . . . 124

4.52 Perfil - Par de Objetos com (1.003 Ohm-m $)^{-1}$ e $1.003(\mathrm{Ohm}-\mathrm{m})^{-1}$ - 32 Eletrodos 124

4.53 Visão Bidimensional - Par de Objetos com (1.003 Ohm-m) $)^{-1}$ e 1.003 (Ohm$\mathrm{m})^{-1}-32$ Eletrodos . . . . . . . . . . . . . . . . . . . . 124

4.54 Visão Tridimensional - Par de Objetos com $(1.003 \text { Ohm-m) })^{-1}$ e 1.003 (Ohm$\mathrm{m})^{-1}-128$ Eletrodos . . . . . . . . . . . . . . . . . . 125

4.55 Perfil - Par de Objetos com (1.003 Ohm-m) $)^{-1}$ e $1.003(\mathrm{Ohm}-\mathrm{m})^{-1}-128$ Eletrodos 125

4.56 Visão Bidimensional - Par de Objetos com (1.003 Ohm-m) $)^{-1}$ e 1.003 (Ohm$\mathrm{m})^{-1}-128$ Eletrodos . . . . . . . . . . . . . . . . . 125 
4.57 Visão Tridimensional - Par de Objetos com (1.016 Ohm-m) $)^{-1}$ e 1.016 (Ohm$\mathrm{m})^{-1}-32$ Eletrodos . . . . . . . . . . . . . . . . . . 126

4.58 Perfil - Par de Objetos com (1.016 Ohm-m) $)^{-1}$ e $1.016(\mathrm{Ohm}-\mathrm{m})^{-1}-32$ Eletrodos 126

4.59 Visão Bidimensional - Par de Objetos com (1.016 Ohm-m) $)^{-1}$ e 1.016 (Ohm$\mathrm{m})^{-1}-32$ Eletrodos . . . . . . . . . . . . . . . . . 126

4.60 Visão Tridimensional - Par de Objetos com (1.016 Ohm-m) $)^{-1}$ e 1.016 (Ohm$\mathrm{m})^{-1}-128$ Eletrodos . . . . . . . . . . . . . . . . . . . 127

4.61 Perfil - Par de Objetos com (1.016 Ohm-m) $)^{-1}$ e 1.016 (Ohm-m) $)^{-1}-128$ Eletrodos 127

4.62 Visão Bidimensional - Par de Objetos com (1.016 Ohm-m) $)^{-1}$ e 1.016 (Ohm$\mathrm{m})^{-1}-128$ Eletrodos . . . . . . . . . . . . . . . . . . 127

4.63 Visão Tridimensional - Par de Objetos com $(1.16 \mathrm{Ohm}-\mathrm{m})^{-1}$ e $1.16(\mathrm{Ohm}-\mathrm{m})^{-1}$ - 32 Eletrodos . . . . . . . . . . . . . . . . . . . . . . 128

4.64 Perfil - Par de Objetos com (1.16 Ohm-m) $)^{-1}$ e $1.16(\mathrm{Ohm}-\mathrm{m})^{-1}$ - 32 Eletrodos 128

4.65 Visão Bidimensional - Par de Objetos com $(1.16 \mathrm{Ohm}-\mathrm{m})^{-1}$ e $1.16(\mathrm{Ohm}-\mathrm{m})^{-1}$ - 32 Eletrodos . . . . . . . . . . . . . . . . . . . . . . . 128

4.66 Visão Tridimensional - Par de Objetos com $(1.16 \mathrm{Ohm}-\mathrm{m})^{-1}$ e $1.16(\mathrm{Ohm}-\mathrm{m})^{-1}$ - 128 Eletrodos . . . . . . . . . . . . . . . . . . . . . . . . . . 129

4.67 Perfil - Par de Objetos com (1.16 Ohm-m) $)^{-1}$ e $1.16(\mathrm{Ohm}-\mathrm{m})^{-1}-128$ Eletrodos 129 4.68 Visão Bidimensional - Par de Objetos com $(1.16 \mathrm{Ohm}-\mathrm{m})^{-1}$ e $1.16(\mathrm{Ohm}-\mathrm{m})^{-1}$ - 128 Eletrodos . . . . . . . . . . . . . . . . . . . . . . . . . . . . 129

4.69 Visão Tridimensional - Par de Objetos com $(1.32 \mathrm{Ohm}-\mathrm{m})^{-1}$ e $1.32(\mathrm{Ohm}-\mathrm{m})^{-1}$ - 32 Eletrodos . . . . . . . . . . . . . . . . . . . . . . . . 130

4.70 Perfil - Par de Objetos com (1.32 Ohm-m $)^{-1}$ e $1.32(\mathrm{Ohm}-\mathrm{m})^{-1}$ - 32 Eletrodos 130

4.71 Visão Bidimensional - Par de Objetos com $(1.32 \mathrm{Ohm}-\mathrm{m})^{-1}$ e $1.32(\mathrm{Ohm}-\mathrm{m})^{-1}$ - 32 Eletrodos . . . . . . . . . . . . . . . . . . . . . . 130

4.72 Visão Tridimensional - Par de Objetos com $(1.32 \mathrm{Ohm}-\mathrm{m})^{-1}$ e $1.32(\mathrm{Ohm}-\mathrm{m})^{-1}$ - 128 Eletrodos . . . . . . . . . . . . . . . . . . . . . . . . . . 131

4.73 Perfil - Par de Objetos com (1.32 Ohm-m $)^{-1}$ e $1.32(\mathrm{Ohm}-\mathrm{m})^{-1}$ - 128 Eletrodos131

4.74 Visão Bidimensional - Par de Objetos com $(1.32 \mathrm{Ohm}-\mathrm{m})^{-1}$ e $1.32(\mathrm{Ohm}-\mathrm{m})^{-1}$ - 128 Eletrodos . . . . . . . . . . . . . . . . . . . . . . . 131

4.75 Teste: Deslocamento de objeto através do Domínio . . . . . . . . . . . . . . 134

4.76 Visão Tridimensional - Deslocamento de objeto de $(1.016 \mathrm{Ohm}-\mathrm{m})^{-1}$ através do domínio . . . . . . . . . . . . . . . . . . . . . . . 135

4.77 Perfil - Deslocamento de objeto de $(1.016 \mathrm{Ohm}-\mathrm{m})^{-1}$ através do domínio . . 136 
4.78 Perfil - Deslocamento de objeto de $(1.016 \mathrm{Ohm}-\mathrm{m})^{-1}$ através do domínio . . 137

4.79 Círculos indicando área ocupada pela reconstrução do objeto em posições diferentes . . . . . . . . . . . . . . . . . . . . . 139

4.80 Simulação da Geometria do Pulmão . . . . . . . . . . . . . . . . . . . . . 140

4.81 Visão Tridimensional - Pulmão Simulado - 128 eletrodos . . . . . . . . . . . 141

4.82 Visão Bidimensional - Pulmão Simulado - 128 eletrodos . . . . . . . . . . . . 141

4.83 Reconstrução da Simulação do Pulmão usando uma imagem de resolução $128 x 128$ pixels . . . . . . . . . . . . . . . . . . . . . . . . 142

4.84 Figura 4.83 com a adição de curvas de nível . . . . . . . . . . . . . . . . 143

4.85 Protótipo construído pelo Laboratório de Pneumologia - Faculdade de Medicina $(\mathrm{USP}) \ldots \ldots \ldots \ldots \ldots \ldots$

4.86 Posições testadas para o cilindro de $1 \mathrm{~cm} \ldots \ldots \ldots$. . . . . . . . . . . 144

4.87 Posições testadas para o cilindro de $3 \mathrm{~cm} \ldots \ldots \ldots \ldots \ldots$. . . . . . . . 145

4.88 Posições testadas para o cilindro de $6 \mathrm{~cm} \ldots \ldots \ldots \ldots$. . . . . . . . 145

4.89 Visão tridimensional - Deslocamento de cilindro de $1 \mathrm{~cm}$ ao longo da cuba . 146

4.90 Perfil - Deslocamento de cilindro de $1 \mathrm{~cm}$ ao longo da cuba . . . . . . . . . 147

4.91 Visão Bidimensional - Deslocamento de cilindro de $1 \mathrm{~cm}$ ao longo da cuba . . 148

4.92 Visão tridimensional - Deslocamento de cilindro de $3 \mathrm{~cm}$ ao longo da cuba . 149

4.93 Perfil - Deslocamento de cilindro de $3 \mathrm{~cm}$ ao longo da cuba . . . . . . . . . 150

4.94 Visão Bidimensional - Deslocamento de cilindro de $3 \mathrm{~cm}$ ao longo da cuba . . 151

4.95 Visão tridimensional - Deslocamento de cilindro de $6 \mathrm{~cm}$ ao longo da cuba . 152

4.96 Perfil - Deslocamento de cilindro de $6 \mathrm{~cm}$ ao longo da cuba . . . . . . . . . 153

4.97 Visão Bidimensional - Deslocamento de cilindro de $6 \mathrm{~cm}$ ao longo da cuba . . 154

4.98 Porco submetido a ventilação artificial, com eletrodos acoplados . . . . . . . 156

4.99 Tomografia de uma secção transversal do porco . . . . . . . . . . . . . . 157

4.100Ciclo respiratório do porco visualizado através do BackProjection . . . . . . 158

A.1 Reta $r_{\alpha}$ e círculos que passam por $\omega$ e $\mathbf{x} \ldots \ldots \ldots \ldots$

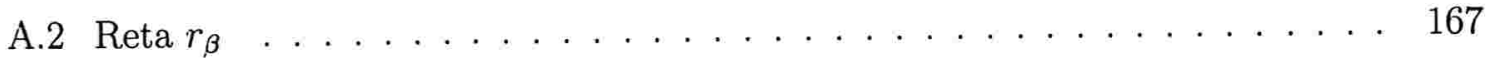

A.3 $\operatorname{Retas} r_{\gamma}$ e $r_{\delta} \ldots \ldots \ldots \ldots \ldots \ldots \ldots \ldots$ 


\section{Capítulo 1}

\section{Diagnóstico Médico por Imagens}

A Medicina tem representado uma fonte de diversos problemas de modelagem matemática nos últimos tempos. Entender o comportamento de uma população viral dentro do organismo, modelar formas geométricas de válvulas cardíacas ou estudar a relação causa-efeito na administração de drogas são alguns dos exemplos de contribuições reais de modelos aplicados. Todos esses exemplos referem-se a trabalhos de pesquisa, mas há também os casos em que a modelagem matemática atua diretamente no dia-a-dia dos médicos. Essas aplicações são vistas principalmente na forma de algoritmos, implementados dentro de programas de computador.

No caso de pacientes internados em Unidades de Terapia Intensiva (UTI), busca-se cada vez mais a criação de equipamentos que dêem suporte aos médicos em vários tipos de diagnósticos à beira do leito. O desafio na implementação desses equipamentos está no tempo de resposta que eles fornecem ao médico, na precisão da informação e na integridade do paciente, isto é, equipamentos que evitem causar traumas ou agressões ao corpo. Todos esses fatores são de extrema importância em uma área como, por exemplo, a de Ventilação Mecânica, que se preocupa com o controle do fluxo respiratório do paciente cujos órgãos responsáveis por esse controle não estão em condições normais de funcionamento.

Seria possível construir um sistema que fornecesse imagens on-line de uma secção transversal do tórax para monitoramento da ação de ventiladores mecânicos nos pulmões? A resposta que a Matemática dá é: sim! A saída seria a utilização de um equipamento semelhante ao da Tomografia Computadorizada (TC). Ela própria não poderia ser utilizada, pois iria requerer o deslocamento do paciente de seu leito e não poderia ser utilizada de forma contínua porque, apesar de ser extremamente precisa, seu tempo de resposta (tempo de reconstrução de imagens) é lento demais para um trabalho em tempo real, e sua forma de funcionamento expõe o paciente à radiação. 
Utilizando o mesmo princípio da TC, a Tomografia por Potencial Aplicado (TPA) é mais um exemplo dos frutos do relacionamento entre a Matemática e a Medicina. Neste capítulo, apresentaremos um paralelo entre a TC e a Tomografia por Potencial Aplicado e mostraremos como esta pode ser aplicada à área de Ventilação Mecânica.

\subsection{Raios X}

Descoberto por acidente em 1895 pelo físico alemão Wilhelm Röentgen, os raios X mostraramse o primeiro método de diagnóstico médico por imagem. Röentgen fazia experimentos com raios de elétrons em um tubo de descarga de gás quando percebeu que uma placa de material fluorescente brilhou. Mesmo ao colocar materiais opacos entre o tubo e a placa, a placa continuou a brilhar, porém, com intensidades diferentes. Ele, então, resolveu fazer o experimento com a mão de sua esposa. Ele colocou a mão dela entre o tubo e a placa que recebia os raios e percebeu que a silhueta dos ossos dela ficaram marcados na tela.

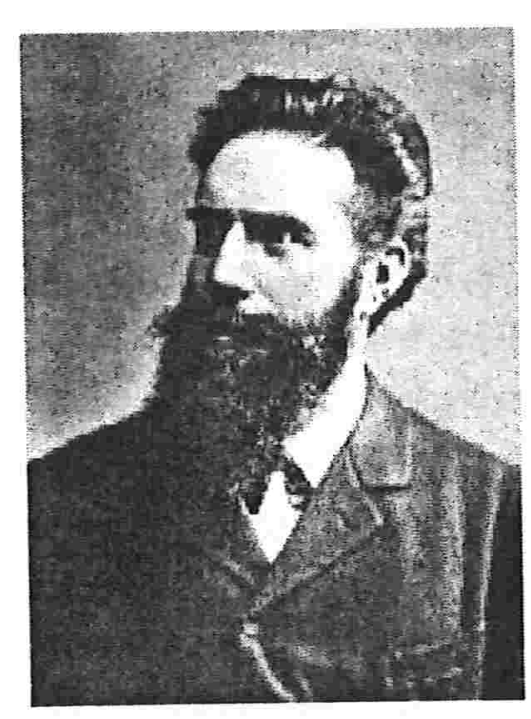

Wilhelm Röentgen

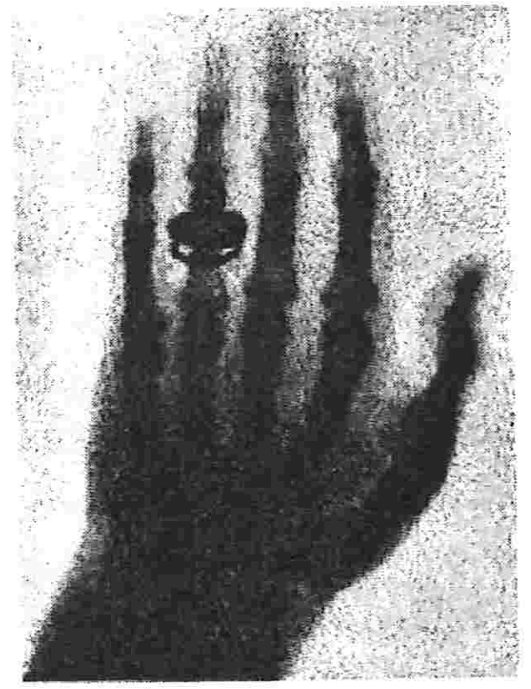

A mão de sua esposa

Raios X são emissões de fótons, produzidos por reações atômicas em uma fonte. A diferença dos fótons dos raios $\mathrm{X}$ para os raios de luz está na quantidade de energia carregada, que é representada pelo comprimento de onda. Os fótons dos raios $\mathrm{X}$ possuem maior energia e menor comprimento de onda, o que torna esses raios invisíveis para o olho humano.

Quando os raios X atingem o corpo humano, alguns tecidos absorvem mais energia (mais fótons) do que outros. No caso, o osso humano absorve muito mais energia que os outros tecidos. Isso faz com que eles sejam mais visíveis em uma radiografia que outros órgãos. 
O princípio da máquina de raio X é o mesmo criado no experimento de Röentgen. Entre uma câmera (que irá captar os raios X) e uma máquina de emissão de raios $\mathrm{X}$, fica o paciente. Após a emissão dos raios, o filme da câmera apresenta a "sombra" do corpo do paciente.

As maiores dificuldades da utilização das imagens geradas por Raios X estão no fato de apresentarem apenas uma projeção do corpo, não permitindo a exata localização (em termos tridimensionais) das partes visíveis e, a "invisibilidade" de outras partes do corpo humano.

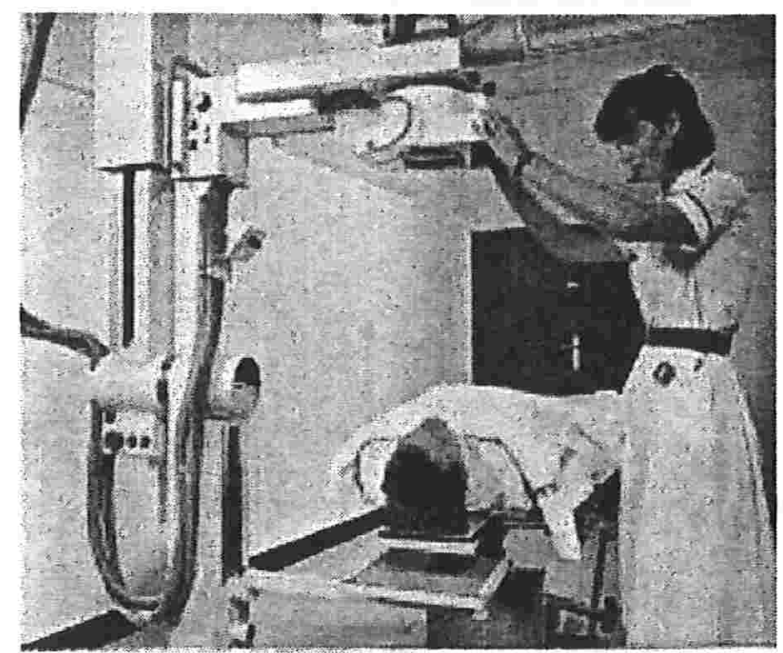

Aparelho atual de radiografia
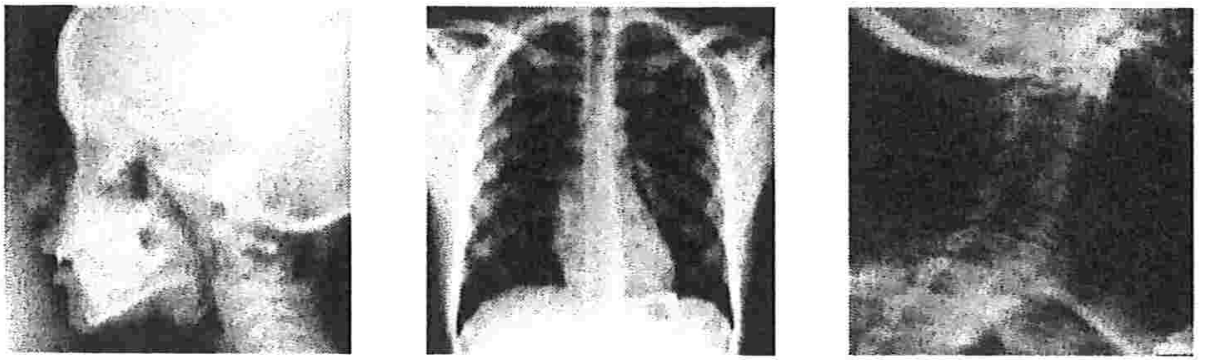

Exemplos de radiografias

Nas figuras acima, os diferentes tons de cinza indicam a quantidade de fótons absorvida na trajetória dos raios $\mathrm{X}$ até a chapa. Quanto mais próximo ao branco, mais energia foi absorvida na trajetória. 


\subsection{Tomografia Computadorizada}

Durante a trajetória de um raio X, energia é absorvida pelo material que o raio atravessa. Assim, a informação que obtemos impressa na chapa mostra apenas a variação total de energia entre a saída (tubo de emissão) e a chegada (chapa de impressão). Essa informação depende, também, da disposição do objeto entre esses dois pontos. Considere o seguinte exemplo da figura 1.1, onde faremos a suposição de que o objeto apresentado é feito de material homogêneo. A emissão dos raios é feita de acordo com o esquema da figura 1.2, onde raios $\mathrm{X}$ de mesma intensidade são projetados perpendicularmente à chapa de impressão.
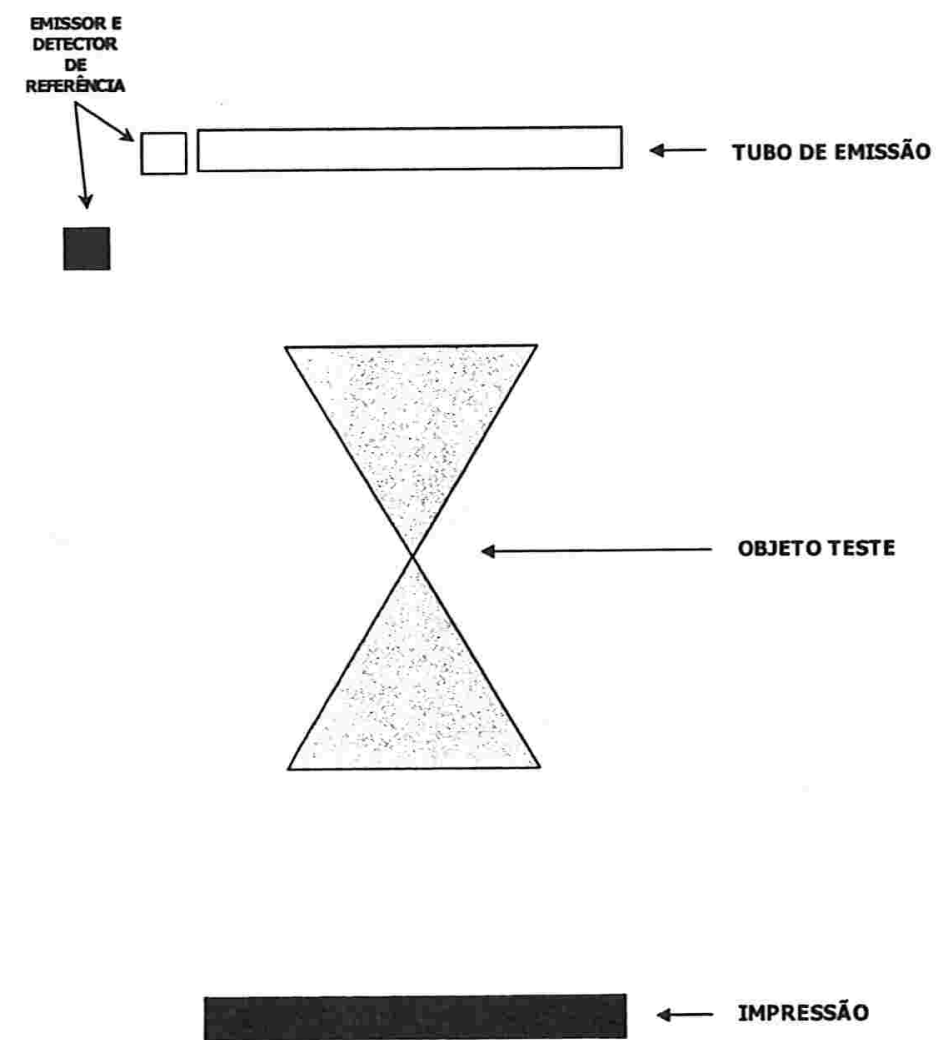

Figura 1.1: Objeto teste colocado entre um tubo de emissão e uma placa de detectores. 


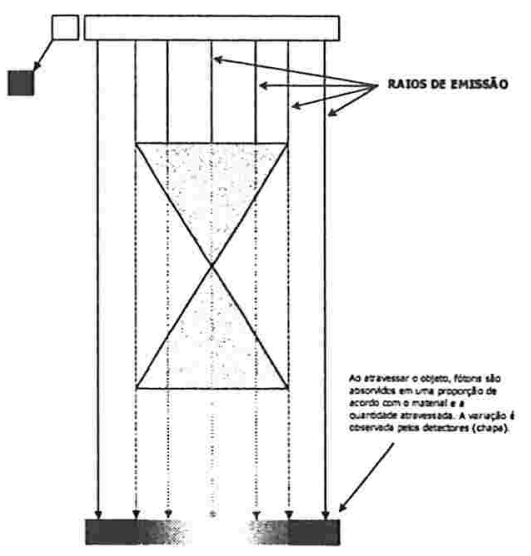

Figura 1.2: Esquema da emissão de raios através do objeto teste.

Observe que, se aproximarmos ou afastarmos o objeto do tubo de emissão (Figura 1.3), a imagem impressa será a mesma, pois os raios $\mathrm{X}$ atravessaram a mesma quantidade de material, independentemente se o objeto estava mais perto ou mais longe.
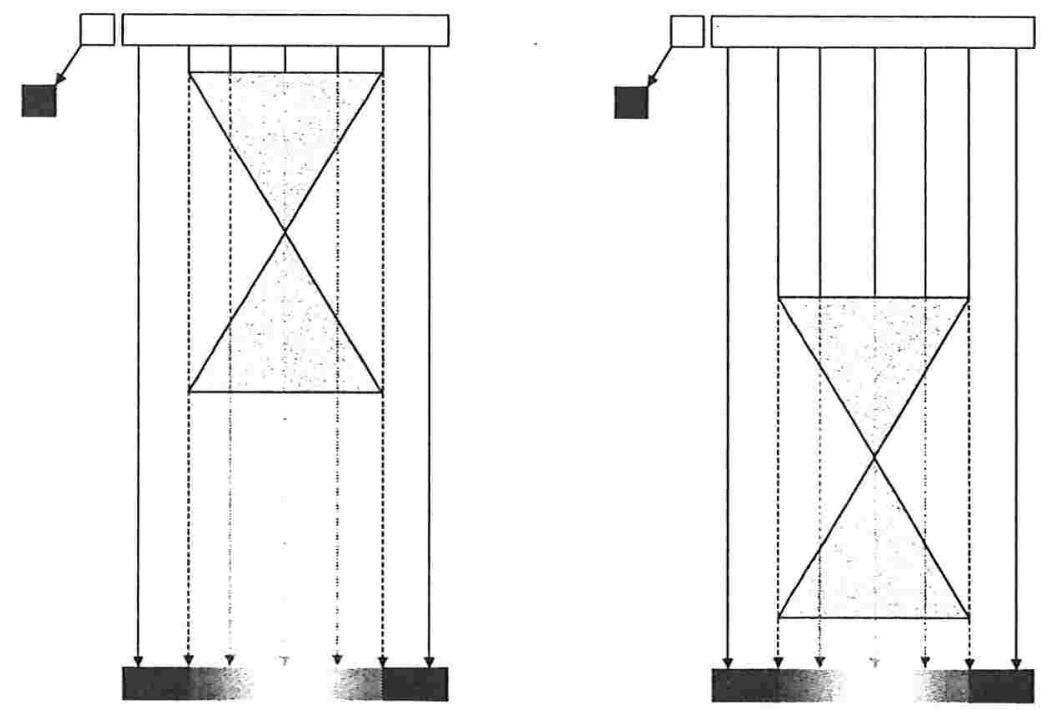

Figura 1.3: Objeto teste colocado mais próximo ou mais afastado do tubo de emissão.

A escala em tons de cinza na parte de baixo das figuras exemplifica a impressão da imagem final. Outra observação é que outros objetos feitos do mesmo material, mas de formas diferentes, podem gerar a mesma imagem (Figura 1.4).

Em ambos os casos, a trajetória dos raios $\mathrm{X}$ atravessou o mesmo tipo e a mesma quantidade de material, produzindo, dessa forma, a mesma imagem impressa. 

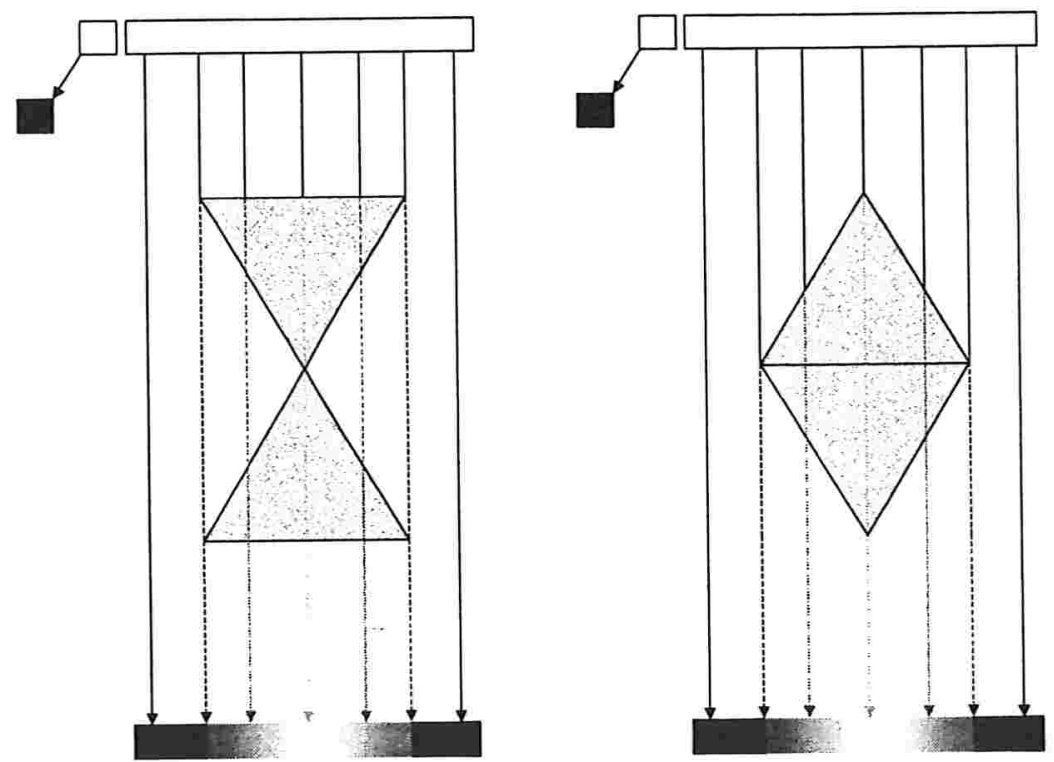

Figura 1.4: Objetos teste de formas diferentes produzem a mesma imagem.

É possível melhorar a quantidade de informação reposicionando o tubo e a chapa de impressão. No caso da posição do objeto, podemos determinar se ele estava mais próximo ou mais afastado da posição anterior do tubo apenas fazendo uma tomada do objeto através da rotação do tubo em 90 graus (sentido horário ou anti-horário) (Figura 1.5).
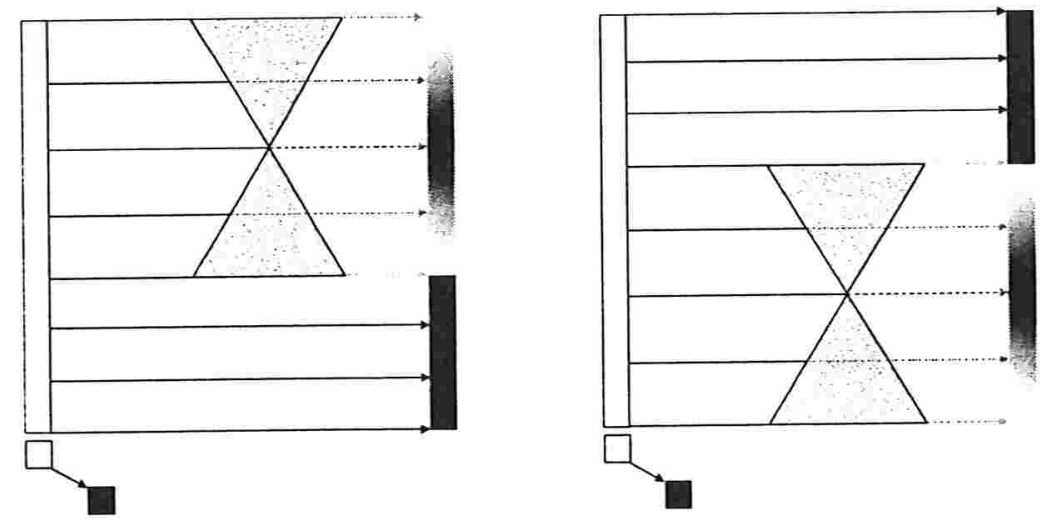

Figura 1.5: Objeto teste fotografado a partir de nova posição do tubo.

Também podemos melhorar a informação sobre a forma do objeto com a mesma tomada, como na Figura 1.6.

Portanto, com essas duas impressões, feitas a partir de posições diferentes do tubo, é 

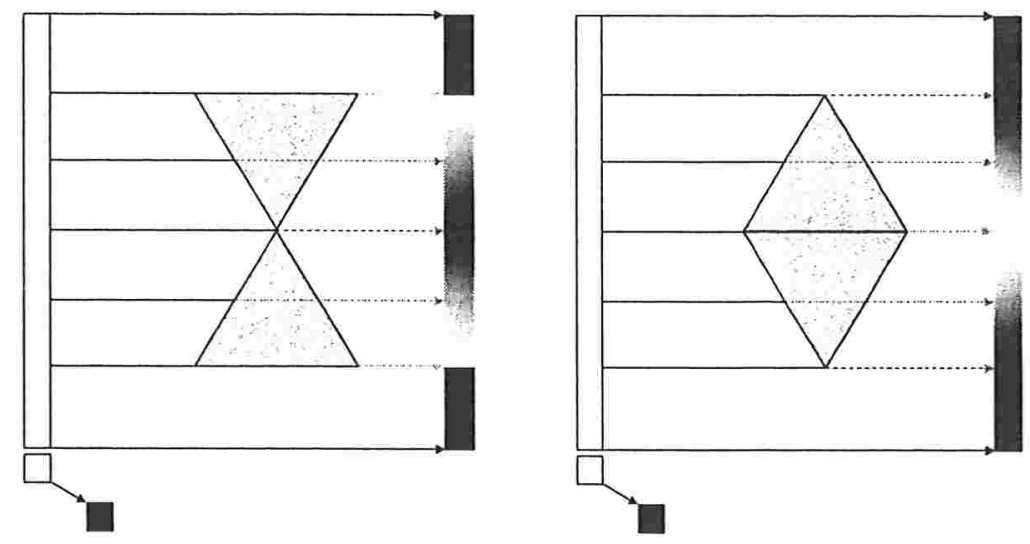

Figura 1.6: Melhoria na determinação da forma do objeto teste.

possível levantar informações sobre posicionamento e disposição do objeto de forma um pouco mais precisa do que simplesmente a impressão da chapa do raio X.

O que mostramos é o princípio da TC. Nela, utilizamos informações de vários ângulos do objeto para compor uma imagem final. No lugar do tubo, é utilizado um conjunto de emissores coplanares e, no lugar da chapa de impressão, são utilizados detectores, coplanares com os emissores, que medem a variação de energia recebida dos raios após a sua trajetória.

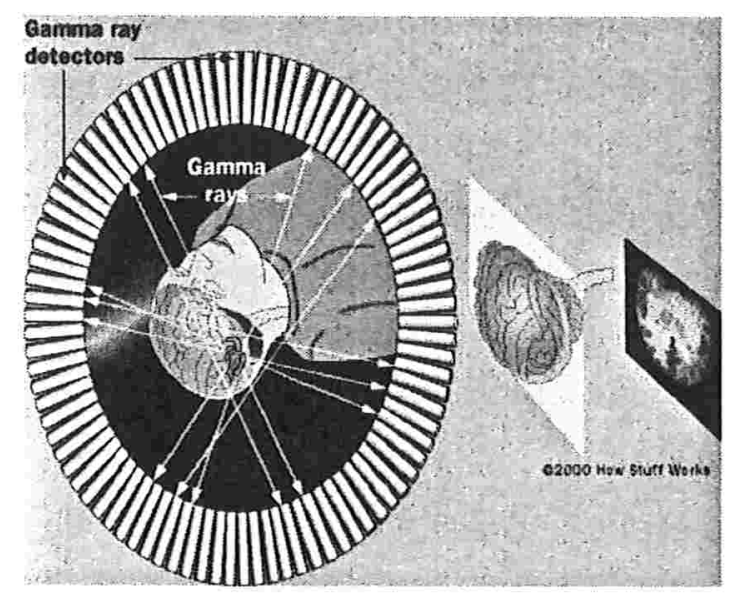

Figura 1.7: Esquema de tomada de dados na Tomografia Computadorizada.

Os emissores e detectores giram em sincronia (Figura 1.7) para obter informações do objeto de diferentes ângulos. Ao final, a informação coletada é combinada de forma a gerar uma única imagem bidimensional. Observe que, se estivermos trabalhando com um objeto tridimensional, a imagem final representará a secção transversal do objeto que está no mesmo 
plano dos emissores e detectores.

\subsection{Princípio do BackProjection}

Com base nas informações coletadas, precisamos de um algoritmo para reconstruir a imagem final. Um dos mais conhecidos em TC é o algoritmo de BackProjection. A idéia do algoritmo é, a partir dos dados medidos nos detectores, estimar a distribuição dos materias ao longo da trajetória dos raios de emissão de fótons (a idéia de "projetar de volta a informação medida").

Uma vez que um detector indique a variação percentual da energia do raio incidente, podemos inferir que em algum ponto (ou parte) da trajetória do raio há um determinado tipo de material que provoque tal variação. Utilizando apenas esse dado, porém, é difícil determinar em que parte da trajetória existe tal material.

A solução para esse problema é "projetar de volta" essa informação, assumindo que o material está presente em toda a trajetória e utilizar medições de outros ângulos para precisar o local exato que provocou tal variação. Isso significa, por exemplo, que se um detector indica queda de $20 \%$ na energia inicialmente liberada, então é assumido que em todo o caminho do raio existe um material que provoca essa queda de $20 \%$, até que seja feita a medição de outro ângulo para verificar que trechos dessa trajetória podem ser descartados como fonte da alteração.

A determinação percentual do valor de queda é feita com base em uma medição tomada em um par emissor-detector, cujo segmento de reta que os une está fora do domínio estudado. Essa é uma forma do equipamento saber qual é o valor de energia livre de variações provocadas pelo objeto estudado que está sendo recebida pelos detectores, isto é, essa é a medida de referência do equipamento.

Vamos utilizar um exemplo ilustrado. Considere o domínio quadriculado da Figura 1.8, que será mapeado utilizando a técnica do BackProjection. O domínio será colocado entre duas placas: uma de emissores e outra de detectores. A placa de emissores emite raios de mesma intensidade que atravessarão o domínio e incidirão perpendicularmente sobre a placa de detectores. Essa experiência será feita de 8 ângulos diferentes, simulando a rotação de ambas as placas ao redor do domínio estudado. Considerando $90^{\circ}$ como a posição $12 \mathrm{~h} 00$ do relógio, as tomadas serão feitas nos ângulos $90^{\circ}, 135^{\circ}, 180^{\circ}, 225^{\circ}, 270^{\circ}, 315^{\circ}, 0^{\circ}$ e $45^{\circ}$.

Inicialmente, todos os detectores na parte de baixo da figura estarão com 0 pontos. Toda vez que a trajetória de um raio passar por um quadrado em tom cinza claro, o detector irá 
somar mais 20 pontos. Toda vez que uma trajetória passar por um quadrado em tom cinza escuro, o detector irá somar mais 60 pontos. O número de pontos representa a quantidade total de energia absorvida em toda a trajetória do raio para uma posição fixa das placas de emissão e detecção. Cada posição destas placas irá contribuir com o valor da soma de pontos de seus detectores para a composição da imagem final, que será obtida através de uma média desses valores.

\begin{tabular}{|l|l|l|l|l|l|l|l|l|l|}
\hline & & & & & & & & & \\
\hline & & & 20 & 20 & 20 & 20 & & & \\
\hline & & & 20 & 20 & 20 & 20 & & & \\
\hline & & & & 20 & 20 & & & & \\
\hline & & & & 60 & 60 & & & & \\
\hline & & & & 60 & 60 & & & & \\
\hline & & & & 20 & 20 & & & & \\
\hline & & & 20 & 20 & 20 & 20 & & & \\
\hline & & & 20 & 20 & 20 & 20 & & & \\
\hline & & & & & & & & & \\
\hline
\end{tabular}

Figura 1.8: Domínio de teste no exemplo do BackProjection.

Após a primeira tomada de dados, os detectores terão medido os valores como na Figura 1.9. Esses valores, então, são assumidos pelo algoritmo como sendo válidos para todos os quadrados que passaram pela trajetória de cada raio. Na mesma figura, pode-se observar a primeira visão que o método tem do domínio.

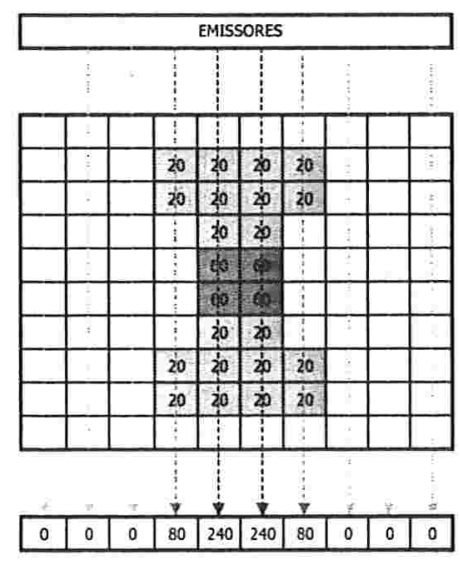

Emissão e Deteç̧ão de Raios

\begin{tabular}{|l|l|l|l|l|l|l|l|l|l|}
\hline & & & 80 & 240 & 240 & 80 & & & \\
\hline & & & 80 & 240 & 240 & 80 & & & \\
\hline & & & 80 & 240 & 240 & 80 & & & \\
\hline & & & 80 & 240 & 240 & 80 & & & \\
\hline & & & 80 & 240 & 240 & 80 & & & \\
\hline & & & 80 & 240 & 240 & 80 & & & \\
\hline & & & 80 & 240 & 240 & 80 & & & \\
\hline & & & 80 & 240 & 240 & 80 & & & \\
\hline & & & 80 & 240 & 240 & 80 & & & \\
\hline & & & 80 & 240 & 240 & 80 & & & \\
\hline
\end{tabular}

Projeção das Somas Encontradas

Figura 1.9: Domínio Teste - Posição $90^{0}$ dos emissores 
As figuras seguintes mostram os resultados das tomadas feitas nas outras posições possíveis do conjunto de emissores.

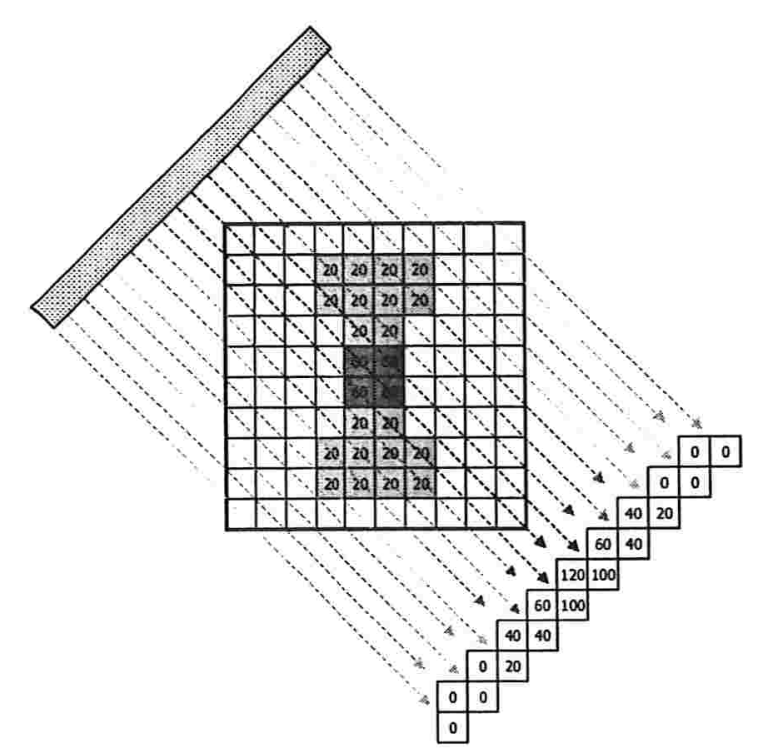

Emissão e Detecção de Raios

\begin{tabular}{|c|c|c|c|c|c|c|c|c|c|}
\hline 120 & 100 & 60 & 40 & 40 & 20 & 0 & 0 & 0 & 0 \\
\hline 100 & 120 & 100 & 60 & 40 & 40 & 20 & 0 & 0 & 0 \\
\hline 60 & 100 & 120 & 100 & 60 & 40 & 40 & 20 & 0 & 0 \\
\hline 40 & 60 & 100 & 120 & 100 & 60 & 40 & 40 & 20 & 0 \\
\hline 40 & 40 & 60 & 100 & 120 & 100 & 60 & 40 & 40 & 20 \\
\hline 20 & 40 & 40 & 60 & 100 & 120 & 100 & 60 & 40 & 40 \\
\hline 0 & 20 & 40 & 40 & 60 & 100 & 120 & 100 & 60 & 40 \\
\hline 0 & 0 & 20 & 40 & 40 & 60 & 100 & 120 & 100 & 60 \\
\hline 0 & 0 & 0 & 20 & 40 & 40 & 60 & 100 & 120 & 100 \\
\hline 0 & 0 & 0 & 0 & 20 & 40 & 40 & 60 & 100 & 120 \\
\hline
\end{tabular}

Projeção das Somas Encontradas

Figura 1.10: Domínio Teste - Posição $135^{0}$ dos emissores

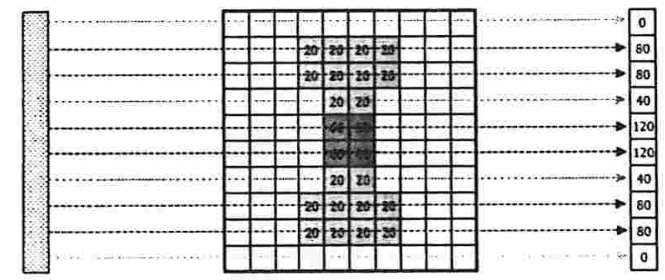

Emissão e Detecção de Raios

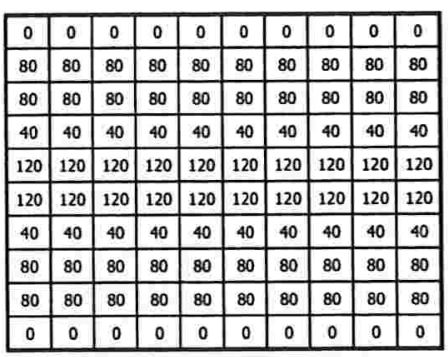

Projeção das Somas Encontradas

Figura 1.11: Domínio Teste - Posição $180^{\circ}$ dos emissores 


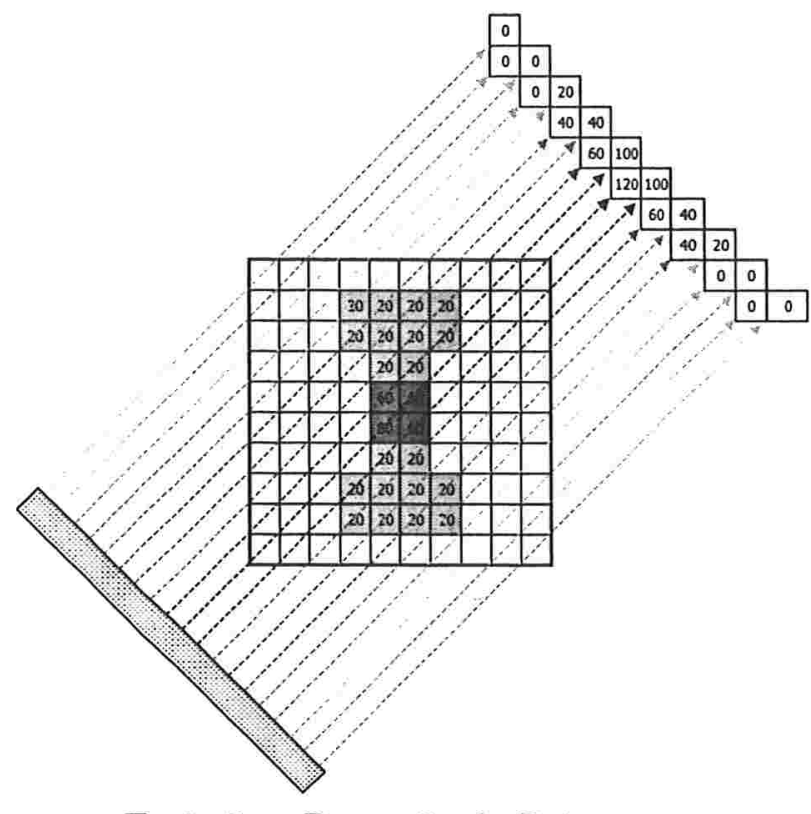

Emissão e Detecção de Raios

\begin{tabular}{|c|c|c|c|c|c|c|c|c|c|}
\hline 0 & 0 & 0 & 0 & 20 & 40 & 40 & 60 & 100 & 120 \\
\hline 0 & 0 & 0 & 20 & 40 & 40 & 60 & 100 & 120 & 100 \\
\hline 0 & 0 & 20 & 40 & 40 & 60 & 100 & 120 & 100 & 60 \\
\hline 0 & 20 & 40 & 40 & 60 & 100 & 120 & 100 & 60 & 40 \\
\hline 20 & 40 & 40 & 60 & 100 & 120 & 100 & 60 & 40 & 40 \\
\hline 40 & 40 & 60 & 100 & 120 & 100 & 60 & 40 & 40 & 20 \\
\hline 40 & 60 & 100 & 120 & 100 & 60 & 40 & 40 & 20 & 0 \\
\hline 60 & 100 & 120 & 100 & 60 & 40 & 40 & 20 & 0 & 0 \\
\hline 100 & 120 & 100 & 60 & 40 & 40 & 20 & 0 & 0 & 0 \\
\hline 120 & 100 & 60 & 40 & 40 & 20 & 0 & 0 & 0 & 0 \\
\hline
\end{tabular}

Projeção das Somas Encontradas

Figura 1.12: Domínio Teste - Posição $225^{0}$ dos emissores

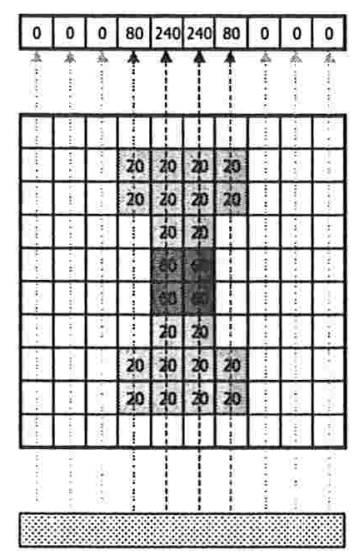

Emissão e Detecção de Raios

\begin{tabular}{|l|l|l|l|l|l|l|l|l|l|}
\hline 0 & 0 & 0 & 80 & 240 & 240 & 80 & 0 & 0 & 0 \\
\hline 0 & 0 & 0 & 80 & 240 & 240 & 80 & 0 & 0 & 0 \\
\hline 0 & 0 & 0 & 80 & 240 & 240 & 80 & 0 & 0 & 0 \\
\hline 0 & 0 & 0 & 80 & 240 & 240 & 80 & 0 & 0 & 0 \\
\hline 0 & 0 & 0 & 80 & 240 & 240 & 80 & 0 & 0 & 0 \\
\hline 0 & 0 & 0 & 80 & 240 & 240 & 80 & 0 & 0 & 0 \\
\hline 0 & 0 & 0 & 80 & 240 & 240 & 80 & 0 & 0 & 0 \\
\hline 0 & 0 & 0 & 80 & 240 & 240 & 80 & 0 & 0 & 0 \\
\hline 0 & 0 & 0 & 80 & 240 & 240 & 80 & 0 & 0 & 0 \\
\hline 0 & 0 & 0 & 80 & 240 & 240 & 80 & 0 & 0 & 0 \\
\hline
\end{tabular}

Projeção das Somas Encontradas

Figura 1.13: Domínio Teste - Posição $270^{\circ}$ dos emissores 


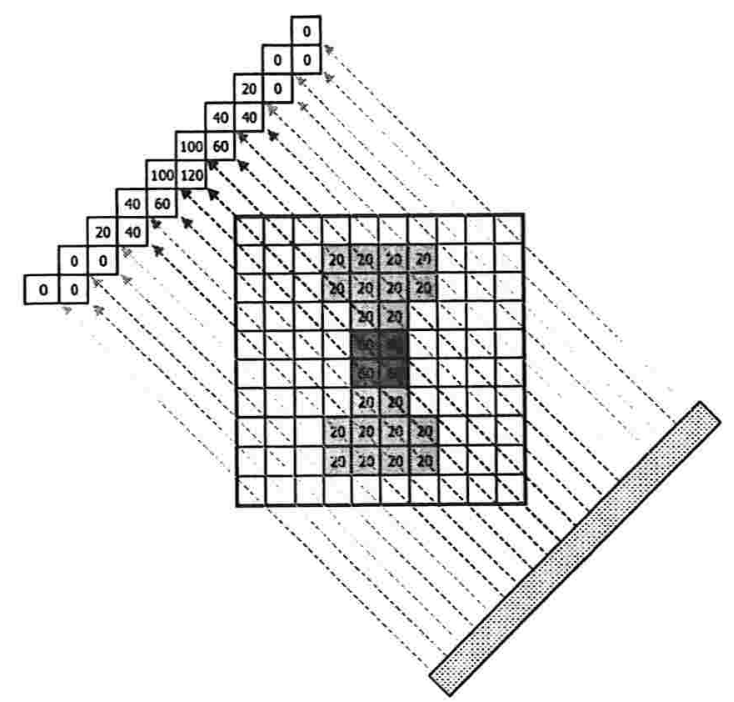

Emissão e Deteç̧ão de Raios

\begin{tabular}{|c|c|c|c|c|c|c|c|c|c|}
\hline 120 & 100 & 60 & 40 & 40 & 20 & 0 & 0 & 0 & 0 \\
\hline 100 & 120 & 100 & 60 & 40 & 40 & 20 & 0 & 0 & 0 \\
\hline 60 & 100 & 120 & 100 & 60 & 40 & 40 & 20 & 0 & 0 \\
\hline 40 & 60 & 100 & 120 & 100 & 60 & 40 & 40 & 20 & 0 \\
\hline 40 & 40 & 60 & 100 & 120 & 100 & 60 & 40 & 40 & 20 \\
\hline 20 & 40 & 40 & 60 & 100 & 120 & 100 & 60 & 40 & 40 \\
\hline 0 & 20 & 40 & 40 & 60 & 100 & 120 & 100 & 60 & 40 \\
\hline 0 & 0 & 20 & 40 & 40 & 60 & 100 & 120 & 100 & 60 \\
\hline 0 & 0 & 0 & 20 & 40 & 40 & 60 & 100 & 120 & 100 \\
\hline 0 & 0 & 0 & 0 & 20 & 40 & 40 & 60 & 100 & 120 \\
\hline
\end{tabular}

Projeção das Somas Encontradas

Figura 1.14: Domínio Teste - Posição $315^{0}$ dos emissores

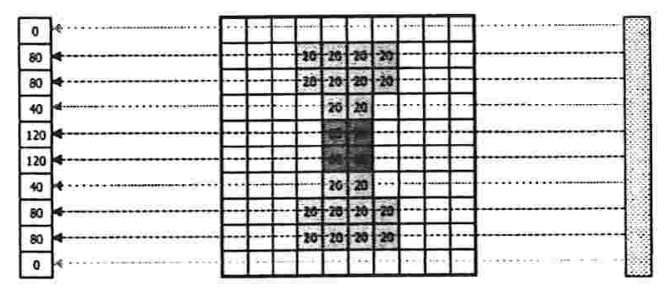

Emissão e Detecção de Raios

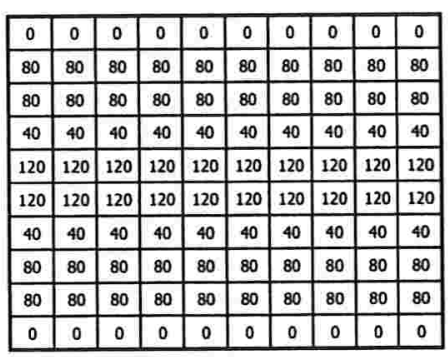

Projeção das Somas Encontradas

Figura 1.15: Domínio Teste - Posição $0^{0}$ dos emissores 


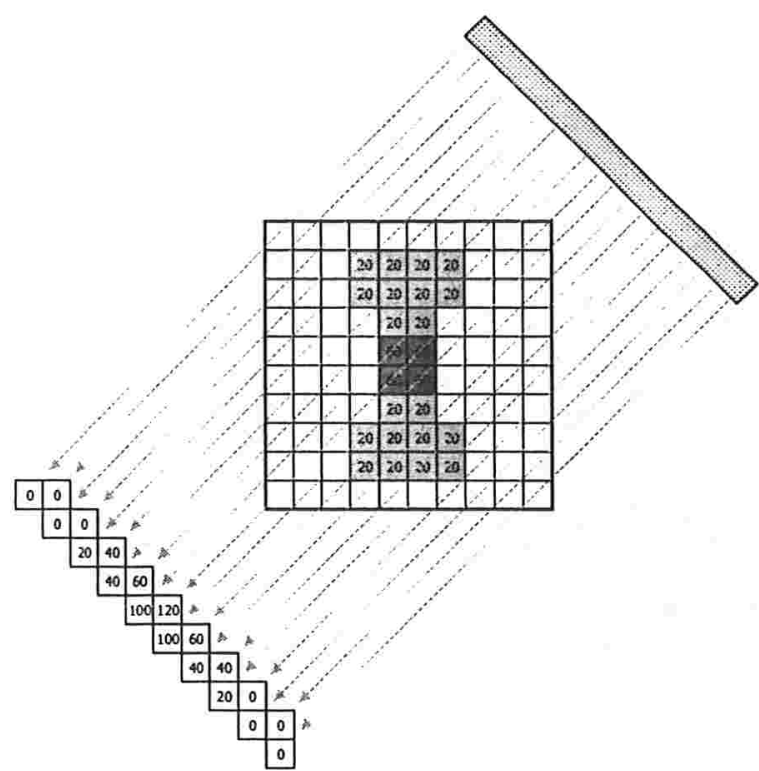

Emissão e Deteç̧ão de Raios

\begin{tabular}{|c|c|c|c|c|c|c|c|c|c|}
\hline 0 & 0 & 0 & 0 & 20 & 40 & 40 & 60 & 100 & 120 \\
\hline 0 & 0 & 0 & 20 & 40 & 40 & 60 & 100 & 120 & 100 \\
\hline 0 & 0 & 20 & 40 & 40 & 60 & 100 & 120 & 100 & 60 \\
\hline 0 & 20 & 40 & 40 & 60 & 100 & 120 & 100 & 60 & 40 \\
\hline 20 & 40 & 40 & 60 & 100 & 120 & 100 & 60 & 40 & 40 \\
\hline 40 & 40 & 60 & 100 & 120 & 100 & 60 & 40 & 40 & 20 \\
\hline 40 & 60 & 100 & 120 & 100 & 60 & 40 & 40 & 20 & 0 \\
\hline 60 & 100 & 120 & 100 & 60 & 40 & 40 & 20 & 0 & 0 \\
\hline 100 & 120 & 100 & 60 & 40 & 40 & 20 & 0 & 0 & 0 \\
\hline 120 & 100 & 60 & 40 & 40 & 20 & 0 & 0 & 0 & 0 \\
\hline
\end{tabular}

Projeção das Somas Encontradas

Figura 1.16: Domínio Teste - Posição $45^{0}$ dos emissores

A imagem final é obtida através de combinações das 8 imagens geradas a cada rotação, pelo cálculo da média aritmética entre elas, que é apresentada na figura 1.17. As cores em cinza denotam a posição original do objeto teste.

\begin{tabular}{|l|l|l|l|l|l|l|l|l|l|}
\hline 30 & 25 & 15 & 30 & 75 & 75 & 30 & 15 & 25 & 30 \\
\hline 45 & 50 & 45 & 60 & 100 & 100 & 60 & 45 & 50 & 45 \\
\hline 35 & 45 & 55 & 75 & 105 & 105 & 75 & 55 & 45 & 35 \\
\hline 20 & 30 & 45 & 70 & 110 & 110 & 70 & 45 & 30 & 20 \\
\hline 45 & 50 & 55 & 90 & 145 & 14 & 90 & 55 & 50 & 45 \\
\hline 45 & 50 & 55 & 90 & 145 & 115 & 90 & 55 & 50 & 45 \\
\hline 20 & 30 & 45 & 70 & 110 & 110 & 70 & 45 & 30 & 20 \\
\hline 35 & 45 & 55 & 75 & 105 & 105 & 75 & 55 & 45 & 35 \\
\hline 45 & 50 & 45 & 60 & 100 & 100 & 60 & 45 & 50 & 45 \\
\hline 30 & 25 & 15 & 30 & 75 & 75 & 30 & 15 & 25 & 30 \\
\hline
\end{tabular}

Figura 1.17: Visão final do algoritmo sobre o domínio teste.

As figuras 1.18 e 1.19 mostram a comparação da superfície correspondente à imagem original com a imagem reconstruída. Nela, observamos que o algoritmo forneceu uma idéia da imagem original, perdendo, contudo, a informação da borda da imagem e os valores precisos do domínio original. Uma das formas adotadas no algoritmo para calibrar esse resultado é a introdução de pesos nas medidas. Ao reconstruirmos a figura 1.17, adotamos a média 
aritmética. Pode-se melhorar a informação considerando-se, por exemplo, o uso de médias ponderadas como forma de aumentar o contraste da imagem segundo algum critério.

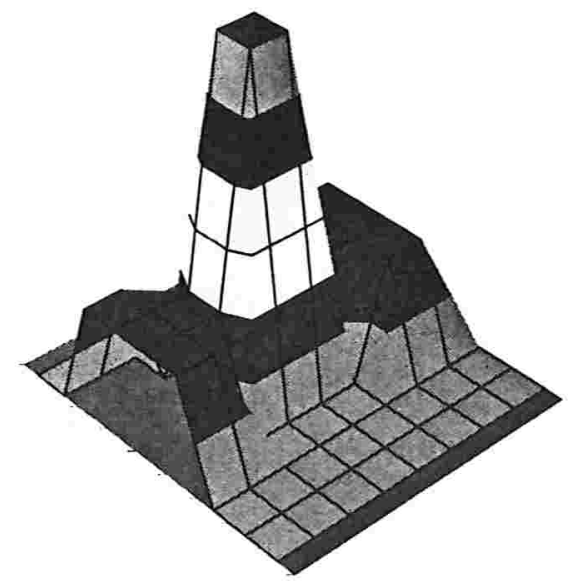

Figura 1.18: Superfície representando o domínio original.

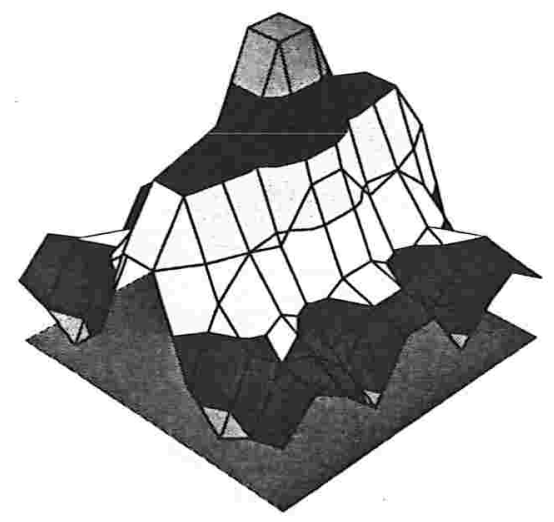

Figura 1.19: Superfície representando o domínio reconstruído.

A decisão pelo peso envolve a informação final que se deseja obter. A ponderação pode envolver informação a priori, ou seja, já há alguma informação sobre o domínio estudado (por exemplo, na disposição de materiais) e utiliza essa informação para filtrar o cálculo executado. Outra forma de ponderação envolve a natureza dos agentes envolvidos no experimento. Por exemplo, se é sabido que a perturbação percebida nos detectores tem maior chance de ter vindo de regiões próximas à fronteira, então, ao propagarmos as medidas para dentro do domínio, tal propagação será mais atenuada nas regiões próximas à borda e menor na região central. 
O peso envolvido no BackProjection aplicado à TC não é foco de nosso estudo. Nos próximos capítulos, discutiremos uma forma de ponderação adequada à TPA, que leva em consideração a natureza do fenômeno e a geometria do experimento.

O exemplo apresentado é o princípio do algoritmo de BackProjection. A técnica completa aplicada à TC envolve outras características e não será abordada neste trabalho. Uma descrição completa pode ser encontrada em [15]. A seguir, veremos como esta idéia pode ser ajustada ao caso da TPA.

\subsection{BackProjection e a Tomografia por Potencial Apli- cado}

Devido às questões levantadas no início deste capítulo, torna-se necessária a utilização de um método alternativo à TC. Como opção à energia nuclear, surge a aplicação de potencial elétrico, de forma contínua e em baixa amperagem para não agredir o corpo do paciente.

O intuito é utilizar o mesmo princípio da TC para utilizarmos uma variação do algoritmo de BackProjection no caso da TPA. No caso da TC, eram usados emissores, detectores e trajetórias de partículas (fótons) conhecidas. A analogia no caso da TPA fica por conta de elétrons e eletrodos. Estes últimos farão o papel de emissores e detectores, enquanto que os elétrons terão papel semelhante aos fótons. A primeira questão a ser resolvida é como traçar um paralelo entre a trajetória dos fótons e a dos elétrons.

No caso da TC, a trajetória dos fótons é em linha reta a partir do tubo de emissão, independentemente do meio que o raio irá atravessar. No caso dos elétrons, suas trajetórias dependerão das condições em que o experimento será feito e do meio condutor. Assim, é necessário definir a forma como ele será realizado. Tal escolha está condicionada à existência de algum modelo que já forneça analiticamente a descrição completa da trajetória dos elétrons. Um modelo que se adequa perfeitamente ao nosso problema é o do Dipolo Elétrico. Ao colocarmos uma fonte de cargas e um sumidouro (um ponto aterrado) próximos em um meio condutor homogêneo, os elétros descrevem trajetórias como na figura 1.20, onde o símbolo "+" indica a fonte e o símbolo "-" indica o sumidouro. Nesse modelo, as trajetórias dos elétrons descrevem arcos de circunferência. O potencial elétrico devido a essas cargas também é conhecido. A distribuição do potencial elétrico pode ser visualizada através das chamadas Linhas Equipontenciais (curvas de nível da função potencial), que possuem a propriedade de serem também arcos de circunferência e ortogonais às linhas de trajetórias dos elétrons (Figura 1.21). 


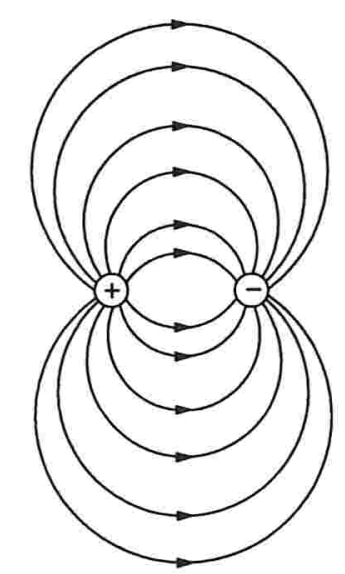

Figura 1.20: Trajetória dos elétrons

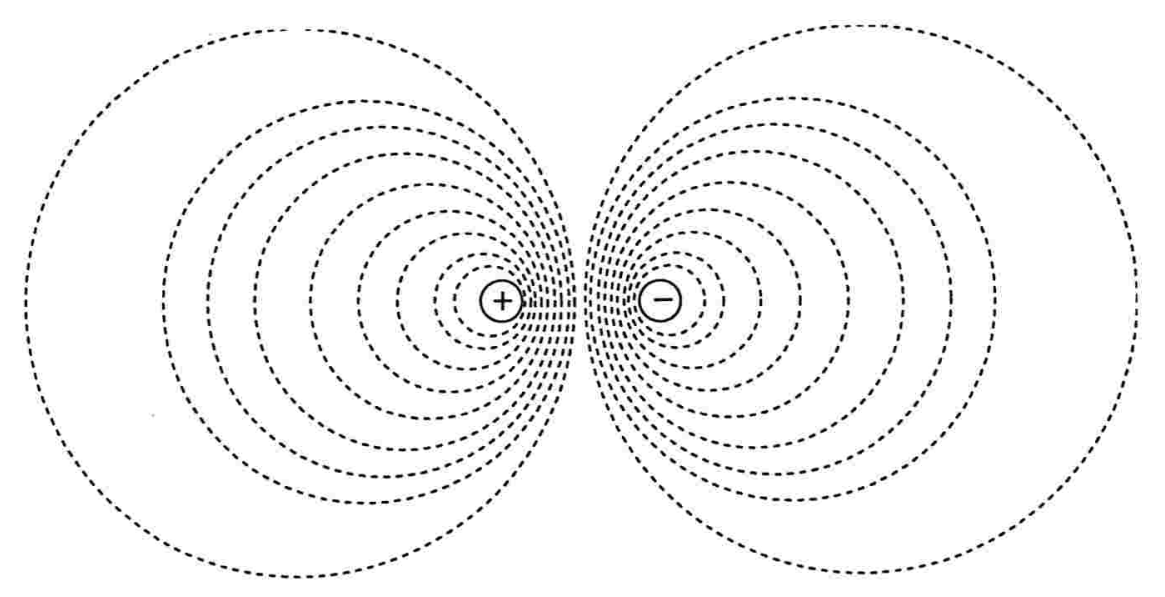

Figura 1.21: Linhas equipotenciais devidas ao potencial gerado por duas cargas opostas

Quando fonte e sumidouro estão muito próximos um do outro, ou seja, quando podemos considerar que a distância entre eles é pequena se comparada ao tamanho do domínio estudado, temos a situação de dipolo. Este é representado por uma singularidade no ponto médio entre a fonte de cargas e o sumidouro (Figura 1.22). As trajetórias e a distribuição de potencial podem ser vistas na Figura 1.23.

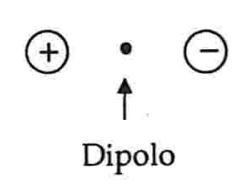

Figura 1.22: Posição do Dipolo em relação às duas cargas 


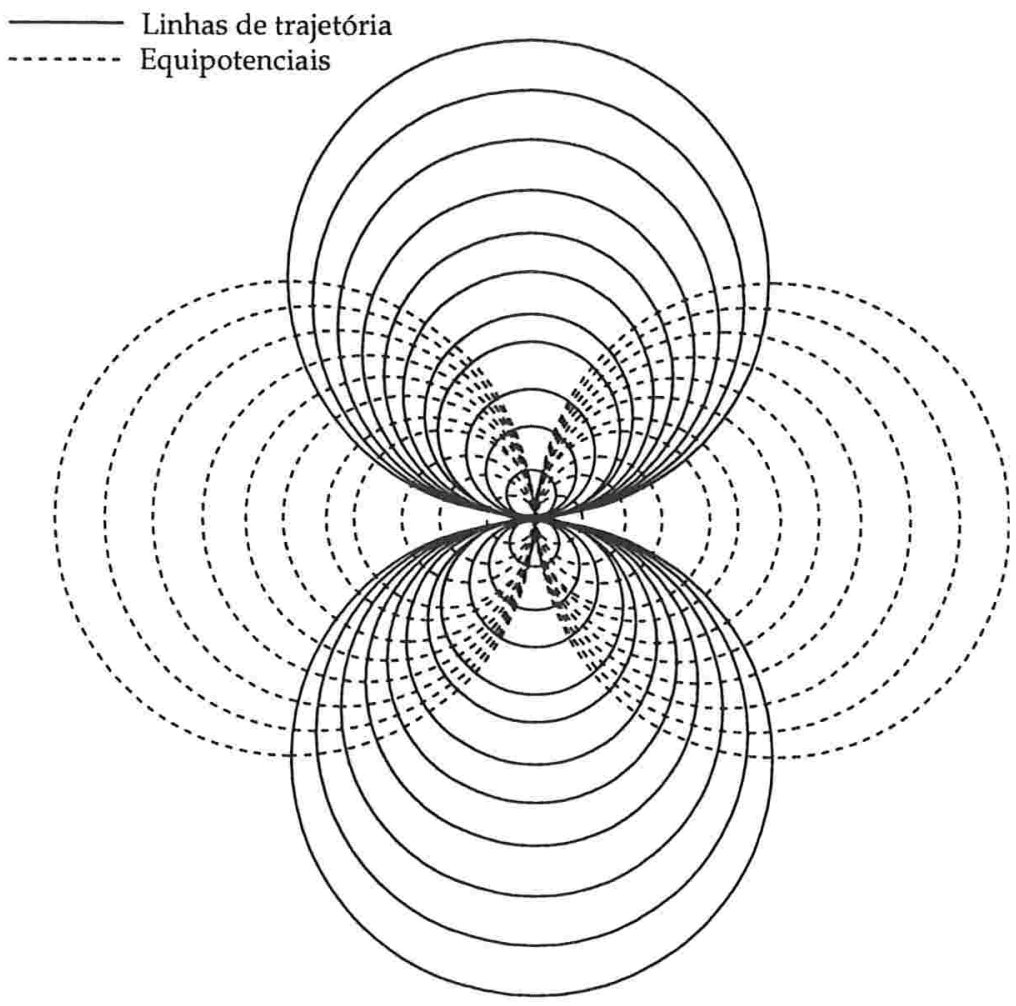

Figura 1.23: Linhas equipotenciais e linhas de trajetória no modelo de dipolo.

A formalização matemática completa desse modelo é dada no próximo capítulo. Com o modelo escolhido, precisamos agora preparar o experimento. Dois eletrodos farão o papel de fonte e sumidouro. Para o dipolo, os eletrodos são colocados sobre a superfície a ser estudada (no caso médico, a região do tórax, por exemplo) próximos um do outro. O esquema do experimento é ilustrado na Figura 1.24.

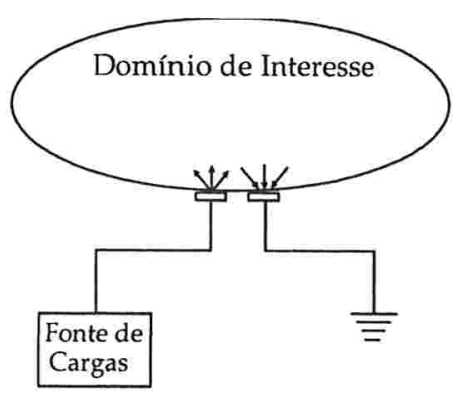

Figura 1.24: Esquema do Experimento. 
É assumido que os elétrons descrevem uma trajetória de acordo com o determinado pelo modelo do dipolo (Figura 1.25), gerando uma distribuição de potencial equivalente (Figura 1.26).

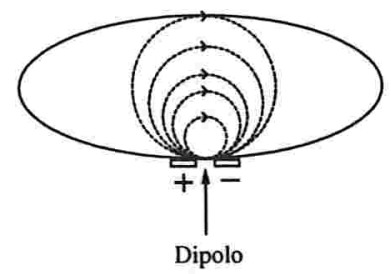

Figura 1.25: Linhas de trajetória no domínio de interesse.

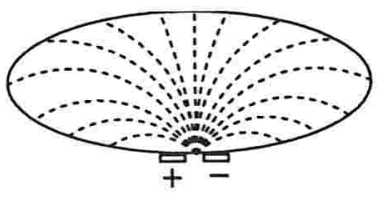

Figura 1.26: Equipotenciais no domínio de interesse.

As linhas equipotenciais possuem uma geometria mais apropriada para a equivalência da TPA com a TC do que as linhas de corrente em si pois, se posicionarmos outros eletrodos ao redor do domínio, estes atuarão como os detectores da TC, medindo voltagens, de acordo com a Figura 1.27.

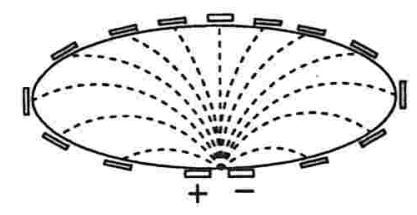

Figura 1.27: Eletrodos colocados ao redor do domínio para medição do potencial.

Assim, o dipolo representa o tubo de emissores da TC, os eletrodos os detectores e as linhas equipotenciais representam a trajetória dos fótons.

Algumas dificuldades encontradas pela modelagem começam a surgir aqui. Se estivermos trabalhando com um meio heterogêneo, não conheceremos, a priori, qual a forma das linhas equipotenciais. Além disso, não possuímos, na mesma tomada de dados, a medida de referência, como acontecia na TC onde tínhamos um par emissor-detector fora do domínio 
de interesse justamente para coletarmos a medida referencial. Assim, teremos que adotar algumas hipóteses simplificadoras para o experimento:

- Geometria das Linhas Equipotenciais: a forma das linhas equipotenciais permanecerá a mesma da modelagem do dipolo apresentada, tanto para um meio homogêneo quanto para um meio heterogêneo.

- Domínio Circular: o domínio terá sempre o formato circular, simplificando a geometria do experimento, que se adequará ao formato das equipotenciais esperado pelo modelo de dipolo.

Apesar de serem fortes hipóteses restritivas, veremos que elas podem distorcer um pouco a visualização do domínio estudado, mas não deixarão de fornecer uma boa compreensão dos resultados.

Há ainda outras hipóteses que vêm da TC e devem permanecer válidas na TPA:

- Co-planaridade de emissores e detectores: os eletrodos deverão estar em um mesmo plano de corte. No caso de um experimento de laboratório, isso pode ser feito manualmente. Já no caso do equipamento médico, isso pode ser feito fixando-se os eletrodos em uma cinta, por exemplo.

- Medida de Referência: como citamos anteriormente, na TC há um par emissor-detector responsável por fornecer o dado de referência para a reconsutrução da imagem. No caso da TPA, como os eletrodos permanecem junto ao domínio estudado (na verdade, sobre uma superfície de contato deste), não é possível usar um eletrodo para a medida de referência, pois não há nenhuma região do domínio onde haja garantia da existência de apenas material homogêneo na área da sua linha equipotencial. Além disso, mesmo em um meio homogêneo, as medidas de voltagens são diferentes para eletrodos em posições diferentes. Portanto, é necessário ter um conjunto completo de medidas para todos os eletrodos como referência.

Veremos que, para alguns experimentos de laboratório feitos com objetos em um tanque preenchido com solução condutora, toma-se, em primeiro lugar, as medidas de voltagem com o tanque preenchido apenas com o material homogêneo para que, em seguida, inicie-se a tomada de dados com objetos no interior dele. No caso do corpo, não é possível obter um "meio homogêneo" da região estudada. Portanto, o primeiro conjunto de dados levantado será a referência para os conjuntos seguintes, permitindo-se apenas a visualização das variações de volume e de substâncias dentro do corpo. 
A última analogia que temos de fazer entre a TC e a TPA refere-se à tomada de dados de ângulos diferentes. Na TC, o equipamento com os emissores e detectores girava ao redor do domínio para tomar dados de diversos ângulos. Na TPA, os eletrodos não serão girados. Ao invés disso, todos os eletrodos estarão preparados para medir voltagens, injetar corrente elétrica e fazer o aterramento do sistema. Desta forma, o processo de giro da TC passa a ser o processo de alocação de eletrodos para serem fonte de cargas ou sumidouro. A cada tomada de dados, um par de eletrodos adjacentes é recrutado para a função. Ao final do processo, teremos a tomada de dados para cada par de eletrodos adjacentes possíveis no experimento.

Com base nas discussões anteriores, estamos prontos para implementar uma versão do algoritmo de BackProjection para a TPA. A medida de cada eletrodo poderá ser comparada com a respectiva medida de referência. Havendo variação, pode-se concluir que houve variação de material em alguma parte do caminho da linha equipotencial. Da mesma forma como na TC, a informação é "projetada de volta" ao longo dessa linha. Na figura 1.28, a informação do círculo espalha-se por todas as linhas equipotenciais que passaram por ele.

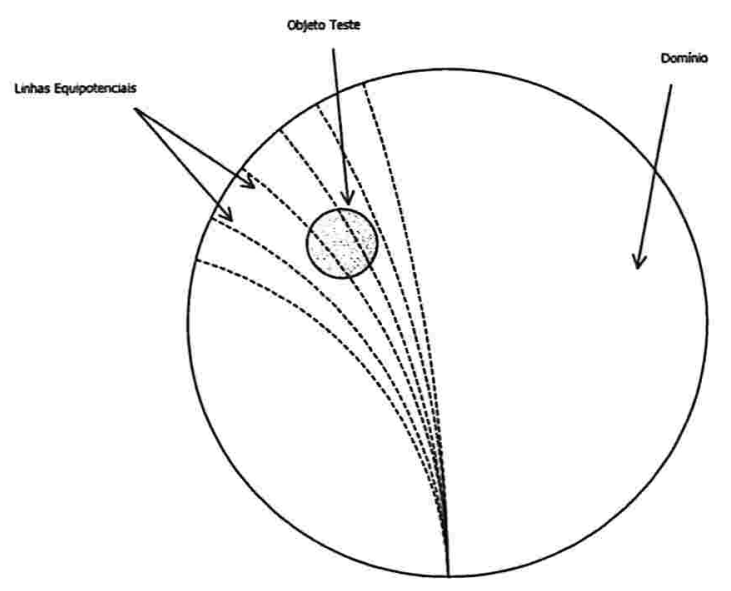

Figura 1.28: Princípio do BackProjection aplicado à TPA

Novamente como na TC, a tomada de vários ângulos nos permitirá precisar forma e disposição do objeto no domínio.

Nos próximos capítulos, iremos formalizar a construção do algoritmo, sua implementação numérica e apresentar resultados coletados em laboratório. 


\subsection{Ventilação Mecânica}

Parte dos pacientes internados em Unidades de Terapia Intensiva sofrem de problemas no sistema respiratório e estão submetidos à ventilação mecânica. De acordo com Amato [2], cerca de 250.000 pacientes por ano são submetidos à ventilação mecânica em UTI. Nos últimos tempos, tem-se constatado que a ventilação mecânica tem um papel mais importante na recuperação do paciente do que simplesmente ser um meio de assistência à recuperação do sistema respiratório. A partir de sua utilização, percebe-se uma melhora global do paciente, evitando a falência circulatória e de outros órgãos.

Devido a disfunção nas trocas gasosas apresentada por alguns pacientes, faz-se necessária a utilização de um volume de ar acima daquele que seria inspirado pelo paciente em situações normais. Este aumento do volume, contudo, pode levar a efeitos colaterais, precedidos de uma inflamação pulmonar. A razão de tal inflamação está associada ao forte estresse mecânico a que é submetido o tecido pulmonar ou, então, ao chamado colapso alveolar, classificado em persistente, quando ocorre durante todo o ciclo respiratório, ou cíclico, quando há abertura dos alvéolos durante a inspiração, e o fechamento durante a expiração. Tal colapso poder amplificar o estresse mecânico ao provocar má distribuição do ar inspirado, deslocamento de células de revestimento e hiper-distensão de regiões dos pulmões.

Com isso, o processo também é responsável por uma parcela da morte de pacientes submetidos a ele. Para combater esse problema, a estratégia de diminuição do volume corrente utilizado pelo ventilador mecânico foi sugerida, procurando-se, assim, diminuir o esforço imposto ao tecido doente. Para a implementação dessa sugestão, porém, era necessário um aumento da freqüência respiratória, para compensar a perda de oxigênio pelo menor volume injetado, obtendo, juntamente, um aumento de gás carbônico no sangue arterial.

Sobrinho [22] sugeriu que a diminuição de volume fosse acompanhada por uma elevação da chamada $P E E P$, sigla que denomina a pressão expiratória residual ao final da expiração, ao final de cada ciclo respiratório. Tal estratégia impede que as paredes alveolares colapsem, evitando a dissipação de energia para o ciclo seguinte. Ainda segundo Amato [2], nos pacientes observados, a abordagem simples de diminuição de volume resultou em uma redução de $25 \%$ na mortalidade, enquanto a segunda abordagem (elevação da $P E E P$ ) resultou em uma redução de $50 \%$, estimando-se, a partir daí, que podem ser evitadas 15.000 mortes por ano, apenas no Brasil.

Ainda em Sobrinho [22], comenta-se as dificuldades em se determinar a melhor relação entre a $P E E P$ escolhida e o volume de ar trabalhado na ventilação mecânica. Uma $P E E P$ baixa pode não ter o efeito esperado de abertura dos alvéolos. Em contrapartida, um maior 
volume (associado a um aumento de pressão) pode levar a sérias lesões do tecido pulmonar. $\mathrm{Na}$ tentativa de se determinar um critério para a escolha dos parâmetros, utiliza-se a chamada curva pressão-volume (PV). A figura 1.29 apresenta um exemplo de uma curva PV para um rato.

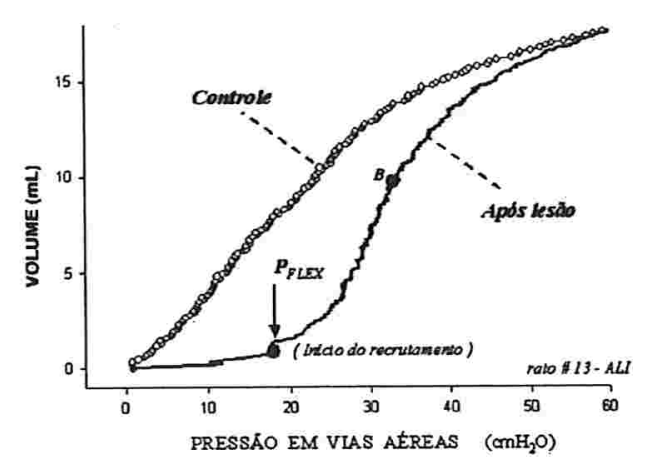

Figura 1.29: Curva Pressão-Volume de um rato.

A curva superior, formada por círculos vazados, representa o rato antes de uma lesão pulmonar induzida. Ela indica a pressão utilizada para se obter o respectivo volume de ar sendo respirado pelo rato. A curva inferior, formada por pequenos círculos cheios, representa o rato após a indução da lesão pulmonar. O ponto denominado $P_{F L E X}$ foi identificado como sendo aquele onde é iniciado o recrutamento dos alvéolos colapsados. A PEEP deveria ser mantida acima deste ponto para obtenção de resultados satisfatórios.

O maior problema no diagnóstico sugerido está justamente na construção da curva PV. Na maioria dos pacientes, somente a pressão medida nas vias aéreas está disponível, e este valor é influenciado por características da parede torácica e do pulmão. Desta forma, a curva acumula informações de todas as regiões pulmonares, não permitindo uma distinção dos fenômenos que estão ocorrendo em regiões diferentes. Algumas unidades pulmonares permanecem colapsadas a pressões de vias aéreas que hiperdistendem outras. Com relação ao volume empregado, a medição do fluxo de ar feita em pacientes refere-se à posição de equilíbrio do pulmão e não reflete valores absolutos, podendo não estar inteiramente pertinente à ventilação usada.

Amato [1] sugeriu que uma melhor forma de se obter uma curva PV mais confiável seria a utilização de imagens de tomografia, tomadas em secções transversais do tórax. A partir destas imagens, é possível identificar a distribuição do volume de ar injetado e, com isso, monitorar o tratamento, permitindo uma escolha dinâmica da $P E E P$ empregada em função do comportamento de cada região do tecido pulmonar, permitindo a distinguibilidade que a simples medição por vias respiratórias não fornece. 
Em função do procedimento necessário para a tomada de dados e da velocidade de reconstrução da imagem, é impossível conciliar o processo de ventilação mecânica simultaneamente à visualização dos tecidos que funcionasse de maneira contínua e numa UTI por TC. Em Amato [1], avalia-se o uso da TPA como uma alternativa e mostra-se que a construção da curva PV a partir dela é possível e confiável. Esta é, com certeza, uma das principais aplicações práticas do algoritmo apresentado neste trabalho. 


\section{Capítulo 2}

\section{Eletrostática aplicada à obtenção de imagens}

Neste capítulo, iremos detalhar aspectos da modelagem físico-matemática que levará ao método de Tomografia por Potencial Aplicado.

Para o estudo, é imprescindível entender o funcionamento de um campo elétrico em um meio condutor. Nosso experimento supõe que temos um meio físico sujeito a um campo elétrico com variação desprezível de suas propriedades em um curto espaço de tempo, levandonos a um problema de eletrostática.

A partir das equações de Maxwell, chegamos à equação diferencial parcial de 2a. ordem que descreve o potencial elétrico em um meio com as características necessárias para a tomografia. Desse modelo geral, obtemos um modelo linearizado que nos fornecerá a geometria necessária para o algoritmo de reconstrução de imagens.

\subsection{Aplicação das Equações de Maxwell}

Nossa modelagem inicia-se com a aplicação das leis clássicas do eletromagnetismo. Em um meio físico $\Omega \subset \mathbb{R}^{n}, n=2,3$, sujeito a um campo eletromagnético, valem as seguintes relações:

$$
\begin{aligned}
\nabla \times \mathbf{E} & =-\partial_{t} \mathbf{B} \\
\nabla \times \mathbf{H} & =J+\partial_{t} \mathbf{D} \\
\nabla \cdot \mathbf{B} & =0 \\
\nabla \cdot \mathbf{D} & =\rho
\end{aligned}
$$


onde

E é o campo elétrico no meio;

$\mathrm{B}$ é o campo magnético no meio;

H é o campo de intensidade magnética;

J é a densidade de corrente;

D é o deslocamento elétrico;

$\rho$ é a densidade de carga.

Vamos trabalhar com a hipótese de que o meio $\Omega$ a ser considerado é linear, isotrópico e não-dispersivo. Para materiais que respeitam essas hipóteses, estabelecem-se as seguintes relações lineares:

$$
\begin{aligned}
\mathbf{D} & =\epsilon \mathrm{E} \\
\mathbf{J} & =\sigma \mathrm{E} \\
\mathbf{B} & =\mu \mathrm{H}
\end{aligned}
$$

onde

$\epsilon$ é permissividade do meio;

$\sigma$ é a condutividade do meio;

$\mu$ é a permeabilidade magnética do meio.

Meios lineares são aqueles onde propriedades como condutividade e permissividade são independentes do campo eletromagnético, podendo haver dependência apenas para campos muito intensos. Experimentalmente, constata-se que grande parte dos materiais são lineares. Meios isotrópicos são aqueles onde as propriedades físicas são as mesmas independentemente do referencial adotado. Em meios não-dispersivos, condutividade e permissividade não variam de acordo com diferentes freqüências.

Com as equações $2.5,2.6$ e 2.7, as equações 2.1 a 2.4 tornam-se: 


$$
\begin{aligned}
\nabla \times \mathbf{E} & =-\partial_{t} \mathbf{B} \\
\nabla \times\left(\frac{1}{\mu} \mathbf{B}\right) & =\sigma \mathbf{E}+\partial_{t} \mathbf{D} \\
\nabla \cdot \mathbf{B} & =0 \\
\nabla \cdot(\epsilon \mathbf{E}) & =\rho
\end{aligned}
$$

Como assumimos que as variações do campo elétrico ao longo do tempo são desprezíveis, as derivadas temporais anulam-se:

$$
\begin{aligned}
\nabla \times \mathbf{E} & =0 \\
\nabla \times\left(\frac{1}{\mu} \mathbf{B}\right) & =\sigma \mathbf{E} \\
\nabla \cdot \mathbf{B} & =0 \\
\nabla \cdot(\epsilon \mathbf{E}) & =\rho
\end{aligned}
$$

A partir da equação 2.12, pode-se concluir que existe uma função escalar (potencial) $u$ tal que

$$
\mathbf{E}=-\nabla u
$$

Tomando o divergente de (2.13), obtemos:

$$
\begin{gathered}
\nabla \cdot\left(\nabla \times\left(\frac{1}{\mu} \mathrm{B}\right)\right)=\nabla \cdot(\sigma \mathrm{E}) \Rightarrow \\
\Rightarrow \nabla \cdot(\sigma \mathrm{E})=0
\end{gathered}
$$

Substituindo 2.16 na equação acima, obtemos:

$$
\nabla \cdot(\sigma \nabla u)=0
$$

Essa é a equação diferencial parcial de 2a. ordem que rege o comportamento do potencial eletrostático no meio a ser estudado.

Para encontrarmos a condição de contorno associada, podemos novamente utilizar a equação 2.6. Vamos denotar a fronteira de nosso meio condutor $\Omega$ por $\partial \Omega$ e supor que essa fronteira é uma superfície ou uma curva regular de classe $\mathcal{C}^{2}$. Seja $\mathbf{n}$ a normal unitária orientada para fora. A partir de 2.6 e 2.16 , podemos obter: 


$$
\begin{aligned}
\mathbf{J}=-\sigma \nabla u & \Rightarrow \mathbf{J} \cdot \mathbf{n}=-(\sigma \nabla u) \cdot \mathbf{n} \Rightarrow \\
& \Rightarrow \sigma \frac{\partial u}{\partial \mathbf{n}}=J_{n}
\end{aligned}
$$

onde $J_{n}=-\mathbf{J} \cdot \mathbf{n}$.

Finalmente, com base nos resultados acima, nosso problema de eletrostática pode ser modelado através do seguinte problema de Neumann:

$$
\left\{\begin{array}{cl}
\nabla \cdot(\sigma \nabla u(x))=0, & x \in \Omega \\
\sigma \frac{\partial u}{\partial \mathbf{n}}(x)=J_{n}(x), & x \in \partial \Omega
\end{array}\right.
$$

Até agora, trabalhamos com um problema geral, sem detalhar muito as condições sobre o domínio considerado. A partir daqui, algumas restrições serão introduzidas, de acordo com o que discutimos na seção 1.4 do capítulo 1 .

Vamos supor que $\Omega$ está contido em $\mathbb{R}^{2}$, é um domínio compacto simplesmente conexo e que sua fronteira é uma curva regular fechada orientada no sentido anti-horário, $\gamma: I \rightarrow \mathbb{R}^{2}$, onde $I$ é um intervalo fechado, de forma que a curva restrita ao interior de $I$ é uma função injetora. Com essas restrições, podemos fazer uma aplicação do Teorema de Gauss e obter as condições de compatibilidade física do sistema.

\subsection{Condições de Compatibilidade}

Com as hipóteses estabelecidas sobre o domínio, podemos utilizar o Teorema de Gauss no plano para encontrar uma condição de compatibilidade das soluções para o problema de Neumann. De acordo com o teorema, se $\vec{F}$ é um campo de vetorial de classe $\mathcal{C}^{1}$ em $\mathbb{R}^{2}$ e $\Omega$ é um compacto com interior não vazio cuja fronteira é a imagem de uma curva $\gamma$ regular fechada de classe $\mathcal{C}^{1}$, então

$$
\oint_{\gamma} \vec{F} \cdot \mathbf{n} d s=\iint_{\Omega} \nabla \cdot \vec{F} d x d y
$$

Substituindo $F=\sigma \nabla u$ na equação acima, obtemos:

$$
\oint_{\gamma} \sigma \nabla u \cdot \mathrm{n} d s=\iint_{\Omega} \nabla \cdot(\sigma \nabla u) d x d y
$$


Aplicando 2.19 à equação (2.21), obtemos:

$$
\begin{gathered}
\oint_{\gamma} \sigma \frac{\partial u}{\partial \mathbf{n}} d s=0 \Rightarrow \\
\Rightarrow \oint_{\gamma} J_{n} d s=0
\end{gathered}
$$

Desta forma, para que o problema 2.19 tenha solução, é necessário que a condição acima seja satisfeita. Em termos práticos, a equação 2.22 diz que a injeção de corrente no meio a ser estudado deverá respeitá-la para que possamos dar confiabilidade às leituras do experimento. Do ponto de vista físico, a equação diz que a quantidade de carga é preservada, isto é, a quantidade de carga que entra é a mesma que sai.

Suponha, agora, que $u$ seja uma solução do problema 2.19. Substituindo $u$ por $u+c$, onde $c$ é uma constante, constatamos que:

$$
\nabla \cdot(\sigma \nabla(u+c))=\nabla \cdot(\sigma \nabla u)=0
$$

e

$$
\sigma \frac{\partial(u+c)}{\partial \mathbf{n}}=\frac{\partial u}{\partial \mathbf{n}}=J_{n}
$$

Logo, $u+c$ também é uma solução. Logo, uma condição que podemos impor para obtermos uma única solução é exigir que

$$
\oint_{\gamma} u d s=0
$$

Em resumo, as equações 2.22 e 2.23 são, respectivamente, condições de existência e unicidade da solução do problema 2.19 .

\subsection{Linearização do Problema Eletrostático}

O problema 2.19 relaciona um meio de condutivididade $\sigma$ com uma distribuição de potencial $u$. Estamos interessados em mensurar a perturbação no potencial $\delta u$ na fronteira de $\Omega$, ocorrida por introduzirmos uma pequena perturbação de condutividade $(\delta \sigma)$ em $\Omega$.

Após adicionar a perturbação $\delta \sigma$ e mantendo a mesma injeção de corrente $J_{n}$, devemos encontrar uma nova solução $u+\delta u$ do problema 2.19 : 


$$
\left\{\begin{array}{lll}
\nabla \cdot((\sigma+\delta \sigma) \nabla(u+\delta u))=0, & \text { em } & \Omega \\
(\sigma+\delta \sigma) \frac{\partial(u+\delta u)}{\partial \mathbf{n}}=J_{n}, & \text { em } & \partial \Omega
\end{array}\right.
$$

Trabalhando na primeira equação, obtemos:

$$
\nabla \cdot(\sigma \nabla u)+\nabla \cdot(\sigma \nabla(\delta u))+\nabla \cdot(\delta \sigma \nabla u)+\nabla \cdot(\delta \sigma \nabla(\delta u))=0
$$

O primeiro termo da soma é nulo pois é a primeira equação em 2.19. O termo $\nabla \cdot(\delta \sigma \nabla(\delta u))$ pode ser desprezado, pois é o divergente de um produto envolvendo $\delta \sigma$ e $\delta u$ que são, por hipótese, variações pequenas quando comparadas a $\sigma$ e $u$ respectivamente. Logo, obtemos:

$$
\begin{aligned}
& \nabla \cdot(\sigma \nabla(\delta u))=-\nabla \cdot(\delta \sigma \nabla u)=-\nabla \cdot\left(\frac{\delta \sigma}{\sigma}(\sigma \nabla u)\right)= \\
& -\nabla\left(\frac{\delta \sigma}{\sigma}\right) \cdot \nabla u-\left(\frac{\delta \sigma}{\sigma}\right) \underbrace{\nabla \cdot(\sigma \nabla u)}_{=0}=-\nabla\left(\frac{\delta \sigma}{\sigma}\right) \cdot \nabla u
\end{aligned}
$$

onde assumimos que $\sigma \neq 0$, que é uma hipótese coerente para os casos reais com os quais trabalharemos. Para a condição de contorno, obtemos:

$$
\begin{gathered}
(\sigma+\delta \sigma) \frac{\partial(u+\delta u)}{\partial \mathbf{n}}=J_{n} \Rightarrow \\
\Rightarrow \sigma \frac{\partial u}{\partial \mathbf{n}}+\sigma \frac{\partial(\delta u)}{\partial \mathbf{n}}+\delta \sigma \frac{\partial u}{\partial \mathbf{n}}+\delta \sigma \frac{\partial(\delta u)}{\partial \mathbf{n}}=J_{n}
\end{gathered}
$$

Novamente, o primeiro termo da soma é igual a $J_{n}$, pois satisfaz a segunda equação de 2.19 e $\delta \sigma \frac{\partial(\delta u)}{\partial \mathbf{n}}$ é desprezado por envolver produto de termos de 1a. ordem. Logo,

$$
\sigma \frac{\partial(\delta u)}{\partial \mathbf{n}}=-\delta \sigma \frac{\partial u}{\partial \mathbf{n}}
$$

Com isso, nosso problema linearizado torna-se:

$$
\left\{\begin{array}{lll}
\nabla \cdot(\sigma \nabla(\delta u))=-\nabla\left(\frac{\delta \sigma}{\sigma}\right) \cdot \nabla u, & \text { em } & \Omega \\
\sigma \frac{\partial(\delta u)}{\partial \mathbf{n}}=-\delta \sigma \frac{\partial u}{\partial \mathbf{n}}, & \text { em } & \partial \Omega
\end{array}\right.
$$

A função do problema linearizado é a de relacionar uma solução conhecida com a perturbação provocada pela alteração de condutividade do meio.

Nos nossos experimentos, o problema 2.19 usualmente se relacionará com um meio homogêneo ou bem conhecido, isto é, onde $\sigma$ é conhecido em todo o domínio e $u$ pode ser determinado analiticamente, numericamente ou experimentalmente. 
A solução do problema 2.27 é a meta de nosso estudo. Na verdade, nosso maior interesse está em descobrir o valor de $\delta \sigma$, que determina o valor de $\sigma+\delta \sigma$ e, consequentemente, nos leva a um perfil de condutividade que dá origem à imagem do meio desconhecido. Dessa forma, precisamos conhecer o valor de $\delta u$ para determinarmos $\delta \sigma$, ou seja, resolver o problema inverso ao problema 2.27 .

Porém, ainda há uma questão pendente antes de partirmos para a resolução do problema. Precisamos conhecer o valor de $\delta u$ em $\Omega$ após a perturbação. O problema é que $\Omega$ perturbado geralmente é um meio onde não é possível efetuar medições diretas, como é o caso do interior do corpo humano (pelo menos não sem causar danos para o paciente).

Para resolver esse problema, precisamos definir em que condições a corrente elétrica é injetada no meio e como as medições de potencial são feitas. Para tal, a noção de dipolo elétrico deve ser introduzida.

\subsection{Potencial de uma carga puntiforme no espaço}

Suponha que exista uma carga elétrica $q$ posicionada em $\mathbf{r}$, onde $\mathbf{r}$ é um vetor de $\mathbb{R}^{2}$. Queremos saber qual o potencial gerado em um ponto $\mathrm{x}$ devido à carga $q$. Coloquemos uma carga teste $q^{\prime}$ posicionada em $\mathbf{x}$. Pela lei de Coulomb, a força aplicada sobre $q$ por $q^{\prime}$ é

$$
F\left(q, q^{\prime}\right)=\frac{1}{4 \pi \epsilon} \frac{q q^{\prime}}{\|\mathbf{x}-\mathbf{r}\|^{2}} \frac{\mathbf{x}-\mathbf{r}}{\|\mathbf{x}-\mathbf{r}\|}
$$

onde $\epsilon$ é a permissividade do meio. O campo elétrico em $\mathbf{x}$ é definido como o seguinte limite:

$$
E(\mathbf{x})=\lim _{q^{\prime} \rightarrow 0} \frac{F\left(q, q^{\prime}\right)}{q^{\prime}}
$$

Com isso,

$$
E(\mathbf{x})=\frac{q}{4 \pi \epsilon} \frac{\mathbf{x}-\mathbf{r}}{\|\mathbf{x}-\mathbf{r}\|^{3}}
$$

Aqui, valem também as equações 2.12 e 2.16. A expressão para o potencial elétrico em $\mathbf{x}$ devido à carga $q$ é dado por

$$
u(\mathbf{x})=\frac{q}{4 \pi \epsilon} \frac{1}{\|\mathbf{x}-\mathbf{r}\|}
$$

\footnotetext{
${ }^{1}$ Por simplicidade, iremos denotar pontos por vetores
} 
O campo elétrico devido a um conjunto de cargas ou a uma distribuição de cargas, é definido como a superposição de campos, isto é, o campo total é a soma (ou a integral) dos campos devidos a todas as cargas atuantes.

\subsection{Potencial bidimensional}

Ao assumirmos que o domínio a ser investigado é bidimensional, assumimos conseqüentemente que as propriedades físicas não possuem variações no sentido perpendicular ao domínio considerado (imaginando que tal domínio está naturalmente imerso em $\mathbb{R}^{3}$ ).

Nosso objetivo é descrever o potencial elétrico devido a alguma fonte/sumidouro de corrente representada por uma carga puntiforme no domínio. Se o domínio está imerso em $\mathbb{R}^{3}$, não podemos considerar tal carga puntiforme no espaço, pois isso implicaria em variações no sentido ortogonal ao domínio. Basta observarmos a equação 2.31 .

A representação ideal da fonte/sumidouro é feita através de uma linha infinita de cargas perpendicular ao domínio. Em termos práticos, tal representação é uma boa aproximação quando a espessura da seç̧ão transversal que estamos investigando é muito menor que o comprimento da fonte/sumidouro utilizada.

\subsubsection{Lei de Gauss}

A partir da equação 2.15, podemos extrair uma ferramenta bastante útil para nosso estudo.

Considere uma superfície fechada $S$ no espaço. Se integrarmos a equação (2.15) no volume $V$ definido por $S$, teremos:

$$
\iiint_{V} \nabla \cdot(\epsilon \mathbf{E}) d V=\iiint_{V} \rho d V
$$

Aplicando o teorema de Gauss, obtemos:

$$
\iint_{S}(\epsilon \mathbf{E}) \cdot \mathbf{n} d S=\iiint_{V} \rho d V
$$

A equação acima é conhecida como Lei de Gauss. Ela é particularmente útil para encontrarmos o potencial de distribuições de cargas com o auxílio de superfícies escolhidas convenientemente. 


\subsubsection{Potencial de uma linha infinita de cargas}

Seja uma linha infinita de cargas com densidade $\rho$, situada sobre o eixo $z$. Devido à simetria, o campo elétrico produzido pela linha sobre qualquer ponto do espaço tem direção paralela ao plano $x y$ e é perpendicular ao eixo $z$ (ou seja, o campo tem sentido radial).

Para mostrar que o campo é paralelo ao plano $x y$, basta observar que, para toda contribuição $d \mathbf{E}$ há uma outra contribuição $d \mathbf{E}^{\prime}$ de mesma intensidade e cuja soma com $d \mathbf{E}$ nos dá um campo paralelo a $x y$. Logo, o campo total produzido será paralelo ao plano $x y$.

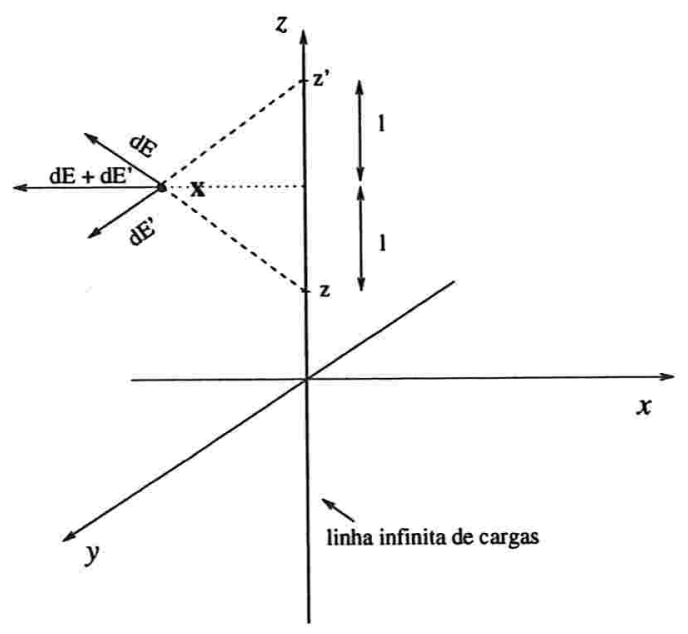

Figura 2.1: Superposição de campos

O fato do campo ser radial vem como consequiência do fato anterior e do fato de o campo ser expresso por (superposição de campos)

$$
\mathbf{E}(\mathbf{x})=\int_{-\infty}^{+\infty} \frac{\rho}{4 \pi \epsilon} \frac{\mathbf{x}-\mathfrak{z}}{\|\mathbf{x}-\mathfrak{z}\|} d \mathfrak{z}
$$

onde $\mathfrak{Z}=(0,0, \mathfrak{z})$. Como sabemos que o campo é paralelo ao plano $x y$, a integral anterior terá que nos fornecer um campo em $\mathbf{x}=(x, y, z)$ paralelo ao vetor $(x, y, 0)$.

Outra observação que podemos fazer é que a intensidade do campo só depende da distância para o eixo $z$. Logo, é conveniente denotar o campo utilizando coordenadas cilíndricas para obtermos a resumida forma:

$$
\mathrm{E}(\mathbf{x})=E_{r} \mathbf{r}
$$

onde $\mathbf{r}=(x, y, 0) / \sqrt{x^{2}+y^{2}}$.

Para determinarmos o valor de $E_{r}$, vamos utilizar a Lei de Gauss. 
Considere um cilindro de raio $r$ e altura $l$, pelo qual através de seu eixo central passa a linha infinita de carga e $S$ denotará a superfície do cilindro considerado. Temos:

$$
\begin{aligned}
\iint_{S}(\epsilon \mathbf{E}) \cdot \mathbf{n} d S & =\iint_{\text {tampa superior }}\left(\epsilon E_{r} \mathbf{r}\right) \cdot \mathbf{n} d S \\
& +\iint_{\text {tampa inferior }}\left(\epsilon E_{r} \mathbf{r}\right) \cdot \mathbf{n} d S \\
& +\iint_{\text {area lateral }}\left(\epsilon E_{r} \mathbf{r}\right) \cdot \mathbf{n} d S
\end{aligned}
$$

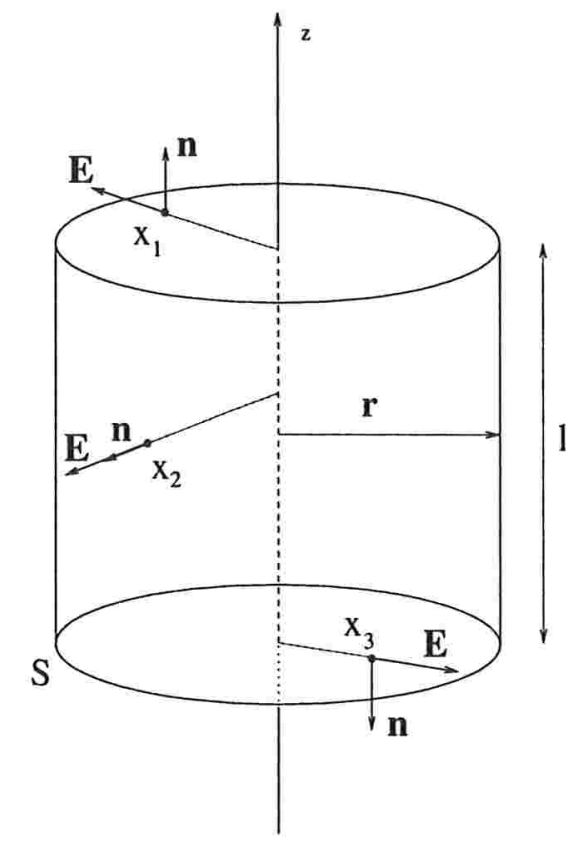

Figura 2.2: Superfície auxiliar para o uso da Lei de Gauss

Tanto na tampa superior quanto na inferior, o campo é ortogonal à normal das superfícies (observe os pontos $x_{1}$ e $x_{3}$ da figura (2.2). Logo, as integrais se anulam.

$\mathrm{Na}$ área lateral o vetor $\mathbf{r}$ é exatamente o vetor normal a superfície (ponto $x_{2}$ ). Com isso, temos:

$$
\begin{aligned}
\iint_{S}(\epsilon \mathbf{E}) \cdot \mathbf{n} d S & =\iint_{\text {area lateral }}\left(\epsilon E_{r} \mathbf{r}\right) \cdot \mathbf{n} d S \\
& =\iint_{\text {area lateral }} \epsilon E_{r} d S \\
& =\epsilon E_{r} \iint_{\text {area lateral }} d S \\
& =\epsilon E_{r} 2 \pi r l
\end{aligned}
$$

Quanto à integral da carga, seu resultado é igual à quantidade de carga na parte da linha no interior da superfície. Logo, 


$$
\iiint_{V} \rho d V=\rho l
$$

Pela Lei de Gauss,

$$
\epsilon E_{r} 2 \pi r l=\rho l \Rightarrow E_{r}=\frac{\rho}{2 \pi \epsilon r}
$$

Assim, a intensidade do campo a uma distância $r$ do eixo $z$ foi determinada independentemente da altura $l$ do cilindro escolhido.

Para obtermos o potencial, utilizamos novamente a equação 2.16 , considerando agora o gradiente em coordenadas cilíndricas:

$$
\mathbf{E}=-\nabla u \Rightarrow\left(-\frac{\rho}{2 \pi \epsilon r}, 0,0\right)=\left(\frac{\partial u}{\partial r}, \frac{1}{r} \frac{\partial u}{\partial \theta}, \frac{\partial u}{\partial z}\right)
$$

De onde concluímos que

$$
\frac{\partial u}{\partial r}=-\frac{\rho}{2 \pi \epsilon r} \Rightarrow u(r)=-\frac{\rho}{2 \pi \epsilon} \ln (r)
$$

Este é o potencial bidimensional utilizado em nossa modelagem. No domínio $\Omega$, uma carga puntiforme é a projeção de uma linha infinita de cargas ortogonal ao plano do domínio.

É importante observar que, no desenvolvimento do potencial bidimensional, estava implícita a hipótese de que o meio possuía condutividade homogênea ( $\sigma$ constante). O potencial encontrado, assim, satisfaz a equação de Laplace 2.17 no plano:

$$
\begin{aligned}
& \nabla \cdot(\sigma \nabla u)=\sigma \nabla^{2} u=\sigma(\frac{1}{r} \frac{\partial}{\partial r}\left(r \frac{\partial u}{\partial r}\right)+\frac{1}{r^{2}} \underbrace{\left(\frac{\partial^{2} u}{\partial \theta^{2}}\right)}_{=0}) \\
& =\sigma\left(\frac{1}{r} \frac{\partial u}{\partial r}+\frac{\partial^{2} u}{\partial r^{2}}\right)=\sigma\left(\frac{1}{r}\left(-\frac{\rho}{4 \pi \epsilon} \frac{1}{r}\right)+\frac{\rho}{4 \pi \epsilon} \frac{1}{r^{2}}\right)=0
\end{aligned}
$$

\subsection{Dipolo Elétrico}

$\mathrm{Na}$ seção anterior, uma carga puntiforme bidimensional representa a projeção de uma linha infinita de cargas ortogonal ao domínio bidimensional considerado. $\mathrm{O}$ objetivo daquele desenvolvimento foi encontrar o potencial dessa projeção. Agora, vamos determinar o potencial devido a duas cargas puntiformes bidimensionais, de mesmo módulo mas sinais opostos, 
colocadas a uma pequena distância se comparada à distância a um ponto do domínio a ser estudado.

Essa situação caracteriza um dipolo elétrico. $E m \mathbb{R}^{3}$, o dipolo é representado por duas cargas puntiformes colocadas próximas uma da outra. No caso bidimensional, o dipolo é representado pela projeção de duas linhas infinitas de cargas opostas, ortogonais ao domínio considerado.

A partir de agora, essas projeções serão referidas como pontos de $\mathbb{R}^{2}$. O domínio de 2.41 será o plano e x será um ponto de $\mathbb{R}^{2}$.

Suponha que $\omega \in \mathbb{R}^{2}$ represente o ponto médio entre as duas cargas e que $\omega+\mathbf{h}$ e $\omega-\mathbf{h}$ representem, respectivamente, as posições das cargas positiva e negativa, onde $h \in \mathbb{R}^{2}$. $\mathrm{O}$ potencial em um ponto $\mathrm{x} \in \mathbb{R}^{2}$ devido a cada uma das cargas será dado por

$$
u_{+}(\mathbf{x})=-C \ln \|\mathbf{x}-\omega-\mathbf{h}\|
$$

para a carga positiva e

$$
u_{-}(\mathbf{x})=C \ln \|\mathbf{x}-\omega+\mathbf{h}\|
$$

para a carga negativa, onde $C=\rho / 4 \pi \epsilon$. O campo total será dado pela superposição dos campos anteriores, ou seja,

$$
u(\mathbf{x})=u_{+}(\mathbf{x})+u_{-}(\mathbf{x})=-C(\ln \|\mathbf{x}-\omega-\mathbf{h}\|-\ln \|\mathbf{x}-\omega+\mathbf{h}\|)
$$

\subsubsection{Aproximação para o potencial do dipolo}

A equação 2.44 não nos permite obter informações sobre a geometria do fenômeno de maneira fácil. Vamos seguir o mesmo procedimento adotado quando se estuda o potencial do dipolo tridimensional, através do qual é feita uma aproximação de primeira ordem do potencial devido as duas cargas.

Será bastante útil utilizarmos algumas ferramentas das variáveis complexas. Considere a relação natural entre $\mathbb{R}^{2}$ e $\mathbb{C}$. Podemos fazer as seguintes associações entre variáveis:

$$
\begin{array}{ll}
\mathbf{x}=(x, y) \in \mathbb{R}^{2} & \mapsto \mathbf{z}=x+\mathrm{i} y \in \mathbb{C} \\
\omega=\left(x_{\omega}, y_{\omega}\right) \in \mathbb{R}^{2} & \mapsto \mathbf{z}_{\omega}=x_{\omega}+\mathrm{i} y_{\omega} \in \mathbb{C} \\
\mathbf{h}=\left(x_{h}, y_{h}\right) \in \mathbb{R}^{2} & \mapsto \mathrm{t}=x_{h}+\mathrm{i} y_{h} \in \mathbb{C}
\end{array}
$$

Com esta associação, podemos definir o potencial complexo 


$$
\mathcal{U}(\mathbf{z})=-C\left(\operatorname{Ln}\left(\mathbf{z}-\mathbf{z}_{\omega}-\mathbf{t}\right)-\operatorname{Ln}\left(\mathbf{z}-\mathbf{z}_{\omega}+\mathbf{t}\right)\right), \quad \mathbf{z} \in \mathbb{C}
$$

onde $\operatorname{Ln}$ denota o ramo principal do logaritmo complexo. Como $\operatorname{Ln}(\mathbf{z})=\ln \|\mathbf{z}\|+\mathbf{i} \arg \mathbf{z}, \mathbf{a}$ parte real de $\mathcal{U}$ é o potencial 2.44 .

Podemos escrever

$$
\begin{gathered}
\operatorname{Ln}\left(\mathbf{z}-\mathbf{z}_{\omega}-\mathbf{t}\right)=\operatorname{Ln}\left(\left(\mathbf{z}-\mathbf{z}_{\omega}\right)\left(1-\frac{\mathbf{t}}{\mathbf{z}-\mathbf{z}_{\omega}}\right)\right) \\
=\operatorname{Ln}\left(\mathbf{z}-\mathbf{z}_{\omega}\right)+\operatorname{Ln}\left(1-\frac{\mathbf{t}}{\mathbf{z}-\mathbf{z}_{\omega}}\right)
\end{gathered}
$$

A hipótese para a situação de dipolo, que é a de distância pequena entre as cargas, é traduzida pela condição $\left\|\mathbf{t} /\left(\mathbf{z}-\mathbf{z}_{\omega}\right)\right\| \ll 1$, pois $2\|\mathbf{t}\|$ é a distância entre a carga positiva e a negativa, e, utilizando a série de Taylor de $\operatorname{Ln}(1+\mathbf{z})$ ao redor de $\mathbf{z}=0$, podemos escrever

$$
\operatorname{Ln}\left(\mathbf{z}-\mathbf{z}_{\omega}-\mathbf{t}\right)=\operatorname{Ln}\left(\mathbf{z}-\mathbf{z}_{\omega}\right)+\sum_{n=1}^{\infty} \frac{(-1)^{n+1}}{n}\left(-\frac{\mathbf{t}}{\mathbf{z}-\mathbf{z}_{\omega}}\right)^{n}
$$

Analogamente, teremos

$$
\operatorname{Ln}\left(\mathbf{z}-\mathbf{z}_{\omega}+\mathbf{t}\right)=\operatorname{Ln}\left(\mathbf{z}-\mathbf{z}_{\omega}\right)+\sum_{n=1}^{\infty} \frac{(-1)^{n+1}}{n}\left(\frac{\mathbf{t}}{\mathbf{z}-\mathbf{z}_{\omega}}\right)^{n}
$$

Substituindo as expressões acima em (2.46), obtemos:

$$
\begin{array}{r}
\mathcal{U}(\mathbf{z})=-C\left(\operatorname{Ln}\left(\mathbf{z}-\mathbf{z}_{\omega}\right)+\sum_{n=1}^{\infty} \frac{(-1)^{n+1}}{n}\left(-\frac{\mathbf{t}}{\mathbf{z}-\mathbf{z}_{\omega}}\right)^{n}-\operatorname{Ln}\left(\mathbf{z}-\mathbf{z}_{\omega}\right)-\right. \\
\left.\sum_{n=1}^{\infty} \frac{(-1)^{n+1}}{n}\left(\frac{\mathbf{t}}{\mathbf{z}-\mathbf{z}_{\omega}}\right)^{n}\right)=-C\left(\sum_{n=1}^{\infty} \frac{(-1)-(-1)^{n+1}}{n}\left(\frac{\mathbf{t}}{\mathbf{z}-\mathbf{z}_{\omega}}\right)^{n}\right) \\
=-C\left(\sum_{m=0}^{\infty}-\frac{2}{2 m+1}\left(\frac{\mathbf{t}}{\mathbf{z}-\mathbf{z}_{\omega}}\right)^{2 m+1}\right)=2 C\left(\sum_{m=0}^{\infty} \frac{1}{2 m+1}\left(\frac{\mathbf{t}}{\mathbf{z}-\mathbf{z}_{\omega}}\right)^{2 m+1}\right)
\end{array}
$$

A aproximação para obtermos o potencial do dipolo é feita tomando-se o primeiro termo da série anterior $(m=0)$ :

$$
\mathcal{U}(\mathbf{z}) \approx \mathcal{U}_{\omega}(\mathbf{z})=2 C \frac{\mathbf{t}}{\mathbf{z}-\mathbf{z}_{\omega}}
$$

Para voltarmos para o caso real, lembremos que o potencial procurado é a parte real do potencial complexo acima. Usando as relações em 2.45 , obtemos: 


$$
\begin{gathered}
\mathcal{U}_{\omega}(\mathbf{z})=2 C \frac{\mathbf{t}}{\mathbf{z}-\mathbf{z}_{\omega}}=2 C \frac{x_{h}+\mathbf{i} y_{h}}{\left(x-x_{\omega}\right)+\mathbf{i}\left(y-y_{\omega}\right)} \\
=2 C \frac{x_{h}+\mathbf{i} y_{h}}{\left(x-x_{\omega}\right)+\mathbf{i}\left(y-y_{\omega}\right)} \frac{\left(x-x_{\omega}\right)-\mathbf{i}\left(y-y_{\omega}\right)}{\left(x-x_{\omega}\right)-\mathbf{i}\left(y-y_{\omega}\right)} \\
=2 C \frac{\left(x_{h}+\mathbf{i} y_{h}\right)\left(\left(x-x_{\omega}\right)-\mathbf{i}\left(y-y_{\omega}\right)\right)}{\left(x-x_{\omega}\right)^{2}+\left(y-y_{\omega}\right)^{2}}= \\
=\frac{x_{h}\left(x-x_{\omega}\right)+y_{h}\left(y-y_{\omega}\right)}{\left(x-x_{\omega}\right)^{2}+\left(y-y_{\omega}\right)^{2}}+\mathbf{i} \frac{y_{h}\left(x-x_{\omega}\right)-x_{h}\left(y-y_{\omega}\right)}{\left(x-x_{\omega}\right)^{2}+\left(y-y_{\omega}\right)^{2}} \\
=\frac{\mathbf{h} \cdot(\mathbf{x}-\omega)}{\|\mathbf{x}-\omega\|^{2}}-\mathbf{i} \frac{\mathbf{h}^{\perp} \cdot(\mathbf{x}-\omega)}{\|\mathbf{x}-\omega\|^{2}}
\end{gathered}
$$

Denotando por

$$
u_{\omega}(\mathbf{x})=\frac{\mathbf{h} \cdot(\mathbf{x}-\omega)}{\|\mathbf{x}-\omega\|^{2}}
$$

$\mathrm{e}$

$$
v_{\omega}(\mathbf{x})=\frac{\mathbf{h}^{\perp} \cdot(\mathbf{x}-\omega)}{\|\mathbf{x}-\omega\|^{2}}
$$

onde $\mathbf{h}^{\perp}=\left(-y_{h}, x_{h}\right)$ é a rotação de $\pi / 2$ de $\mathbf{h}$, obtemos

$$
\mathcal{U}_{\omega}(\mathbf{z})=\mathcal{U}_{\omega}(\mathbf{x})=2 C\left(u_{\omega}(\mathbf{x})-\mathbf{i} v_{\omega}(\mathbf{x})\right)
$$

e $u_{\omega}$ é o potencial elétrico associado ao dipolo em um meio homogêneo de condutividade $\sigma$.

\subsubsection{Dipolo na bola unitária}

Vamos deduzir a expressão do potencial do dipolo quando ele está sobre a fronteira da bola unitária de $\mathbb{R}^{2}$, ou seja, $\|\omega\|=1$, e, para $\mathbf{h}$, a situação ideal é que ele seja tangente à bola. Assim, as cargas que irão simular a situação de dipolo elétrico estarão muito próximas da fronteira. Portanto, h será da forma

$$
\mathbf{h}=\lambda \omega^{\perp}, \quad \lambda \in \mathbb{R}
$$

ou seja, h é ortogonal a $\omega$.

Substituindo a expressão acima em (2.53) e (2.54), obtemos 


$$
u_{\omega}(\mathbf{x})=\frac{\lambda \omega^{\perp} \cdot(\mathbf{x}-\omega)}{\|\mathbf{x}-\omega\|^{2}}=\frac{\lambda \omega^{\perp} \cdot \mathbf{x}}{\|\mathbf{x}-\omega\|^{2}}
$$

$\mathrm{e}$

$$
v_{\omega}(\mathbf{x})=\frac{\lambda\left(\omega^{\perp}\right)^{\perp} \cdot(\mathbf{x}-\omega)}{\|\mathbf{x}-\omega\|^{2}}=\frac{\lambda(-\omega) \cdot(\mathbf{x}-\omega)}{\|\mathbf{x}-\omega\|^{2}}=\frac{\lambda(1-\omega \cdot \mathbf{x})}{\|\mathbf{x}-\omega\|^{2}}
$$

pois $\left(\omega^{\perp}\right)^{\perp}=-\omega$. Agora, observemos que $\left\{\omega, \omega^{\perp}\right\}$ é uma base ortonormal de $\mathbb{R}^{2}$. Assim, o ponto $\mathrm{x}$ nesta base deve ter a mesma norma que na base canônica. Logo,

$$
\mathbf{x} \cdot \mathbf{x}=(\mathbf{x} \cdot \omega)^{2}+\left(\mathbf{x} \cdot \omega^{\perp}\right)^{2}
$$

Com isso, temos

$$
\begin{gathered}
\|\mathbf{x}-\omega\|^{2}=(\mathbf{x}-\omega) \cdot(\mathbf{x}-\omega)=\mathbf{x} \cdot \mathbf{x}-2 \mathbf{x} \cdot \omega+1= \\
=(\mathbf{x} \cdot \omega)^{2}+\left(\mathbf{x} \cdot \omega^{\perp}\right)^{2}-2 \mathbf{x} \cdot \omega+1=\left(\mathbf{x} \cdot \omega^{\perp}\right)^{2}+(1-\mathbf{x} \cdot \omega)^{2}
\end{gathered}
$$

Assim, se fizermos as seguintes associações:

$$
\begin{aligned}
& \mathbf{x} \mapsto \phi(\mathbf{x})=\mathbf{x} \cdot \omega^{\perp} \\
& \mathbf{x} \mapsto \varphi(\mathbf{x})=1-\mathbf{x} \cdot \omega
\end{aligned}
$$

podemos escrever as equações 2.57 e 2.58 como

$$
u_{\omega}(\mathbf{x})=\lambda \frac{\phi(\mathbf{x})}{\phi(\mathbf{x})^{2}+\varphi(\mathbf{x})^{2}}
$$

$\mathrm{e}$

$$
v_{\omega}(\mathbf{x})=\lambda \frac{\varphi(\mathbf{x})}{\phi(\mathbf{x})^{2}+\varphi(\mathbf{x})^{2}}
$$

Estamos interessados na geometria associada às novas variáveis $u_{\omega}$ e $v_{\omega}$. Logo, podemos desconsiderar aqui o valor de $\lambda$ pois é apenas um fator de reescala, para podermos simplesmente escrever:

$$
u_{\omega}(\mathbf{x})=\frac{\phi(\mathbf{x})}{\phi(\mathbf{x})^{2}+\varphi(\mathbf{x})^{2}}
$$

$\mathrm{e}$

$$
v_{\omega}(\mathbf{x})=\frac{\varphi(\mathbf{x})}{\phi(\mathbf{x})^{2}+\varphi(\mathbf{x})^{2}}
$$


É importante observar que, sendo nosso domínio de interesse a bola unitária, o potencial complexo encontrado é uma função analítica no interior do domínio e $-u_{\omega}$ e $v_{\omega}$ são funções harmônicas conjugadas. Em termos práticos, a função $\mathrm{x} \mapsto\left(-u_{\omega}, v_{\omega}\right)$ é uma transformação conforme entre o domínio e o semi-plano superior $\left\{v_{\omega}>1 / 2\right\}$. Assim, os ângulos das interseç̧ões entre as linhas $u_{\omega} \equiv$ cte e $v_{\omega} \equiv$ cte são ortogonais em ambos os domínios.
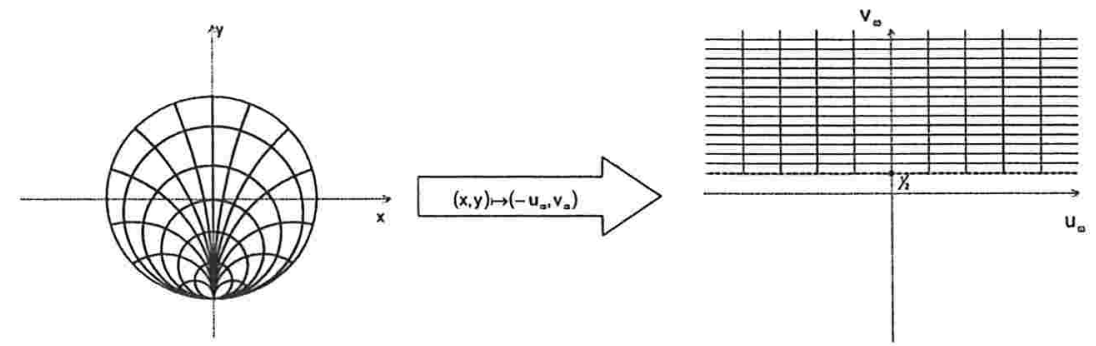

Figura 2.3: Transformação conforme entre o domínio $\Omega$ e o semi-plano $\left\{v_{\omega}>1 / 2\right\}$

\subsection{Cálculo do BackProjection}

Com base no que foi desenvolvido até aqui, o BackProjection calcula a variação de condutividade $\delta \sigma$ correspondente à variação de voltagem $\delta u$ detectada na fronteira de $\Omega$. É necessário, portanto, introduzir um meio de referência, que será escolhido como $\sigma \equiv 1$, ou seja, o meio de referência é o meio homogêneo. A situação de dipolo elétrico é assumida tanto no meio de referência quanto no meio de estudo. Com estas hipóteses, o problema 2.27 torna-se:

$$
\left\{\begin{array}{lll}
\nabla^{2}(\delta u)=-\nabla(\delta \sigma) \cdot \nabla u, & \text { em } & \Omega \\
\frac{\partial(\delta u)}{\partial \mathbf{n}}=-\delta \sigma \frac{\partial u}{\partial \mathbf{n}}, & \text { em } & \partial \Omega
\end{array}\right.
$$

Nas equações acima, $u$ é o potencial do dipolo elétrico, explicitado na equação 2.62. Se considerarmos as variáveis $u_{\omega}$ e $v_{\omega}$ temos, portanto,

$$
u\left(u_{\omega}, v_{\omega}\right)=u_{\omega}
$$

Pode-se mostrar que o Laplaciano nestas coordenadas escreve-se como:

$$
\nabla_{(x, y)}^{2} g=\frac{\partial^{2} g}{\partial x^{2}}+\frac{\partial^{2} g}{\partial y^{2}}=\rho^{2}\left(\frac{\partial^{2} f}{\partial u_{\omega}^{2}}+\frac{\partial^{2} f}{\partial v_{\omega}^{2}}\right)=\rho^{2} \nabla_{\left(u_{\omega}, v_{\omega}\right)}^{2} f
$$


onde $\rho^{2}=\left\|\nabla_{(x, y)} u_{\omega}\right\|^{2}$ e $f\left(u_{\omega}(x, y), v_{\omega}(x, y)\right)=g(x, y)$. Da mesma forma, o gradiente escrevese como

$$
\nabla_{(x, y)} g=\left[\begin{array}{cc}
\frac{\partial u_{\omega}}{\partial x} & \frac{\partial u_{\omega}}{\partial y} \\
\frac{\partial u_{\omega}}{\partial y} & -\frac{\partial u_{\omega}}{\partial x}
\end{array}\right] \nabla_{\left(u_{\omega}, v_{\omega}\right)} f
$$

Logo, a primeira equação de 2.66 escreve-se, nas coordenadas $\left(u_{\omega}, v_{\omega}\right)$, como:

$$
\begin{gathered}
\rho^{2} \nabla_{\left(u_{\omega}, v_{\omega}\right)}^{2}(\delta u)=-\left(\left[\begin{array}{cc}
\frac{\partial u_{\omega}}{\partial x} & \frac{\partial u_{\omega}}{\partial y} \\
\frac{\partial u_{\omega}}{\partial y} & -\frac{\partial u_{\omega}}{\partial x}
\end{array}\right] \nabla_{\left(u_{\omega}, v_{\omega}\right)}(\delta \sigma)\right) \cdot\left(\left[\begin{array}{cc}
\frac{\partial u_{\omega}}{\partial x} & \frac{\partial u_{\omega}}{\partial y} \\
\frac{\partial u_{\omega}}{\partial y} & -\frac{\partial u_{\omega}}{\partial x}
\end{array}\right] \nabla_{\left(u_{\omega}, v_{\omega}\right)} u\right) \Longrightarrow \\
\Longrightarrow \rho^{2} \nabla_{\left(u_{\omega}, v_{\omega}\right)}^{2}(\delta u)=-\left(\left[\begin{array}{cc}
\frac{\partial u_{\omega}}{\partial x} & \frac{\partial u_{\omega}}{\partial y} \\
\frac{\partial u_{\omega}}{\partial y} & -\frac{\partial u_{\omega}}{\partial x}
\end{array}\right]^{2} \nabla_{\left(u_{\omega}, v_{\omega}\right)}(\delta \sigma)\right) \cdot \nabla_{\left(u_{\omega}, v_{\omega}\right)} u \Longrightarrow \\
\Longrightarrow \rho^{2} \nabla_{\left(u_{\omega}, v_{\omega}\right)}^{2}(\delta u)=-\left(\left[\begin{array}{cc}
\rho^{2} & 0 \\
0 & \rho^{2}
\end{array}\right] \nabla_{\left(u_{\omega}, v_{\omega}\right)}(\delta \sigma)\right) \cdot \nabla_{\left(u_{\omega}, v_{\omega}\right)} u=-\rho^{2}\left(\nabla_{\left(u_{\omega}, v_{\omega}\right)}(\delta \sigma) \cdot \nabla_{\left(u_{\omega}, v_{\omega}\right)} u\right)
\end{gathered}
$$

e, portanto,

$$
\nabla_{\left(u_{\omega}, v_{\omega}\right)}^{2}(\delta u)=-\nabla_{\left(u_{\omega}, v_{\omega}\right)}(\delta \sigma) \cdot \nabla_{\left(u_{\omega}, v_{\omega}\right)} u
$$

No meio de referência, a geometria do potencial refere-se às linhas equipotenciais dadas por $u_{\omega} \equiv$ cte. Logo, não há variação de $u$ na direção de $v_{\omega}$ e, portanto, o último termo do lado direito da equação 2.70 se anula. Unindo esta observação com a equação 2.67 , obtém-se:

$$
\nabla_{\left(u_{\omega}, v_{\omega}\right)}^{2}(\delta u)=-\frac{\partial(\delta \sigma)}{\partial u_{\omega}} \underbrace{\frac{\partial u}{\partial u_{\omega}}}_{=1}-\frac{\partial(\delta \sigma)}{\partial v_{\omega}} \underbrace{\frac{\partial u}{\partial v_{\omega}}}_{=0}=-\frac{\partial(\delta \sigma)}{\partial u_{\omega}}
$$

Com relação à condição de contorno, o vetor normal à fronteira do domínio transformado $\left\{v_{\omega}>1 / 2\right\}$ é dado por $(0,1)_{\left(u_{\omega}, v_{\omega}\right)}$. Com isso, as variações de $u$ e $\delta u$ na direção normal à fronteira são proporcionais à variação deles na direção de $v_{\omega}$. Novamente, como não há variação de $u$ na direção de $v_{\omega}$, conclui-se que

$$
-\delta \sigma \frac{\partial u}{\partial \mathbf{n}} \propto-\delta \sigma \frac{\partial u}{\partial v_{\omega}}=0 \Longrightarrow-\delta \sigma \frac{\partial u}{\partial \mathbf{n}}=0
$$

e, desta forma,

$$
\frac{\partial(\delta u)}{\partial v_{\omega}} \propto \frac{\partial(\delta u)}{\partial \mathbf{n}}=0 \Longrightarrow \frac{\partial(\delta u)}{\partial v_{\omega}}=0
$$


Logo, a condição de fronteira torna-se:

$$
\frac{\partial(\delta u)}{\partial v_{\omega}}=0
$$

Com as equações 2.71 e 2.74 , o problema, nas coordenadas $\left(u_{\omega}, v_{\omega}\right)$ torna-se:

$$
\left\{\begin{array}{lll}
\nabla_{\left(u_{\omega}, v_{\omega}\right)}^{2}(\delta u)=-\frac{\partial(\delta \sigma)}{\partial u_{\omega}}, & \text { em } & \left\{v_{\omega}>1 / 2\right\} \\
\frac{\partial(\delta u)}{\partial v_{\omega}}=0, & \text { em } & \left\{v_{\omega}=1 / 2\right\}
\end{array}\right.
$$

Barber [6] observou que uma solução do problema 2.75 é dada por

$$
\delta \sigma=-\frac{\partial(\delta u)}{\partial u_{\omega}}\left(u_{\omega}, 1 / 2\right)
$$

que pode ser verificada por inspeção direta. Esta solução refere-se à variação de condutividade detectada por uma posição fixada do dipolo. Barber [6] sugeriu que uma aproximação para a variação de condutividade do meio pode ser identificada através das variações detectadas por diferentes posições dos dipolos, representada pela média

$$
B(\mathbf{x})=-\frac{1}{2 \pi} \int_{\|\omega\|=1}\left(\frac{\partial(\delta u)}{\partial u_{\omega}}\left(u_{\omega}(\mathbf{x}), 1 / 2, \omega\right)\right)\left(2 v_{\omega}(\mathbf{x})-1\right) d S_{\omega}
$$

O parâmetro $\omega$ dentro da derivada parcial do integrando é para indicar o dipolo ao qual a variação se refere. Santosa [21] demonstrou que a integral acima pode ser encarada como uma aproximação de primeira ordem de $\delta \sigma$, utilizando Transformada Generalizada de Radon, comprovando que Barber acertou na escolha tanto do integrando quanto da ponderação, mesmo que tenha utilizado um método heurístico para a construção da integral.

Ainda em Santosa [21], sugere-se que a derivada parcial do integrando fosse calculada através de

$$
\frac{\partial(\delta u)}{\partial u_{\omega}}\left(u_{\omega}(\mathbf{x}), 1 / 2, \omega\right)=\frac{\frac{\partial(\delta u)}{\partial \tau}}{\frac{\partial u}{\partial \tau}}\left(u_{\omega}(\mathbf{x}), 1 / 2, \omega\right)
$$

A razão para a expressão acima consiste na coleta de informações. $\mathrm{Na}$ hipótese do dipolo elétrico, $u$ coincide com $u_{\omega}$. Porém, para o cálculo de $u_{\omega}$, precisaríamos estimar, por exemplo, o parâmetro $\lambda$ das equações 2.57 e 2.58, ou então obter as medidas empiricamente. No caso do algoritmo, a segunda opção está prevista. Apenas para não criar confusão entre sistemas de coordenadas e medidas, utilizou-se $u$ e não $u_{\omega}$ na equação 2.78. Assim, pode-se estimar a derivada parcial do integrando de 2.77 calculando-se as variações de $\delta u$ e $u$ tangenciais à fronteira do domínio $\Omega$. 
Definindo a grandeza $W$ como

$$
W(\mathbf{s}, \omega)=-\frac{\frac{\partial}{\partial \tau} \delta u(\mathbf{s}, \omega)}{\frac{\partial}{\partial \tau} u(\mathbf{s}, \omega)}
$$

reescreve-se a integral 2.77 como

$$
B(\mathbf{x})=-\frac{1}{2 \pi} \int_{\|\omega\|=1} W\left(u_{\omega}(\mathbf{x}), \omega\right)\left(2 v_{\omega}(\mathbf{x})-1\right) d S_{\omega}
$$

O parâmetro $1 / 2$ foi omitido das fórmulas anteriores, mas deve-se subentender que o cálculo das variações de $u$ e $\delta u$ devem ser feitos na fronteira do domínio.

O método de BackProjection baseia-se no cálculo da integral 2.80 para todos os pontos do domínio $\Omega$. Por ser uma aproximação da solução real $\delta \sigma$, espera-se que sua implementação numérica precise de um tratamento mais sofisticado do que simplesmente o cálculo numérico da integral. Veremos, no próximo capítulo, detalhes da implementação do algoritmo e filtros que ajudarão a melhorar a qualidade da solução final gerada. 


\section{Capítulo 3}

\section{Implementação Numérica}

Neste capítulo, trataremos das questões relacionadas à implementação do algoritmo de BackProjection, considerando desde o tratamento na entrada de dados até a imagem de saída.

Em sua essência, o BackProjection é implementado através do cálculo da integral

$$
B(\mathbf{x})=\frac{1}{2 \pi} \int_{\|\omega\|=1} W\left(u_{\omega}(\mathbf{x}), \omega\right)\left(2 v_{\omega}(\mathbf{x})-1\right) d S_{\omega}
$$

onde $\mathrm{x}$ é um ponto do domínio considerado. A integral é calculada sobre a posição $\omega$ do dipolo. A grandeza $W(s, \omega)$ é dada por

$$
W(\mathbf{s}, \omega)=-\frac{\frac{\partial}{\partial \tau} \delta u(\mathbf{s}, \omega)}{\frac{\partial}{\partial \tau} u(\mathbf{s}, \omega)}
$$

e os valores de $u_{\omega}$ e $v_{\omega}$ são oriundos das equações (2.64) e (2.65):

$$
\begin{aligned}
& u_{\omega}(\mathbf{x})=\frac{\mathbf{x} \cdot \omega^{\perp}}{\left(\mathbf{x} \cdot \omega^{\perp}\right)^{2}+(1-\mathbf{x} \cdot \omega)^{2}} \\
& v_{\omega}(\mathbf{x})=\frac{1-\mathbf{x} \cdot \omega}{\left(\mathbf{x} \cdot \omega^{\perp}\right)^{2}+(1-\mathbf{x} \cdot \omega)^{2}}
\end{aligned}
$$

A grandeza $W$ é a razão entre $\delta u$, a variação de potencial entre os meios de estudo e de referência, e $u$, o potencial efetivamente medido no meio de referência. As derivadas são calculadas na direção da variável $v_{\omega}$, lembrando que $\left(u_{\omega}, v_{\omega}\right)$ definem um novo sistema de coordenadas.

O cálculo de $W$ é baseado no valor de potencial associado ao ponto $\mathbf{x}$, mas nem sempre é possível tomar medidas no interior do domínio. No caso da TPA aplicada para obtenção de imagens do tórax, $\delta u$ e $u$ não podem ser medidas em x. Utilizando a hipótese de que o meio de referência é um meio homogêneo e, portanto, as linhas equipotenciais são bem definidas, 
podemos estimar as grandezas $\delta u$ e $u$ a partir do ponto da fronteira $\left(\mathrm{x}^{f}\right)$ cujo nível de linha equipotencial é o mesmo do ponto $\mathbf{x}$ (Figura 3.1).

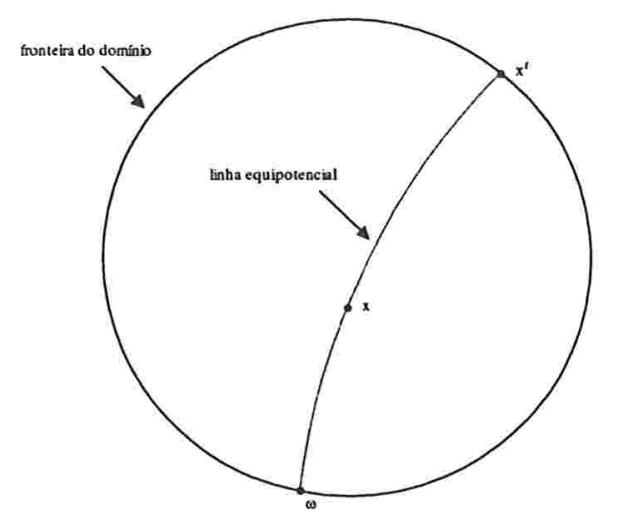

Figura 3.1: Linha equipotencial utilizada no cálculo de $W(\mathbf{s}, \omega)$.

Dessa forma, teremos:

$$
\delta u\left(u_{\omega}(\mathbf{x}), \omega\right)=\delta u\left(u_{\omega}\left(\mathbf{x}^{f}\right), \omega\right)
$$

$\mathrm{e}$

$$
u\left(u_{\omega}(\mathbf{x}), \omega\right)=u\left(u_{\omega}\left(\mathbf{x}^{f}\right), \omega\right)
$$

Como essas igualdades são válidas para todo x no domínio, teremos:

$$
W\left(u_{\omega}(\mathbf{x}), \omega\right)=W\left(u_{\omega}\left(\mathbf{x}^{f}\right), \omega\right)
$$

Com base nos dados tomados na fronteira, podemos calcular a integral para todos os pontos no interior do domínio. Isto é essencial para a implementação de uma técnica de diagnóstico não-invasiva.

Com relação ao termo $2 v_{\omega}(\mathbf{x})-1$, sua função será a ponderação no cálculo da integral. À medida que o ponto $\mathrm{x}$ fica próximo à posição do dipolo, o termo $v_{\omega}(\mathrm{x})$ cresce consideravelmente. $\mathrm{Na}$ integral, pontos em regiões próximas ao dipolo recebem uma maior ponderação.

Trataremos com mais detalhes do cálculo de $W$ e $2 v_{\omega}(\mathbf{x})-1$ nas próximas seções, quando iremos discretizar o cálculo da integral e mostrar sua implementação computacional. 


\subsection{Discretização da Integral do BackProjection}

A integral 3.1 pode ser reescrita da seguinte forma:

$$
B(\mathbf{x})=\frac{1}{2 \pi} \int_{0}^{2 \pi}\left[W\left(u_{\omega}(\mathbf{x}), \omega\right)\left(2 v_{\omega}(\mathbf{x})-1\right)\right]_{\omega=(\cos \theta, \sin \theta)} d \theta
$$

Para discretizá-la, consideremos $n+1$ posições sobre o círculo unitário, igualmente espaçadas, dadas por

$$
\omega_{i}=\left(\cos \theta_{i}, \sin \theta_{i}\right), i=0, \ldots, n
$$

onde $\theta_{i}=\frac{2 \pi i}{n}$. No caso, $\omega_{0}=\omega_{n}$ para podermos considerar uma fronteira fechada para o domínio. A aproximação para $B$ pelo método dos n-trapézios será dada por

$$
\begin{array}{rlr}
B(\mathbf{x}) & =\frac{1}{2 \pi}\left(\frac{2 \pi}{n}\right)\left[\frac{1}{2} W\left(u_{\omega_{0}}(\mathbf{x}), \omega_{0}\right)\left(2 v_{\omega_{0}}(\mathbf{x})-1\right)+\right. \\
& +\sum_{i=1}^{n-1} W\left(u_{\omega_{i}}(\mathbf{x}), \omega_{i}\right)\left(2 v_{\omega_{i}}(\mathbf{x})-1\right)+ \\
& \left.+\frac{1}{2} W\left(u_{\omega_{n}}(\mathbf{x}), \omega_{n}\right)\left(2 v_{\omega_{n}}(\mathbf{x})-1\right)\right] \\
& +E(\eta)
\end{array}
$$

onde

$$
E(\eta)=-\frac{(2 \pi)^{3}}{12 n^{2}} \frac{\partial^{2}}{\partial \theta^{2}}\left[W\left(u_{\omega}(\mathbf{x}), \omega\right)\left(2 v_{\omega}(\mathbf{x})-1\right)\right]_{\omega=(\cos \eta, \sin \eta)}
$$

para algum $\eta \in(0,2 \pi)$. Como $\omega_{0}=\omega_{n}$, podemos estimar $B$ por

$$
B(\mathbf{x}) \approx \tilde{B}(\mathbf{x})=\frac{1}{n}\left[\sum_{i=1}^{n} W\left(u_{\omega_{i}}(\mathbf{x}), \omega_{i}\right)\left(2 v_{\omega_{i}}(\mathbf{x})-1\right)\right]
$$

A determinação do número $n$ está diretamente condicionada ao número total de eletrodos do hardware. Do ponto de vista matemático, é desejável conhecer as voltagens na fronteira de forma contínua, o que implica em termos infinitos eletrodos na fronteira. Porém, independentemente do fator custo, não há tecnologia capaz de representar essa situação. Atualmente, devido à interferência de sinal e ruído, é muito difícil construir um equipamento com grande quantidade de eletrodos. Assim, $n$ é um parâmetro que será fornecido pelo experimento, e não definido pelo algoritmo.

\subsection{Cálculo da grandeza $W$}

Para o cálculo dos valores $W\left(u_{\omega_{i}}(\mathbf{x}), \omega_{i}\right)$, vamos utilizar as igualdades 3.5 e 3.6. Para isso, devemos determinar os pontos $\mathbf{x}^{f}$ que dependem da posição $\omega$ dos dipolos e do ponto $\mathbf{x}$ : 


$$
\mathbf{x}^{f}=\mathbf{x}^{f}(\mathbf{x}, \omega)
$$

Pode-se mostrar (Apêndice A) que o ponto $\mathbf{x}^{f}$ que satisfaz a condição $u_{\omega}(\mathbf{x})=u_{\omega}\left(\mathbf{x}^{f}\right)$, quando $\mathrm{x} \neq 0$, é dado por

$$
\mathbf{x}^{f}(\mathbf{x}, \omega)=2 \frac{\omega \cdot \mathbf{x}^{c}}{\left\|\mathbf{x}^{c}\right\|^{2}} \mathbf{x}^{c}-\omega
$$

onde

$$
\mathbf{x}^{c}(\mathbf{x}, \omega)=\omega+\beta \omega^{\perp}
$$

e

$$
\beta(\mathbf{x}, \omega)=\frac{1}{2} \frac{\|\omega-\mathbf{x}\|^{2}}{\omega^{\perp} \cdot \mathbf{x}}
$$

A partir das equações anteriores, para $\mathbf{x}=(0.3,-0.2)$ e $n=8$, as posições $\mathbf{x}^{f}$ para cada dipolo são dadas na tabela 3.1.

\begin{tabular}{|c|c|c|c|c|c|}
\hline $\mathrm{i}$ & $\theta_{i}$ & \multicolumn{2}{|c|}{$\omega_{i}$} & \multicolumn{2}{c|}{$\mathrm{x}^{f}\left(\mathrm{x}, \omega_{i}\right)$} \\
\hline 0 & 0.0000 & 1.0000 & 0.0000 & -0.2742 & -0.9617 \\
\hline 1 & 0.7854 & 0.7071 & 0.7071 & 0.4407 & -0.8976 \\
\hline 2 & 1.5708 & 0.0000 & 1.0000 & 0.6798 & -0.7334 \\
\hline 3 & 2.3562 & -0.7071 & 0.7071 & 0.8070 & -0.5906 \\
\hline 4 & 3.1416 & -1.0000 & 0.0000 & 0.8985 & -0.4390 \\
\hline 5 & 3.9270 & -0.7071 & -0.7071 & 0.9737 & -0.2277 \\
\hline 6 & 4.7124 & 0.0000 & -1.0000 & 0.9811 & 0.1936 \\
\hline 7 & 5.4978 & 0.7071 & -0.7071 & -0.1395 & 0.9902 \\
\hline 8 & 6.2832 & 1.0000 & 0.0000 & -0.2742 & -0.9617 \\
\hline
\end{tabular}

Tabela 3.1: Valores de $\mathrm{x}^{f}$ para diferentes posições do dipolo

A distribuição dos pontos $\mathrm{x}^{f}(\mathrm{x}, \omega)$ é mostrada na figura 3.2.

Notemos que há uma concentração de pontos $\mathrm{x}^{f}(\mathrm{x}, \omega)$ na região sudeste do círculo unitário e, quanto mais próximo o ponto $\mathbf{x}$ da fronteira, maior será a concentração de pontos $\mathbf{x}^{f}$, conforme as figuras 3.3 e 3.4, lembrando que os dipolos estão distribuídos de forma homogênea no círculo unitário. 


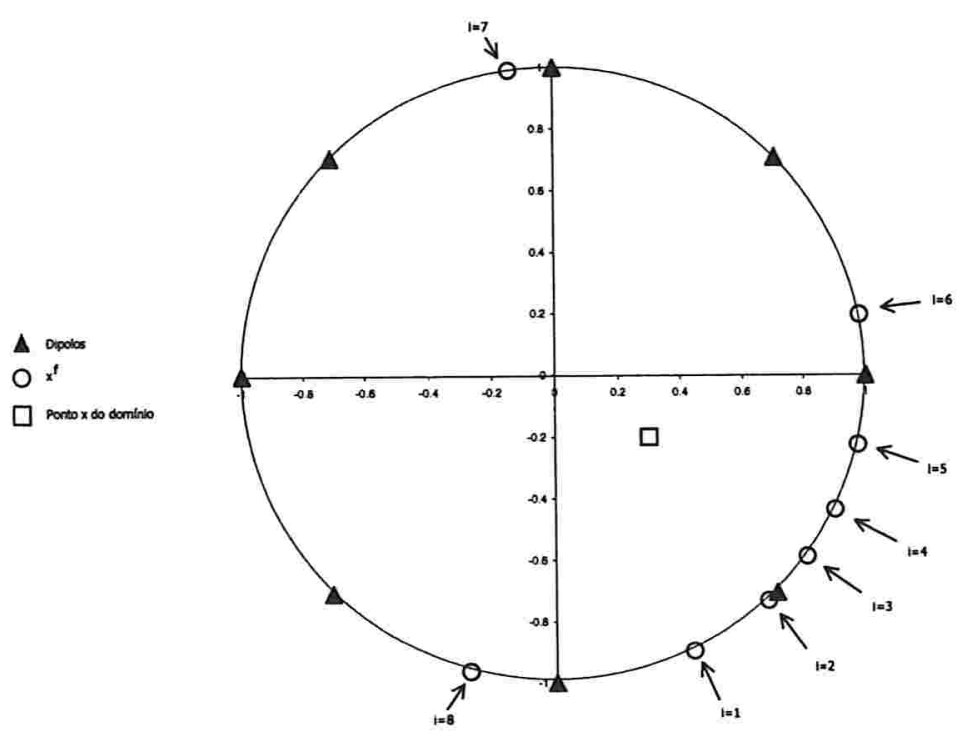

Figura 3.2: Pontos $\mathbf{x}^{f}$ para $n=8$ e $\mathbf{x}=(0.3,-0.2)$

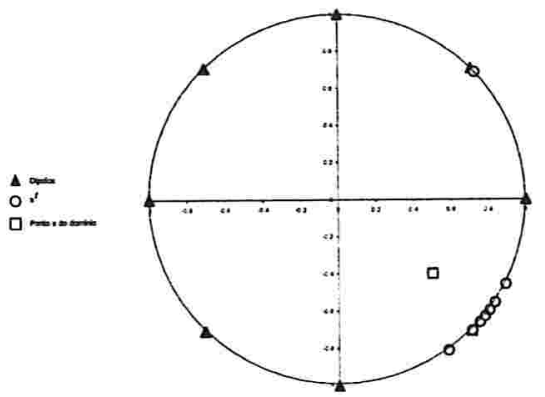

Figura 3.3: Pontos $\mathbf{x}^{f}$ para $n=8$ e $\mathbf{x}=(0.5,-0.4)$

O único caso em que tais pontos estarão igualmente espaçados será quando $\mathbf{x}=0$. Neste caso, os pontos $\mathrm{x}^{f}$ são os pontos do círculo diametralmente opostos aos dipolos.

Desta forma, não é possível garantir a obtenção de $W$ apenas nos pontos correspondentes 


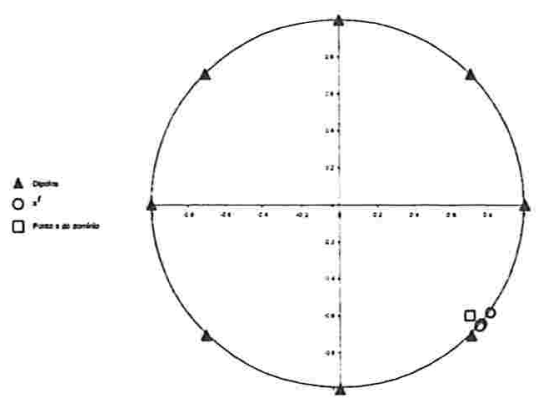

Figura 3.4: Pontos $\mathrm{x}^{f}$ para $n=8$ e $\mathrm{x}=(0.7,-0.6)$

às posições dos dipolos, sendo necessário utilizar uma função aproximadora para estimar a função nos outros pontos da fronteira do domínio $\Omega$.

Para tanto, as derivadas $\partial u / \partial \tau$ e $\partial(\delta u) / \partial \tau$ nesses pontos serão calculadas através de diferenças finitas centradas, baseadas nas medições de voltagens nos eletrodos. Com isso, as estimativas para as derivadas serão feitas justamente sobre as possíveis posições dos dipolos no círculo unitário.

Para ilustrarmos a situação, consideremos $n=8$ e $\omega_{0}=0$. Teremos a disposição dos eletrodos como na figura 3.5 .

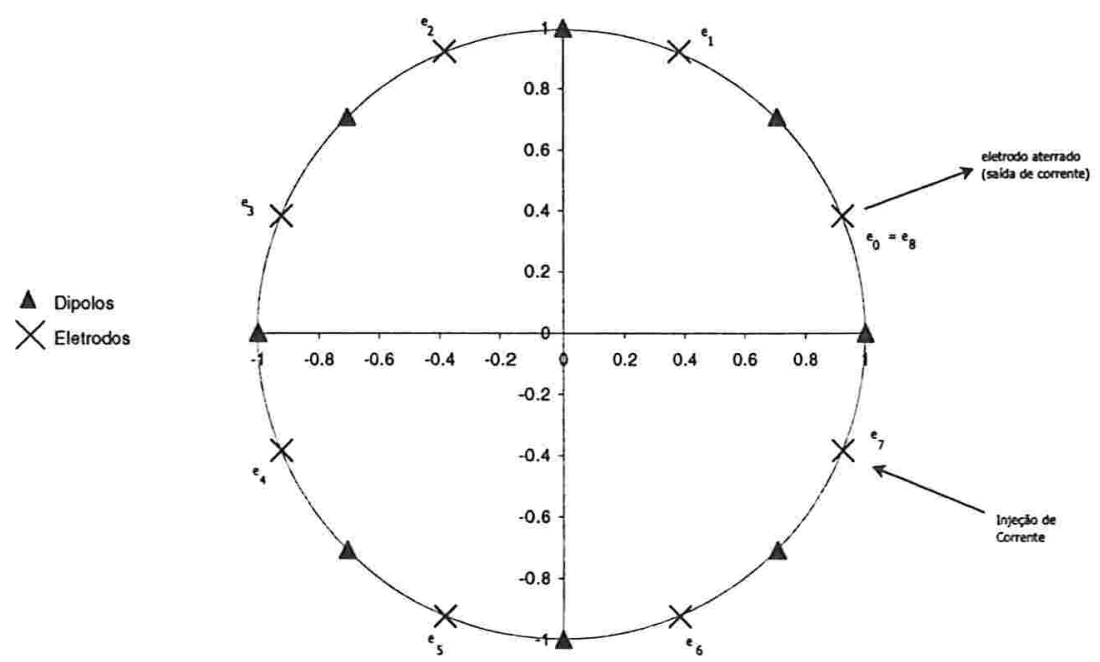

Figura 3.5: Disposição dos eletrodos para $n=8$ e $\omega_{0}=0$ 
Chamando os pontos da fronteira que representam os eletrodos de

$$
e_{k}=\left(\cos \left(\psi_{k}+\frac{\pi}{8}\right), \sin \left(\psi_{k}+\frac{\pi}{8}\right)\right), k=0, \ldots, 8, \psi_{k}=\frac{2 \pi k}{8}
$$

são obtidos os valores de $u\left(u_{\omega_{0}}\left(e_{k}\right), \omega_{0}\right)$ do experimento. Dessa forma, uma estimativa válida de $\partial u / \partial \tau$ para o ponto $e_{k+\frac{1}{2}}$, que é o ponto médio sobre o arco de circunferência entre $e_{k} \mathrm{e}$ $e_{k+1}$, será:

$$
\frac{\partial u}{\partial \tau}\left(u_{\omega_{0}}\left(e_{k+\frac{1}{2}}\right), \omega_{0}\right) \approx \frac{u\left(u_{\omega_{0}}\left(e_{k+1}\right), \omega_{0}\right)-u\left(u_{\omega_{0}}\left(e_{k}\right), \omega_{0}\right)}{\left\|e_{k+1}-e_{k}\right\|}
$$

Geometricamente, $e_{k+\frac{1}{2}}$ é o mesmo ponto $\omega_{k+1}$. Porém, não faremos essa associação, pois os pontos têm funções diferentes no algoritmo.

Considerando a equação 3.18, se denotarmos por $u^{*}$ as voltagens no meio estudado e por $u$ as voltagens no meio homogêneo, a grandeza $W$, nos pontos $e_{k+\frac{1}{2}}$, é dada por

$$
W_{k, 0}=W\left(u_{\omega_{0}}\left(e_{k+\frac{1}{2}}\right), \omega_{0}\right) \approx 1-\frac{u^{*}\left(u_{\omega_{0}}\left(e_{k+1}\right), \omega_{0}\right)-u^{*}\left(u_{\omega_{0}}\left(e_{k}\right), \omega_{0}\right)}{u\left(u_{\omega_{0}}\left(e_{k+1}\right), \omega_{0}\right)-u\left(u_{\omega_{0}}\left(e_{k}\right), \omega_{0}\right)}
$$

Convencionando que $W_{8,0}=W_{0,0}$, podemos usar os pontos $\left\{W_{k, 0}\right\}_{k=0, \ldots, 8}$ para estimar uma função aproximadora $\tilde{W}_{0}$ tal que

$$
\tilde{W}_{0}\left(\frac{2 \pi k}{8}\right)=W_{k, 0}, k=0, \ldots, 8
$$

Todo o processo pode ser feito para $n$ genérico e $\omega_{i}$ como na equação 3.9 para obtermos funções aproximadoras da forma:

$$
\tilde{W}_{i}:[0,2 \pi] \longrightarrow \mathbb{R}, i=0, \ldots, n
$$

tal que

$$
\tilde{W}_{i}\left(\theta_{k}\right)=W_{k, i}, i, k=0, \ldots, n
$$

onde

$$
W_{k, i}=1-\frac{u^{*}\left(u_{\omega_{i}}\left(e_{k+1}\right), \omega_{i}\right)-u^{*}\left(u_{\omega_{i}}\left(e_{k}\right), \omega_{i}\right)}{u\left(u_{\omega_{i}}\left(e_{k+1}\right), \omega_{i}\right)-u\left(u_{\omega_{i}}\left(e_{k}\right), \omega_{i}\right)}
$$

Os valores de $u^{*}\left(u_{\omega_{i}}\left(e_{k}\right), \omega_{i}\right)$ e $u\left(u_{\omega_{i}}\left(e_{k}\right), \omega_{i}\right)$ são os valores de voltagens tomados nos eletrodos respectivamente nos meios de estudo e de referência. Tais valores darão origem à matriz $\left[W_{k, i}\right]$, onde a linha $i$ representa o padrão de voltagens gerado pela injeção de corrente 
pelo par de eletrodos $\left(e_{i-1}, e_{i}\right)$, que dá origem ao dipolo $\omega_{i}$ (considere $e_{-1}=e_{7}$ ). Introduzindo a notação

$$
u_{k, i}^{*}=u^{*}\left(u_{\omega_{i}}\left(e_{k}\right), \omega_{i}\right)
$$

e

$$
u_{k, i}=u\left(u_{\omega_{i}}\left(e_{k}\right), \omega_{i}\right)
$$

podemos reescrever 3.23 como

$$
W_{k, i}=1-\frac{u_{k+1, i}^{*}-u_{k, i}^{*}}{u_{k+1, i}-u_{k, i}}
$$

Como podemos observar em 3.26, o número $W_{k, i}$ representa uma variação percentual de mudança das voltagens do meio de referência para o meio de estudo. Como temos $W\left(u_{\omega}(\mathbf{x}), \omega\right)=W\left(u_{\omega}\left(\mathbf{x}^{f}\right), \omega\right)$, onde $\mathbf{x}$ é um ponto do domínio e $\mathbf{x}^{f}$ é dado por 3.14 , o método de BackProjection propaga essa variação percentual ao longo da linha equipotencial dada por $u_{\omega}\left(\mathrm{x}^{f}\right)$. Assim, o resultado da expressão 3.12 será a variação percentual de condutividade detectada no ponto de estudo $\mathbf{x}$, do meio de referência para o meio de estudo.

Para as funções aproximadoras $\tilde{W}_{i}$, Santosa [21] sugeriu que se utilizasse a interpolação linear dos valores de $W_{k, i}$. Esta solução é a mais simples e a de mais fácil implementação. Porém, trabalharemos também com as alternativas de Séries de Fourier e Splines Cúbicos. Séries de Fourier são amplamente utilizadas no tratamento de sinais sendo, portanto, aplicáveis ao nosso problema. Splines Cúbicos permitem a construção de uma função aproximadora mais suave e mais estável no sentido de evitar variações bruscas na função, como ocorre nas interpolações polinomiais simples. Uma comparação entre as implementações pode ser vista em [8].

\subsection{Algoritmo Preliminar}

A entrada de dados do algoritmo é composta pelo número de eletrodos utilizado, $n$, pelas matrizes de voltagens tanto do meio de referência, $\left[u_{k, i}\right]$, quanto do meio de estudo, $\left[u_{k, i}^{*}\right]$, assim como pela dimensão da imagem $N$ (a imagem será composta por uma matriz $N \times N$ ). A implementação é apresentada no Algoritmo 1.

Alguns comentários sobre essa primeira implementação do BackProjection: 


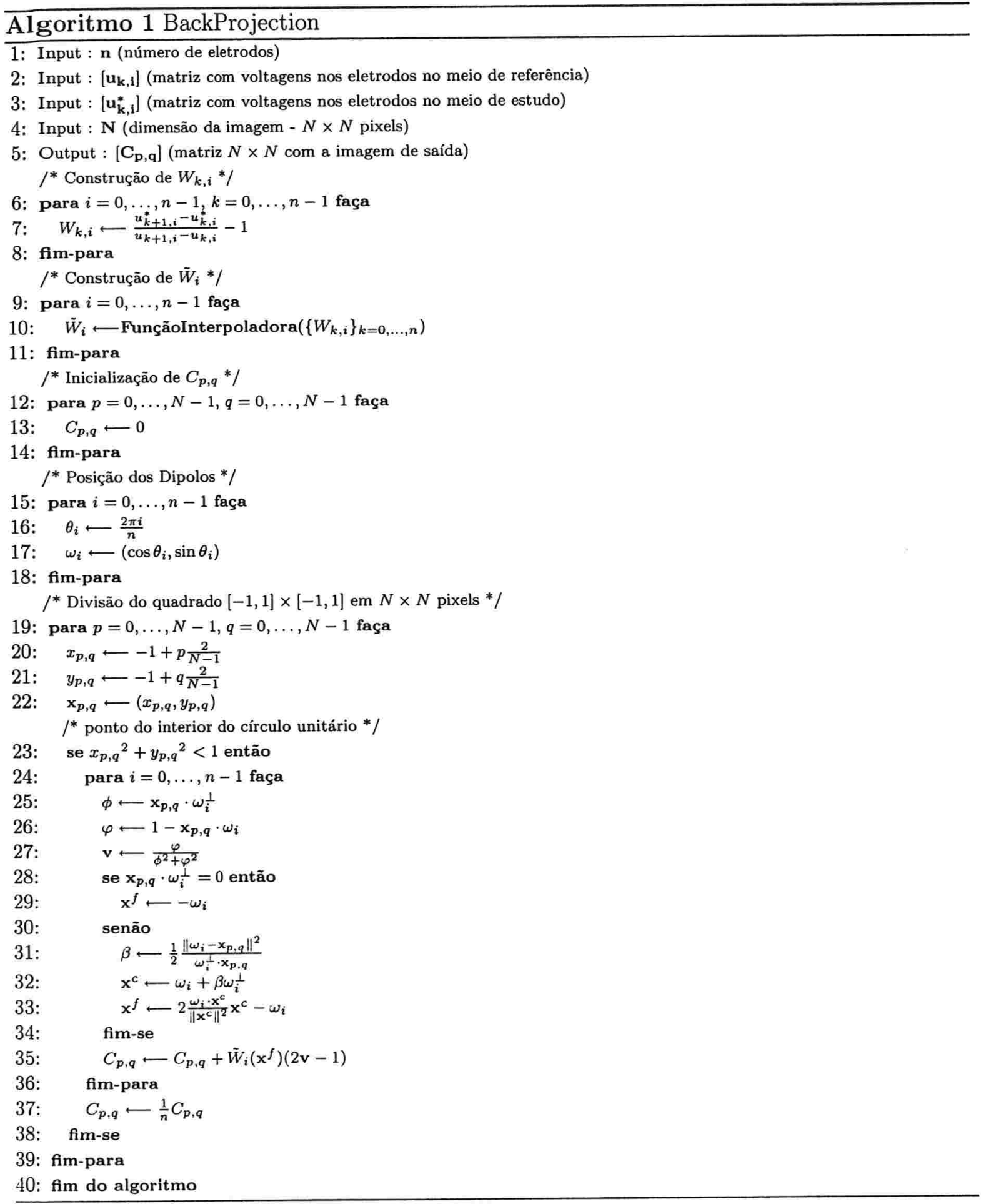


a) Em todas as partes do algoritmo, o eletrodo $n$ é também o eletrodo 0 . Assim, $u_{n, i}=u_{0, i}$, $u_{n, i}^{*}=u_{0, i}^{*}, u_{k, n}=u_{k, 0}, u_{k, n}^{*}=u_{k, 0}^{*}, W_{n, i}=W_{0, i}$ e $W_{k, n}=W_{k, 0}$.

b) A matriz de saída $\left(C_{p, q}\right)$, que representa o valor de condutividade em cada pixel, é uma matriz numérica ainda com a saída pura do algoritmo, sem tratamento para exibição na tela. Para tal, a faixa de valores deverá ser transformada numa escala de cores ou tons de cinza, para exibição na tela de um computador.

c) A função interpoladora que aparece na linha de $\tilde{W}_{i}$ poderá ser, como comentado antes, uma série de Fourier, Spline Cúbico ou simplesmente uma interpolação linear simples. A interpolação é função da posição do ponto sobre o círculo unitário.

d) O cálculo de $\phi, \varphi$ e v foram extraídos da sub-seção 2.6.2.

e) Aqui, cabe um comentário sobre os dados de entrada. Os valores armazenados nas matrizes $\left[u_{k, i}\right]$ e $\left[u_{k, i}^{*}\right]$ representam a diferença de potencial entre o eletrodo em questão e o eletrodo aterrado do padrão. Isto significa que $u_{k, i}$ é a diferença de potencial entre o eletrodo $e_{k}$ e o eletrodo $e_{i}$. O algoritmo, da forma como foi concebido, espera que as voltagens sejam tomadas dessa forma. Em caso de outro padrão de tomadas (por exemplo, a diferença entre de potencial entre dois eletrodos adjacentes), será necessário uma adaptação de algumas expressões do algoritmo apresentado para obtermos os mesmos resultados.

O algoritmo apresentado já é capaz de reconstruir imagens completas. Para verificarmos seu desempenho, vamos rodar o algoritmo para dados simulados, fornecidos através de programa desenvolvido pelo Departamento de Engenharia Mecânica da Escola Politécnica (USP), baseado em um método de Elementos Finitos (Molina [19]) que produz voltagens com um erro estimado de $1 \%$. A interface gráfica do programa é exibida na figura 3.6.

A malha de elementos finitos a ser usada possui 1.224 elementos triangulares e 32 elementos de 4 arestas representando os eletrodos. Para a simulação, consideraremos esses 32 eletrodos dispostos na fronteira de um domínio circular homogêneo de condutividade 1 (Ohm-m $)^{-1}$, onde uma corrente de $1 \mathrm{~mA}$ será injetada, usando o padrão adjacente. Com isso, o programa irá fornecer os dados de voltagens para os eletrodos. A seguir, uma região circular ocupando cerca de $5 \%$ da área total do domínio será colocada a nordeste do centro do domínio, de acordo com a figura 3.7, e sua condutividade será de $(1.003 \mathrm{Ohm}-\mathrm{m})^{-1}$. Novamente, o programa irá simular os valores de voltagens para os eletrodos para a mesma injeção de corrente. 


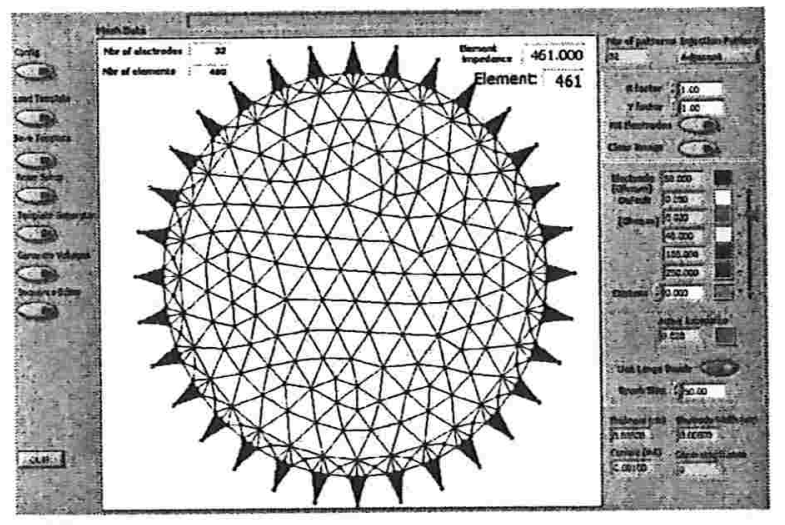

Figura 3.6: Tela do Programa Simulador de Voltagens

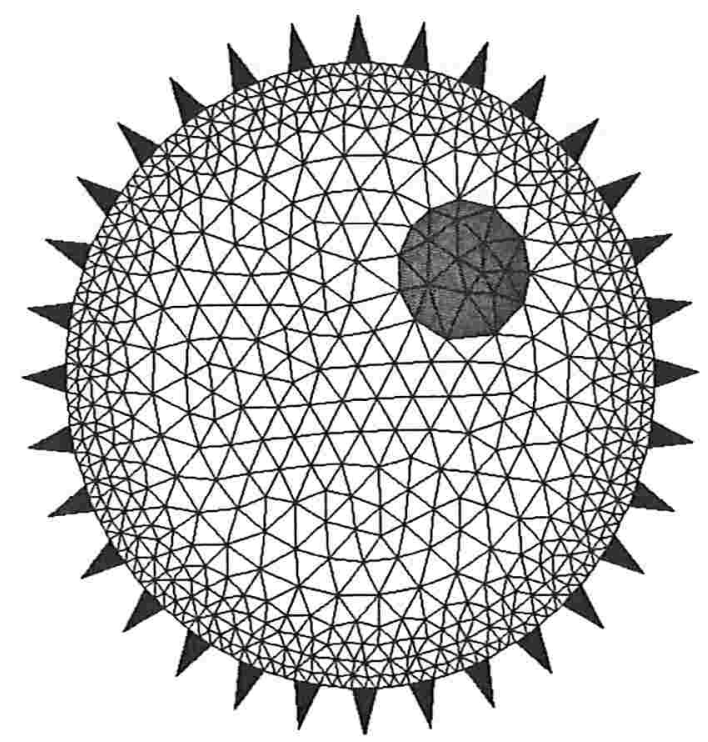

Figura 3.7: Problema Teste para o Algoritmo 1

Com as matrizes de entrada do método geradas, seus dados são aplicados ao algoritmo 1 , implementado através de programa escrito em $\mathrm{C}$, produzindo os resultados das figuras 3.8 e 3.9. Ambas as figuras possuem resolução de $64 \times 64$ pixels. Para a função interpoladora do algoritmo, foram utilizados Splines Cúbicos Naturais.

Por esses resultados, podemos verificar que, mesmo sendo apenas uma versão inicial, o algoritmo teve a capacidade de identificar o formato e a posição do objeto teste (figura 3.10). Porém, há alguns aspectos que podem ser aprimorados. Em primeiro lugar, há um forte ruído gerado na região da fronteira do domínio. Este efeito pode ser explicado se analisarmos a 

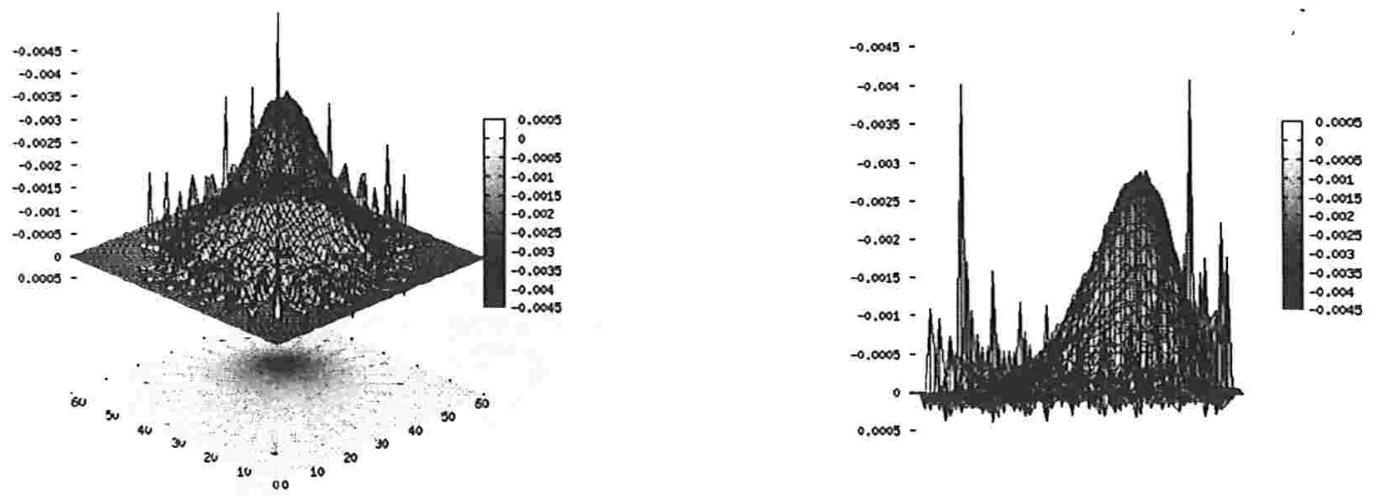

Figura 3.8: Visão Tridimensional dos Resultados do Teste Inicial - Algoritmo 1

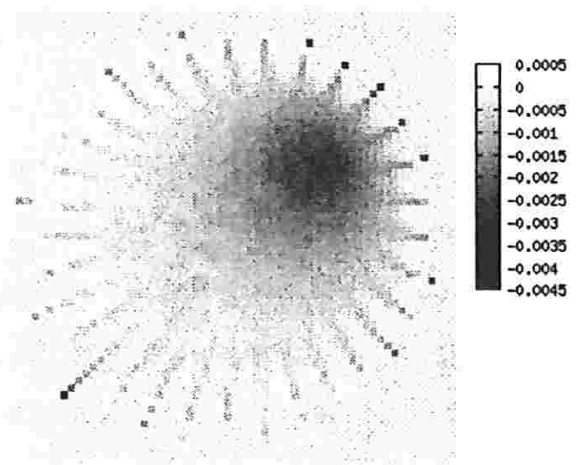

Figura 3.9: Visão Bidimensional dos Resultados do Teste Inicial - Algoritmo 1

equação 2.65 , que dá origem ao peso da integral 3.1. O denominador dessa equação refere-se à distância entre o ponto da imagem e a localização do dipolo. Logo, os dipolos que estão mais próximos do ponto terão maior ponderação do que os dipolos mais distantes, o que significa que qualquer ruído gerado pelo algoritmo nas proximidades da fronteira será amplificado pelo peso na imagem final, gerando o resultado visualizado.

Outra situação que podemos perceber pelos resultados apresentados está no espalhamento 


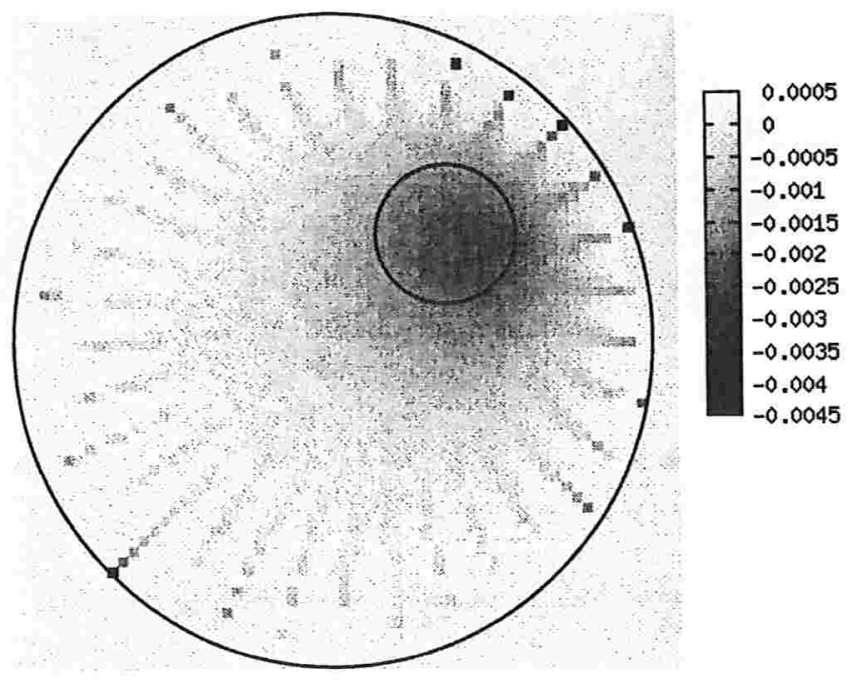

Figura 3.10: Comparação do Resultado do Teste Inicial com a Posição Real do Objeto - Algoritmo 1

da informação do objeto para outras regiões do domínio. Observando a figura 3.10, nota-se que a dimensão do objeto reconstruído é maior do que o tamanho do objeto real, mostrando que houve uma dispersão do valor de variação de condutividade detectado. Além disso, é visível que a informação do objeto espalhou-se na direção das linhas equipotenciais que saíram dos eletrodos e passaram pela região de interesse. A sugestão para a resolução destas questões está na aplicação de filtros pré e pós-processamento da imagem. Os filtros aplicados no préprocessamento atuarão sobre os dados de entrada, enquanto que os filtros pós-processamento farão um tratamento sobre os dados de variação de condutividade calculados pelo algoritmo.

\subsection{Pré-filtro dos dados de entrada}

Como vimos na seção anterior, precisamos obter duas matrizes, $\left[u_{k, i}^{*}\right]$ e $\left[u_{k, i}\right]$, para calcularmos a matriz de entrada do algoritmo, $\left[W_{k, i}\right]$. As duas primeiras matrizes representam dados simulados, calculados ou tomados empiricamente. Levando em consideração o último caso, defrontamo-nos com a possibilidade de ruídos nas medições.

Segundo Barber e Brown ([5] e [7]), uma das maiores dificuldades na implementação completa da TPA está nos eletrodos usados no experimento. Suas características de condutividade e resistividade são significantes se comparadas com as mesmas características dos 
tecidos humanos em baixas freqüências (altas freqüências estão descartadas por serem agressivas ao corpo humano). Segundo esses estudos, seria importante um sistema de coleta de dados com uma precisão de medida de menos de $1 \%$, mas a resistividade dos eletrodos prejudica a obtenção dessa precisão. Ainda de acordo com os estudos citados, os casos mais severos estão justamente nos eletrodos que atuam como o par de injeção, assim como os eletrodos vizinhos a estes. As medidas tomadas por estes eletrodos não possuem confiabilidade e deverão ser substituídas por valores estimados.

Desta forma, o algoritmo deverá possuir a flexibilidade de suavizar as medidas recebidas com o objetivo de tentar diminuir o ruído na entrada dos dados. Tal filtro consiste de duas etapas: estimar voltagens nos eletrodos do par de injeção e de seus vizinhos e suavizar o restante das medidas.

Aqui, vale uma consideração sobre a forma como as medidas serão feitas. As medidas de voltagens nos eletrodos são representadas pela diferença de potencial entre o eletrodo medido e o aterrado. Com isso, o valor de voltagem do eletrodo aterrado sempre será zero.

Por exemplo, consideremos $n=32$, as posições dos eletrodos dadas por 3.17, o eletrodo aterrado dado por $e_{0}=(0.99518,0.09802)$ e o eletrodo de injeção de corrente dado por $e_{31}=(0.99518,-0.09802)$, temos $\omega_{0}=(0.99518,0)$ e $\mathrm{h}_{0}=(0,-0.09802)$ (lembrando que $\mathbf{h}$ representa a metade da distância entre as cargas positiva e negativa no modelo de dipolo). De acordo com a equação 2.53, as voltagens esperadas (sem levarmos em conta o valor do parâmetro $C$, que dependeria das condições do experimento) para um meio condutor homogêneo são mostradas na tabela 3.2 .

Nessa tabela, a última coluna mostra a diferença de potencial entre os eletrodos e o eletrodo $e_{0}$. As voltagens calculadas nessa tabela não levaram em conta as condições do meio (condutividade, corrente elétrica injetada) ao ignorarmos o parâmetro $C$. O perfil de voltagens, desta forma, possui o perfil mostrado na figura 3.11 .

Portanto, é esperado que o perfil de voltagens a ser obtido através de medições experimentais ou simulações possua a forma apresentada no gráfico, que deverá ser o padrão procurado ao analisarmos as diferenças de potencial enviadas para o algoritmo. Logo, quando a fonte de dados possuir também uma fonte de ruídos, devemos tratar a informação obtida para que se aproxime do padrão apresentado em 3.11. A utilização de uma função aproximadora é conveniente neste caso, substituindo os dados recebidos por dados suavizados.

Algumas famílias de funções são candidatas a função aproximadora das voltagens, como polinômios, tangente, arco-seno etc. Para o algoritmo, foi implementada a aproximação por uma família polinomial. 


\begin{tabular}{|c|c|c|c|c|}
\hline$k$ & \multicolumn{2}{|c|}{$e_{k}$} & $\begin{array}{c}\text { Voltagens dadas } \\
\text { por } 2.53\end{array}$ & $\begin{array}{c}\text { Diferença para } \\
\text { voltagem de } e_{0}\end{array}$ \\
\hline 0 & 0.99518 & 0.09802 & -1.00000 & 0.00000 \\
\hline 1 & 0.95694 & 0.29028 & -0.33190 & 0.66810 \\
\hline 2 & 0.88192 & 0.47140 & -0.19658 & 0.80342 \\
\hline 3 & 0.77301 & 0.63439 & -0.13763 & 0.86237 \\
\hline 4 & 0.63439 & 0.77301 & -0.10412 & 0.89588 \\
\hline 5 & 0.47140 & 0.88192 & -0.08216 & 0.91784 \\
\hline 6 & 0.29028 & 0.95694 & -0.06640 & 0.93360 \\
\hline 7 & 0.09802 & 0.99518 & -0.05433 & 0.94567 \\
\hline 8 & -0.09802 & 0.99518 & -0.04463 & 0.95537 \\
\hline 9 & -0.29028 & 0.95694 & -0.03652 & 0.96348 \\
\hline 10 & -0.47140 & 0.88192 & -0.02952 & 0.97048 \\
\hline 11 & -0.63439 & 0.77301 & -0.02329 & 0.97671 \\
\hline 12 & -0.77301 & 0.63439 & -0.01762 & 0.98238 \\
\hline 13 & -0.88192 & 0.47140 & -0.01234 & 0.98766 \\
\hline 14 & -0.95694 & 0.29028 & -0.00730 & 0.99270 \\
\hline 15 & -0.99518 & 0.09802 & -0.00242 & 0.99758 \\
\hline 16 & -0.99518 & -0.09802 & 0.00242 & 1.00242 \\
\hline 17 & -0.95694 & -0.29028 & 0.00730 & 1.00730 \\
\hline 18 & -0.88192 & -0.47140 & 0.01234 & 1.01234 \\
\hline 19 & -0.77301 & -0.63439 & 0.01762 & 1.01762 \\
\hline 20 & -0.63439 & -0.77301 & 0.02329 & 1.02329 \\
\hline 21 & -0.47140 & -0.88192 & 0.02952 & 1.02952 \\
\hline 22 & -0.29028 & -0.95694 & 0.03652 & 1.03652 \\
\hline 23 & -0.09802 & -0.99518 & 0.04463 & 1.04463 \\
\hline 24 & 0.09802 & -0.99518 & 0.05433 & 1.05433 \\
\hline 25 & 0.29028 & -0.95694 & 0.06640 & 1.06640 \\
\hline 26 & 0.47140 & -0.88192 & 0.08216 & 1.08216 \\
\hline 27 & 0.63439 & -0.77301 & 0.10412 & 1.10412 \\
\hline 28 & 0.77301 & -0.63439 & 0.13763 & 1.13763 \\
\hline 29 & 0.88192 & -0.47140 & 0.19658 & 1.19658 \\
\hline 30 & 0.95694 & -0.29028 & 0.33190 & 1.33190 \\
\hline 31 & 0.99518 & -0.09802 & 1.00000 & 2.00000 \\
\hline
\end{tabular}

Tabela 3.2: Valores de voltagens esperados pela equação 2.53

Em primeiro lugar é preciso estimar as medidas vindas dos eletrodos não confiáveis. Como mencionado anteriormente, os eletrodos não confiáveis constituem o par de injeção e seus vizinhos imediatos. Na figura 3.12, o eletrodo aterrado é o de índice 1 , o de injeção é o de índice 32 e seus vizinhos são, respectivamente, 2 e 31 . Para a estimativa desses valores, serão usados os 3 valores vizinhos próximos de cada extremidade, como na figura 3.13. Para cada extremidade, os 3 valores selecionados são usados para determinar um polinômio interpolador de 2o. grau. Os valores dos extremos, a seguir, são estimados por extrapolação polinomial. A escolha pelo polinômio de 2o. grau deve-se ao fato de que a concavidade será mantida, evitando que o perfil de voltagens torne-se uma função diferente da esperada teoricamente. 


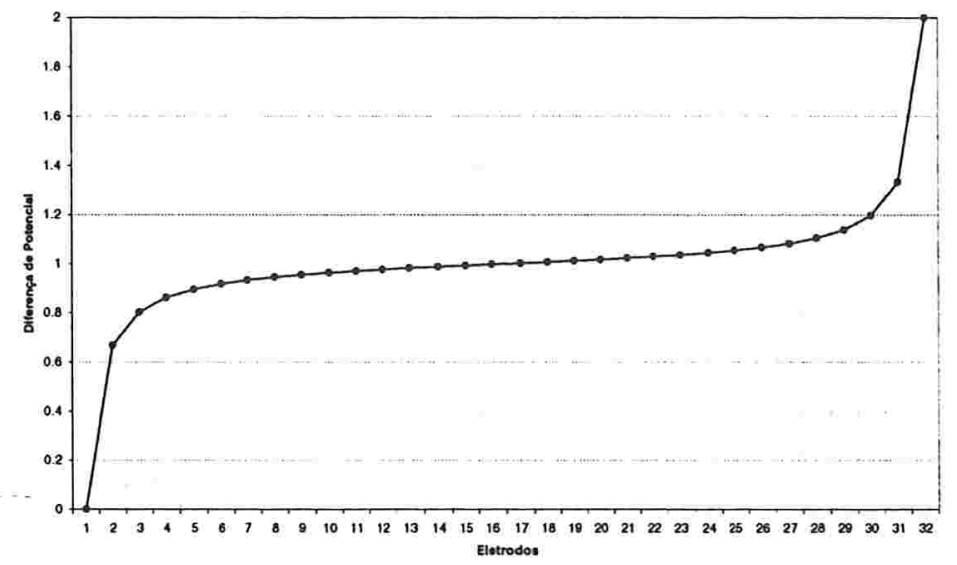

Figura 3.11: Perfil das Voltagens Esperadas Reescalonadas

Vale lembrar que este procedimento deve ser adotado quando as medidas são fornecidas experimentalmente e em função da confiabilidade dos dados.

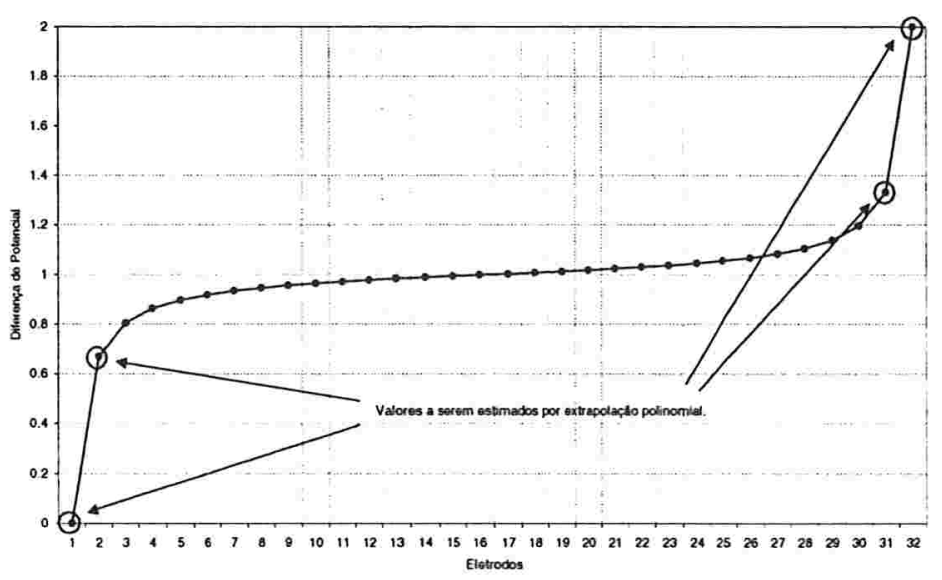

Figura 3.12: Valores do perfil de voltagens a serem estimados

O segundo passo para a filtragem dos dados de entrada consiste na suavização de todos os 


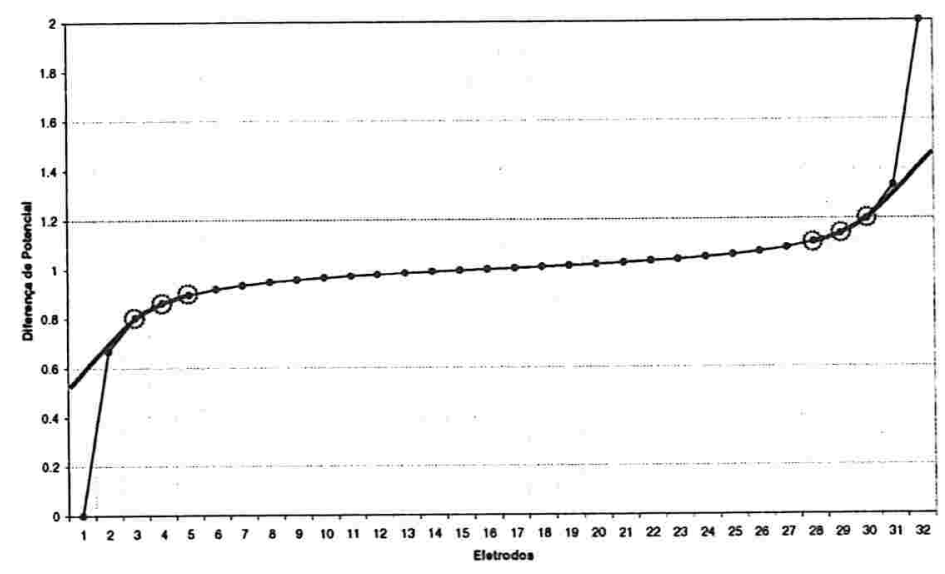

Figura 3.13: Extrapolação dos Valores de Voltagens

valores de voltagens tomados. Será usado um polinômio de grau 9 fornecido pelo método de mínimos quadrados, para cada padrão de injeção (cada conjunto de $n$ medidas de potencial, onde $n$ é o número de eletrodos, para cada par de injeção). A escolha do grau foi identificada por experimentação numérica, considerando a capacidade de identificar pequenas variações na função, a preservação da forma geral do perfil de voltagens (concavidades da função) e a estabilidade numérica da solução, isto é, evitar que a função reconstruída possua picos e variações indesejáveis. Sendo assim, para cada perfil de voltagens fornecidos por um determinado par de injeção, aplica-se o método de mínimos quadrados para determinar o polinômio aproximador, e as medidas de voltagens são substituídas pelos valores suavizados.

Os dois métodos sugeridos devem ser aplicados como passos opcionais do algoritmo. Em alguns casos, quando a precisão das medidas for suficiente para permitir a visualização dos objetos, os métodos não precisam ser aplicados. Outra situação onde o método não deverá ser aplicado é quando a variação de voltagens provocada pelo objeto for pequena o suficiente para estar dentro da margem de erro do experimento. Uma suavização neste caso poderia "destruir" a informação sobre o objeto.

Para testarmos o desempenho dos filtros sugeridos, vamos utilizar o mesmo conjunto de dados simulados do problema da seção anterior, representado na figura 3.7, adicionando um ruído gaussiano de desvio padrão $10^{-4}$ aos valores da simulação original. As figuras 3.14 e 3.15 mostram os resultados obtidos pelo BackProjection. 

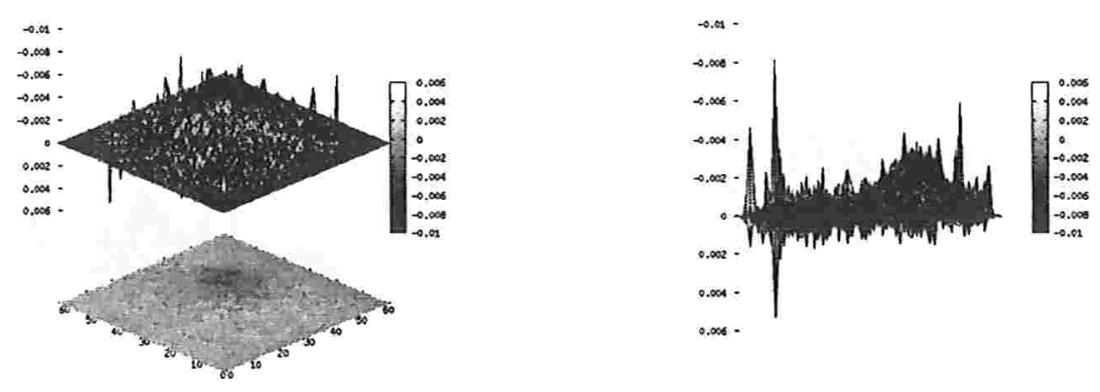

Figura 3.14: Reconstrução a partir de dados com ruído gaussiano $O\left(10^{-4}\right)$

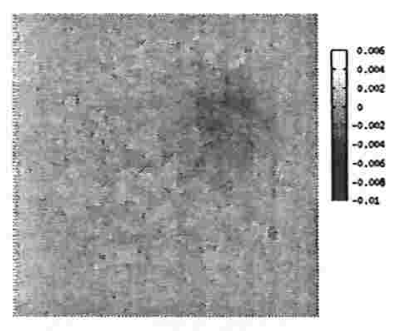

Figura 3.15: Reconstrução a partir de dados com ruído gaussiano $O\left(10^{-4}\right)(2)$

Apesar de ainda ser possível identificar o objeto, os ruídos introduzidos na imagem original foram amplificados de forma a praticamente eliminar as informações sobre o objeto. Aplicando, aos mesmos dados com ruído, apenas o ajuste nos valores do par de injeção e de seus vizinhos de 1a. ordem, os resultados são dados por 3.16 e 3.17 .

Aplicando os 2 filtros simultaneamente, os resultados são apresentados pelas figuras 3.18 e 3.19, onde é possível observar a diminuição do ruído além do objeto aparecer mais focado.

A tabela 3.3 apresenta uma comparação das saídas geradas. Para as imagens vindas dos dados com ruídos, foram incluídas duas colunas: uma com as informações da imagem (valores máximo, mínimo, médio e desvio padrão dos pontos) e outra com as mesmas informações extraídas da imagem de diferença, isto é, a imagem dada pelos valores da imagem reconstruída com ruído menos os valores da imagem sem ruído.

No caso específico deste teste, foi importante utilizar a estimativa das medidas do par de injeção e vizinhos. Sem ele, a média em termos absolutos e o desvio padrão das diferenças 

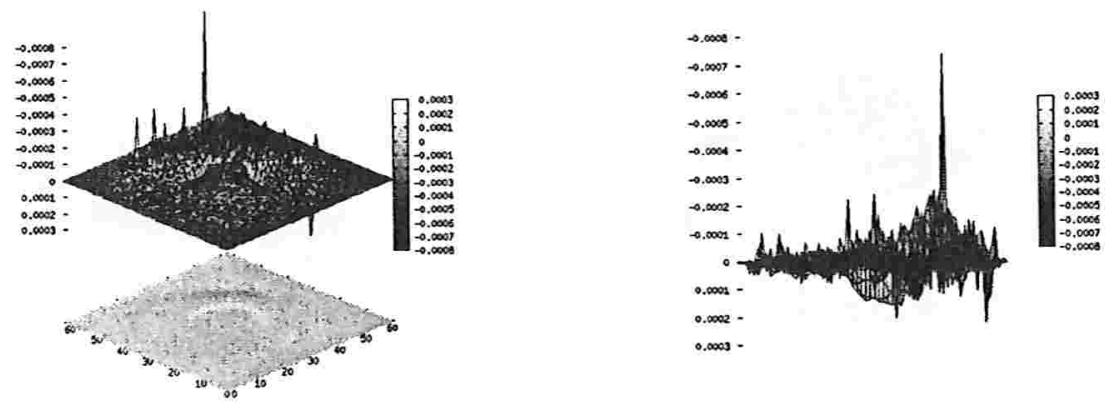

Figura 3.16: Reconstrução a partir de dados com ruído gaussiano $O\left(10^{-4}\right)$ - Apenas com a suavização polinomial dos extremos

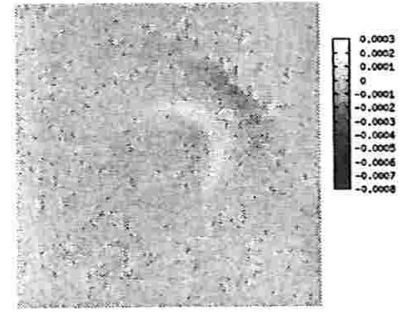

Figura 3.17: Reconstrução a partir de dados com ruído gaussiano $O\left(10^{-4}\right)$ - Apenas com a suavização polinomial dos extremos (2)
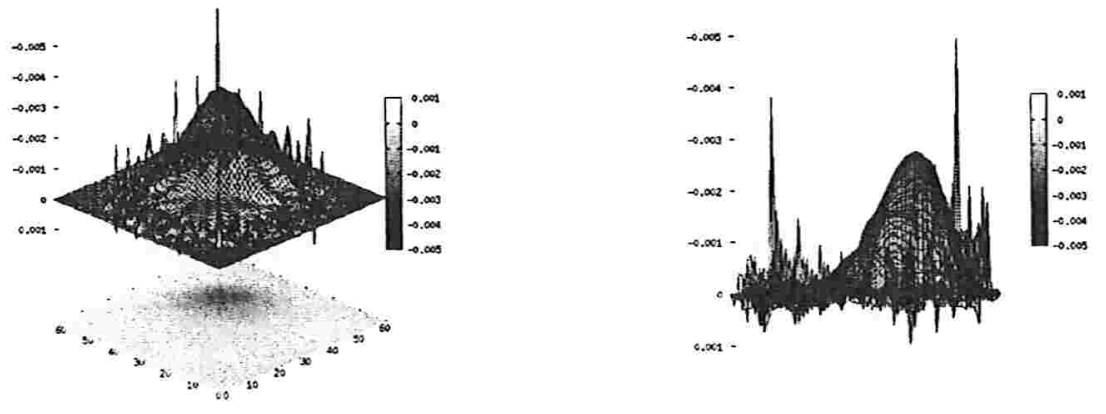

Figura 3.18: Reconstrução a partir de dados com ruído gaussiano $O\left(10^{-4}\right)$ - Aplicação dos Filtros 
Figura 3.19: Reconstrução a partir de dados com ruído gaussiano $O\left(10^{-4}\right)$ - Aplicação dos Filtros (2)

\begin{tabular}{|c|c|c|c|c|c|c|c|}
\hline & Imagem Original & \multicolumn{2}{|c|}{$\begin{array}{c}\text { Imagem com Rufdo } \\
\text { Sem Filtro }\end{array}$} & \multicolumn{2}{c|}{$\begin{array}{c}\text { Imagem com Rufdo } \\
\text { Filtro dos Extremos }\end{array}$} & \multicolumn{2}{c|}{$\begin{array}{c}\text { Imagem com Rufdo } \\
\text { Ambos os Filtros }\end{array}$} \\
\hline Informação & Dif. de Pot. & Dif. de Pot. & $\begin{array}{c}\text { Relat. à Im. } \\
\text { Original }\end{array}$ & Dif. de Pot. & $\begin{array}{c}\text { Relat. à Im. } \\
\text { Original }\end{array}$ & $\begin{array}{c}\text { Dif. de Pot. } \\
\text { Relat. à Im. } \\
\text { Original }\end{array}$ \\
\hline máximo & $\mathbf{3 . 7 4 1 5 6}$ & 52.52657 & 52.53848 & 2.14995 & 39.40939 & $\mathbf{9 . 5 5 6 6 1}$ & 8.29327 \\
\hline mínimo & -40.68344 & -81.59779 & -59.14770 & -7.41149 & -4.08794 & -49.5523 & -8.86882 \\
\hline média & -2.82910 & -2.87640 & -0.04729 & -0.02650 & 2.80261 & -2.83154 & -0.00244 \\
\hline desvio padrão & 5.87881 & 7.35574 & 4.29722 & 0.37260 & 5.80390 & 5.93093 & 1.26613 \\
\hline
\end{tabular}

Tabela 3.3: Comparação dos filtros aplicados aos dados de entrada (valores multiplicados por $10^{4}$ )

entre as imagens sem filtro e com filtro aumentaram consideravelmente. Já quando ambos os filtros foram utilizados, houve uma redução de $70 \%$ no desvio padrão das diferenças e a média aproximou-se do zero. Conforme colocado anteriormente, a aplicação desses dois filtros deve ser opcional mas, no caso do teste apresentado, foi importante a utilização de ambos. Entretanto, não se pode prever com antecipação o que acontecerá no caso real, quando a máquina nos fornecerá os dados de pacientes dos quais não se tem nenhuma informação $a$ priori.

Mesmo com a aplicação destes dois filtros, não foi possível reduzir os picos de ruídos visualizados na fronteira do domínio de reconstrução. O objetivo desses dois filtros foi diminuir o ruído presente nos dados de entrada, mas eles não evitaram o desaparecimento de ruídos impostos pela geometria do algoritmo. Nas próximas seções, veremos algumas técnicas que trabalharão no sentido de suavizar a imagem final, removendo os picos e suavizando as formas dos objetos reconstruídos. 


\subsection{Interpolação de Dipolos e Eletrodos}

Uma das questões que levantamos ao longo do desenvolvimento deste trabalho considerou o número de eletrodos na experiência. Como foi comentado, um grande número de eletrodos ajudaria a aumentar a precisão da reconstrução da imagem, pois permitiria uma melhor estimativa das derivadas das voltagens na fronteira do domínio de reconstrução. Porém, a dificuldade estava na implementação prática dessa teoria. Atualmente, ainda é grande a dificuldade na construção de um hardware com tantos eletrodos e que forneça medidas com alta precisão.

Se a dificuldade existe com o hardware, pode-se tentar contorná-la a partir de software, através de simulação de eletrodos a partir dos dados observados. A partir dos padrões de voltagens medidos, estimam-se outros padrões de voltagens, caso existissem mais eletrodos no experimento. Desta forma, o conceito principal deste processo de estimação não está em simplesmente interpolar valor de voltagens entre os eletrodos. A família de funções interpoladoras citadas na equação (3.21) já faz esse papel. Estamos interessados na estimativa de novos padrões de voltagens, ou seja, novos dipolos.

Para interpolarmos os novos dipolos, vamos trabalhar com a matriz $\left[W_{k, i}\right]$. A idéia é simples: transformar a matriz numa outra maior, interpolando valores tanto nas linhas quanto nas colunas. A interpolação de valores nas linhas representaria a interpolação de dipolos, enquanto a interpolação nas colunas representaria a interpolação de eletrodos. Devido à geometria das linhas equipotenciais, um pequeno deslocamento da posição do dipolo pode modificar consideravelmente o valor medido por um eletrodo. Portanto, a estimativa de um valor medido por um eletrodo é baseada na sua posição relativa ao dipolo.

Para aplicarmos esta idéia à expansão da matriz $\left[W_{k, i}\right]$, devemos expandir as linhas no sentido diagonal, conforme o esquema da figura 3.20, onde o número de dipolos e eletrodos foi duplicado. Para interpolarmos os últimos valores, repetem-se as primeiras linha e coluna da matriz. A nova matriz expandida será enviada para o algoritmo e, a partir daí, trabalha-se como se o número de eletrodos e dipolos fosse o número de interpolações executadas. $\mathrm{Na}$ figura, os quadrados pretos representam os valores medidos (filtrados ou não) para a matriz e os cinzas representam os valores interpolados. 
Representação Simbólica da Matriz Original

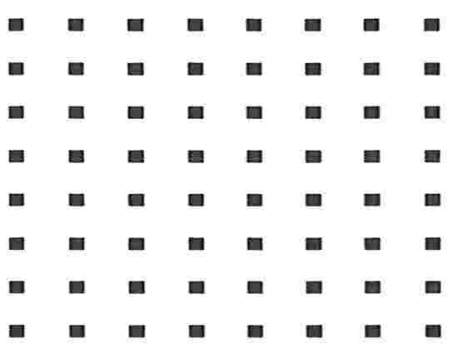

Repetição da primeira linha

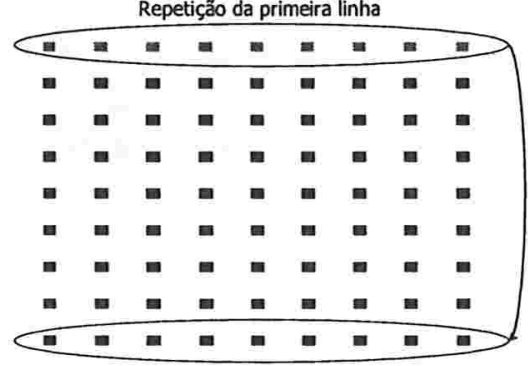

Interpolação de Dipolos

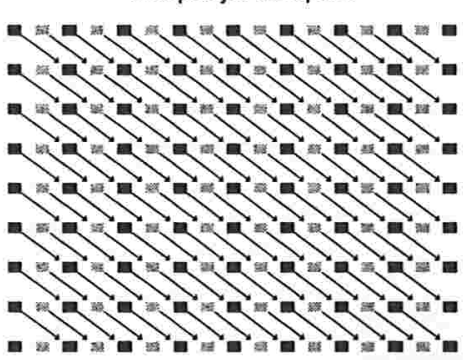

Repetição da primeira coluna

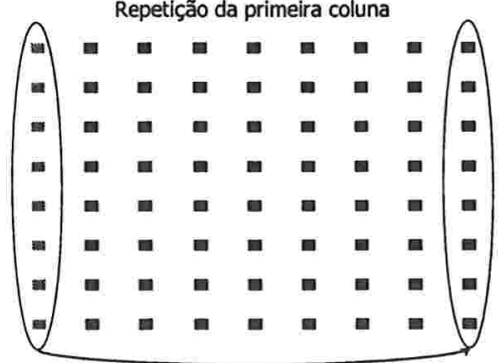

Interpolação de Eletrodos

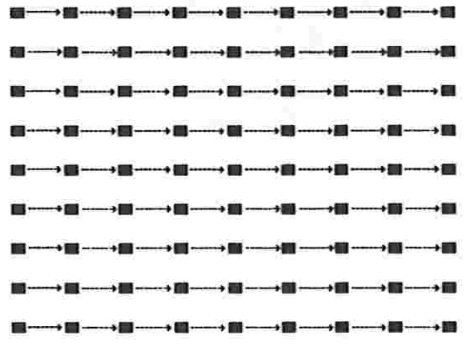

Resultado da Interpolação

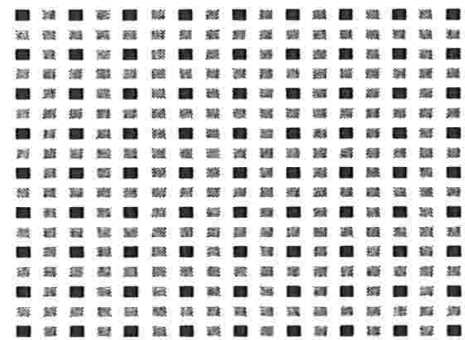

Representação final da matriz expandida

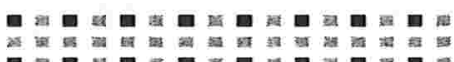

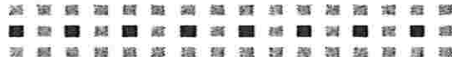

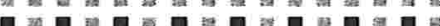

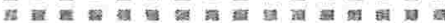

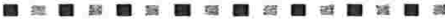

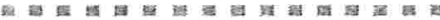

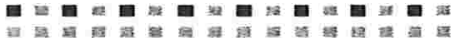

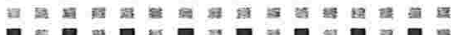

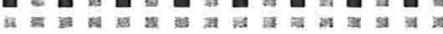

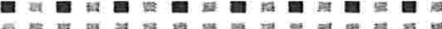

เ

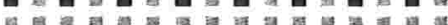

Figura 3.20: Interpolação de Dipolos - Passos na Expansão da matriz $\left[W_{k, i}\right]$ 
Mais uma vez, para testarmos o método sugerido, voltemos aos dados do teste da seção 3.3, dessa vez sem acrescentar a fonte de ruído. A matriz $\left[W_{k, i}\right]$ será expandida de $32 \times 32$ para $64 \times 64$ e 128x128. As figuras 3.21 e 3.22 mostram o resultado do BackProjection da expansão para $64 x 64$, enquanto que as figuras 3.23 e 3.24 referem-se à expansão para 128x128.
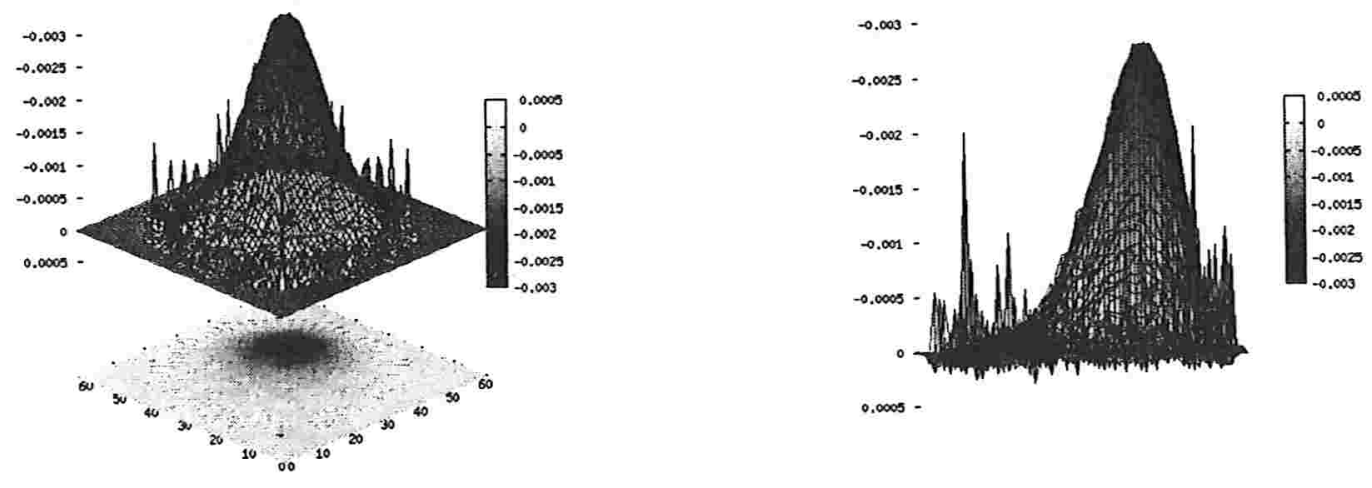

Figura 3.21: Interpolação de Dipolos - Expansão da matriz $\left[W_{k, i}\right]$ para $64 \times 64$

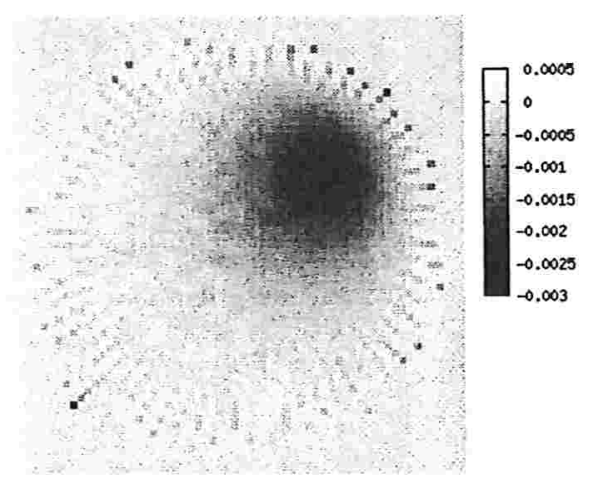

Figura 3.22: Interpolação de Dipolos - Expansão da matriz $\left[W_{k, i}\right]$ para $64 \times 64$ (2) 

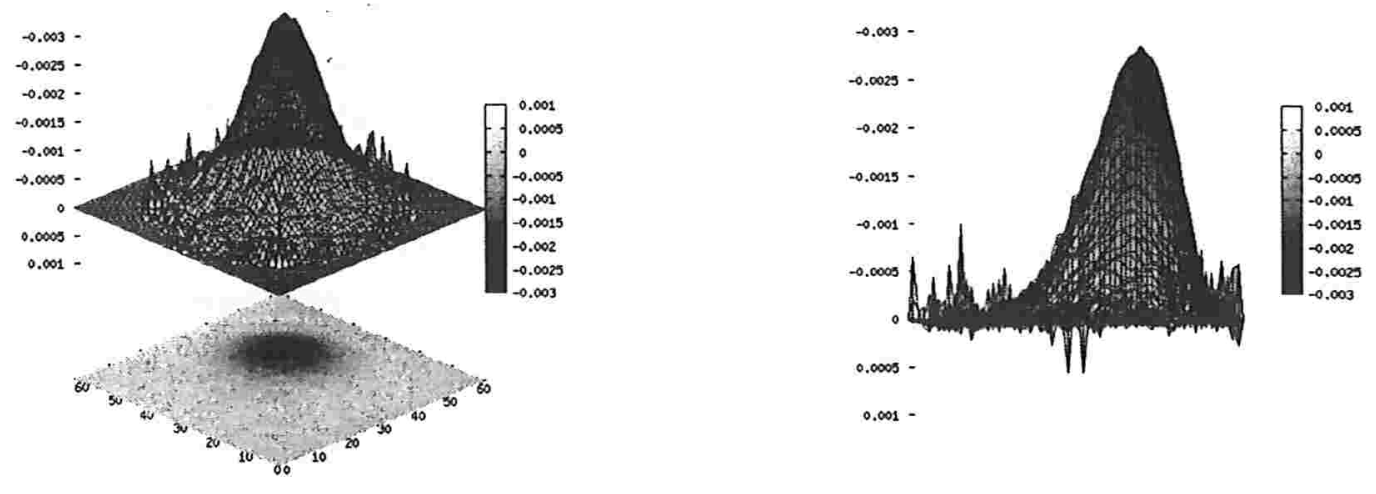

Figura 3.23: Interpolação de Dipolos - Expansão da matriz $\left[W_{k, i}\right]$ para $128 \times 128$

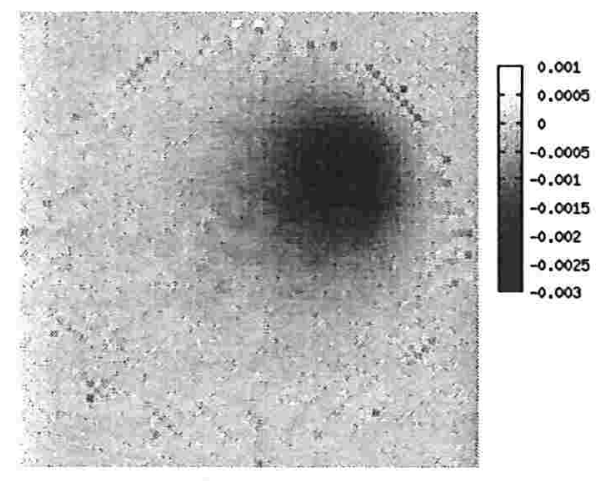

Figura 3.24: Interpolação de Dipolos - Expansão da matriz $\left[W_{k, i}\right]$ para 128x128 (2) 
A tabela 3.4 resume a informação gerada pelos testes e mostra que a distribuição dos valores das imagens não sofreu significativa alteração, se olharmos para as variáveis média e desvio padrão de cada uma. Houve uma diminuição considerável do ruído da borda. Os picos antes visíveis, que chegam a possuir valores em módulo maiores do que o pico do objeto reconstruído foram eliminados. Na tabela 3.4, pode-se perceber que os valores mínimo para as imagens com interpolação de dipolos deixaram de ser os ocasionados pelos ruídos para tornarem-se os valores do pico do objeto.

\begin{tabular}{|c|c|c|c|}
\hline Informação & Imagem Original & Interpolação para 64×64 & Interpolação para 128x128 \\
\hline máximo & 3.74156 & 2.65699 & 5.376713 \\
\hline mínimo & -40.68344 & -28.33999 & -28.52257 \\
\hline média & -2.82910 & -2.81837 & -2.81779 \\
\hline desvio padrão & 5.87881 & 5.70451 & 5.64574 \\
\hline $\begin{array}{c}\text { mínimo (região } \\
\text { do objeto) }\end{array}$ & -29.02026 & -28.33999 & -28.5227 \\
\hline
\end{tabular}

Tabela 3.4: Comparação da Interpolação de Dipolos (valores multiplicados por $10^{4}$ )

Um aumento na interpolação da matriz $\left[W_{k, i}\right]$ ajuda na redução dos ruídos, porém, há um custo computacional no método sugerido. Devemos lembrar que uma das preocupações da TPA é a velocidade de reconstrução de imagens, permitindo um monitoramento contínuo dos pacientes a beira do leito. Quando interpolamos a matriz do teste de $32 \times 32$ para $64 \times 64$, multiplicamos por 4 a dimensão do problema, pois dobramos o número de padrões e o de eletrodos e o tempo computacional é acrescido nesta proporção.

Essa interpolação é aplicada de forma opcional no algoritmo e, para a reconstrução em tempo real do domínio, pode ser desligada ou usada apenas para dobrar o número de padrões. Na próxima seção será apresentado um filtro simples mas que ajudará a diminuir o ruído ainda existente na borda sem comprometer o tempo do algoritmo.

\subsection{Um Filtro Pós-Processamento: Média da Vizinhança}

Já apresentamos algumas técnicas que trabalham no tratamento de dados antes do processamento do algoritmo. Apesar de terem mostrado eficiência na suavização e eliminação de ruídos consideráveis na imagem reconstruída, a imagem apresenta ruídos na região da fronteira do domínio de reconstrução.

Para o seu tratamento, vamos aplicar um filtro bastante simples e conhecido do tratamento de imagens: o Filtro da Vizinhança. Este filtro atua em cada pixel da imagem, substituindo seu valor por uma média (ponderada ou não) de seus vizinhos. Sua função é reduzir a variação 
de intensidade entre um pixel e seus vizinhos, de forma a "suavizar" a imagem final. Com isso, procura-se reduzir o ruído total.

Para a implementação do algoritmo, vamos considerar a média simples entre os pontos da vizinhança de cada pixel. Assim, o parâmetro para a aplicação do filtro é o tamanho da vizinhança (número de pixels de altura e de largura). O esquema do filtro é apresentado na figura 3.25 .
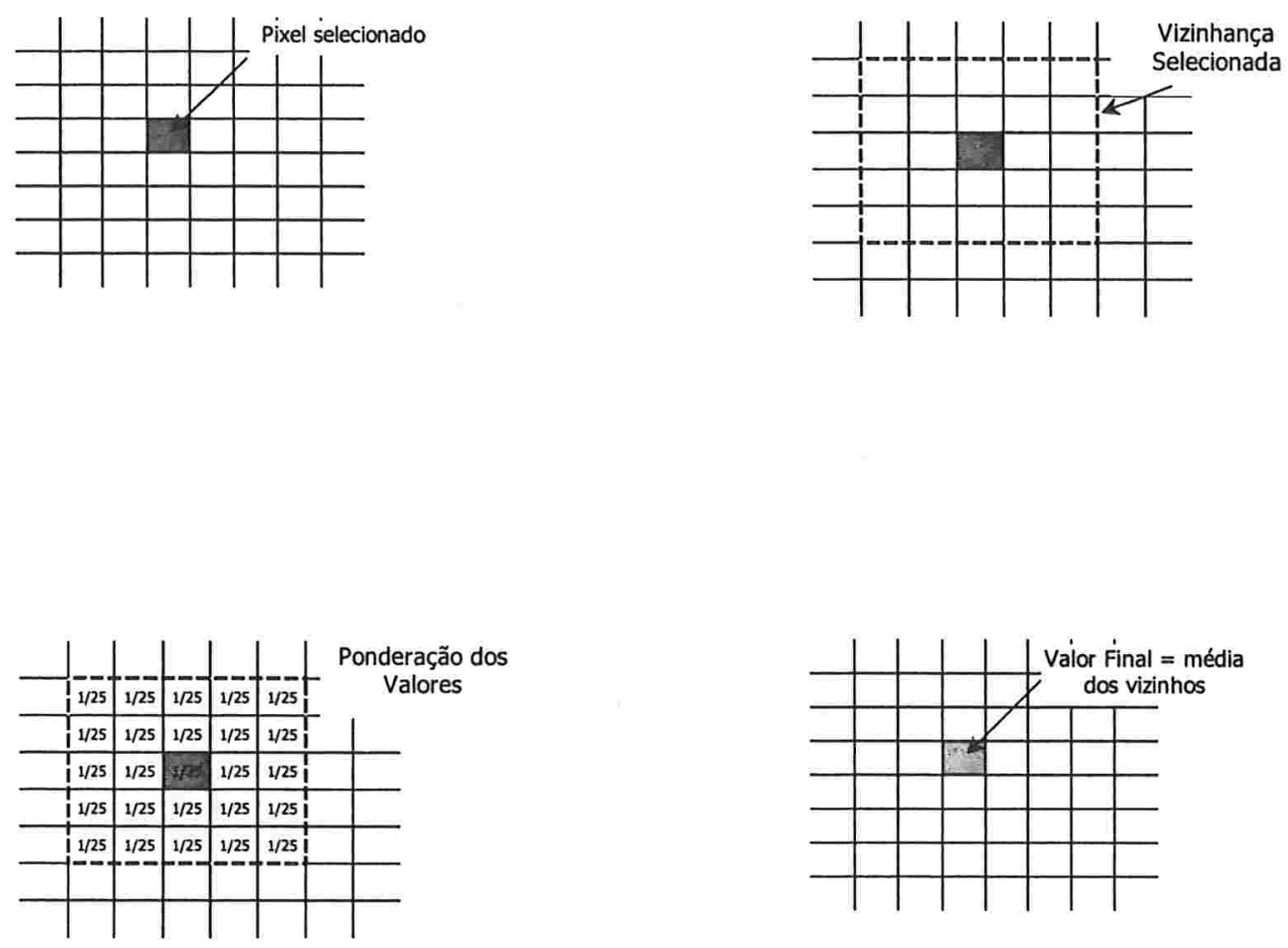

Figura 3.25: Filtro da Vizinhança - Passos da Implementação

Para a visualização dos resultados, vamos aplicar o filtro da vizinhança na saída das figuras 3.8 e 3.9. Para cada pixel da imagem, vamos substituir seu valor pelas médias de uma vizinhança quadrada de lado 5 pixels. Os resultados estão nas figuras 3.26 e 3.27. A tabela 3.5 apresenta a comparação da imagem original com a imagem filtrada.

Analisando os resultados gerados, podemos verificar que o efeito de redução de ruído foi 

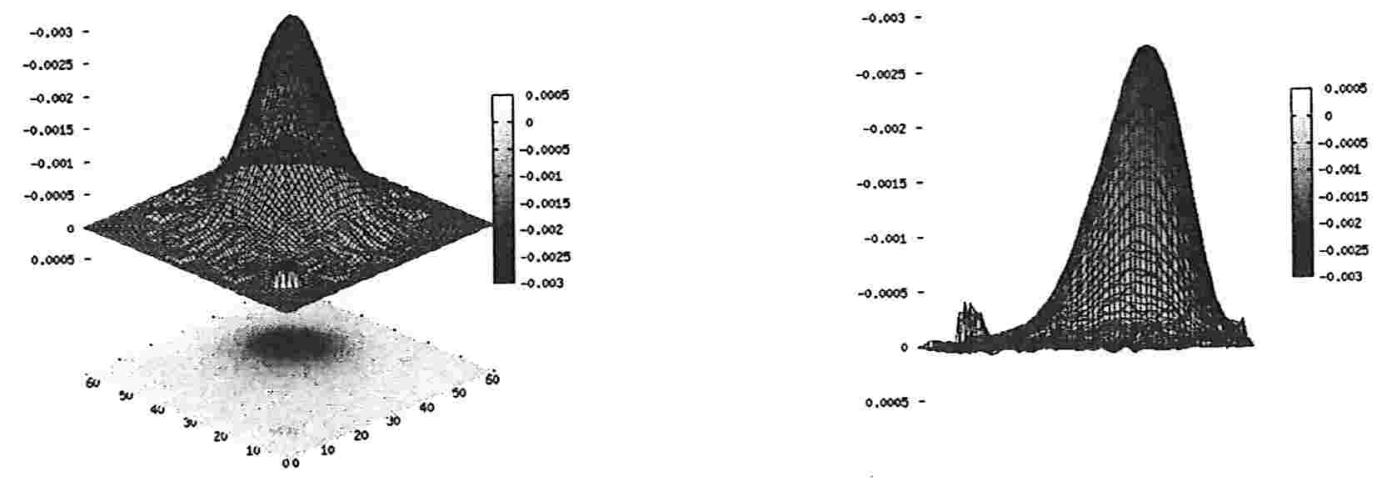

Figura 3.26: Aplicação do Filtro da Vizinhança 5x5

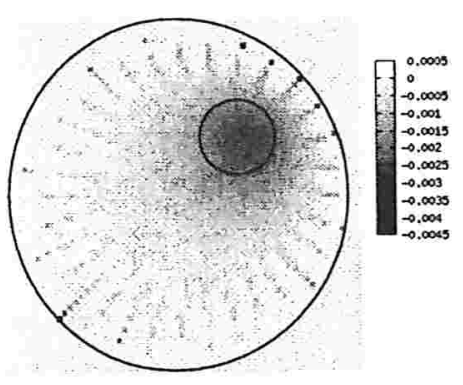

Sem Filtro

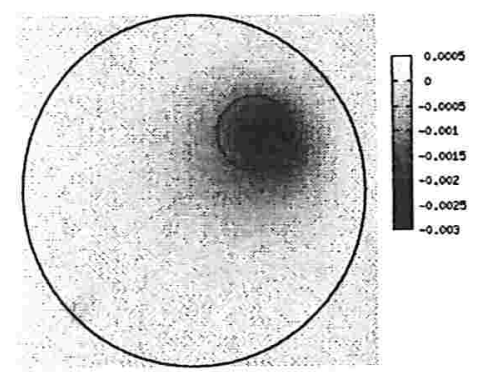

Com Filtro

Figura 3.27: Aplicação do Filtro da Vizinhança 5x5 (2)

\begin{tabular}{|c|c|c|}
\hline Informação & Imagem Original & Após o Filtro da Vizinhança \\
\hline máximo & 3.74156 & 0.62074 \\
\hline mínimo & -40.68344 & -27.35665 \\
\hline média & -2.82910 & -2.83150 \\
\hline desvio padrão & 5.87881 & 5.48002 \\
\hline $\begin{array}{c}\text { mínimo (região } \\
\text { do objeto) }\end{array}$ & -29.02026 & -27.35665 \\
\hline
\end{tabular}

Tabela 3.5: Comparação da Aplicação do Filtro da Vizinhança 5x5 (valores multiplicados por $10^{4}$ )

bem melhor que o método anterior de interpolação de dipolos. O ruído da borda praticamente desapareceu, o ruído na direção das linhas equipotenciais também foi bem reduzido e a imagem adquiriu formas bem mais suaves. Porém, o valor do pico (valor mínimo) do objeto 
reconstruído sofreu uma redução maior do que o do método anterior. Enquanto lá o pico sofreu uma redução entre $1.7 \%$ e $2.3 \%$, o filtro da vizinhança reduziu o pico em $5.7 \%$. Desta forma, o filtro é bom para redução de ruído, mas sua aplicação pode resultar em perda de informação dos objetos a serem identificados.

\subsection{Teste Geral: Aplicação Simultânea dos Filtros}

Para testarmos a eficácia dos filtros apresentados quando aplicados simultaneamente, vamos considerar os dados com ruídos usados na seção 3.4. Para aqueles dados, vamos aplicar a suavização polinomial com estimativa dos extremos, a expansão da matriz $\left[W_{k, i}\right]$ para $128 \times 128$ e o filtro da Vizinhança com tamanho 5x5. Os resultados estão nas figuras 3.28 e 3.29.

Pelos resultados visuais, podemos constatar que a aplicação simultânea dos filtros foi capaz de eliminar praticamente todo o ruído da imagem, reconstruindo uma forma muito parecida com os resultados das imagens 3.26 e 3.27, por exemplo. Assim, o uso de tais filtros, apesar de opcionais no algoritmo, constituem uma poderosa ferramenta para o tratamento dos sinais enviados para o algoritmo de forma a garantir qualidade visual à reconstrução do domínio estudado.
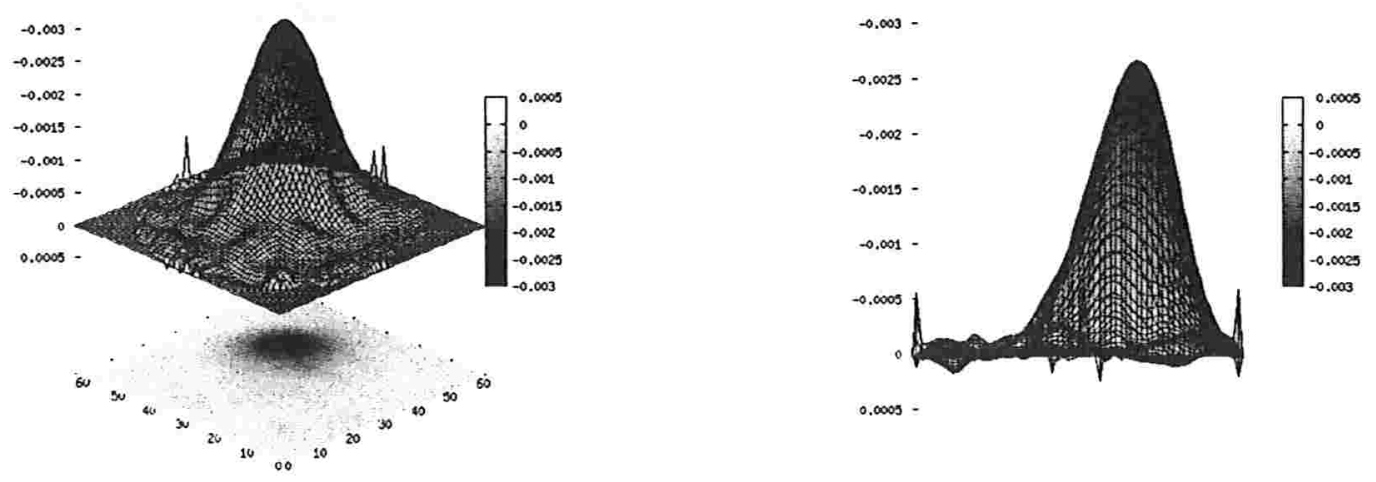

Figura 3.28: Aplicação Simultânea dos Filtros 


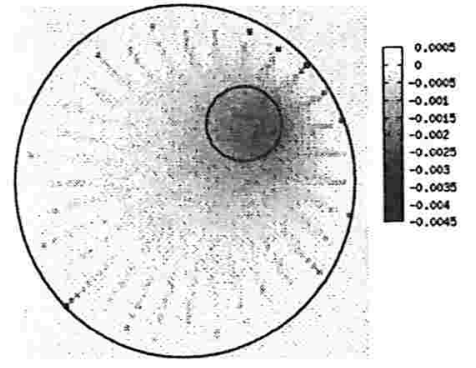

Sem Filtro

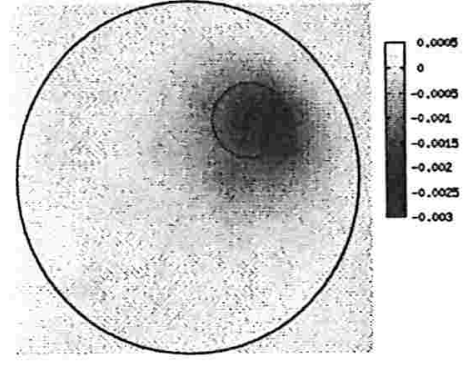

Com Filtro

Figura 3.29: Aplicação Simultânea dos Filtros (2)

\subsection{Algoritmo Completo}

Com os métodos de filtragem, podemos completar o Algoritmo 1 para obtermos o algoritmo completo sugerido para o BackProjection aplicado à TPA. No algoritmo, os métodos de filtragem são opcionais e devem ser solicitados através de parâmetros enviados ao programa, juntamente com os parâmetros necessários para que eles sejam aplicados.

O Algoritmo completo foi dividido em três partes: Processamento Inicial de $\left[W_{k, i}\right]$ (Algoritmo 2), onde são feitas as suavizações na entrada e expansão da matriz; Reconstrução da Imagem (Algoritmo 3) onde o BackProjection é efetivamente aplicado; Filtro da Vizinhança (Algoritmo 4) onde a suavização final na imagem pronta é aplicada.

No próximo capítulo, o algoritmo completo será aplicado para dados simulados e experimentais. 


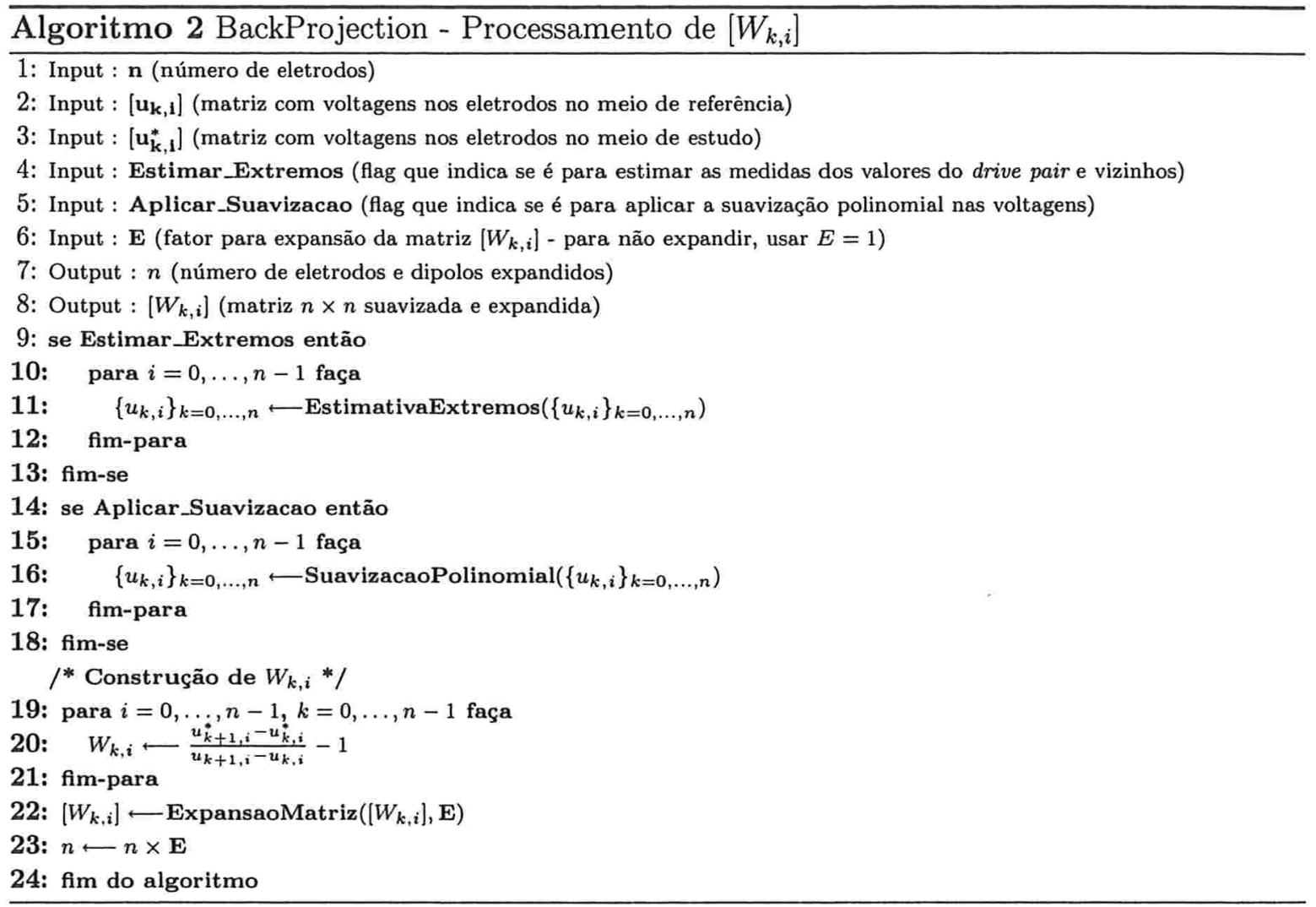




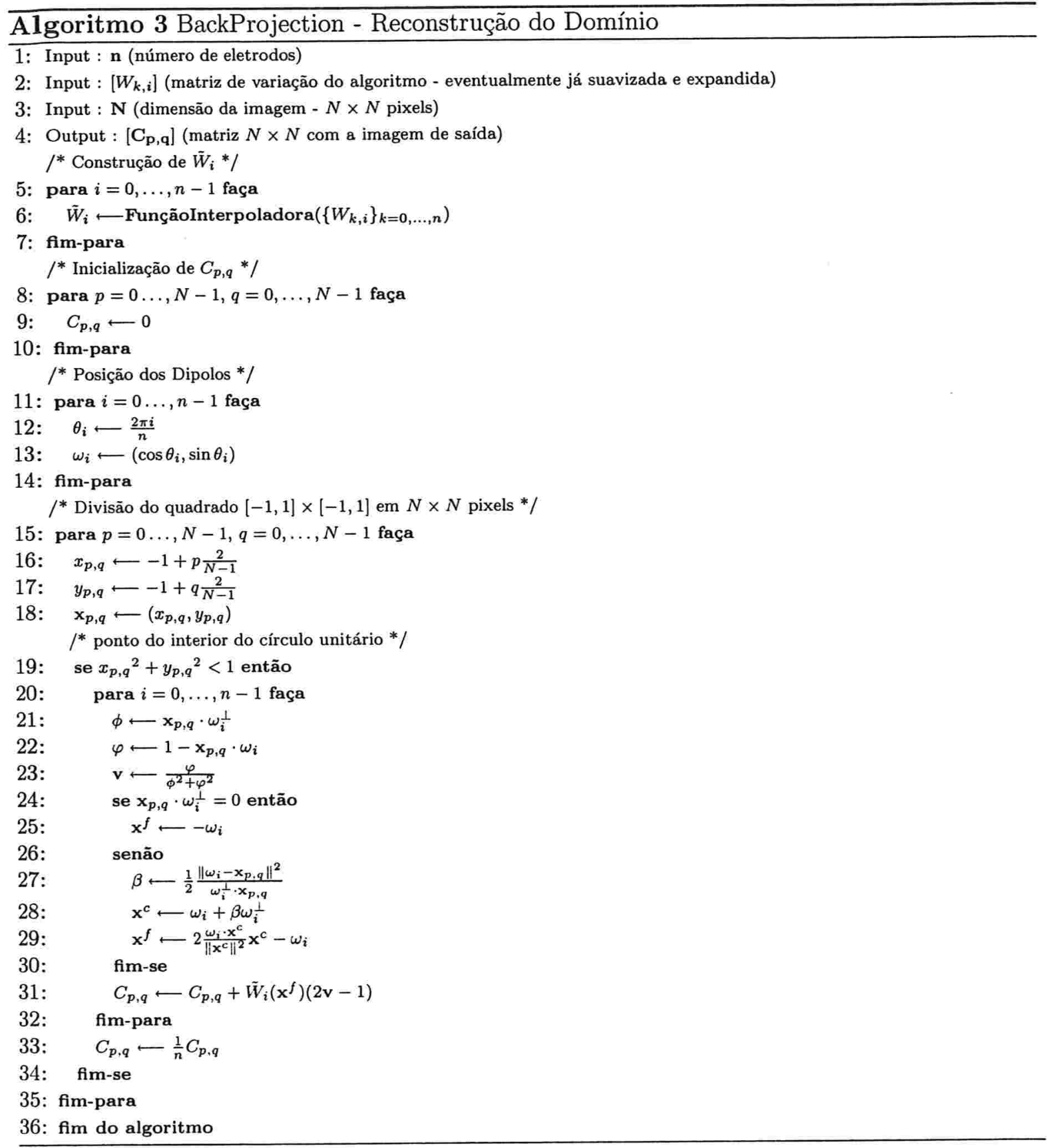




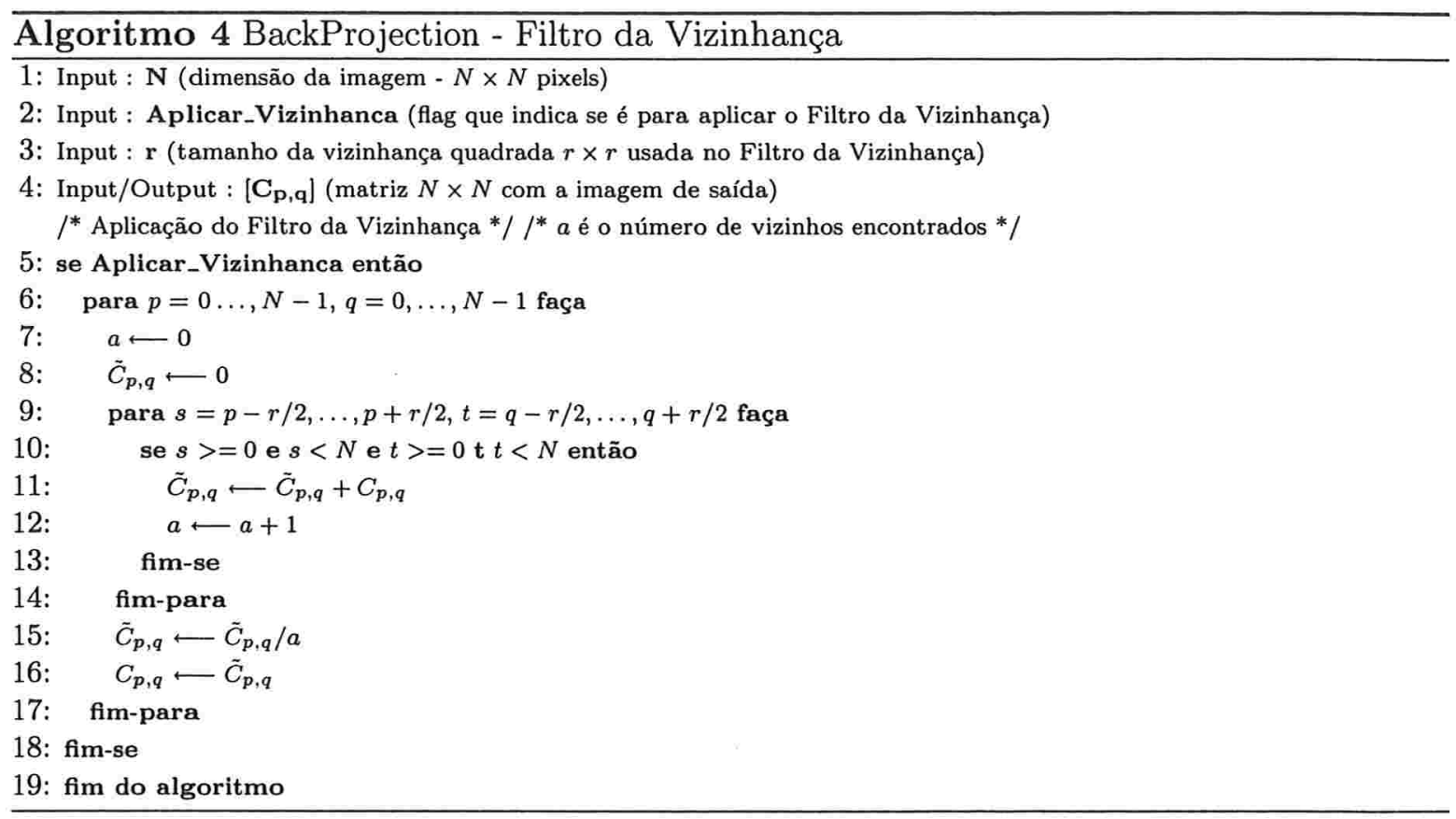




\section{Capítulo 4}

\section{Resultados}

Com a apresentação completa do algoritmo, feita no capítulo anterior, diferentes conjuntos de dados serão testados. Serão usados conjuntos de dados simulados, utilizando-se o programa de simulação apresentado na seção 3.3, e dados medidos experimentalmente pelo Laboratório de Pneumologia da Faculdade de Medicina (USP), coordenado pelo Prof. Dr. Carlos R. R. Carvalho.

O Algoritmo foi implementado em linguagem $\mathrm{C}$ através do ambiente Visual Studio .NET 2002. As interfaces de entrada e saída são feitas via arquivos no formato texto. As visualizações apresentadas foram geradas através do GnuPlot.

\subsection{Tempos de Processamento}

Uma das questões mais relevantes na implementação do BackProjection e no seu desempenho está ligada ao tempo de execução do programa para a reconstrução da imagem. É importante que o algoritmo forneça no mínimo 20 imagens por segundo para permitir que o monitoramento de um paciente à beira do leito seja feito de forma contínua. Como mencionado na seção 1.5, uma das aplicações do BackProjection é a Ventilação Artificial, onde o médico necessita de respostas rápidas às suas ações no controle da respiração do paciente.

Para os testes, o mesmo conjunto de dados foi submetido à reconstrução de imagens, variando-se os seguintes parâmetros:

- Tamanho da Imagem: Foram reconstruídas imagens de tamanho 64x64 pixels e 128x128 pixels;

- Aplicação da Suavização dos Dados: Como visto na seção 3.4, a suavização dos dados de entrada pode ajudar na redução dos ruídos do experimento, melhorando considera- 
velmente o resultado final da imagem. Portanto, seria válido verificar o tempo adicional gasto com ele;

- Aplicação do Filtro da Vizinhança: Como filtro "pós-processamento", apresentado na seção 3.6, ele poderia ser aplicado pelo algoritmo de BackProjection após a reconstrução ou em um momento posterior, por outro programa. O objetivo é verificar se o impacto de tempo que ele ocasiona é significante.

Os testes foram realizados em um computador com processador Intel@Pentium@IV 1.8 $\mathrm{GHz}$, com $384 \mathrm{Mb}$ de memória RAM, rodando sistema operacional Windows 2000 Professional. Para cada combinação Algoritmo+Aplicação de Filtros, o programa foi rodado 30 vezes, resultando nas médias e desvios apresentados nas tabelas 4.1 e 4.2 .

\begin{tabular}{|c|c|c|c|c|c|c|c|c|}
\hline $\begin{array}{c}\text { Eletrodos } \\
\text { Interpolados }\end{array}$ & \multicolumn{2}{|c|}{ Sem Filtros } & \multicolumn{2}{c|}{$\begin{array}{c}\text { Apenas com Suavização } \\
\text { Dados de Entrada }\end{array}$} & $\begin{array}{c}\text { Apenas com Filtro } \\
\text { da Vizinhança }\end{array}$ & \multicolumn{2}{c|}{$\begin{array}{c}\text { Com Ambos os } \\
\text { Filtros }\end{array}$} \\
\hline & média & desv. pad. & média & desv. pad. & média & desv. pad. & média & desv. pad. \\
\hline 32 & 0.2125 & 0.0077 & 0.2219 & 0.0061 & 0.2151 & 0.0113 & 0.2213 & 0.0057 \\
\hline 64 & 0.4052 & 0.0067 & 0.4156 & 0.0087 & 0.4083 & 0.0068 & 0.4157 & 0.0077 \\
\hline 128 & 0.8156 & 0.0142 & 0.8239 & 0.0127 & 0.8166 & 0.0080 & 0.8230 & 0.0093 \\
\hline
\end{tabular}

Tabela 4.1: Reconstrução de Imagens $64 \times 64$ pixels - tempos em segundos

\begin{tabular}{|c|c|c|c|c|c|c|c|c|}
\hline $\begin{array}{c}\text { Eletrodos } \\
\text { Interpolados }\end{array}$ & \multicolumn{2}{|c|}{ Sem Filtros } & \multicolumn{2}{c|}{$\begin{array}{c}\text { Apenas com Suavização } \\
\text { Dados de Entrada }\end{array}$} & \multicolumn{2}{c|}{$\begin{array}{c}\text { Apenas com Filtro } \\
\text { da Vizinhança }\end{array}$} & \multicolumn{2}{c|}{$\begin{array}{c}\text { Com Ambos os } \\
\text { Filtros }\end{array}$} \\
\hline & média & desv. pad. & média & desv. pad. & média & desv. pad. & média & desv. pad. \\
\hline 32 & 0.8328 & 0.0326 & 0.8396 & 0.0114 & 0.8360 & 0.0113 & 0.8443 & 0.0154 \\
\hline 64 & 1.6297 & 0.0140 & 1.6376 & 0.0178 & 1.6416 & 0.0127 & 1.6464 & 0.0163 \\
\hline 128 & 3.2298 & 0.0167 & 3.2438 & 0.0158 & 3.2411 & 0.0183 & 3.2468 & 0.0199 \\
\hline
\end{tabular}

Tabela 4.2: Reconstrução de Imagens $128 \times 128$ pixels - tempos em segundos

Pelos valores apresentados, podemos concluir que a aplicação dos filtros representa um consumo muito baixo de tempo dentro do algoritmo. Todos os valores médios numa mesma linha ficaram próximos, se analisarmos os respectivos desvios. Se compararmos as colunas "Sem Filtro" e "Com Ambos os Filtros", as variações para um mesmo número de eletrodos interpolados foram de $0.53 \%$ a $4.14 \%$. Logo, comparativamente, estes filtros consomem muito 
pouco tempo e seu uso será apenas limitado pela qualidade da imagem que irão produzir, isto é, para dados que não precisam de tratamento, seu uso é opcional.

Para que uma seqüência de imagens possa transmitir uma sensação de continuidade, é necessária uma taxa de produção de no mínimo 20 imagens por segundo (a mesma taxa utilizada no cinema). Para isso, o algoritmo de BackProjection teria um tempo total de 0.05 segundos, o que incluiria a reconstrução da imagem e a exibição na tela de um computador. Com a implementação produzida para este trabalho, o melhor tempo para uma imagem $64 \times 64$ foi de 0.2125 segundos. Logo, pode-se esperar que uma redução do tamanho da imagem para $32 \times 32$ traria o tempo do algoritmo para algo em torno de 0.0531 segundos, valor bem próximo do tempo ideal, porém com o custo da perda de definição da imagem. Como este tempo refere-se apenas à reconstrução, haveria ainda um tempo necessário para a exibição na tela. Porém, este processamento final poderia ser feito em paralelo, liberando o algoritmo deste custo.

Os próximos testes mostram o resultado da reconstrução do BackProjection para diversos conjuntos de dados. Em quase todos os testes, os objetos presentes provocam diminuição de condutividade no meio no local onde se encontram. Com isso, a variação detectada pelo algoritmo é negativa, razão pela qual os gráficos foram traçados com o eixo vertical invertido, pois o "pico" dos objetos representa, na verdade, o valor mínimo de variação de condutividade encontrada.

\subsection{Variação de Condutividade para um Único Objeto}

Vamos repetir o teste da seção 3.3 variando, porém, o valor de condutividade do objeto. Além do valor original de $(1.003 \mathrm{Ohm}-\mathrm{m})^{-1}$, vamos trabalhar com $(1.016 \mathrm{Ohm}-\mathrm{m})^{-1},(1.16 \mathrm{Ohm}-$ $\mathrm{m})^{-1}$ e $(1.32 \mathrm{Ohm}-\mathrm{m})^{-1}$. Para os testes, vamos comparar as saídas com 32 e 128 eletrodos (neste último caso, eletrodos interpolados) e também com a aplicação ou não do filtro da vizinhança. Em todos os casos, será aplicado o filtro da suavização dos dados de entrada. As imagens possuem 64x64 pixels. 


\subsubsection{Condutividade $(1.003 \text { Ohm-m })^{-1}$}

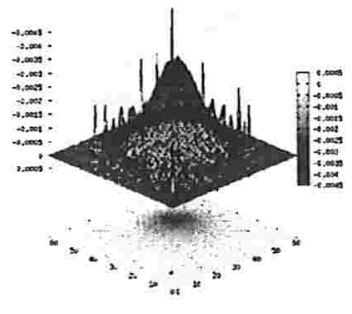

Sem Filtro

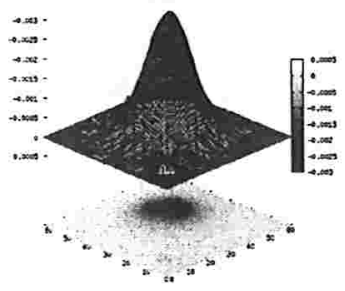

Com Filtro

Figura 4.1: Visão Tridimensional - Objeto com $(1.003 \mathrm{Ohm}-\mathrm{m})^{-1}-32$ Eletrodos

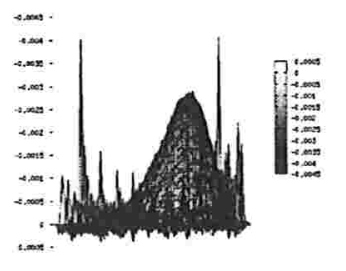

Sem Filtro

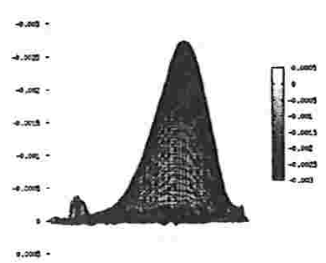

Com Filtro

Figura 4.2: Perfil - Objeto com (1.003 Ohm-m $)^{-1}$ - 32 Eletrodos

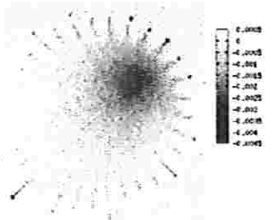

Sem Filtro

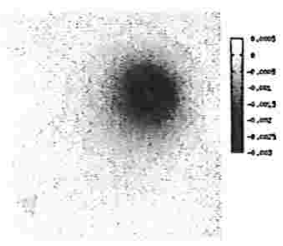

Com Filtro

Figura 4.3: Visão Bidimensional - Objeto com $(1.003 \mathrm{Ohm}-\mathrm{m})^{-1}-32$ Eletrodos 


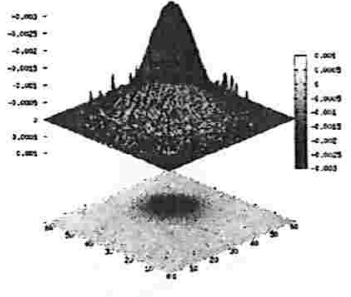

Sem Filtro

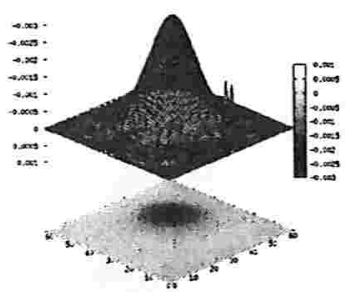

Com Filtro

Figura 4.4: Visão Tridimensional - Objeto com $(1.003 \mathrm{Ohm}-\mathrm{m})^{-1}-128$ Eletrodos

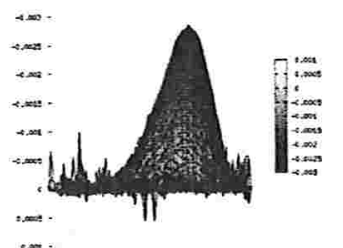

Sem Filtro

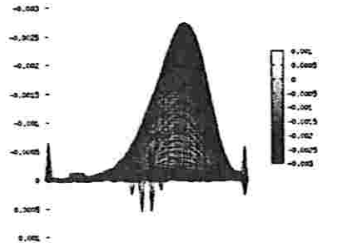

Com Filtro

Figura 4.5: Perfil - Objeto com (1.003 Ohm-m $)^{-1}-128$ Eletrodos

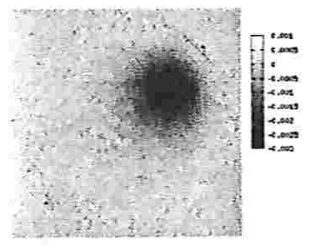

Sem Filtro

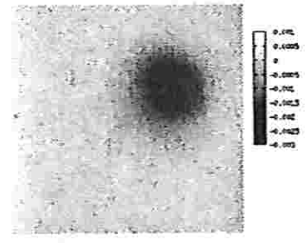

Com Filtro

Figura 4.6: Visão Bidimensional - Objeto com $(1.003 \mathrm{Ohm}-\mathrm{m})^{-1}-128$ Eletrodos 


\subsubsection{Condutividade $(1.016 \mathrm{Ohm}-\mathrm{m})^{-1}$}

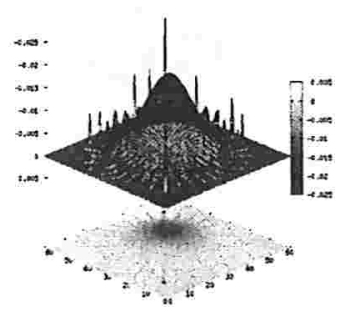

Sem Filtro

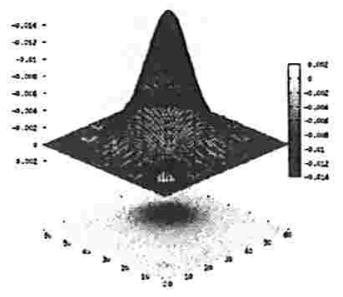

Com Filtro

Figura 4.7: Visão Tridimensional - Objeto com $(1.016 \mathrm{Ohm}-\mathrm{m})^{-1}-32$ Eletrodos

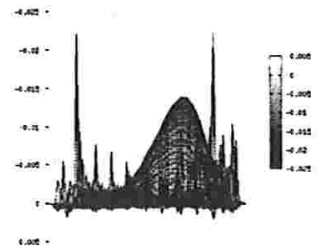

Sem Filtro

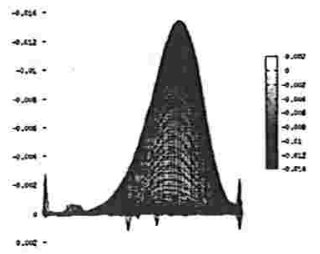

Com Filtro

Figura 4.8: Perfil - Objeto com (1.016 Ohm-m $)^{-1}-32$ Eletrodos

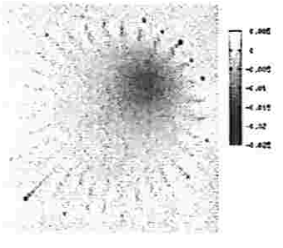

Sem Filtro

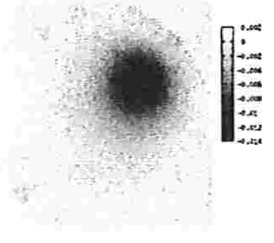

Com Filtro

Figura 4.9: Visão Bidimensional - Objeto com $(1.016 \mathrm{Ohm}-\mathrm{m})^{-1}-32$ Eletrodos 


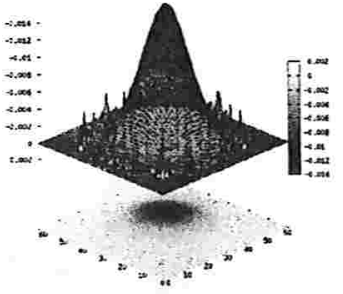

Sem Filtro

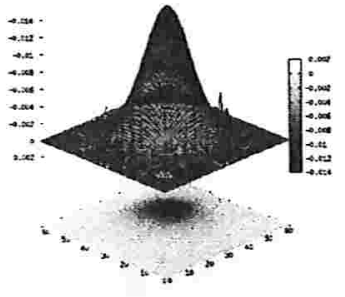

Com Filtro

Figura 4.10: Visão Tridimensional - Objeto com $(1.016 \mathrm{Ohm}-\mathrm{m})^{-1}-128$ Eletrodos

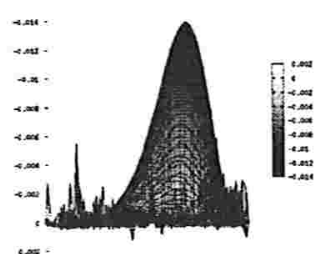

Sem Filtro

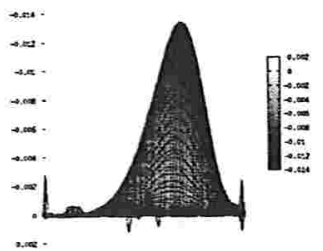

Com Filtro

Figura 4.11: Perfil - Objeto com (1.016 Ohm-m $)^{-1}-128$ Eletrodos

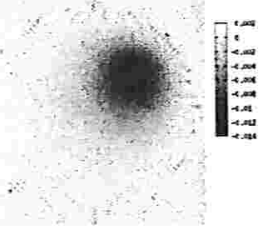

Sem Filtro
Com Filtro

Figura 4.12: Visão Bidimensional - Objeto com $(1.016 \mathrm{Ohm}-\mathrm{m})^{-1}-128$ Eletrodos 


\subsubsection{Condutividade $(1.16 \mathrm{Ohm}-\mathrm{m})^{-1}$}

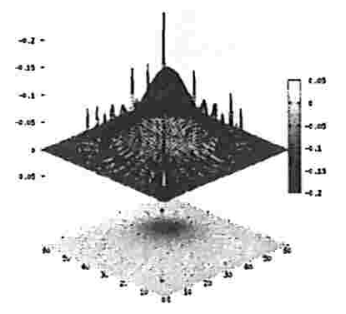

Sem Filtro

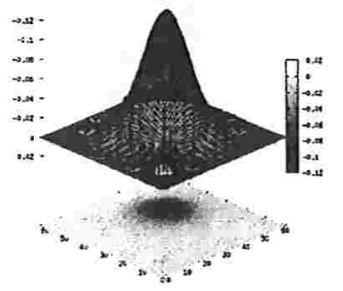

Com Filtro

Figura 4.13: Visão Tridimensional - Objeto com $(1.16 \mathrm{Ohm}-\mathrm{m})^{-1}-32$ Eletrodos

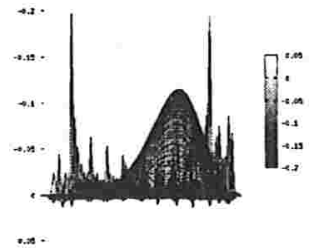

Sem Filtro

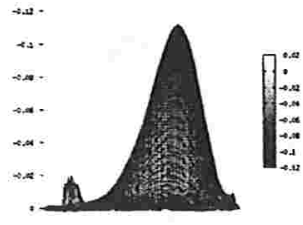

Figura 4.14: Perfil - Objeto com $(1.16 \mathrm{Ohm}-\mathrm{m})^{-1}-32$ Eletrodos

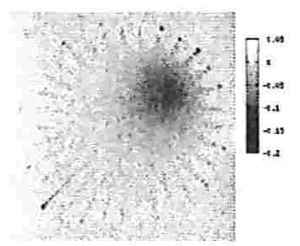

Sem Filtro

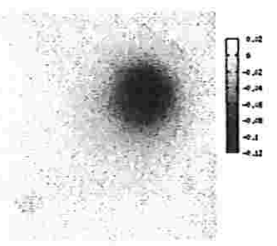

Com Filtro

Figura 4.15: Visão Bidimensional - Objeto com $(1.16 \mathrm{Ohm}-\mathrm{m})^{-1}-32$ Eletrodos 


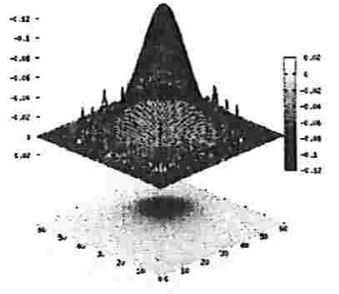

Sem Filtro

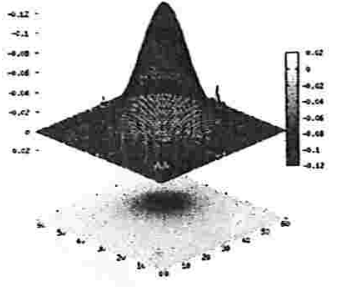

Com Filtro

Figura 4.16: Visão Tridimensional - Objeto com $(1.16 \mathrm{Ohm}-\mathrm{m})^{-1}$ - 128 Eletrodos

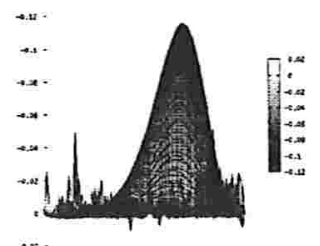

Sem Filtro

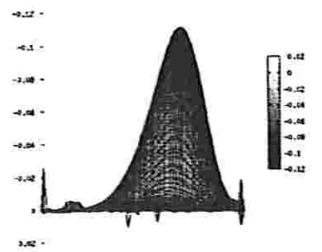

Com Filtro

Figura 4.17: Perfil - Objeto com (1.16 Ohm-m $)^{-1}-128$ Eletrodos

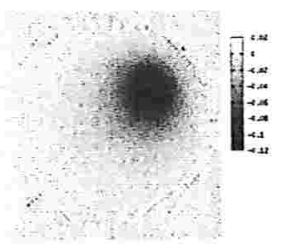

Sem Filtro

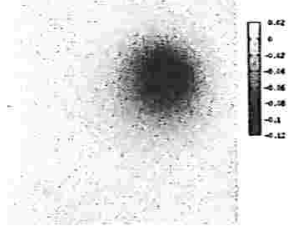

Com Filtro

Figura 4.18: Visão Bidimensional - Objeto com $(1.16 \mathrm{Ohm}-\mathrm{m})^{-1}$ - 128 Eletrodos 


\subsubsection{Condutividade $(1.32 \mathrm{Ohm}-\mathrm{m})^{-1}$}

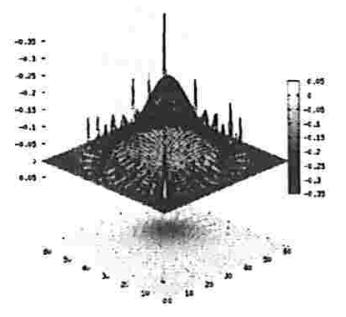

Sem Filtro

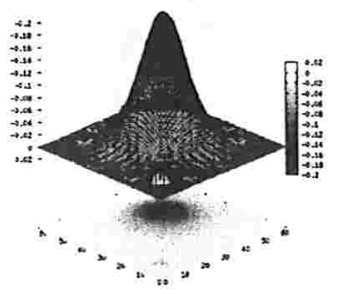

Com Filtro

Figura 4.19: Visão Tridimensional - Objeto com $(1.32 \mathrm{Ohm}-\mathrm{m})^{-1}-32$ Eletrodos

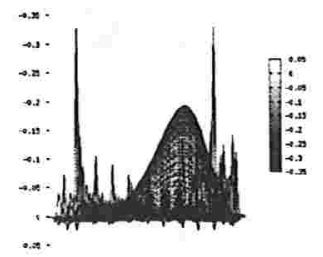

Sem Filtro

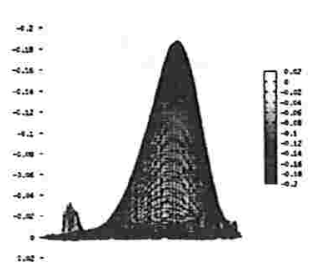

Com Filtro

Figura 4.20: Perfil - Objeto com (1.32 Ohm-m $)^{-1}-32$ Eletrodos

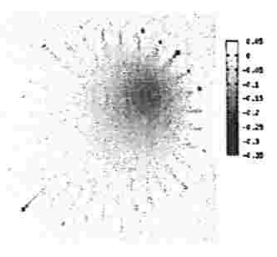

Sem Filtro

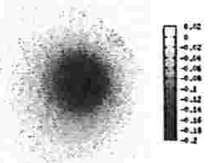

Com Filtro

Figura 4.21: Visão Bidimensional - Objeto com $(1.32 \mathrm{Ohm}-\mathrm{m})^{-1}-32$ Eletrodos 


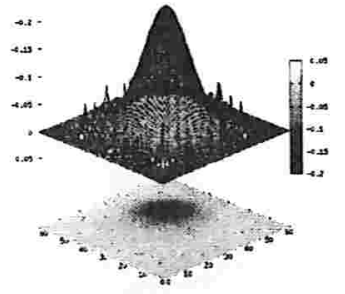

Sem Filtro

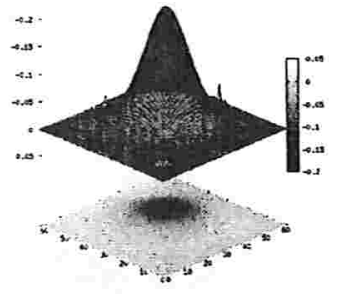

Com Filtro

Figura 4.22: Visão Tridimensional - Objeto com $(1.32 \mathrm{Ohm}-\mathrm{m})^{-1}-128$ Eletrodos

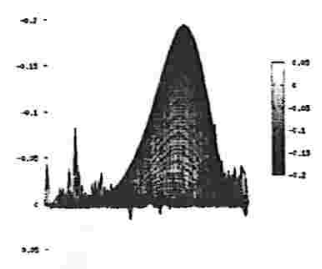

Sem Filtro

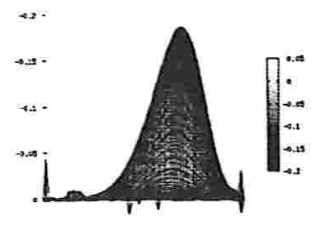

...

Com Filtro

Figura 4.23: Perfil - Objeto com $(1.32 \mathrm{Ohm}-\mathrm{m})^{-1}-128$ Eletrodos

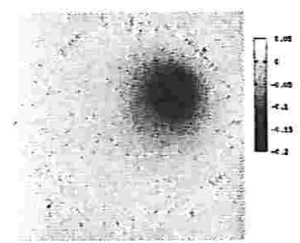

Sem Filtro

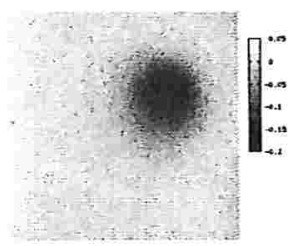

Com Filtro

Figura 4.24: Visão Bidimensional - Objeto com $(1.32 \mathrm{Ohm}-\mathrm{m})^{-1}-128$ Eletrodos 
As tabelas 4.3 a 4.6 mostram os valores de variação de condutividade respectivamente para as condutividades listadas.

\begin{tabular}{|c|c|c|c|c|}
\hline Informação $\left(\times 10^{-4}\right)$ & \multicolumn{2}{|c|}{32 Eletrodos } & \multicolumn{2}{c|}{128 Eletrodos } \\
\hline & Sem Filtro & Com Filtro & Sem Filtro & Com Filtro \\
\hline máximo & 3.74156 & 0.62074 & 5.37671 & 5.37671 \\
\hline mínimo & -40.68344 & -27.35665 & -28.52257 & -27.36067 \\
\hline média & -2.82910 & -2.83150 & -2.81779 & -2.82130 \\
\hline desvio padrão & 5.87881 & 5.48002 & 5.64574 & 5.48434 \\
\hline
\end{tabular}

Tabela 4.3: Teste - 1 Objeto de Condutividade $(1.003 \mathrm{Ohm}-\mathrm{m})^{-1}$ -

\begin{tabular}{|c|c|c|c|c|}
\hline Informação $\left(\times 10^{-4}\right)$ & \multicolumn{2}{|c|}{32 Eletrodos } & \multicolumn{2}{c|}{128 Eletrodos } \\
\hline & Sem Filtro & Com Filtro & Sem Filtro & Com Filtro \\
\hline máximo & 19.93904 & 2.07562 & 11.86558 & 11.86558 \\
\hline mínimo & -223.25324 & -134.43481 & -139.44704 & -134.39329 \\
\hline média & -13.87774 & -13.88937 & -13.79633 & -13.81537 \\
\hline desvio padrão & 28.82447 & 26.92584 & 27.66288 & 26.92075 \\
\hline
\end{tabular}

Tabela 4.4: Teste - 1 Objeto de Condutividade $(1.016 \mathrm{Ohm}-\mathrm{m})^{-1}$

\begin{tabular}{|c|c|c|c|c|}
\hline Informação $\left(\times 10^{-4}\right)$ & \multicolumn{2}{|c|}{32 Eletrodos } & \multicolumn{2}{c|}{128 Eletrodos } \\
\hline & Sem Filtro & Com Filtro & Sem Filtro & Com Filtro \\
\hline máximo & 130.89669 & 15.28542 & 96.99443 & 96.99443 \\
\hline mínimo & -1968.82716 & -1114.21007 & -1153.49107 & -1114.23756 \\
\hline média & -114.57567 & -114.67355 & -113.79386 & -113.94465 \\
\hline desvio padrão & 238.93906 & 222.69142 & 228.71194 & 222.56456 \\
\hline
\end{tabular}

Tabela 4.5: Teste - 1 Objeto de Condutividade $(1.16 \mathrm{Ohm}-\mathrm{m})^{-1}$

\begin{tabular}{|c|c|c|c|c|}
\hline Informação $\left(\times 10^{-4}\right)$ & \multicolumn{2}{|c|}{32 Eletrodos } & \multicolumn{2}{c|}{128 Eletrodos } \\
\hline & Sem Filtro & Com Filtro & Sem Filtro & Com Filtro \\
\hline máximo & 220.83741 & 26.87562 & 162.95278 & 162.95278 \\
\hline mínimo & -3305.39140 & -1871.27606 & -1937.44893 & -1871.35802 \\
\hline média & -191.79404 & -191.95716 & -190.51542 & -190.76782 \\
\hline desvio padrão & 400.60923 & 373.37835 & 383.46837 & 373.14196 \\
\hline
\end{tabular}

Tabela 4.6: Teste - 1 Objeto de Condutividade $(1.32 \mathrm{Ohm}-\mathrm{m})^{-1}$

Em todos os casos, o objeto reconstruído foi localizado na posição correta. Houve, porém, degradação do valor mínimo do objeto. A tabela 4.7 mostra que, à medida que a perturbação provocada aumenta, maior também é a distância entre o valor esperado para a reconstrução 
e o valor calculado pelo algoritmo. Os valores resconstruídos dessa tabela foram tomados da reconstrução utilizando interpolação de 128 eletrodos e filtro da vizinhança. Devemos, contudo, levar em conta que, quanto maior a perturbação, mais estaremos violando as hipóteses utilizadas para a construção de nossa versão do algoritmo de BackProjection, que assume que apenas pequenas variações ocorrem no sistema. Portanto, é de se esperar que o erro no cálculo seja maior.

\begin{tabular}{|c|c|c|c|}
\hline $\begin{array}{c}\text { Valor da Condutividade } \\
(\text { Ohm-m })^{-1}\end{array}$ & $\begin{array}{c}\text { Valor Esperado do } \\
\text { Algoritmo }\left(\times 10^{-4}\right)\end{array}$ & $\begin{array}{c}\text { Valor Reconstruído } \\
\left(\times 10^{-4}\right)\end{array}$ & \% do Valor Esperado \\
\hline$\frac{1}{1.003}$ & -29.91027 & -27.36067 & 91.48 \\
\hline$\frac{1}{1.016}$ & -157.48031 & -134.39329 & 85.34 \\
\hline$\frac{1}{1.16}$ & -1379.31034 & -1114.23756 & 80.78 \\
\hline$\frac{1}{1.32}$ & -2424.24242 & -1871.35802 & 77.19 \\
\hline
\end{tabular}

Tabela 4.7: Comparativos do Valor Esperado com o Reconstruído

\subsection{Variação de Condutividade para um Par de Obje- tos}

O objetivo deste teste é testar a capacidade do algoritmo de distinguir dois objetos diferentes na mesma imagem. Para isso, dois objetos (conforme figura 4.25) foram colocados diametralmente opostos no domínio, com condutividades idênticas. Novamente foram utilizados os 4 valores de condutividade do primeiro teste.

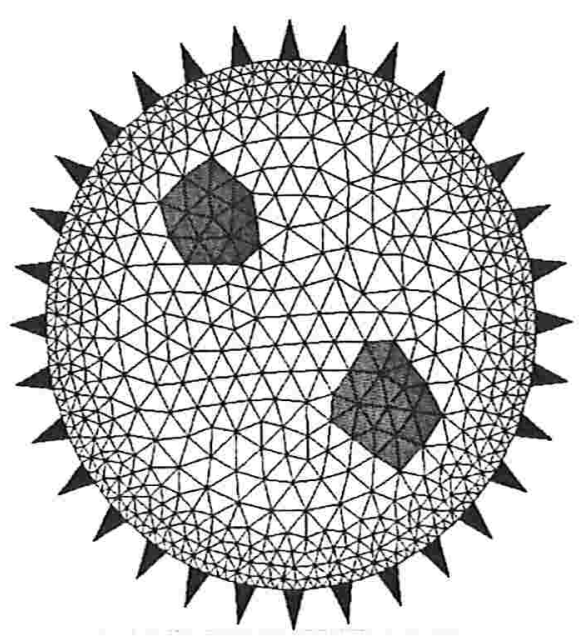

Figura 4.25: Teste: Par de objetos diametralmente opostos 


\subsubsection{Condutividade $(1.003 \mathrm{Ohm}-\mathrm{m})^{-1}$}

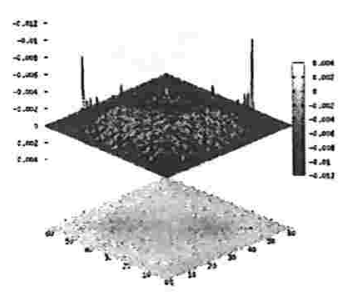

Sem Filtro

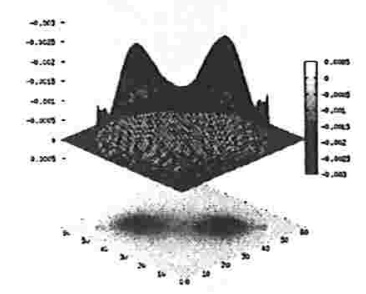

Com Filtro

Figura 4.26: Visão Tridimensional - Par de Objetos com (1.003 Ohm-m $)^{-1}-32$ Eletrodos

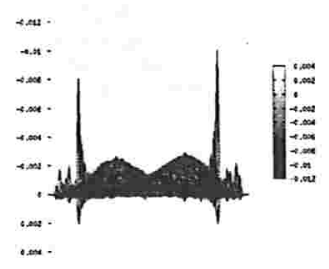

Sem Filtro

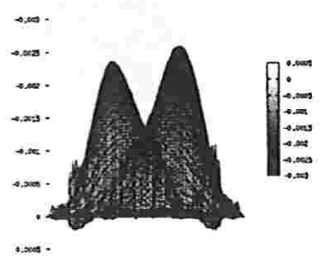

Com Filtro

Figura 4.27: Perfil - Par de Objetos com (1.003 Ohm-m $)^{-1}-32$ Eletrodos

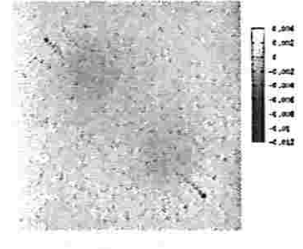

Sem Filtro

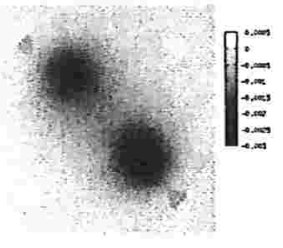

Com Filtro

Figura 4.28: Visão Bidimensional - Par de Objetos com $(1.003 \mathrm{Ohm}-\mathrm{m})^{-1}-32$ Eletrodos 


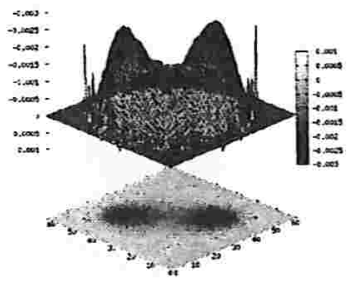

Sem Filtro

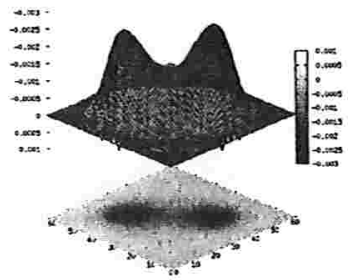

Com Filtro

Figura 4.29: Visão Tridimensional - Par de Objetos com (1.003 Ohm-m $)^{-1}-128$ Eletrodos

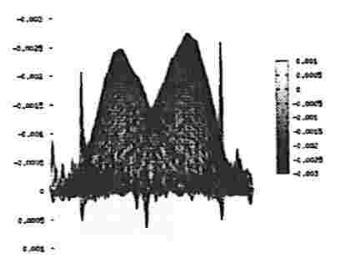

Sem Filtro

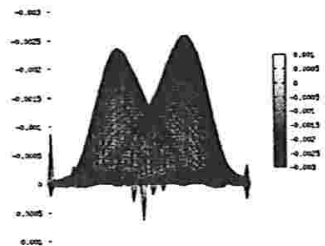

Com Filtro

Figura 4.30: Perfil - Par de Objetos com $(1.003 \mathrm{Ohm}-\mathrm{m})^{-1}-128$ Eletrodos

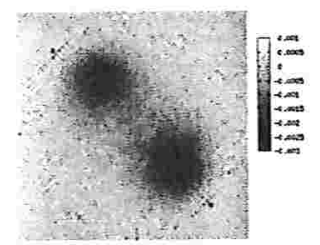

Sem Filtro

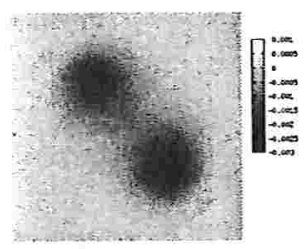

Com Filtro

Figura 4.31: Visão Bidimensional - Par de Objetos com (1.003 Ohm-m) $)^{-1}-128$ Eletrodos 


\subsubsection{Condutividade $(1.016 \mathrm{Ohm}-\mathrm{m})^{-1}$}

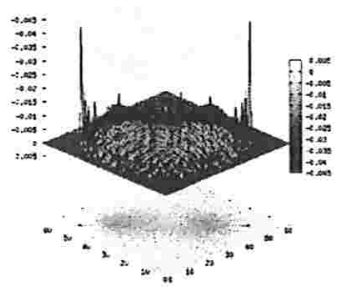

Sem Filtro

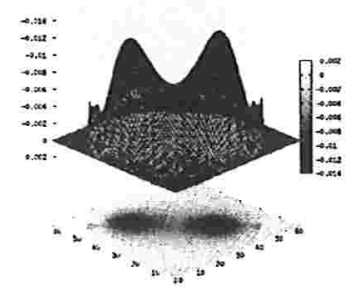

Com Filtro

Figura 4.32: Visão Tridimensional - Par de Objetos com $(1.016 \mathrm{Ohm}-\mathrm{m})^{-1}-32$ Eletrodos

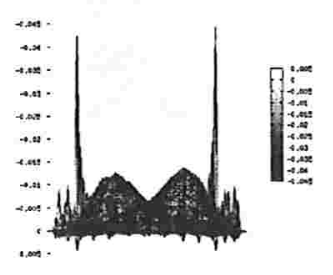

Sem Filtro

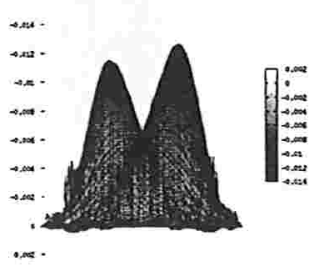

Com Filtro

Figura 4.33: Perfil - Par de Objetos com (1.016 Ohm-m $)^{-1}-32$ Eletrodos

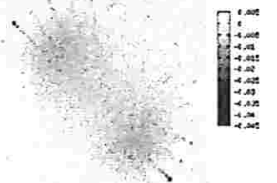

Sem Filtro

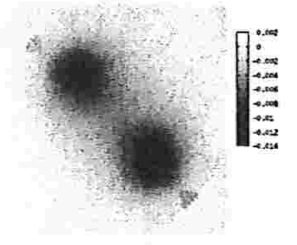

Com Filtro

Figura 4.34: Visão Bidimensional - Par de Objetos com (1.016 Ohm-m $)^{-1}-32$ Eletrodos 


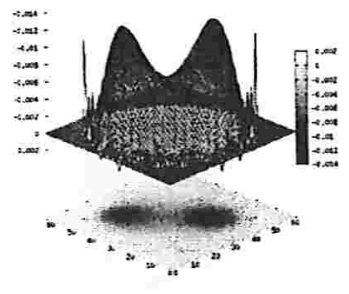

Sem Filtro

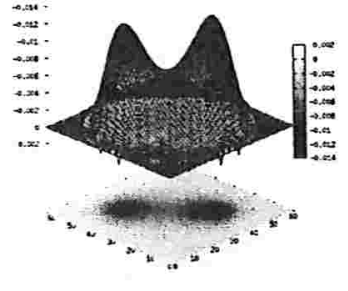

Com Filtro

Figura 4.35: Visão Tridimensional - Par de Objetos com $(1.016 \mathrm{Ohm}-\mathrm{m})^{-1}-128$ Eletrodos

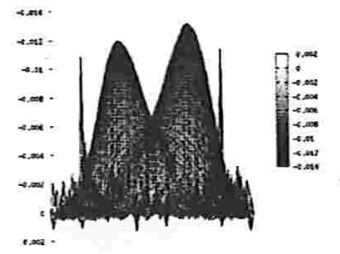

Sem Filtro

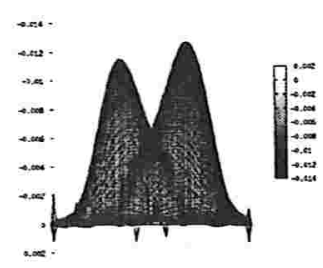

Com Filtro

Figura 4.36: Perfil - Par de Objetos com (1.016 Ohm-m $)^{-1}-128$ Eletrodos

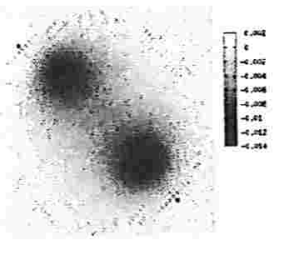

Sem Filtro

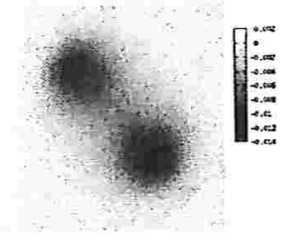

Com Filtro

Figura 4.37: Visão Bidimensional - Par de Objetos com (1.016 Ohm-m) $)^{-1}-128$ Eletrodos 


\subsubsection{Condutividade $(1.16 \mathrm{Ohm}-\mathrm{m})^{-1}$}

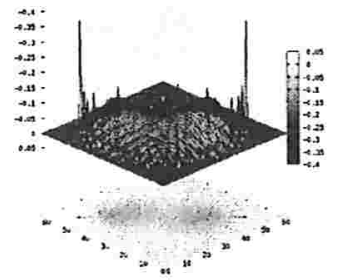

Sem Filtro

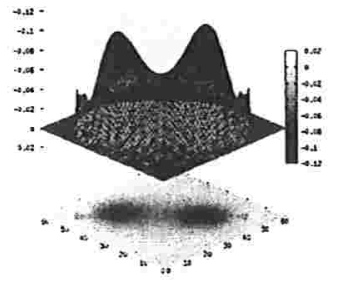

Com Filtro

Figura 4.38: Visão Tridimensional - Par de Objetos com (1.16 Ohm-m $)^{-1}-32$ Eletrodos

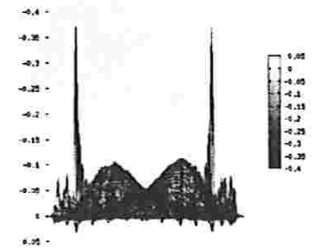

Sem Filtro

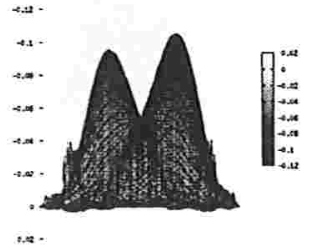

Com Filtro

Figura 4.39: Perfil - Par de Objetos com $(1.16 \mathrm{Ohm}-\mathrm{m})^{-1}-32$ Eletrodos

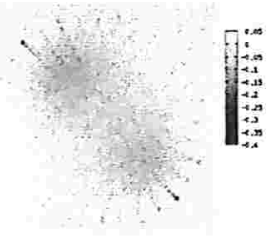

Sem Filtro

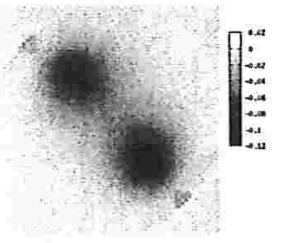

Com Filtro

Figura 4.40: Visão Bidimensional - Par de Objetos com $(1.16 \mathrm{Ohm}-\mathrm{m})^{-1}-32$ Eletrodos 


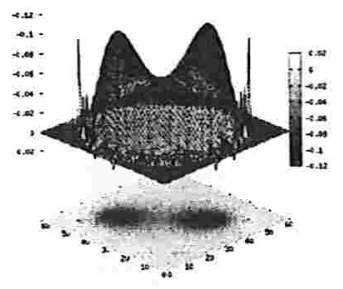

Sem Filtro

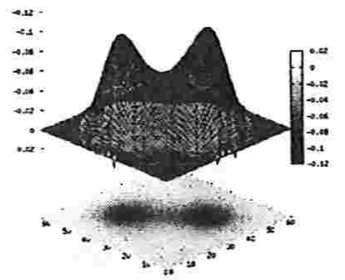

Com Filtro

Figura 4.41: Visão Tridimensional - Par de Objetos com (1.16 Ohm-m $)^{-1}-128$ Eletrodos

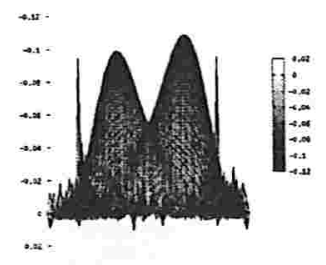

Sem Filtro

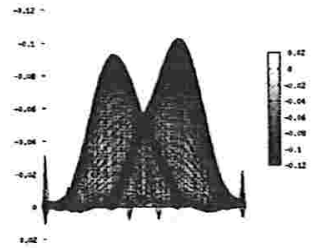

Com Filtro

Figura 4.42: Perfil - Par de Objetos com (1.16 Ohm-m $)^{-1}-128$ Eletrodos

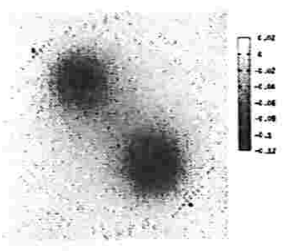

Sem Filtro

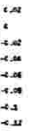

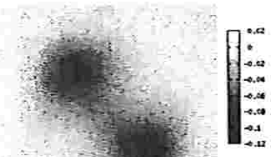

Com Filtro

Figura 4.43: Visão Bidimensional - Par de Objetos com $(1.16 \mathrm{Ohm}-\mathrm{m})^{-1}-128$ Eletrodos 


\subsubsection{Condutividade $(1.32 \mathrm{Ohm}-\mathrm{m})^{-1}$}

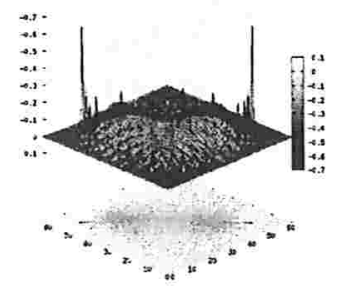

Sem Filtro

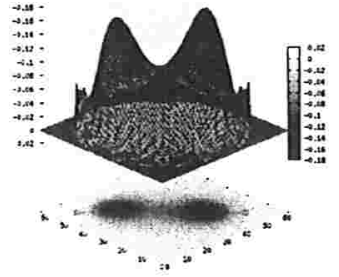

Com Filtro

Figura 4.44: Visão Tridimensional - Par de Objetos com (1.32 Ohm-m $)^{-1}-32$ Eletrodos

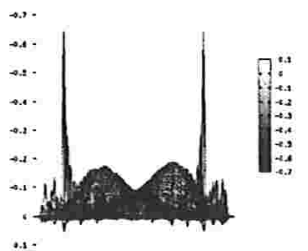

Sem Filtro

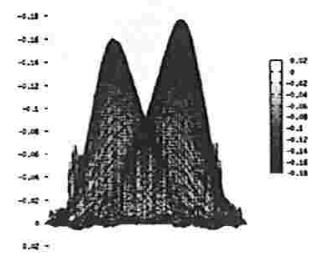

Com Filtro

Figura 4.45: Perfil - Par de Objetos com (1.32 Ohm-m $)^{-1}-32$ Eletrodos

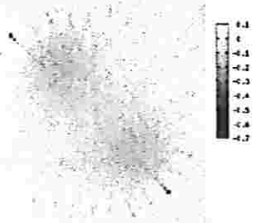

Sem Filtro

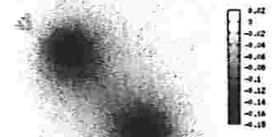

Com Filtro

Figura 4.46: Visão Bidimensional - Par de Objetos com (1.32 Ohm-m $)^{-1}-32$ Eletrodos 


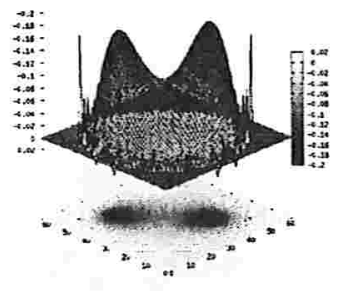

Sem Filtro

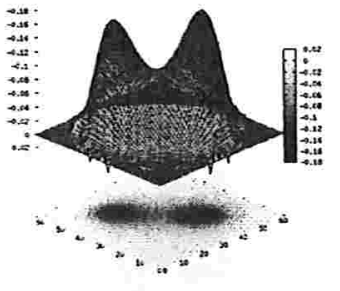

Com Filtro

Figura 4.47: Visão Tridimensional - Par de Objetos com $(1.32 \mathrm{Ohm}-\mathrm{m})^{-1}-128$ Eletrodos

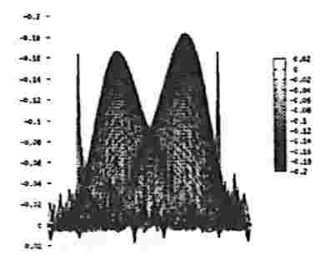

Sem Filtro

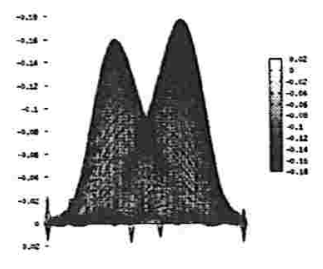

Com Filtro

Figura 4.48: Perfil - Par de Objetos com (1.32 Ohm-m $)^{-1}-128$ Eletrodos

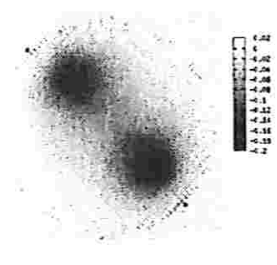

Sem Filtro

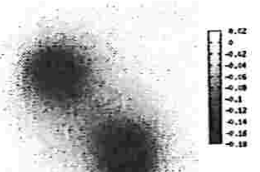

Com Filtro

Figura 4.49: Visão Bidimensional - Par de Objetos com (1.32 Ohm-m $)^{-1}-128$ Eletrodos

As tabelas 4.8 a 4.11 mostram os valores de variação de condutividade respectivamente para as condutividades listadas. 


\begin{tabular}{|c|c|c|c|c|}
\hline Informação $\left(\times 10^{-4}\right)$ & \multicolumn{2}{|c|}{32 Eletrodos } & \multicolumn{2}{c|}{128 Eletrodos } \\
\hline & Sem Filtro & Com Filtro & Sem Filtro & Com Filtro \\
\hline máximo & 20.05931 & 2.07354 & 6.27386 & 6.27386 \\
\hline mínimo & -101.01590 & -25.87791 & -27.50681 & -25.90818 \\
\hline média & -4.75317 & -4.75746 & -4.72232 & -4.72803 \\
\hline desvio padrão & 7.17522 & 6.44501 & 6.64142 & 6.42601 \\
\hline valor (pico 1) & -26.78862 & -23.65872 & -24.76423 & -23.66094 \\
\hline valor (pico 2) & -29.59985 & -25.87791 & -27.50681 & -25.90818 \\
\hline ponto máximo (vale) & -10.77035 & -12.36103 & -10.76901 & -12.37137 \\
\hline
\end{tabular}

Tabela 4.8: Teste - Par de Objetos de Condutividade (1.003 Ohm-m $)^{-1}$ -

\begin{tabular}{|c|c|c|c|c|}
\hline Informação $\left(\times 10^{-4}\right)$ & \multicolumn{2}{|c|}{32 Eletrodos } & \multicolumn{2}{c|}{128 Eletrodos } \\
\hline & Sem Filtro & Com Filtro & Sem Filtro & Com Filtro \\
\hline máximo & 40.01929 & 4.11430 & 12.50154 & 12.50154 \\
\hline mínimo & -444.82409 & -126.52746 & -131.27682 & -126.78863 \\
\hline média & -23.35620 & -23.37740 & -23.15989 & -23.18821 \\
\hline desvio padrão & 34.91084 & 31.59395 & 32.49572 & 31.50465 \\
\hline valor (pico 1) & -128.61733 & -115.50163 & -119.46815 & -115.52265 \\
\hline valor (pico 2) & -138.22528 & -126.52746 & -131.27682 & -126.78863 \\
\hline ponto máximo (vale) & -60.67938 & -61.20762 & -60.68067 & -61.21510 \\
\hline
\end{tabular}

Tabela 4.9: Teste - Par de Objetos de Condutividade (1.016 Ohm-m $)^{-1}$

\begin{tabular}{|c|c|c|c|c|}
\hline Informação $\left(\times 10^{-4}\right)$ & \multicolumn{2}{|c|}{ 32 Eletrodos } & \multicolumn{2}{c|}{128 Eletrodos } \\
\hline & Sem Filtro & Com Filtro & Sem Filtro & Com Filtro \\
\hline máximo & 299.97466 & 30.51874 & 100.22347 & 100.38929 \\
\hline mínimo & -3699.77032 & -1050.20239 & -1086.48186 & -1024.26616 \\
\hline média & -193.15076 & -193.32809 & -191.47741 & -193.07732 \\
\hline desvio padrão & 290.03021 & 261.90672 & 269.38073 & 262.47671 \\
\hline valor (pico 1) & -1071.98442 & -953.99833 & -989.53173 & -927.30133 \\
\hline valor (pico 2) & -1141.77750 & -1050.20239 & -1086.48186 & -1024.26616 \\
\hline ponto máximo (vale) & -514.89380 & -516.47345 & -514.89718 & -528.74864 \\
\hline
\end{tabular}

Tabela 4.10: Teste - Par de Objetos de Condutividade $(1.16 \mathrm{Ohm}-\mathrm{m})^{-1}$

\begin{tabular}{|c|c|c|c|c|}
\hline Informação $\left(\times 10^{-4}\right)$ & \multicolumn{2}{|c|}{32 Eletrodos } & \multicolumn{2}{c|}{ 128 Eletrodos } \\
\hline & Sem Filtro & Com Filtro & Sem Filtro & Com Filtro \\
\hline máximo & 499.98321 & 50.95337 & 164.31339 & 164.31339 \\
\hline mínimo & -6448.07756 & -1770.24644 & -1832.16888 & -1774.12419 \\
\hline média & -324.58172 & -324.87855 & -321.61125 & -322.00390 \\
\hline desvio padrão & 489.84442 & 440.97858 & 453.58981 & 439.60579 \\
\hline valor (pico 1) & -1810.40675 & -1602.17819 & -1662.79151 & -1604.28013 \\
\hline valor (pico 2) & -1929.60520 & -1770.24644 & -1832.16888 & -1774.12419 \\
\hline ponto máximo (vale) & -880.89586 & -881.22180 & -880.89398 & -881.20971 \\
\hline
\end{tabular}

Tabela 4.11: Teste - Par de Objetos de Condutividade $(1.32 \mathrm{Ohm}-\mathrm{m})^{-1}$ 
Apesar das imagens demonstrarem que os objetos foram corretamente localizados, o espalhamento da informação dos objetos pelo algoritmo não identificou dois objetos completamente isolados. As tabelas 4.8 a 4.11 indicam os valores encontrados para os picos e os vales. Esperava-se que o valor fosse próximo de zero. A tabela 4.12 mostra a comparação do valor do vale com os dois picos dos objetos reconstruídos (levando-se em conta a suavização dos dados de entrada e o filtro da vizinhança. Em todos os casos, o valor do vale foi de aproximadamente $50 \%$ do valor do pico. Portanto, ainda há a necessidade de se trabalhar no algoritmo como, por exemplo, a ponderação da integral do BackProjection, para se obter uma melhor separação dos objetos na imagem final.

\begin{tabular}{|c|c|c|c|c|c|}
\hline $\begin{array}{c}\text { Condutividade } \\
(\text { Ohm-m })^{-1}\end{array}$ & $\begin{array}{c}\text { Valor do Vale } \\
\left(\times 10^{-4}\right)\end{array}$ & $\begin{array}{c}\text { Valor do Pico 1 } \\
\left(\times 10^{-4}\right)\end{array}$ & $\begin{array}{c}\text { \% do Vale relativo } \\
\text { ao Pico 1 }\end{array}$ & $\begin{array}{c}\text { Valor do Pico 2 } \\
\left(\times 10^{-4}\right)\end{array}$ & $\begin{array}{c}\text { \% do Vale relativo } \\
\text { ao Pico 2 }\end{array}$ \\
\hline$\frac{1}{1.003}$ & -12.37137 & -23.66094 & 52.29 & -25.90818 & 47.75 \\
\hline$\frac{1}{1.016}$ & -61.21510 & -115.52265 & 52.99 & -126.78863 & 48.28 \\
\hline$\frac{1}{1.16}$ & -528.74864 & -927.30133 & 57.02 & -1024.26616 & 51.62 \\
\hline$\frac{1}{1.32}$ & -881.20971 & -1604.28013 & 54.93 & -1774.12419 & 49.67 \\
\hline
\end{tabular}

Tabela 4.12: Comparativos do Valor do Vale com os Picos 


\subsection{Par de Objetos com Condutividades Diferentes}

Para este teste, vamos usar uma disposição parecida com a da seção anterior. Para as condutividades, porém, utilizaremos como condutividade de um dos objetos o valor inverso do outro. Assim, teremos um par com condutividades $(1.003 \mathrm{Ohm}-\mathrm{m})^{-1}$ e $1.003(\mathrm{Ohm}-\mathrm{m})^{-1}$, o segundo com valores $(1.016 \mathrm{Ohm}-\mathrm{m})^{-1}$ e $1.016(\mathrm{Ohm}-\mathrm{m})^{-1}$ e assim por diante. Os valores esperados para a reconstrução estão na tabela 4.13 .

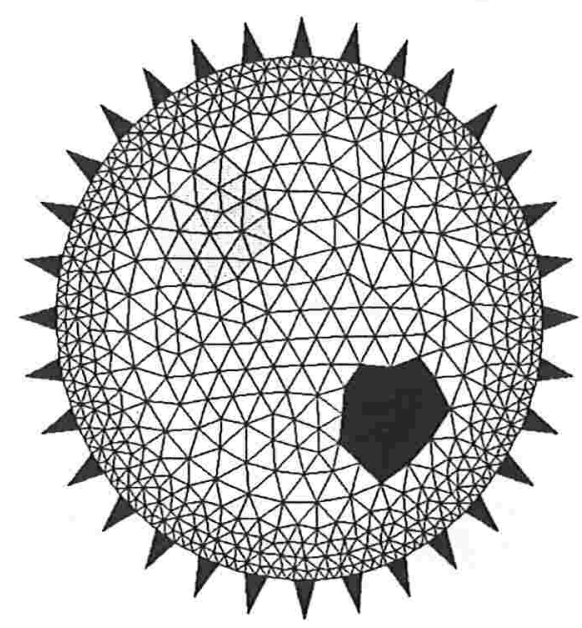

Figura 4.50: Teste: Par de objetos diametralmente opostos com condutividades diferentes

\begin{tabular}{|c|c|c|}
\hline Par Reverso & $\begin{array}{c}\text { Variação Esperada - Pico 1 } \\
\left(\times 10^{-4}\right)\end{array}$ & $\begin{array}{c}\text { Variação Esperada - Pico 2 } \\
\left(\times 10^{-4}\right)\end{array}$ \\
\hline 1 & -29.91027 & 30.00000 \\
\hline 2 & -157.48032 & 160.00000 \\
\hline 3 & -1379.31035 & 1600.00000 \\
\hline 4 & -2424.24242 & 3200.00000 \\
\hline
\end{tabular}

Tabela 4.13: Valores esperados de reconstrução 


\subsubsection{Condutividades $(1.003 \mathrm{Ohm}-\mathrm{m})^{-1}$ e $1.003(\mathrm{Ohm}-\mathrm{m})^{-1}$}

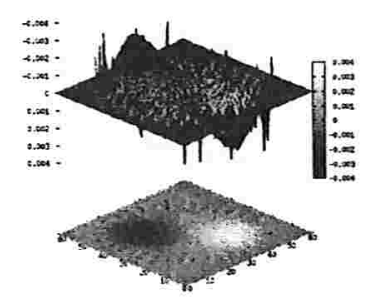

Sem Filtro

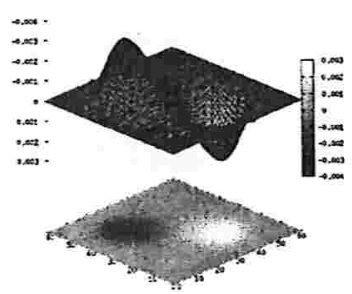

Com Filtro

Figura 4.51: Visão Tridimensional - Par de Objetos com $(1.003 \mathrm{Ohm}-\mathrm{m})^{-1}$ e $1.003(\mathrm{Ohm}-\mathrm{m})^{-1}-32$ Eletrodos

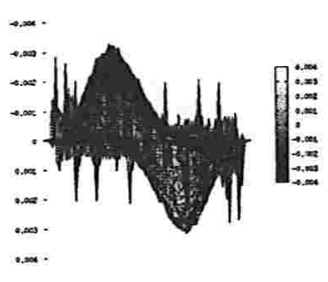

Sem Filtro

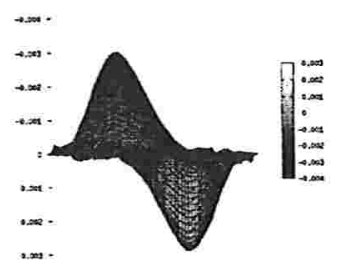

Com Filtro

Figura 4.52: Perfil - Par de Objetos com $(1.003 \mathrm{Ohm}-\mathrm{m})^{-1}$ e $1.003(\mathrm{Ohm}-\mathrm{m})^{-1}-32$ Eletrodos

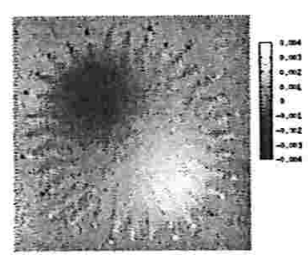

Sem Filtro

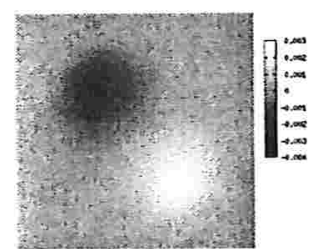

Com Filtro

Figura 4.53: Visão Bidimensional - Par de Objetos com (1.003 Ohm-m $)^{-1}$ e $1.003(\mathrm{Ohm}-\mathrm{m})^{-1}$ - 32 Eletrodos 


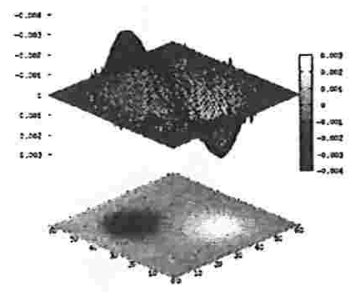

Sem Filtro

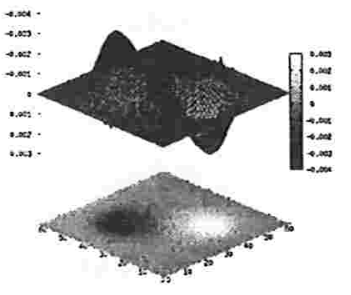

Com Filtro

Figura 4.54: Visão Tridimensional - Par de Objetos com (1.003 Ohm-m $)^{-1}$ e $1.003(\mathrm{Ohm}-\mathrm{m})^{-1}-128$ Eletrodos

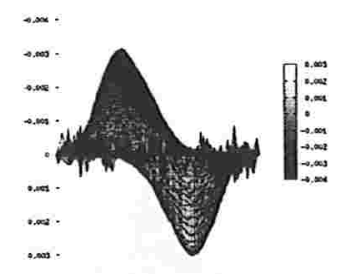

Sem Filtro

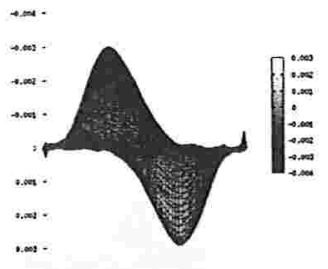

Com Filtro

Figura 4.55: Perfil - Par de Objetos com (1.003 Ohm-m $)^{-1}$ e 1.003 (Ohm-m $)^{-1}$ - 128 Eletrodos

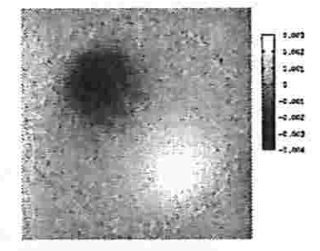

Sem Filtro

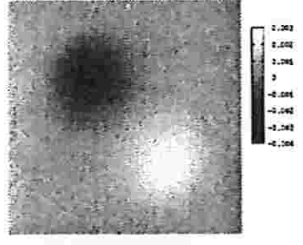

Com Filtro

Figura 4.56: Visão Bidimensional - Par de Objetos com (1.003 Ohm-m $)^{-1}$ e $1.003(\mathrm{Ohm}-\mathrm{m})^{-1}-128$ Eletrodos 


\subsubsection{Condutividades $(1.016 \mathrm{Ohm}-\mathrm{m})^{-1}$ e $1.016(\mathrm{Ohm}-\mathrm{m})^{-1}$}

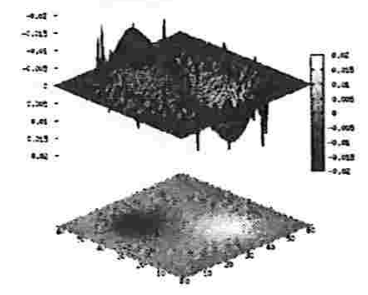

Sem Filtro

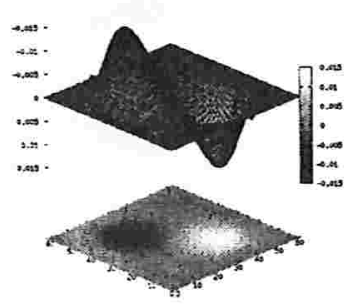

Com Filtro

Figura 4.57: Visão Tridimensional - Par de Objetos com $(1.016 \mathrm{Ohm}-\mathrm{m})^{-1}$ e $1.016(\mathrm{Ohm}-\mathrm{m})^{-1}-32$ Eletrodos

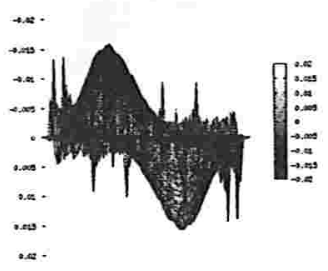

Sem Filtro

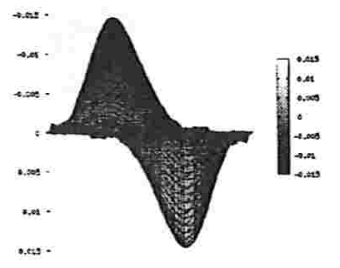

Com Filtro

Figura 4.58: Perfil - Par de Objetos com $(1.016 \mathrm{Ohm}-\mathrm{m})^{-1}$ e $1.016(\mathrm{Ohm}-\mathrm{m})^{-1}$ - 32 Eletrodos

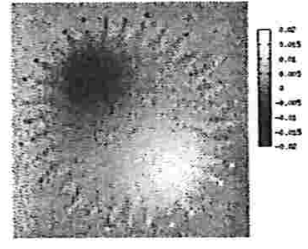

Sem Filtro

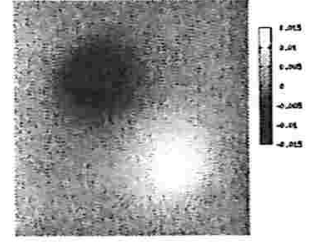

Com Filtro

Figura 4.59: Visão Bidimensional - Par de Objetos com $(1.016 \mathrm{Ohm}-\mathrm{m})^{-1}$ e $1.016(\mathrm{Ohm}-\mathrm{m})^{-1}$ - 32 Eletrodos 


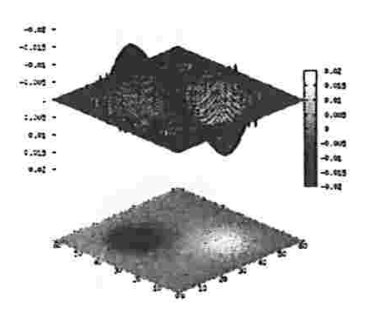

Sem Filtro

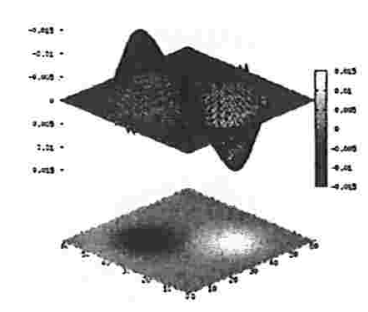

Com Filtro

Figura 4.60: Visão Tridimensional - Par de Objetos com (1.016 Ohm-m $)^{-1}$ e $1.016(\mathrm{Ohm}-\mathrm{m})^{-1}$ - 128 Eletrodos

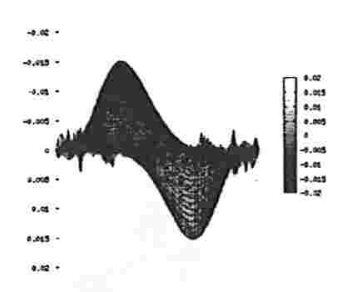

Sem Filtro

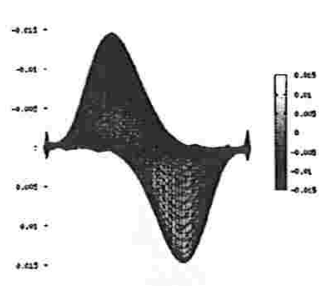

Com Filtro

Figura 4.61: Perfil - Par de Objetos com (1.016 Ohm-m) $)^{-1}$ e $1.016(\mathrm{Ohm}-\mathrm{m})^{-1}$ - 128 Eletrodos

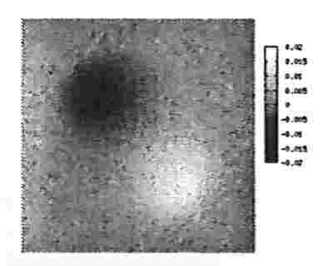

Sem Filtro

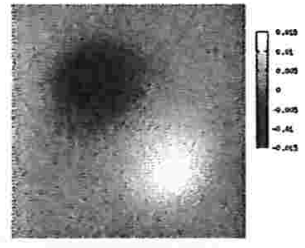

Com Filtro

Figura 4.62: Visão Bidimensional - Par de Objetos com (1.016 Ohm-m $)^{-1}$ e $1.016(\mathrm{Ohm}-\mathrm{m})^{-1}$ - 128 Eletrodos 


\subsubsection{Condutividades $(1.16 \mathrm{Ohm}-\mathrm{m})^{-1}$ e $1.16(\mathrm{Ohm}-\mathrm{m})^{-1}$}

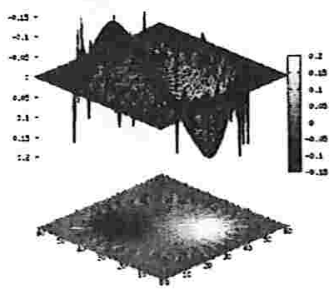

Sem Filtro

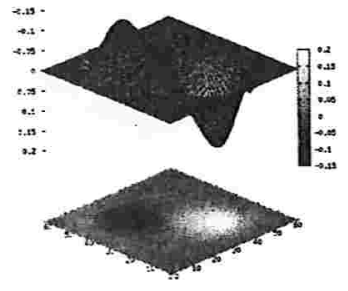

Com Filtro

Figura 4.63: Visão Tridimensional - Par de Objetos com $(1.16 \mathrm{Ohm}-\mathrm{m})^{-1}$ e $1.16(\mathrm{Ohm}-\mathrm{m})^{-1}-32$ Eletrodos

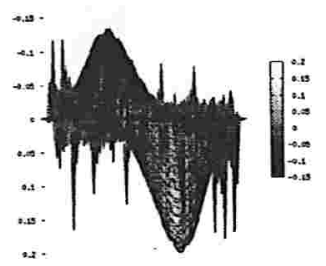

Sem Filtro

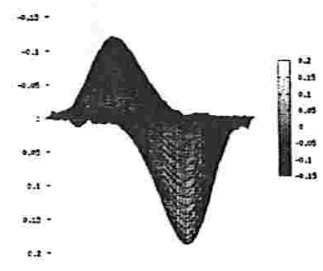

Com Filtro

Figura 4.64: Perfil - Par de Objetos com $(1.16 \mathrm{Ohm}-\mathrm{m})^{-1}$ e $1.16(\mathrm{Ohm}-\mathrm{m})^{-1}-32$ Eletrodos

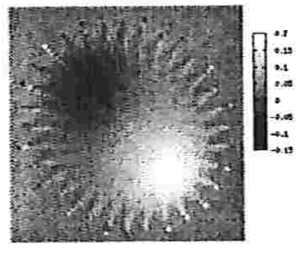

Sem Filtro

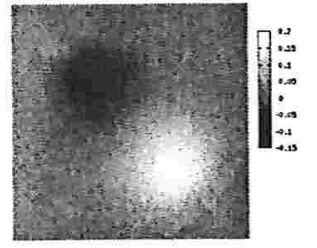

Com Filtro

Figura 4.65: Visão Bidimensional - Par de Objetos com (1.16 Ohm-m) $)^{-1}$ e $1.16(\mathrm{Ohm}-\mathrm{m})^{-1}-32$ Eletrodos 


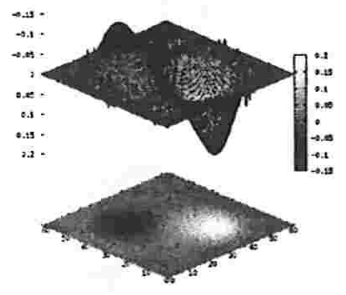

Sem Filtro

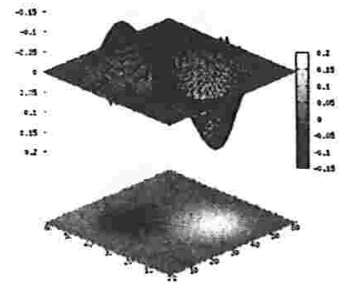

Com Filtro

Figura 4.66: Visão Tridimensional - Par de Objetos com $(1.16 \mathrm{Ohm}-\mathrm{m})^{-1}$ e $1.16(\mathrm{Ohm}-\mathrm{m})^{-1}-128$ Eletrodos

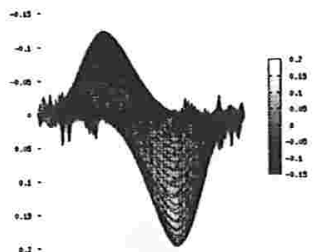

Sem Filtro

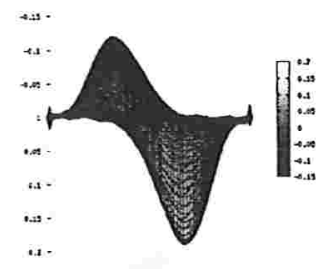

Com Filtro

Figura 4.67: Perfil - Par de Objetos com $(1.16 \mathrm{Ohm}-\mathrm{m})^{-1}$ e $1.16(\mathrm{Ohm}-\mathrm{m})^{-1}-128$ Eletrodos

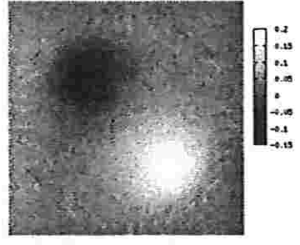

Sem Filtro

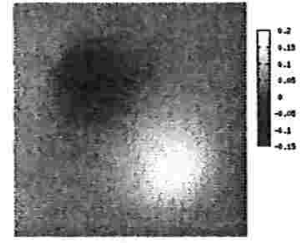

Com Filtro

Figura 4.68: Visão Bidimensional - Par de Objetos com $(1.16 \mathrm{Ohm}-\mathrm{m})^{-1}$ e $1.16(\mathrm{Ohm}-\mathrm{m})^{-1}$ - 128 Eletrodos 


\subsubsection{Condutividades $(1.32 \mathrm{Ohm}-\mathrm{m})^{-1}$ e $1.32(\mathrm{Ohm}-\mathrm{m})^{-1}$}

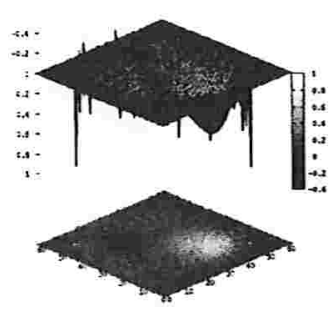

Sem Filtro

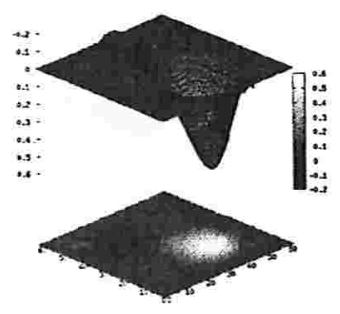

Com Filtro

Figura 4.69: Visão Tridimensional - Par de Objetos com $(1.32 \mathrm{Ohm}-\mathrm{m})^{-1}$ e $1.32(\mathrm{Ohm}-\mathrm{m})^{-1}$ - 32 Eletrodos

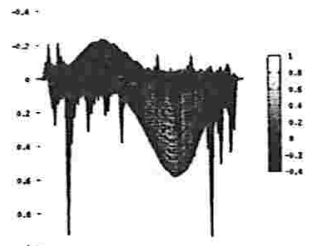

Sem Filtro

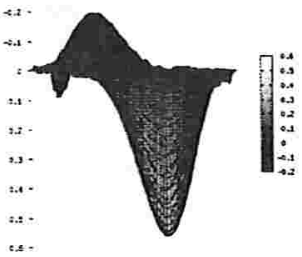

Com Filtro

Figura 4.70: Perfil - Par de Objetos com $(1.32 \mathrm{Ohm}-\mathrm{m})^{-1}$ e $1.32(\mathrm{Ohm}-\mathrm{m})^{-1}$ - 32 Eletrodos

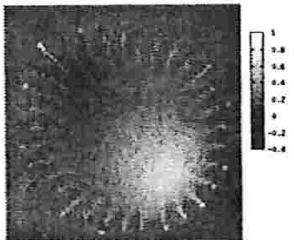

Sem Filtro

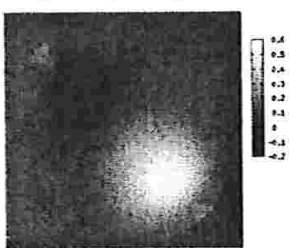

Com Filtro

Figura 4.71: Visão Bidimensional - Par de Objetos com $(1.32 \mathrm{Ohm}-\mathrm{m})^{-1}$ e $1.32(\mathrm{Ohm}-\mathrm{m})^{-1}$ - 32 Eletrodos 


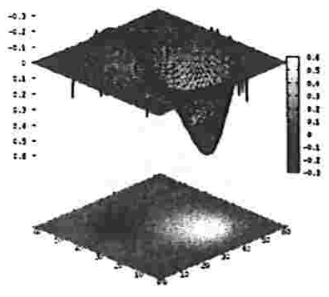

Sem Filtro

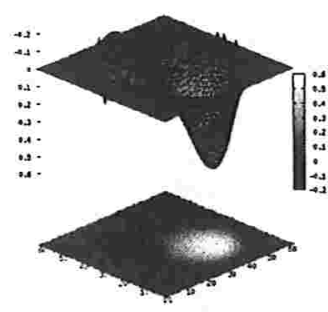

Com Filtro

Figura 4.72: Visão Tridimensional - Par de Objetos com $(1.32 \mathrm{Ohm}-\mathrm{m})^{-1}$ e $1.32(\mathrm{Ohm}-\mathrm{m})^{-1}$ - 128 Eletrodos

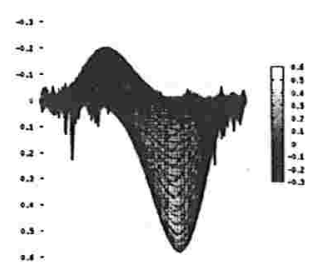

Sem Filtro

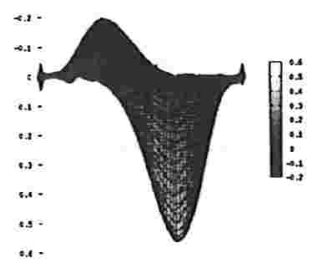

Com Filtro

Figura 4.73: Perfil - Par de Objetos com $(1.32 \mathrm{Ohm}-\mathrm{m})^{-1}$ e $1.32(\mathrm{Ohm}-\mathrm{m})^{-1}-128$ Eletrodos

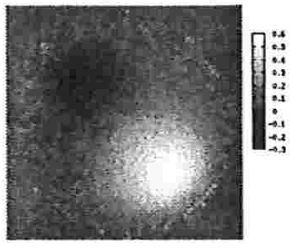

Sem Filtro

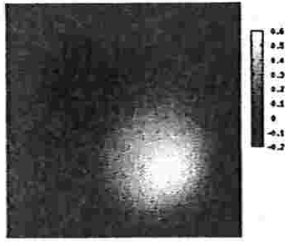

Com Filtro

Figura 4.74: Visão Bidimensional - Par de Objetos com $(1.32 \mathrm{Ohm}-\mathrm{m})^{-1}$ e $1.32(\mathrm{Ohm}-\mathrm{m})^{-1}$ - 128 Eletrodos 


\begin{tabular}{|c|c|c|c|c|}
\hline Informação $\left(\times 10^{-4}\right)$ & \multicolumn{2}{|c|}{32 Eletrodos } & \multicolumn{2}{c|}{128 Eletrodos } \\
\hline & Sem Filtro & Com Filtro & Sem Filtro & Com Filtro \\
\hline máximo & 31.24030 & 28.52442 & 29.88559 & 28.61217 \\
\hline mínimo & -32.83778 & -30.09033 & -31.39533 & -30.14536 \\
\hline média & -0.24369 & -0.24377 & -0.23924 & -0.23928 \\
\hline desvio padrão & 9.16381 & 8.65900 & 8.89141 & 8.65876 \\
\hline valor (pico 1) & -32.83778 & -30.09033 & -31.39533 & -30.14536 \\
\hline valor (pico 2) & 31.24030 & 28.52442 & 29.88559 & 28.61217 \\
\hline
\end{tabular}

Tabela 4.14: Teste - Par de Objetos de Condutividade (1.003 Ohm-m) ${ }^{-1}$ e $1.003(\mathrm{Ohm}-\mathrm{m})^{-1}$

\begin{tabular}{|c|c|c|c|c|}
\hline Informação $\left(\times 10^{-4}\right)$ & \multicolumn{2}{|c|}{32 Eletrodos } & \multicolumn{2}{c|}{128 Eletrodos } \\
\hline & Sem Filtro & Com Filtro & Sem Filtro & Com Filtro \\
\hline máximo & 156.64922 & 144.90290 & 150.06551 & 145.16166 \\
\hline mínimo & -158.86435 & -146.08011 & -151.51630 & -146.46379 \\
\hline média & -0.54258 & -0.54244 & -0.55802 & -0.55935 \\
\hline desvio padrão & 45.51412 & 43.18835 & 44.32976 & 43.21090 \\
\hline valor (pico 1) & -158.86435 & -146.08011 & -151.51630 & -146.46379 \\
\hline valor (pico 2) & 156.64922 & 144.90290 & 150.06551 & 145.16166 \\
\hline
\end{tabular}

Tabela 4.15: Teste - Par de Objetos de Condutividade $(1.016 \mathrm{Ohm}-\mathrm{m})^{-1}$ e $1.016(\mathrm{Ohm}-\mathrm{m})^{-1}$

\begin{tabular}{|c|c|c|c|c|}
\hline Informação $\left(\times 10^{-4}\right)$ & \multicolumn{2}{|c|}{32 Eletrodos } & \multicolumn{2}{c|}{128 Eletrodos } \\
\hline & Sem Filtro & Com Filtro & Sem Filtro & Com Filtro \\
\hline máximo & 1975.13675 & 1869.62460 & 1935.19783 & 1872.50329 \\
\hline mínimo & -1336.59280 & -1198.41062 & -1243.32582 & -1200.95988 \\
\hline média & 64.54200 & 64.60416 & 63.58753 & 63.64693 \\
\hline desvio padrão & 490.81778 & 464.11057 & 476.56799 & 464.37890 \\
\hline valor (pico 1) & -1336.59280 & -1198.41062 & -1243.32582 & -1200.95988 \\
\hline valor (pico 2) & 1975.13675 & 1869.62460 & 1935.19783 & 1872.50329 \\
\hline
\end{tabular}

Tabela 4.16: Teste - Par de Objetos de Condutividade $(1.16 \mathrm{Ohm}-\mathrm{m})^{-1}$ e $1.16(\mathrm{Ohm}-\mathrm{m})^{-1}$

\begin{tabular}{|c|c|c|c|c|}
\hline Informação $\left(\times 10^{-4}\right)$ & \multicolumn{2}{|c|}{ 32 Eletrodos } & \multicolumn{2}{c|}{ 128 Eletrodos } \\
\hline & Sem Filtro & Com Filtro & Sem Filtro & Com Filtro \\
\hline máximo & 9354.32843 & 5586.11633 & 5766.74240 & 5588.90559 \\
\hline mínimo & -2356.69921 & -1970.96022 & -2048.50897 & -1972.21999 \\
\hline média & 366.72835 & 367.05412 & 361.66024 & 362.03381 \\
\hline desvio padrāo & 1314.07868 & 1228.74195 & 1261.91675 & 1228.56937 \\
\hline valor (pico 1) & -2356.69921 & -1970.96022 & -2048.50897 & -1972.21999 \\
\hline valor (pico 2) & 5797.87941 & 5586.11633 & 5766.74240 & 5588.90559 \\
\hline
\end{tabular}

Tabela 4.17: Teste - Par de Objetos de Condutividade $(1.32 \text { Ohm-m })^{-1}$ e $1.32(\mathrm{Ohm}-\mathrm{m})^{-1}$ 
Novamente, o algoritmo foi capaz de reconstruir os objetos nas posições corretas. Porém, ao aumentarmos a perturbação causada por eles, o valor reconstruído ficou muito distante do valor esperado. A tabela 4.18 mostra o comparativo dos valores reconstruídos utilizando-se a interpolação de 128 eletrodos e o filtro da vizinhança com os valores esperados.

\begin{tabular}{|c|c|c|c|c|c|c|}
\hline Par & $\begin{array}{c}\text { Valor Esperado } \\
\text { Pico 1 }\left(\times 10^{-4}\right)\end{array}$ & $\begin{array}{c}\text { Valor Reconstruído } \\
\text { Pico } 1\left(\times 10^{-4}\right)\end{array}$ & $\begin{array}{c}\text { \% do Valor } \\
\text { Esperado }\end{array}$ & $\begin{array}{c}\text { Valor Esperado } \\
\text { Pico } 2\left(\times 10^{-4}\right)\end{array}$ & $\begin{array}{c}\text { Valor Reconstruído } \\
\text { Pico } 2\left(\times 10^{-4}\right)\end{array}$ & $\begin{array}{c}\text { \% do Valor } \\
\text { Esperado }\end{array}$ \\
\hline 1 & -29.910270 & -30.145360 & 100.79 & 30.000000 & 28.612170 & 95.37 \\
\hline 2 & -157.480320 & -146.463790 & 93.00 & 160.000000 & 145.161660 & 90.73 \\
\hline 3 & -1379.310350 & -1200.959880 & 87.07 & 1600.000000 & 1872.503290 & 117.03 \\
\hline 4 & -2424.242420 & -1972.219990 & 81.35 & 3200.000000 & 5588.905590 & 174.65 \\
\hline
\end{tabular}

Tabela 4.18: Comparativos dos Valores Esperados com os Reconstruídos

Como ponto positivo, os valores invertidos dos picos ajudaram a reduzir o ruído original da fronteira na reconstrução. Seus valores balancearam o espalhamento do BackProjection, ajudando a reduzir a propagação de erros. Nos pares de menor condutividade, os picos já eram os valores máximo e mínimo antes mesmo da aplicação dos filtros. 


\subsection{Reconstrução de acordo com a posição do objeto}

Como vimos nas seções anteriores, o algoritmo sempre consegue posicionar corretamente o objeto, independentemente da variação provocada no meio. Quando tal variação é grande, porém, o valor reconstruído fica muito distante do valor esperado. Este resultado é esperado, uma vez que tais variações violam as hipóteses utilizadas na construção do modelo.

Vamos analisar, agora, o que acontece quando um objeto que causa pequena perturbação no meio é posicionado em diferentes locais no meio de estudo. Objetos de tamanhos semelhantes e de condutividade $(1.016 \mathrm{Ohm}-\mathrm{m})^{-1}$ foram colocados nas posições indicadas na figura 4.75. Cada objeto foi colocado em sua posição isoladamente, para que seus valores de reconstrução não fossem prejudicados pela presença de outro objeto.

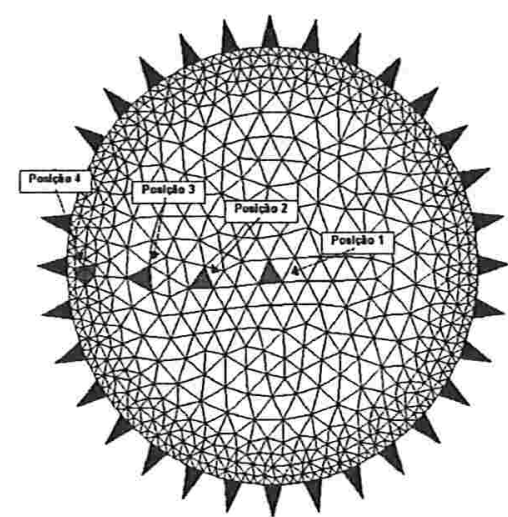

Figura 4.75: Teste: Deslocamento de objeto através do Domínio

O primeiro objeto está bem no centro da figura, e os outros objetos foram colocados de forma a simular um deslocamento radial no sentido da fronteira do domínio. A peculiaridade aqui é que estamos trabalhando com um objeto de pequeno tamanho comparado com os outros testes. Isso deverá simular algo próximo a uma perturbação quase pontual no domínio. 


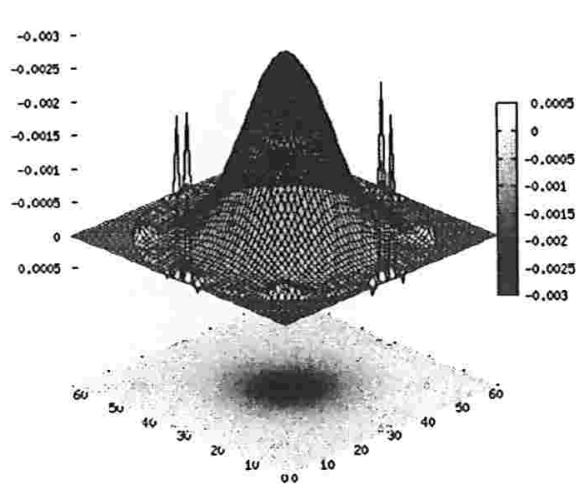

Posição 1

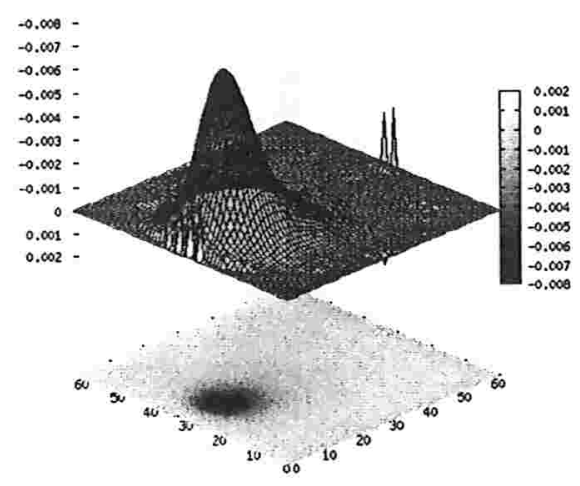

Posição 3

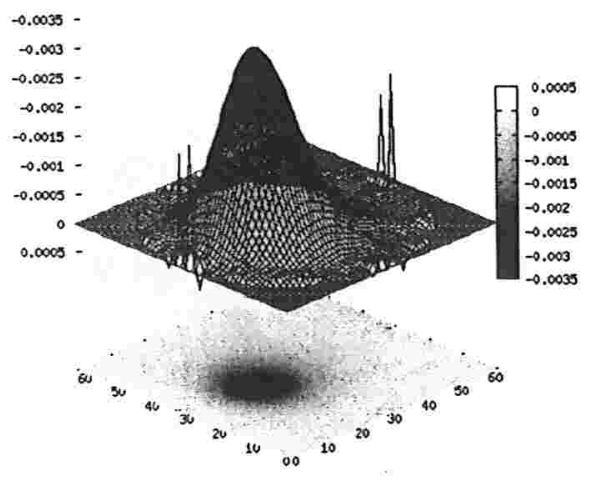

Posição 2

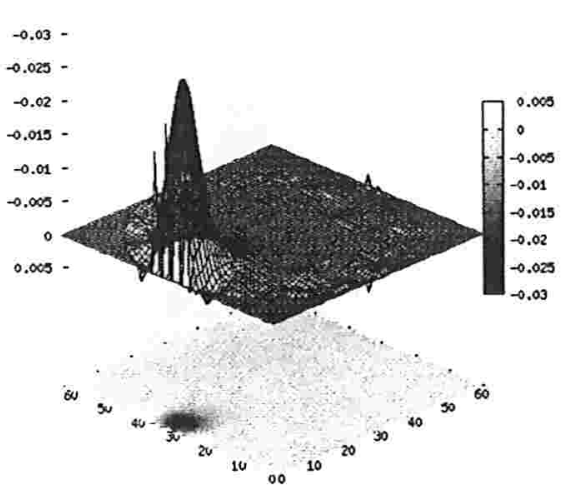

Posição 4

Figura 4.76: Visão Tridimensional - Deslocamento de objeto de $(1.016 \mathrm{Ohm}-\mathrm{m})^{-1}$ através do domínio 


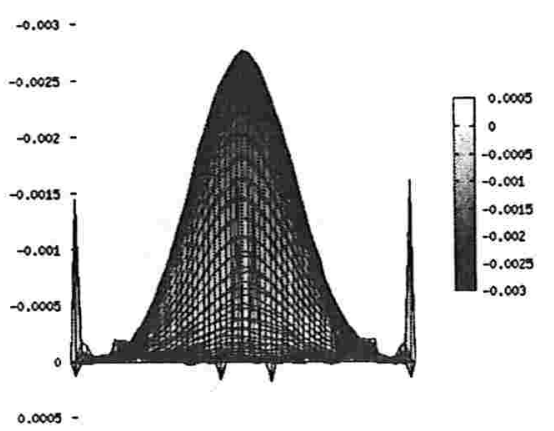

Posição 1

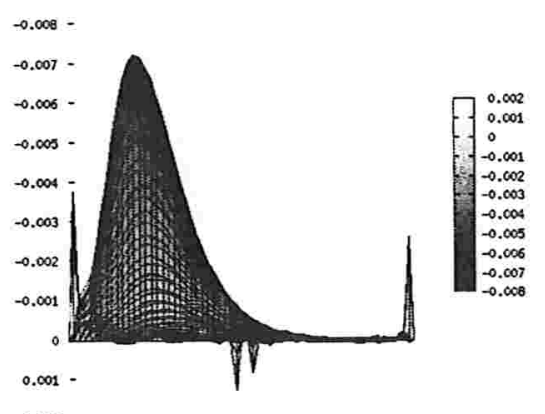

Posição 3

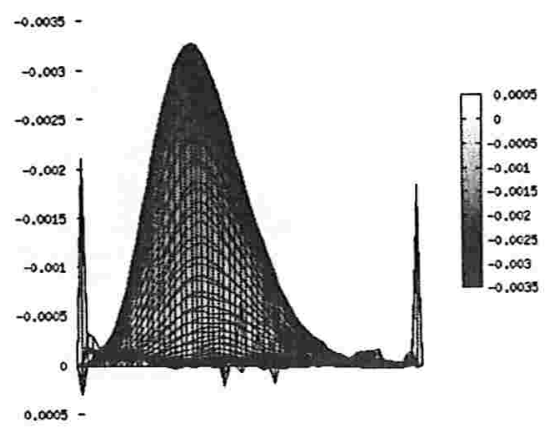

Posição 2

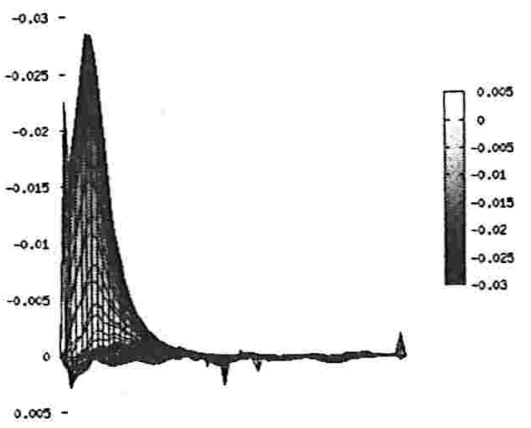

Posição 4

Figura 4.77: Perfil - Deslocamento de objeto de $(1.016 \mathrm{Ohm}-\mathrm{m})^{-1}$ através do domínio 


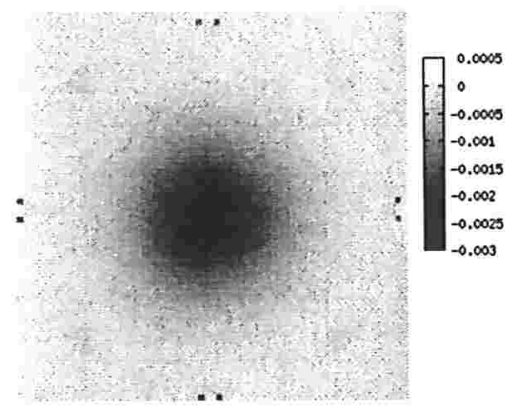

Posição 1

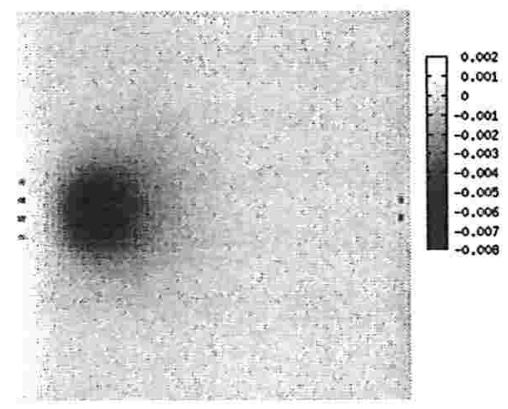

Posição 3

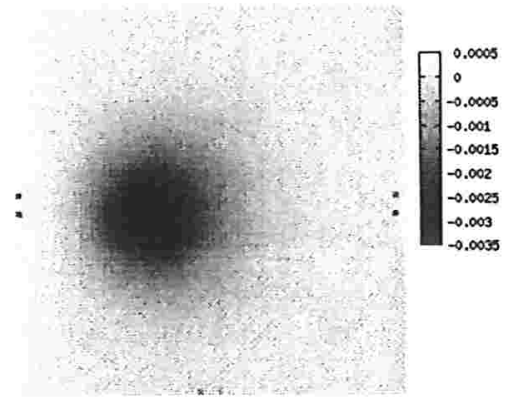

Posição 2

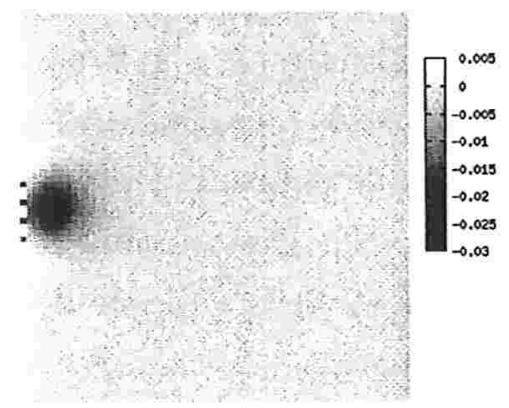

Posição 4

Figura 4.78: Perfil - Deslocamento de objeto de $(1.016 \mathrm{Ohm}-\mathrm{m})^{-1}$ através do domínio 
Pelos resultados, podemos observar que houve uma redução considerável do espalhamento do objeto quando deslocado do centro para a fronteira do domínio, e o valor do pico do objeto reconstruído sofreu um aumento significativo, saindo de um valor muito baixo no centro para um valor praticamente 10 vezes maior próximo à borda, extrapolando o valor de $-157.48031 \times 10^{-4}$ esperado para a reconstrução, de acordo com a tabela 4.19.

\begin{tabular}{|c|c|c|c|c|}
\hline Posição & 1 & 2 & 3 & 4 \\
\hline pico $\left(\times 10^{-4}\right)$ & -27.71658 & -32.75891 & -71.98426 & -285.10551 \\
\hline média $\left(\times 10^{-4}\right)$ & -3.56467 & -3.56434 & -4.81080 & -5.728443 \\
\hline desvio padrão $\left(\times 10^{-4}\right)$ & 6.10472 & 6.695125 & 11.60275 & 27.71785 \\
\hline área ocupada $(\%$ da figura) & 28.88 & 25.12 & 16.24 & 4.37 \\
\hline integral da figura $\left(\times 10^{-4}\right)$ & -14.25866 & -14.25734 & -19.24321 & -17.99643 \\
\hline
\end{tabular}

Tabela 4.19: Resultados - Deslocamento de objeto de $(1.016 \mathrm{Ohm}-\mathrm{m})^{-1}$ pelo domínio

Para o cálculo da área ocupada, foram considerados os pixels que tiveram valores que variaram do pico do objeto (valor mínimo) a $10 \%$ deste valor. Pela tabela anterior, podese concluir que o aumento drástico do pico do objeto é proporcional à diminuição da área ocupada. Ao calcularmos a integral da figura, verifica-se que seu valor se mantem dentro de uma determinada faixa de valores, confirmando a proporção entre o valor mínimo e a área ocupada. Desta forma, a informação sobre o pico do objeto pode não ser suficiente para a estimativa da variação de condutividade. Um melhor recurso seria o cálculo da média da área ocupada pelo objeto reconstruído.

A figura 4.79 mostra as posições dos objetos reconstruídos. Os números na figura indicam onde o pico foi atingido para cada uma das posições originais do teste.

Obviamente, seria desejável que, independentemente da posição do objeto, tanto o pico quanto a área ocupada permanecessem com o mesmo valor. Para tanto, uma possibilidade é explorar alterações na ponderação da integral do BackProjection, o que não será abordado neste trabalho. 


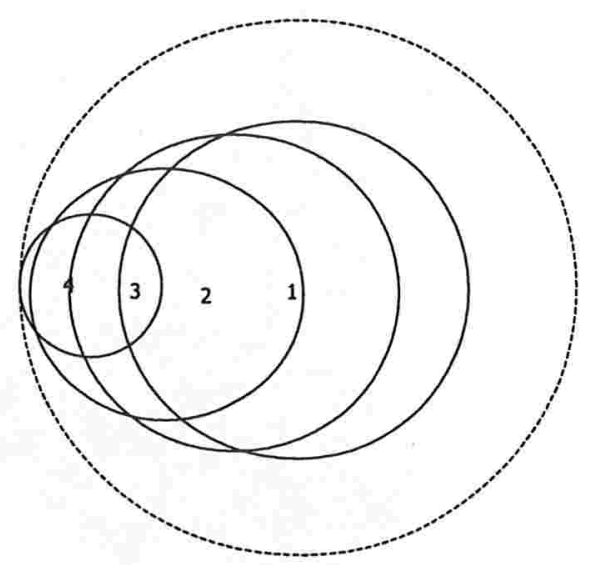

Figura 4.79: Círculos indicando área ocupada pela reconstrução do objeto em posições diferentes 


\subsection{Teste: Geometria do Pulmão}

Para aproximar nossos testes das aplicações clínicas que o algoritmo possui, vamos simular a geometria e as condutividades de uma secção transversal do tórax que possui parte dos pulmões e do coração. Inicialmente, será simulado um meio homogêneo que possui condutividade semelhante à pele humana. Em seguida, serão posicionados objetos com formatos semelhantes aos pulmões e coração (Figura 4.80), com condutividades também semelhantes à destes tecidos, de acordo com a tabela 4.20. Os valores de condutividade foram extraídos de Faes [12].

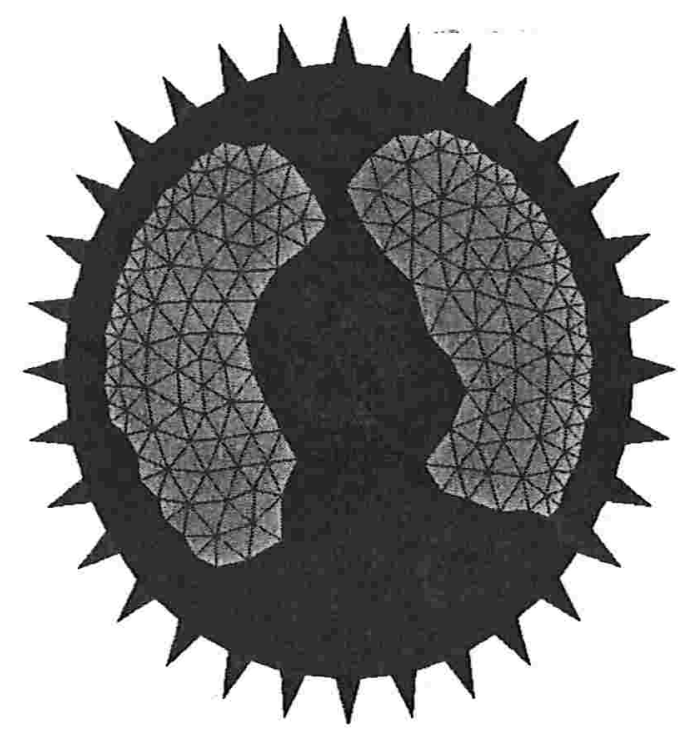

Figura 4.80: Simulação da Geometria do Pulmão

\begin{tabular}{|c|c|c|}
\hline Tecido & Condutividade $(\mathrm{Ohm}-\mathrm{m})^{-1}$ & Variação relativa à pele (\%) \\
\hline Pulmão & 6.3694 & 109.55 \\
\hline Coração & 5.7143 & 88.00 \\
\hline Pele & 3.0395 & - \\
\hline
\end{tabular}

Tabela 4.20: Condutividades dos tecidos

As figuras 4.81 e 4.82 mostram a reconstrução em uma imagem $64 x 64$ pixels, utilizando-se a interpolação de 128 eletrodos e filtro da vizinhança. 

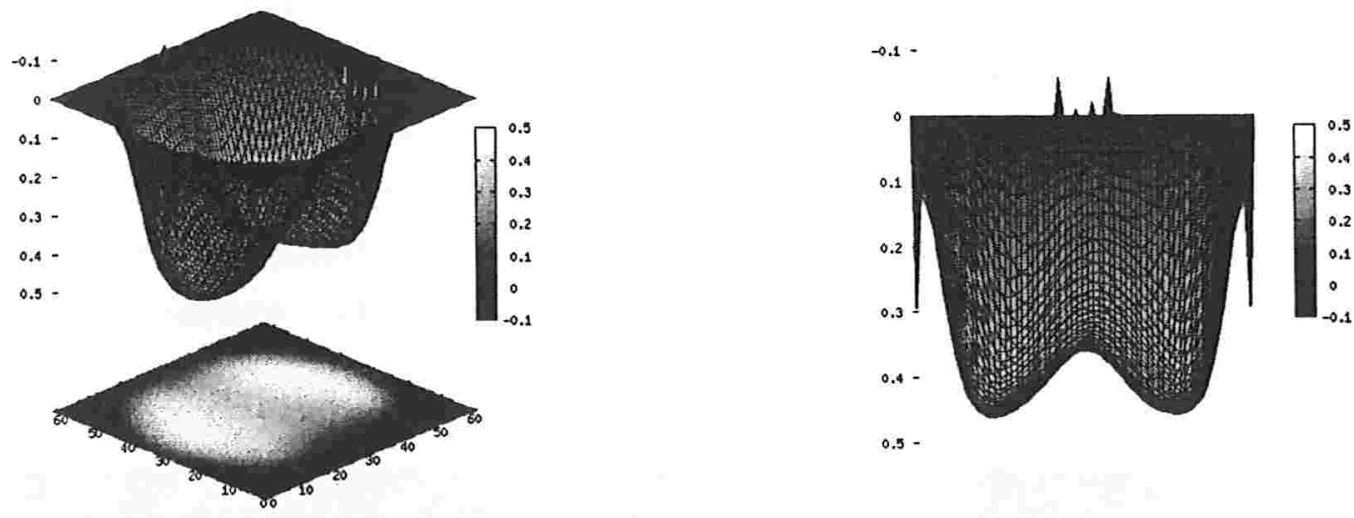

Figura 4.81: Visão Tridimensional - Pulmão Simulado - 128 eletrodos

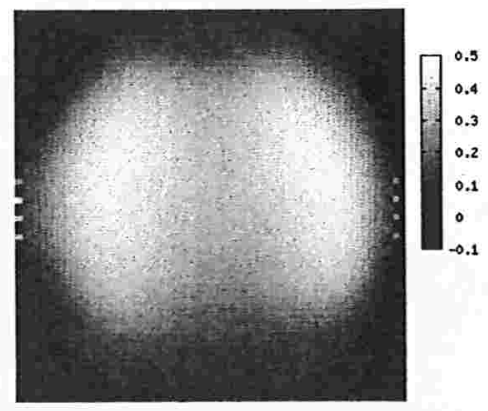

Figura 4.82: Visão Bidimensional - Pulmão Simulado - 128 eletrodos 
Como pode ser observado, o espalhamento da informação prejudicou um pouco a visualização dos resultados, mas pode-se observar claramente a disposição dos dois pulmões. Não fica clara a posição do coração na reconstrução, provavelmente porque o espalhamento da reconstrução dos pulmões prejudicou seu posicionamento.

Se aumentarmos, porém, a resolução da imagem, podemos melhorar a informação gerada como poder ser visto na figura 4.83, onde foi gerada uma imagem de tamanho 128x128 pixels. A figura 4.84 mostra a mesma imagem com a adição de linhas representando as curvas de nível da imagem, onde é possível detectar a região onde está o coração.

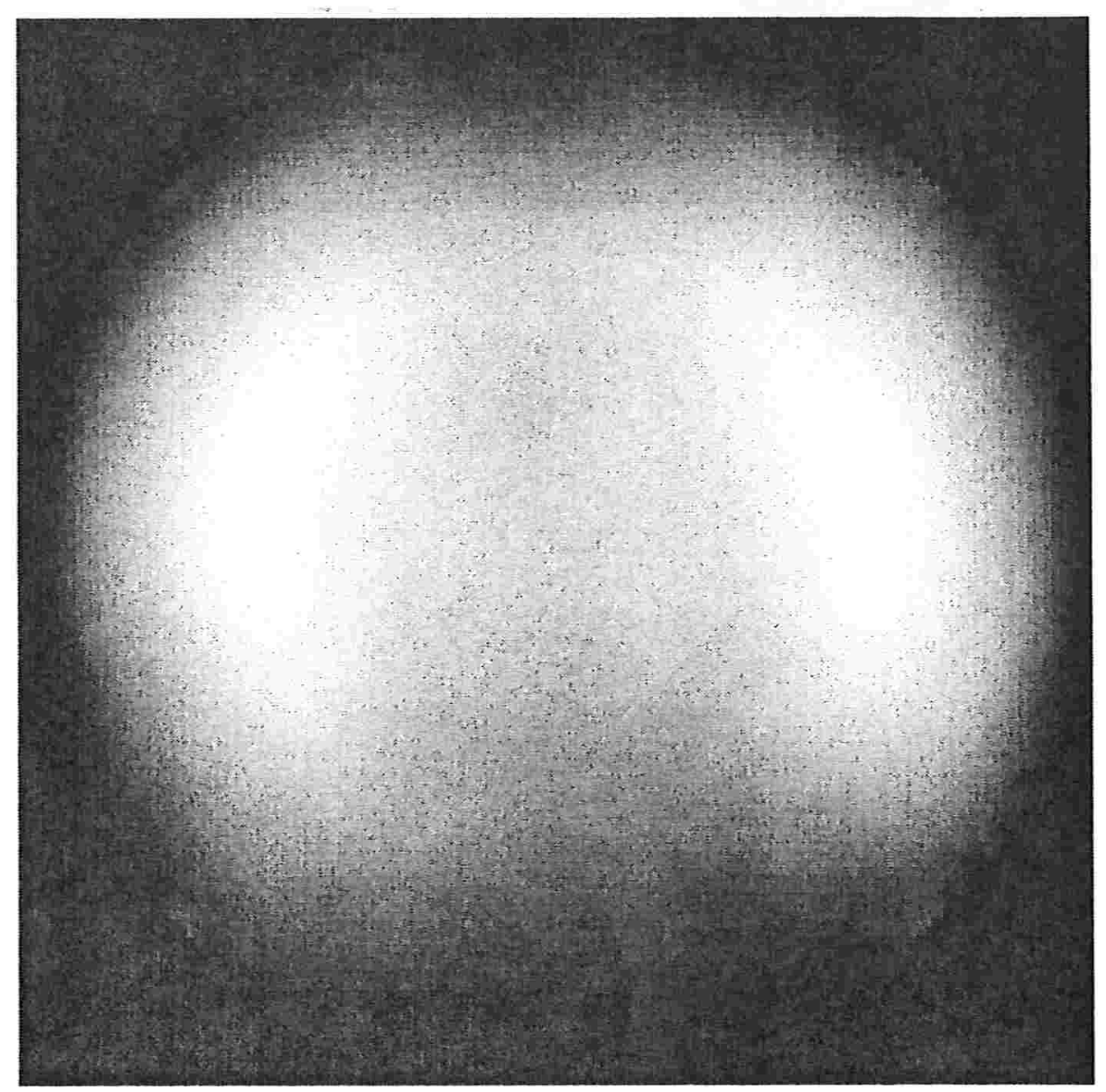

Figura 4.83: Reconstrução da Simulação do Pulmão usando uma imagem de resolução $128 \times 128$ pixels

Um dos aspectos importantes deste teste está na capacidade de simularmos um meio de referência para o experimento real. No caso de pacientes, não teremos a priori uma medida de um meio de referência para as suas medidas. Portanto, pode ser necessária a utilização de 


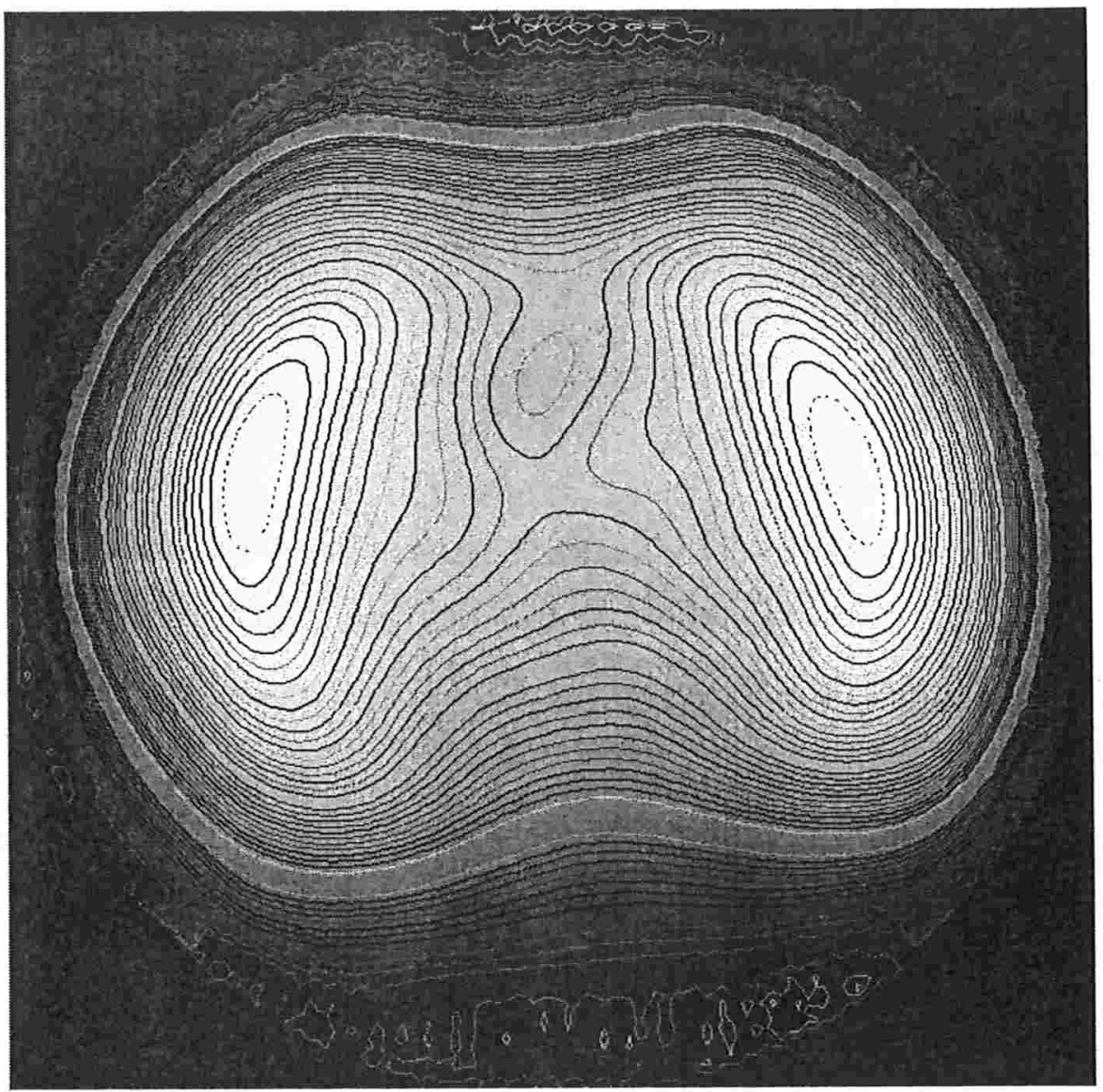

Figura 4.84: Figura 4.83 com a adição de curvas de nível

uma simulação do meio de referência a partir da condutividade de um tecido humano, como no exemplo mostrado.

Como os pacientes terão diferentes formas de tórax e, possivelmente, diferentes condutividades em seu interior, a condutividade de referência a ser escolhida poderia ser um parâmetro do equipamento, que seria ajustada para melhorar a imagem gerada. Poderia ser interessante usar uma condutividade intermediária entre o coração e o pulmão para aumentar o contraste entre estes tecidos.

\subsection{Dados Experimentais: Tanque com Solução Salina}

Para o próximo teste, vamos utilizar dados fornecidos pelo Laboratório de Pneumologia da Faculdade de Medicina (USP), que construiu um protótipo para TPA com 30 eletrodos 
(Figura 4.85). O equipamento foi ligado a um tanque, onde foi depositada uma solução salina.

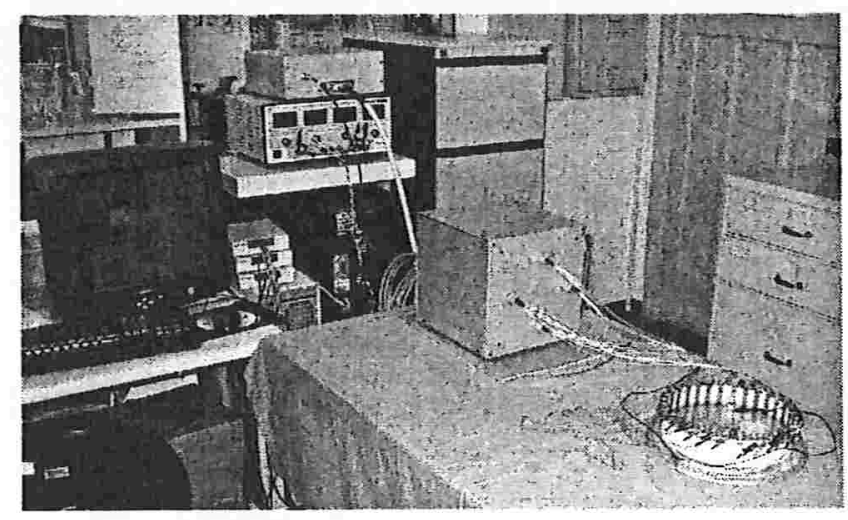

Figura 4.85: Protótipo construído pelo Laboratório de Pneumologia - Faculdade de Medicina (USP)

Para o experimento, foram utilizados cilindros de tamanhos $1 \mathrm{~cm}, 3 \mathrm{~cm}$ e $6 \mathrm{~cm}$, colocados um de cada vez dentro da cuba de acordo com a disposição das figuras 4.86, 4.87 e 4.88. O teste será muito parecido com o da seção 4.5. Nosso intuito aqui, porém, é verificar como o algoritmo se comporta com dados coletados experimentalmente. A reconstrução utilizou novamente a interpolação de 128 eletrodos e aplicação do filtro da vizinhança.

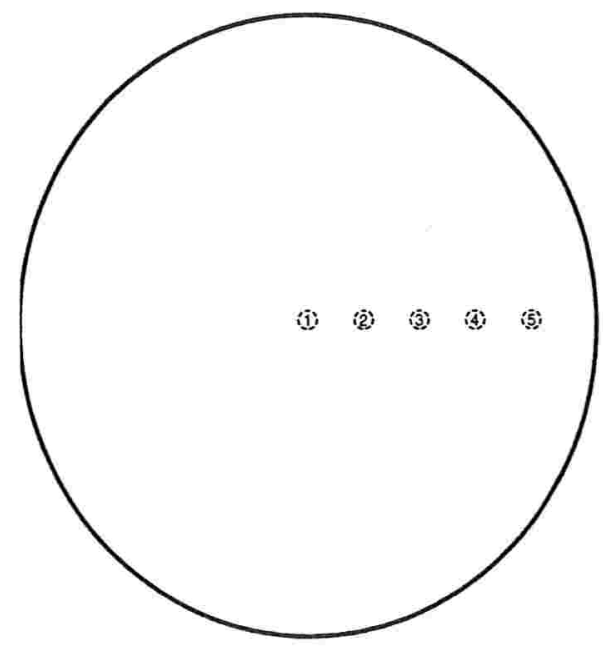

Figura 4.86: Posições testadas para o cilindro de $1 \mathrm{~cm}$ 


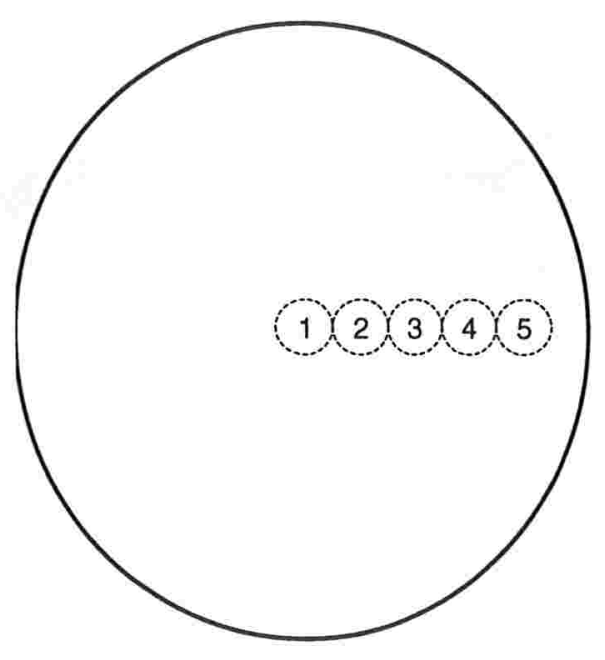

Figura 4.87: Posições testadas para o cilindro de $3 \mathrm{~cm}$

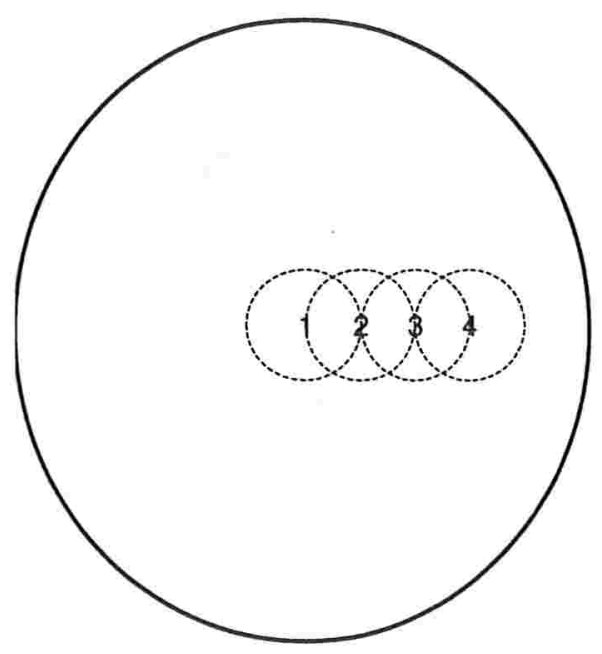

Figura 4.88: Posições testadas para o cilindro de $6 \mathrm{~cm}$ 


\subsubsection{Deslocamento do cilindro de $1 \mathrm{~cm}$ de raio}

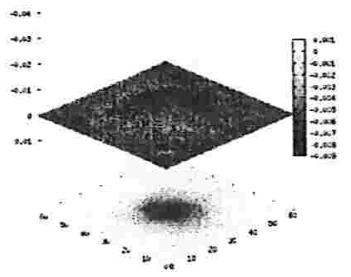

Objeto no centro

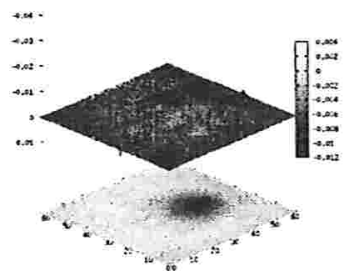

A $6 \mathrm{~cm}$ do centro

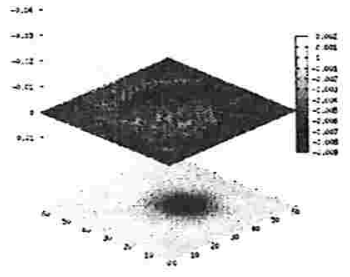

A $3 \mathrm{~cm}$ do centro

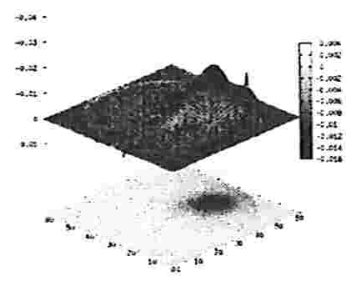

A $9 \mathrm{~cm}$ do centro

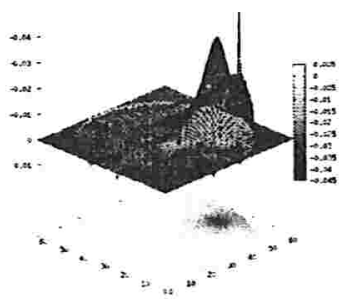

A $12 \mathrm{~cm}$ do centro

Figura 4.89: Visão tridimensional - Deslocamento de cilindro de $1 \mathrm{~cm}$ ao longo da cuba 


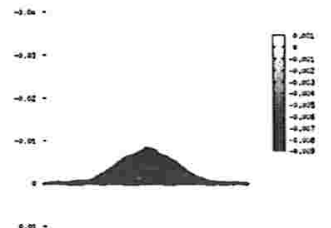

Objeto no centro

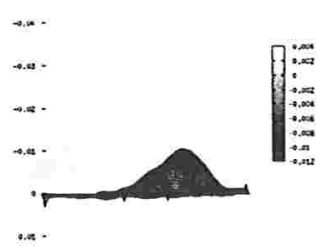

A $6 \mathrm{~cm}$ do centro

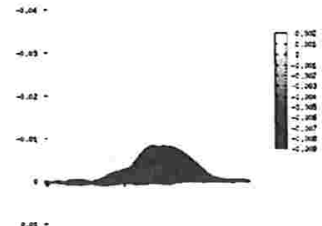

A $3 \mathrm{~cm}$ do centro

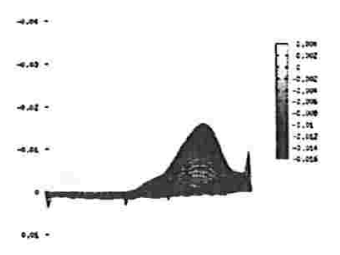

A $9 \mathrm{~cm}$ do centro

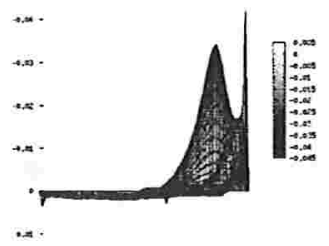

A $12 \mathrm{~cm}$ do centro

Figura 4.90: Perfil - Deslocamento de cilindro de $1 \mathrm{~cm}$ ao longo da cuba 


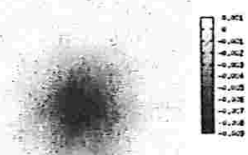

Objeto no centro

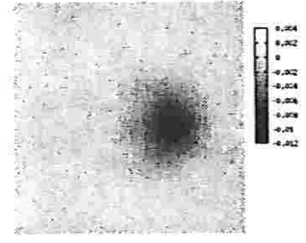

A $6 \mathrm{~cm}$ do centro

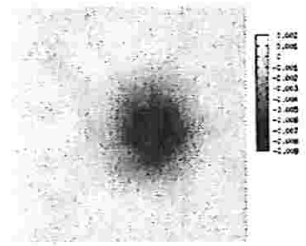

A $3 \mathrm{~cm}$ do centro

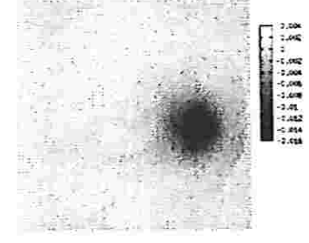

A $9 \mathrm{~cm}$ do centro

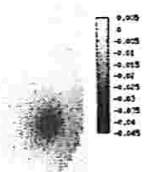

A $12 \mathrm{~cm}$ do centro

Figura 4.91: Visão Bidimensional - Deslocamento de cilindro de $1 \mathrm{~cm}$ ao longo da cuba 


\subsubsection{Deslocamento do cilindro de $3 \mathrm{~cm}$ de raio}

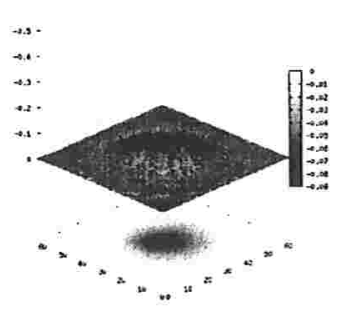

Objeto no centro

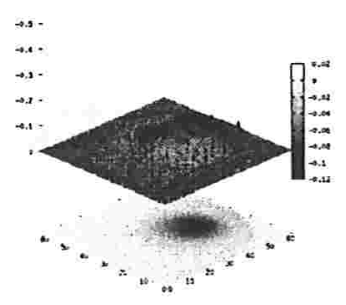

A $6 \mathrm{~cm}$ do centro

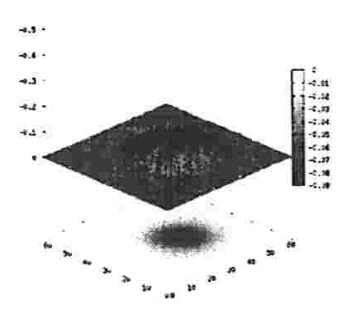

A $3 \mathrm{~cm}$ do centro

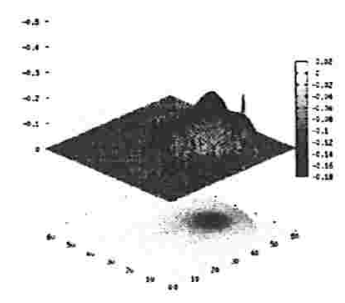

A $9 \mathrm{~cm}$ do centro

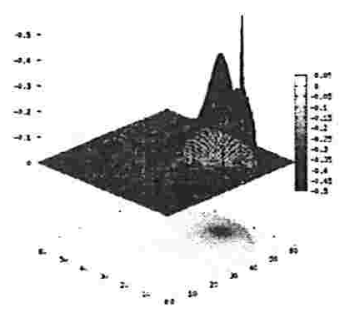

A $12 \mathrm{~cm}$ do centro

Figura 4.92: Visão tridimensional - Deslocamento de cilindro de $3 \mathrm{~cm}$ ao longo da cuba 


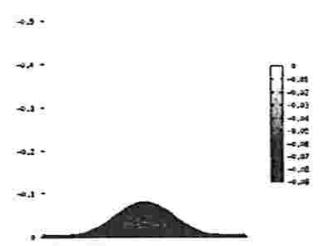

Objeto no centro

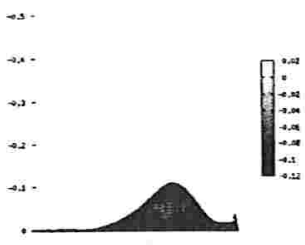

A $6 \mathrm{~cm}$ do centro

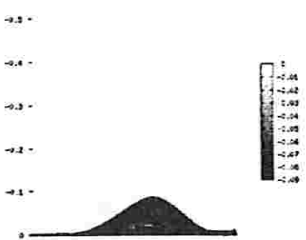

A $3 \mathrm{~cm}$ do centro

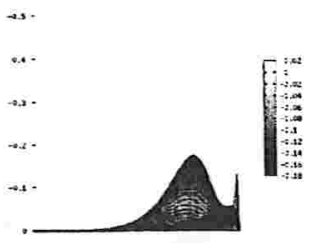

A $9 \mathrm{~cm}$ do centro

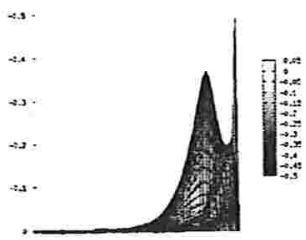

A $12 \mathrm{~cm}$ do centro

Figura 4.93: Perfil - Deslocamento de cilindro de $3 \mathrm{~cm}$ ao longo da cuba 


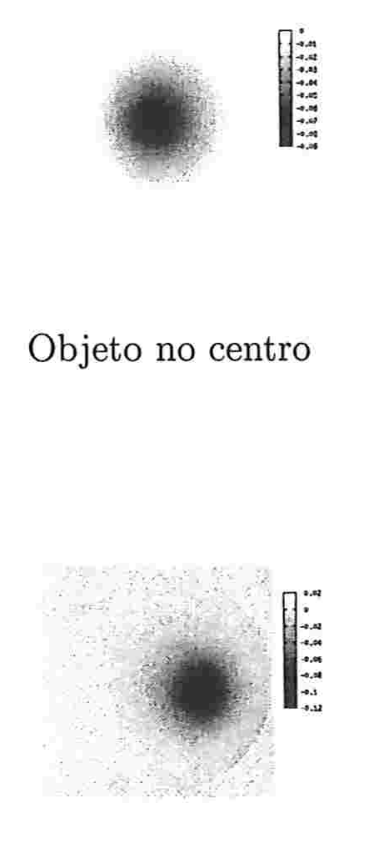

A $6 \mathrm{~cm}$ do centro

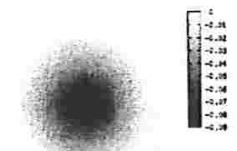

A $3 \mathrm{~cm}$ do centro

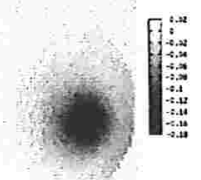

A $9 \mathrm{~cm}$ do centro

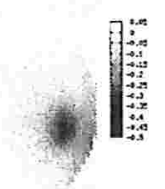

A $12 \mathrm{~cm}$ do centro

Figura 4.94: Visão Bidimensional - Deslocamento de cilindro de $3 \mathrm{~cm}$ ao longo da cuba 


\subsubsection{Deslocamento do cilindro de $6 \mathrm{~cm}$ de raio}

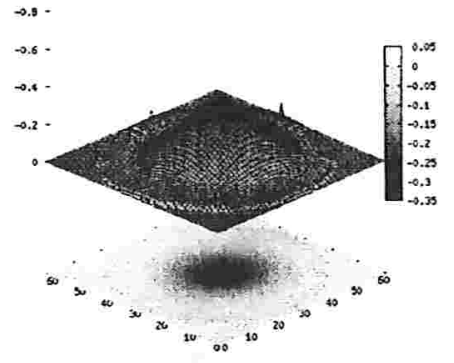

Objeto no centro

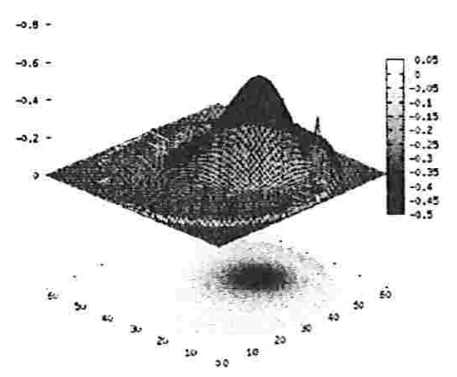

A $6 \mathrm{~cm}$ do centro

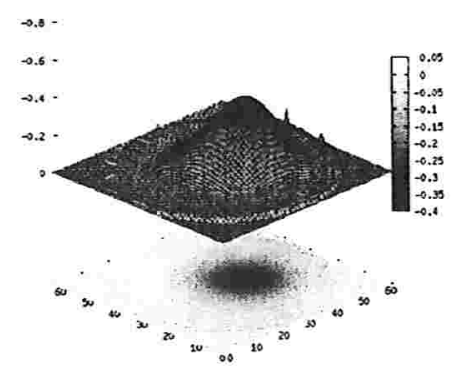

A $3 \mathrm{~cm}$ do centro

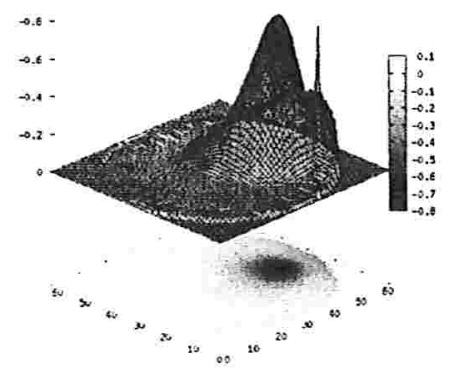

A $9 \mathrm{~cm}$ do centro

Figura 4.95: Visão tridimensional - Deslocamento de cilindro de $6 \mathrm{~cm}$ ao longo da cuba 


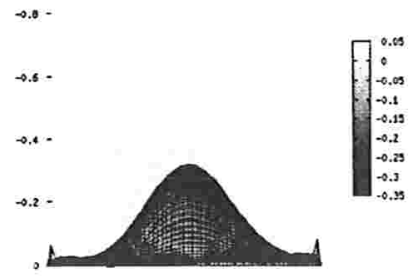

Objeto no centro

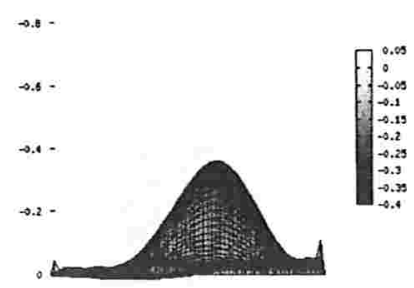

A $3 \mathrm{~cm}$ do centro

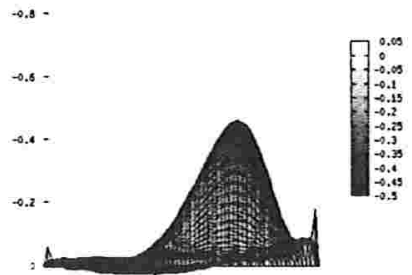

A $6 \mathrm{~cm}$ do centro

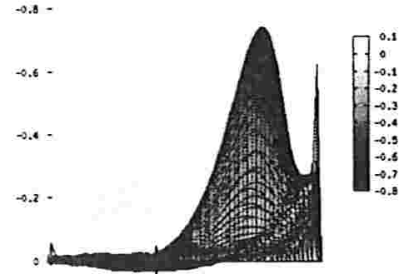

A $9 \mathrm{~cm}$ do centro

Figura 4.96: Perfil - Deslocamento de cilindro de $6 \mathrm{~cm}$ ao longo da cuba 


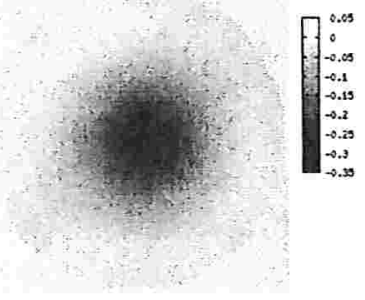

Objeto no centro

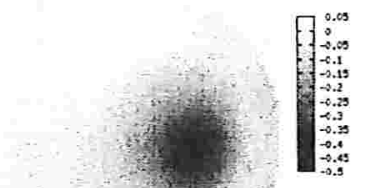

A $6 \mathrm{~cm}$ do centro

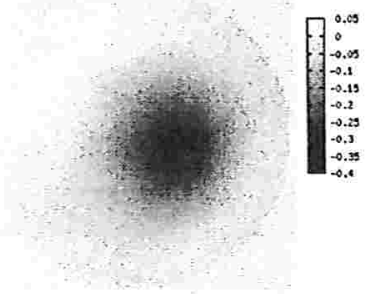

A $3 \mathrm{~cm}$ do centro

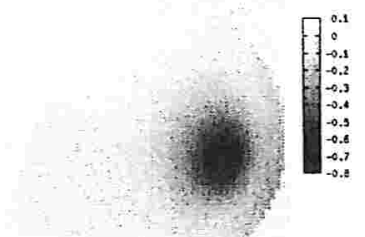

A $9 \mathrm{~cm}$ do centro

Figura 4.97: Visão Bidimensional - Deslocamento de cilindro de $6 \mathrm{~cm}$ ao longo da cuba 
Os resultados indicam que o algoritmo comportou-se consistentemente com as simulações efetuadas anteriormente. No entanto, as últimas posições dos cilindros de $1 \mathrm{~cm}$ e $3 \mathrm{~cm}$ tiveram suas reconstruções prejudicadas devido ao ruído que surgiu na fronteira próximo aos objetos.

Outra observação importante é que o tamanho do objeto influencia na estabilidade da solução. Assim como nas simulações anteriores, os valores dos picos e das áreas ocupadas foram inversamente proporcionais, mas esperava-se que a integral se preservasse. Podemos observar, pelas tabelas 4.21 a 4.23 , que o cilindro de menor tamanho teve sua integral prejudicada, com tendência de redução se desconsiderarmos a última posição do teste. Nos outros casos, a integral manteve-se estável dentro de uma faixa de valores para cada cilindro.

\begin{tabular}{|c|c|c|c|c|c|}
\hline Posição & 1 & 2 & 3 & 4 & 5 \\
\hline pico $\left(\times 10^{-4}\right)$ & -85.60808 & -83.38173 & -105.73221 & -159.47484 & -416.39593 \\
\hline média $\left(\times 10^{-4}\right)$ & -9.51606 & -7.76825 & -7.08069 & -6.751125 & -9.18597 \\
\hline desvio padrão $\left(\times 10^{-4}\right)$ & 17.21846 & 18.29122 & 20.45497 & 28.09645 & 48.57204 \\
\hline área ocupada $(\%$ da figura) & 25.49 & 22.22 & 20.78 & 17.26 & 9.89 \\
\hline integral da figura $\left(\times 10^{-4}\right)$ & -38.06425 & -31.07301 & -28.32277 & -21.20929 & -28.85857 \\
\hline
\end{tabular}

Tabela 4.21: Resultados - Deslocamento do cilindro de $1 \mathrm{~cm}$

\begin{tabular}{|c|c|c|c|c|c|}
\hline Posição & 1 & 2 & 3 & 4 & 5 \\
\hline pico $\left(\times 10^{-4}\right)$ & -817.23819 & -878.64104 & -1111.23212 & -1743.54080 & -4921.72141 \\
\hline média $\left(\times 10^{-4}\right)$ & -112.42530 & -113.54989 & -120.68245 & -142.15093 & -186.21941 \\
\hline desvio padrão $\left(\times 10^{-4}\right)$ & 176.92495 & 186.91277 & 219.96750 & 304.85338 & 522.79955 \\
\hline área ocupada $(\%$ da figura) & 29.05 & 27.86 & 27.95 & 21.22 & 10.69 \\
\hline integral da figura $\left(\times 10^{-4}\right)$ & -449.70120 & -454.19955 & -482.72982 & -446.58033 & -585.02552 \\
\hline
\end{tabular}

Tabela 4.22: Resultados - Deslocamento do cilindro de $3 \mathrm{~cm}$

\begin{tabular}{|c|c|c|c|c|}
\hline Posição & 1 & 2 & 3 & 4 \\
\hline pico $\left(\times 10^{-4}\right)$ & -3213.91263 & -3611.69982 & -4594.68956 & -7391.09410 \\
\hline média $\left(\times 10^{-4}\right)$ & -497.18356 & -507.03256 & -541.80992 & -671.35521 \\
\hline desvio padrão $\left(\times 10^{-4}\right)$ & 724.59955 & 793.58767 & 941.53861 & 1360.82179 \\
\hline área ocupada $(\%$ da figura) & 36.28 & 33.50 & 30.52 & 23.02 \\
\hline integral da figura $\left(\times 10^{-4}\right)$ & -1988.73425 & -2028.13025 & -2167.23967 & -2109.12458 \\
\hline
\end{tabular}

Tabela 4.23: Resultados - Deslocamento do cilindro de $6 \mathrm{~cm}$

De qualquer forma, o algoritmo está preparado para ser executado em um ambiente real, pois foi capaz de recuperar posição e forma dos objetos-teste. 


\subsection{Dados Experimentais: Sr. Porco}

Esta seção irá testar o algoritmo em uma das situações idealizadas para o uso prático do BackProjection. A experiência consiste no monitoramento do volume de ar no pulmão de um porco submetido à ventilação artificial. Este é um dos objetivos principais da aplicação médica para o método.

A experiência também foi conduzida pelo Laboratório de Pneumologia (FM-USP). Os 30 eletrodos do mesmo equipamento que forneceu medidas para a seção 4.7 foram colocados em uma secção transversal do tórax do porco, de acordo com a figura 4.98. Inicialmente, foram tomados dados com o porco em regime de respiração normal para, em seguida, iniciar o aumento do volume de ar no pulmão do animal através de ventilação.

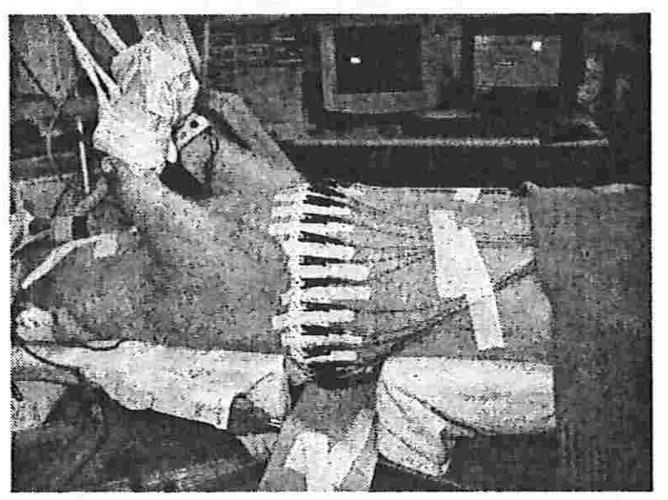

Figura 4.98: Porco submetido a ventilação artificial, com eletrodos acoplados

A figura 4.99 mostra a imagem da secção transversal do tórax do porco que foi analisada, tomada através de tomografia computadorizada. A região escura indica a parte do pulmão preenchida com ar. Nesta seç̧ão, pode-se observar que o tórax é praticamente circular e que o coração não está visível na imagem.

No experimento, infelizmente não temos à disposição a tomada de dados de um meio homogêneo. Teremos que utilizar um conjunto de medidas tomado no porco durante sua respiração normal. Desta forma, não será possível visualizarmos uma imagem próxima à da foto de tomografia. Poderemos detectar, apenas, a variação provocada pela entrada de ar provido pela ventilação artificial.

Os dados enviados pelo laboratório foram rodados no algoritmo de BackProjection, e seus resultados são apresentados nas figuras seguintes. Para a reconstrução, foram utilizadas a interpolação de 120 eletrodos, aplicação do filtro da vizinhança e reconstrução em uma imagem $128 \times 128$ pixels. 


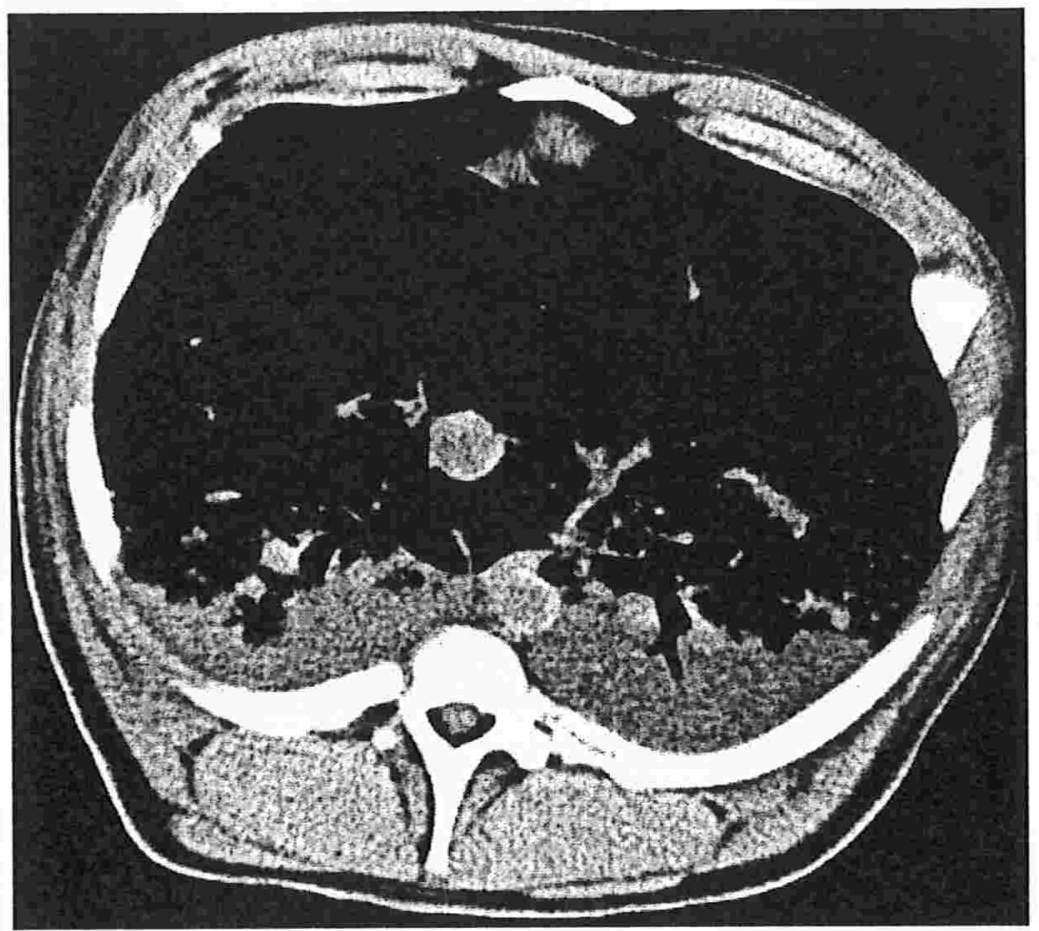

Figura 4.99: Tomografia de uma seç̧ão transversal do porco 

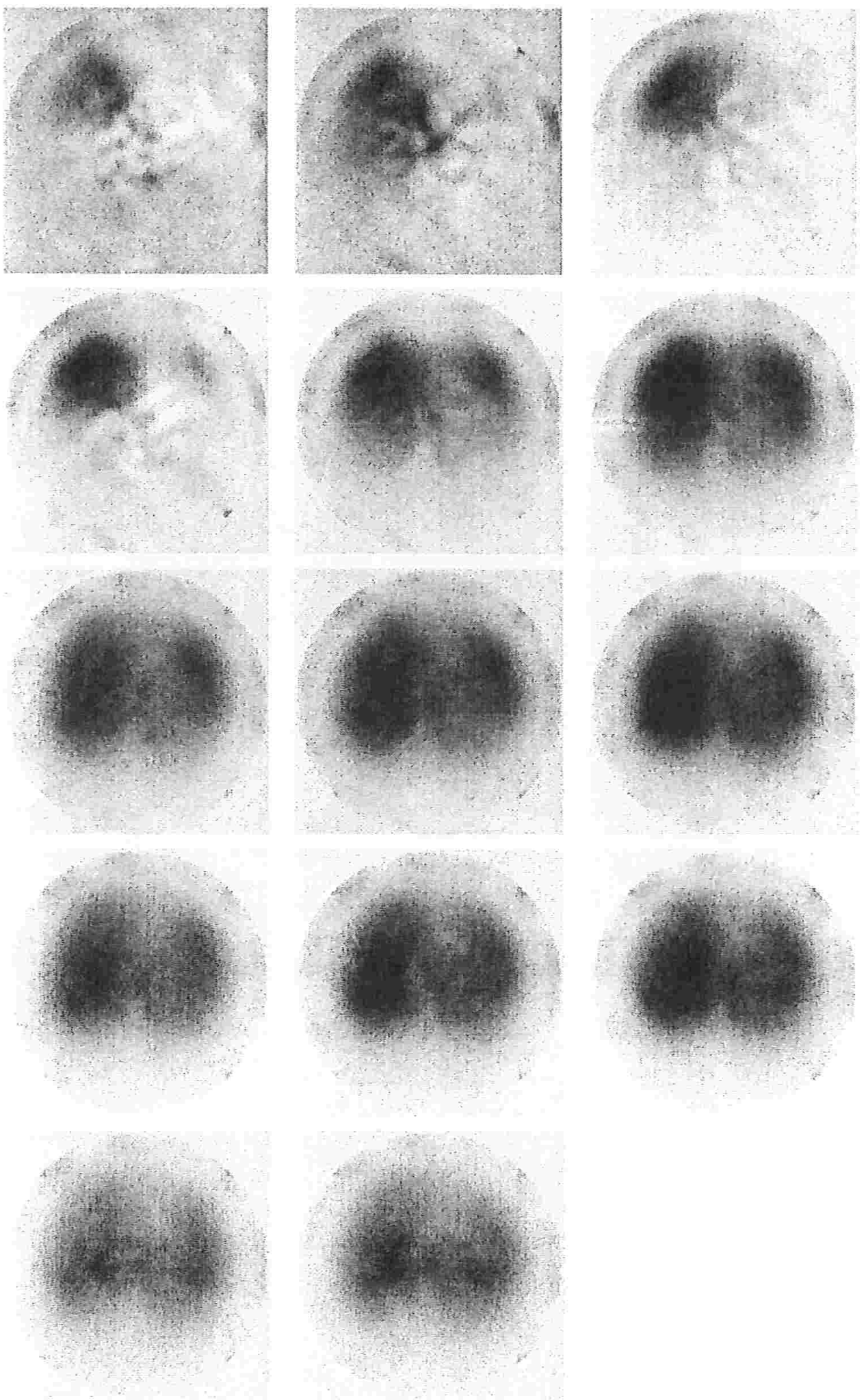

Figura 4.100: Ciclo respiratório do porco visualizado através do BackProjection 


\begin{tabular}{|c|c|c|}
\hline Figura 4.100 - Imagem & Valor Mínimo & Valor Médio \\
\hline 1 & -0.03390 & -0.00131 \\
\hline 2 & -0.03103 & -0.00426 \\
\hline 3 & -0.05333 & -0.00751 \\
\hline 4 & -0.06624 & -0.00919 \\
\hline 5 & -0.13259 & -0.03163 \\
\hline 6 & -0.15662 & -0.04239 \\
\hline 7 & -0.30109 & -0.08910 \\
\hline 8 & -0.28120 & -0.08489 \\
\hline 9 & -0.38831 & -0.11695 \\
\hline 10 & -0.45806 & -0.13135 \\
\hline 11 & -0.39378 & -0.11607 \\
\hline 12 & -0.47050 & -0.13638 \\
\hline 13 & -0.54701 & -0.16034 \\
\hline 14 & -0.51206 & -0.15413 \\
\hline
\end{tabular}

Tabela 4.24: Resultados - Coleta de Dados no Porco

O experimento representou um verdadeiro desafio para o algoritmo de BackProjection. Algumas das recomendações na implantação do método foram violadas, como a falta de um meio homogêneo de referência e o formato circular do domínio, mas ele mostrou-se versátil para permitir uma reconstrução do que fosse possível observar (no caso do porco, a variação provocada pela entrada de ar adicional da ventilação).

A coluna de valor médio da tabela 4.24 mostra que é possível estimar o volume de ar injetado através da variação de condutividade detectada. No caso, a variação média registrada foi de $-0.13 \%$ no início do processo a $-15.41 \%$ ao final.

Este ferramental, assim, mostra-se extremamente útil para o diagnóstico médico, pois atinge o objetivo que comentamos ao longo de todo este trabalho. 


\section{Conclusão e Trabalhos Futuros}

A Tomografia por Potencial Aplicado tem sido amplamente pesquisada ao redor do mundo, gerando diversas formas de se resolver o problema inverso relacionado. Barber ([7]) apresentou sua primeira versão analítica, utilizando um equipamento de 16 eletrodos. Desde então, pesquisadores têm procurado alternativas, como o aumento do número de eletrodos, algoritmos iterativos e algoritmos específicos de processamento de imagens para melhorar a qualidade do resultado. Outros pesquisadores trabalham na formulação puramente teórica do problema, procurando fornecer algum ferramental matemático que permita a construção de um algoritmo mais preciso.

Em seu artigo original, Barber ([5]) discute o problema da escolha do número de eletrodos para a construção do equipamento, devido à relação ruído e quantidade de eletrodos. Neste trabalho, procuramos fornecer uma alternativa de simulação de eletrodos (seção 3.5) para permitir que o equipamento tenha uma menor quantidade deles.

Santosa ([21]) mostrou que tanto a ponderação sugerida por Barber quanto a integral do BackProjection definem uma fórmula que pode ser vista como a inversa de uma Transformada Generalizada de Radon, fechando com a teoria iniciada com Calderón ([9]). No mesmo trabalho, foi sugerido um algoritmo iterativo de refinamento, baseado em Gradientes Conjugados, para melhorar o contraste da imagem final gerada. Como mostramos anteriormente (seção 4.1), a questão do tempo é algo crucial para a viabilidade prática do algoritmo. Portanto, um método de refinamento como esse ou deve ser aplicado em paralelo com o BackProjection ou em um momento posterior para estudo de uma foto específica da seqüência gravada.

Em outro trabalho, Barber ([4]) sugere a utilização de filtros de imagens como forma de melhorarmos a resolução espacial dos objetos. Neste trabalho, inclusive, é apresentado um exemplo muito próximo ao mostrado na seção 4.5. No trabalho, exploramos apenas o filtro da vizinhança, pois sua implementação é simples e eficiente. Porém, há uma grande quantidade de filtros ([17]), inclusive para o aumento de contraste, que não foram testados. Todos esses filtros são excelentes alternativas, mas devem ser implementados sempre levando 
em consideração o tempo disponível para sua aplicação.

Numa outra tentativa de melhorar a qualidade da imagem através da redução de ruído, Avis ([3]) sugere a utilização de outras configurações de injeção para o par de injeção, utilizando eletrodos não adjacentes. O trabalho mostra que a configuração adjacente é responsável por uma considerável fonte de ruído e, portanto, configurações como a injeção usando eletrodos diametralmente opostos podem ser usadas para uma melhor qualidade dos objetos reconstruídos. Tais configurações, porém, podem violar algumas hipóteses utilizadas na construção do modelo do dipolo, pois a distância entre os eletrodos do par de injeção vai crescendo. Nestes casos, deverá ser analisada a possibilidade do abandono do potencial do dipolo e uso do potencial de duas cargas, sem a aproximação linear feita na seção 2.6. Isto deverá mudar as equações do BackProjection.

Cherepenin ([10]) desenvolveu uma variação do BackProjection associada a um método de mínimos quadrados para produzir imagens em um equipamento de 16 eletrodos. De acordo com o trabalho, a baixa resolução espacial da EIT não permite uma exata localização de tumores dentro do pulmão. Porém, é possível estimar o grau de dano causado ao pulmão através de imagens tomadas de diferentes secções transversais do tórax. O tumor causa uma queda na circulação de ar dentro do pulmão, que pode ser visualizada através de um aumento anormal de condutividade. Assim, as secções onde há detecção de aumento da condutividade podem indicar a posição de tumores.

A versão do algoritmo de BackProjection aplicada à Tomografia por Potencial Aplicado, apresentada neste trabalho, demonstrou ser muito eficiente na localização e posicionamento de objetos, além de ser rápida e de simples implementação. Em todos os testes realizados, o algoritmo foi capaz reconstruir os objetos propostos com um bom grau de precisão, desde que as medidas respeitassem as hipóteses do algoritmo.

No caso dos dados vindo do Sr. Porco, provamos que é possível estimar a variação de volume injetada no animal por ventilação artificial, mesmo com a violação de recomendações como o uso de um meio homogêneo para referência e o formato circular do domínio. Isto indica que há uma real chance do sucesso prático do algoritmo, levando à construção de um equipamento de monitoramento à beira do leito rápido e eficiente.

Há uma série de algoritmos sendo propostos para resolver a TPA através de métodos iterativos e/ou de otimização. Tais algoritmos, porém, sempre correrão o risco da estabilidade de sua execução, um problema inexistente no BackProjection. Um algoritmo iterativo, por exemplo, precisa de informação a priori para iniciar sua execução. Além disso, seu tempo de execução é variável e não é possível estabelecer um limite de tempo para sua execução. 
O BackProjection, ao contrário, está apenas limitado à resolução da imagem, ao número de eletrodos utilizado no experimento e à relação sinal/ruído dos dados.

O desenvolvimento do algoritmo, porém, não deve ser considerado terminado. Como vimos, há questões a serem resolvidas relacionadas à precisão das medidas e separação dos objetos e algumas a serem melhoradas, como o tempo de execução do mesmo.

Para a precisão e espalhamento, será necessário trabalhar a função peso, usada na integral do método. Apesar do embasamento teórico, a função peso ajuda a propagar ruídos próximos à borda, ocasionando os picos visualizados nos resultados numéricos. A função também poderia atuar na diminuição do espalhamento do objeto, atuando como um filtro de constrate da imagem.

Uma idéia a ser testada no algoritmo para diminuição do espalhamento e melhor separação física dos objetos está ligada às linhas equipotenciais. Na integral do BackProjection, aplicamos o peso aos valores vindos das equipotenciais sem fazermos qualquer crítica a tais valores. Para cada pixel, poder-se-ia estudar a distribuição de valores vindos das equipotenciais que passam por ele e se determinar qual o valor mais razoável de variação aceito para o ponto. Uma distribuição concentrada indicaria que a média ponderada realmente seria a mais adequada para o ponto. Por outro lado, uma distribuição menos concentrada poderia indicar que as variações detectadas não pertencem ao ponto analisado.

Com relação ao tempo, há duas frentes a serem atacadas: pré-processamento e paralelismo. Independentemente do meio a ser estudado, as posições da imagem são fixas e, portanto, a geometria das equipotenciais é definida antes do início da coleta de dados. No algoritmo 3 , grande parte do trabalho está na determinação do ponto onde cada equipotencial que passa pelo ponto cruza a fronteira. Se os pontos são fixados na imagem, poderia haver um processamento inicial baseado apenas na disposição da fronteira do domínio, em que todos os pontos de fronteira associados aos pontos do domínio fossem calculados e guardados na memória. Com isso, a execução do algoritmo ficará restrita a cálculos das funções interpoladoras das linhas da matriz $\left[W_{k, i}\right]$. Esta técnica poderá permitir que imagens com maior resolução possam ser calculadas de forma mais rápida.

Com relação ao paralelismo, na linguagem de Computação, o BackProjection é um algoritmo "embaraçosamente" paralelizável. Os dados de cada dipolo poderiam ser enviados para um processador para montar a imagem relativa a cada um deles. Seria como rodar o método para apenas um padrão de injeção em cada um dos processadores. Ao final, a imagem resultante seria uma média das imagens geradas, trecho que também poderia ser paralelizado, enviando um pedaço da imagem final para cada processador para ser calculada. 
Outra alternativa para ganho de velocidade está, por exemplo, na programação do algoritmo em linguagem de máquina (Assembly). Todas as sugestões anteriores, aliadas ao avanço na tecnologia dos equipamentos de computação, devem levar o BackProjection a ser uma das mais rápidas alternativas para a viabilidade prática em larga escala da TPA. 


\section{Apêndice A}

\section{Determinação do ponto de fronteira}

Um dos problemas na implementação do algoritmo de BackProjection é a determinação do ponto de fronteira equipotencial ao ponto $\mathrm{x}$ estudado. Para encontrarmos esse ponto, vamos utilizar a hipótese de que as linhas equipotenciais são arcos de circunferência e um método geométrico para a determinação do ponto.

Sejam $\mathbf{x}$ um ponto do domínio $\Omega, \omega$ a posição do dipolo sobre a fronteira de $\Omega(\omega \in \partial \Omega)$ e $\mathbf{x}^{f}$ o ponto sobre a fronteira $\left(\mathbf{x}^{f} \in \partial \Omega\right)$ equipotencial a $\mathbf{x}$, relativamente ao dipolo $\omega$.

A reta que passa pelo ponto médio entre $\omega$ e $\mathbf{x}$ e que é ortogonal a esse segmento contém todos os centros das circunferências que passam por esses dois pontos. Vamos denotar essa reta por $r_{\alpha}$. Na figura A.1, os círculos tracejados indicam as possíveis circunferências que passam por ambos os pontos, e os pequenos círculos vazados representam os centros dessas circunferências.

A expressão para a reta $r_{\alpha}$ é dada por

$$
r_{\alpha}: \frac{1}{2}(\omega+\mathbf{x})+\alpha(\omega-\mathbf{x})^{\perp}, \alpha \in \mathbb{R}
$$

A linha equipotencial na qual estamos interessados é um arco de uma das circunferências cujos centros se encontram sobre a reta $r_{\alpha}$ e que passam pelos pontos $\omega$ e x. Para determinarmos qual delas é a circunferência desejada, devemos levar em conta a transformação que leva o sistema de coordenadas $(x, y)$ em $\left(u_{\omega}(x, y), v_{\omega}(x, y)\right)$. Na sub-seção 2.6.2, comentamos que essa transformação é conforme. Logo, os ângulos são preservados. Como o sistema $(x, y)$ é ortogonal, temos que o sistema $\left(u_{\omega}, v_{\omega}\right)$ é ortogonal. Desta forma, como as equipotenciais são justamente as linhas $u_{\omega} \equiv$ cte e o círculo unitário é representado por $v_{\omega} \equiv \frac{1}{2}$, então a equipotencial cruza o círculo unitário em $\omega$ perpendicularmente, isto é, seus vetores tangentes serão ortogonais. 


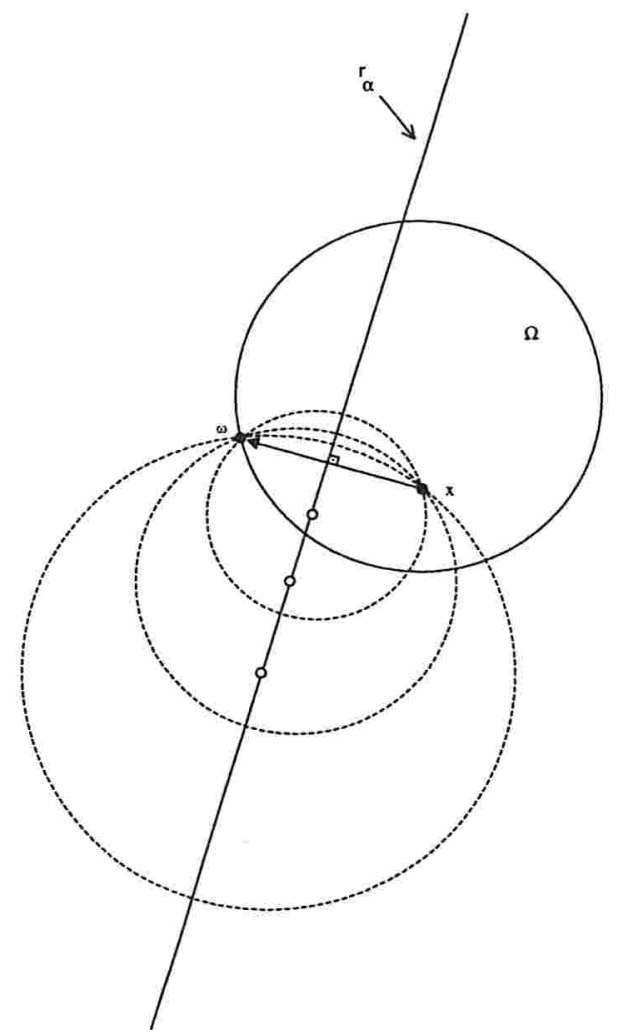

Figura A.1: Reta $r_{\alpha}$ e círculos que passam por $\omega$ e $\mathbf{x}$

Desta forma, um vetor tangente ao círculo unitário $\omega$ será normal à circunferência da qual a linha equipotencial faz parte. Um vetor que satisfaz essa condição é $\omega^{\perp}$. Assim, a reta orientada por $\omega^{\perp}$ e que passa por $\omega$, a qual denotaremos por $r_{\beta}$, passa pelo centro da circunferência que possui a equipotencial, conforme a figura A.2.

Podemos representar $r_{\beta}$ pela expressão

$$
r_{\beta}: \omega+\beta \omega^{\perp}, \beta \in \mathbb{R}
$$

O centro da circunferência será dado, portanto, pelo encontro das retas $r_{\alpha}$ e $r_{\beta}$ :

$$
\begin{gathered}
r_{\alpha}=r_{\beta} \Longrightarrow \\
\Longrightarrow \frac{1}{2}(\omega+\mathbf{x})+\alpha(\omega-\mathbf{x})^{\perp}=\omega+\beta \omega^{\perp}
\end{gathered}
$$

Fazendo o produto interno de ambos os lados de A.3 com $(\omega-\mathbf{x})$, teremos: 


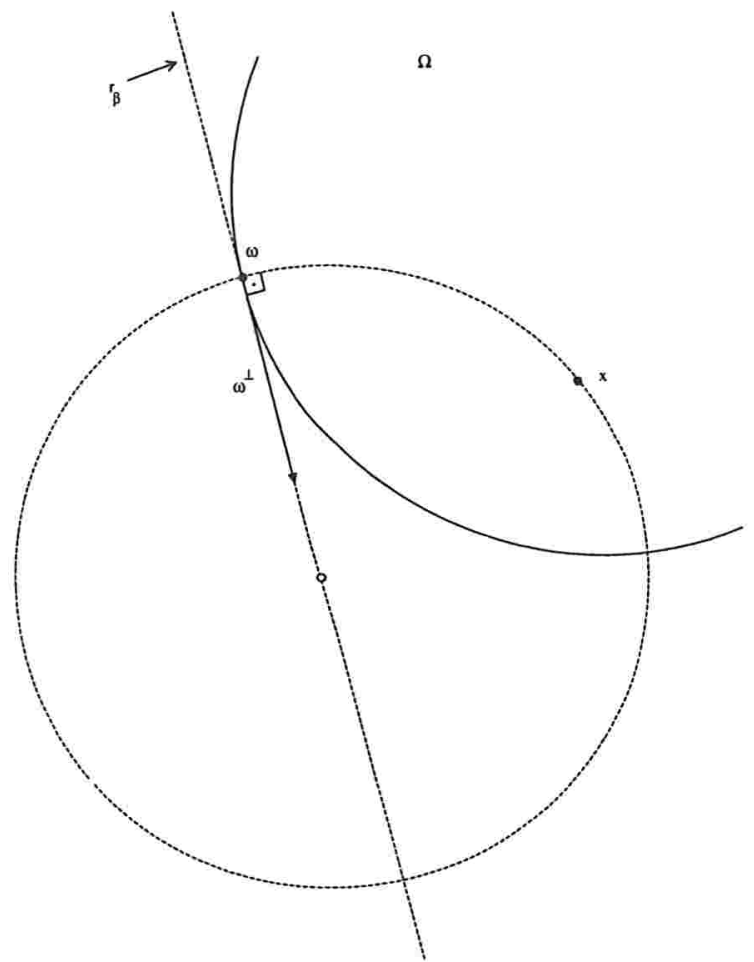

Figura A.2: Reta $r_{\beta}$

$$
\frac{1}{2}(\omega+\mathbf{x}) \cdot(\omega-\mathbf{x})+\alpha \underbrace{(\omega-\mathbf{x})^{\perp} \cdot(\omega-\mathbf{x})}_{=0}=\omega \cdot(\omega-\mathbf{x})+\beta \omega^{\perp} \cdot(\omega-\mathbf{x})
$$

Usando a propriedade distributiva do produto interno e o fato de que $(\omega-\mathbf{x})^{\perp}=\omega^{\perp}-\mathbf{x}^{\perp}$, temos:

$$
\begin{gathered}
\frac{1}{2}(\omega \cdot \omega-\mathbf{x} \cdot \mathbf{x})=\omega \cdot \omega-\omega \cdot \mathbf{x}+\beta\left(-\omega^{\perp} \cdot \mathbf{x}\right) \Longrightarrow \\
\frac{1}{2}(\omega \cdot \omega-\mathbf{x} \cdot \mathbf{x})=\omega \cdot \omega-\omega \cdot \mathbf{x}+\beta\left(-\omega^{\perp} \cdot \mathbf{x}\right)
\end{gathered}
$$

Isolando o termo $\operatorname{com} \beta$ :

$$
-\frac{1}{2}(\omega \cdot \omega+\mathbf{x} \cdot \mathbf{x}+2 \omega \cdot \mathbf{x})=\beta\left(-\omega^{\perp} \cdot \mathbf{x}\right)
$$

No caso em que $\omega^{\perp} \cdot \mathrm{x}=0$, a equipotencial é a reta que passa por $\omega$ e $\mathbf{x}$ e, portanto, o ponto de fronteira procurado será o ponto diametralmente oposto ao dipolo. Assim, se 
$\omega^{\perp} \cdot \mathbf{x} \neq 0$, então:

$$
\beta=\frac{1}{2} \frac{\omega \cdot \omega+\mathbf{x} \cdot \mathbf{x}+2 \omega \cdot \mathbf{x}}{\omega^{\perp} \cdot \mathbf{x}}
$$

Levando em conta que $\|\omega-\mathbf{x}\|^{2}=\omega \cdot \omega+\mathbf{x} \cdot \mathbf{x}+2 \omega \cdot \mathbf{x}$, podemos escrever:

$$
\beta=\frac{1}{2} \frac{\|\omega-\mathbf{x}\|^{2}}{\omega^{\perp} \cdot \mathbf{x}}
$$

Com isso, o centro da circunferência da qual a linha equipotencial considerada faz parte será denotado por $\mathbf{x}^{c}$ e é dado pela expressão:

$$
\mathbf{x}^{c}(\mathbf{x}, \omega)=\omega+\frac{1}{2} \frac{\|\omega-\mathbf{x}\|^{2}}{\omega^{\perp} \cdot \mathbf{x}} \omega^{\perp}
$$

Passemos, agora, a determinar o ponto de interseç̧ão da equipotencial com o círculo unitário, $\mathrm{x}^{f}$. Vamos considerar a reta que passa pela origem e pelo $\mathrm{x}^{c}$, que denotaremos por $r_{\delta}$.

$$
r_{\delta}: \delta \mathbf{x}^{c}, \delta \in \mathbb{R}
$$

Como $\omega$ e $\mathrm{x}^{f}$ possuem o mesmo comprimento e estão sobre um círculo de centro em $\mathbf{x}^{c}$, a reta $r_{\delta}$ atua como a bissetriz do ângulo formado por $\omega \mathrm{e} \mathrm{x}^{f}$ e passa pelo ponto médio entre os dois (figura A.3).

Vamos denotar por $r_{\gamma}$ a reta que passa por $\mathbf{x}^{f}$ e $\omega$. Para expressarmos esta reta, ao invés de utilizaremos o vetor $\mathrm{x}^{f}-\omega$ para orientar a reta, vamos utilizar o vetor $\left(\mathrm{x}^{c}\right)^{\perp}$, pois isso elimina a presença de $\mathrm{x}^{f}$, que é o ponto que queremos determinar. Assim, $r_{\gamma}$ é dado por

$$
r_{\gamma}: \omega+\gamma\left(\mathbf{x}^{c}\right)^{\perp}, \gamma \in \mathbb{R}
$$

O ponto médio entre $\mathbf{x}^{f}$ e $\omega$ é o encontro de $r_{\delta} \operatorname{com} r_{\gamma}$ :

$$
\begin{gathered}
r_{\delta}=r_{\gamma} \Longrightarrow \\
\delta \mathbf{x}^{c}=\omega+\gamma\left(\mathbf{x}^{c}\right)^{\perp}
\end{gathered}
$$

Fazendo o produto interno de ambos os lados de A.12 com $\mathrm{x}^{c}$, teremos:

$$
\delta \mathbf{x}^{c} \cdot \mathbf{x}^{c}=\omega \cdot \mathbf{x}^{c}+\gamma \underbrace{\left(\mathbf{x}^{c}\right)^{\perp} \cdot \mathbf{x}^{c}}_{=0} \Longrightarrow
$$




\section{Referências Bibliográficas}

[1] AMATO, Marcelo Britto Passos. et al Regional pressure volume curves by electrical impedance tomography in a model of acute lung injury. American Journal of Respiratory and Critical Care Medicine, 2000, 28:178-183.

[2] AMATO, Marcelo Britto Passos (coordenador). Novas Estratégias em Ventilação Artificial: Diagnóstico e Prevenção do Barotrauma / Biotrauma através da Tomografia por Impedância Elétrica (TIE). Projeto Temático apresentado para a FAPESP. Março, 2001.

[3] AVIS, N.J. BARBER, D.C. Image reconstruction using non-adjacent drive configurations. Physiol. Meas. 15 (1994) A153-A160.

[4] BARBER, David. Quantification in impedance imaging. Clin. Phys. Physiol. Meas., 1990, Vol. 11, Suppl. A, 45-56.

[5] BARBER, David. BROWN, Brian. Applied Potential Tomography. J. Phys. E: Sci. Instrum. Vol. 17, pp. 723-733, 1984.

[6] BARBER, Davida, BROWN, Brian. Recent developments in applied potential tomography. Amsterdan S. Bacharach ed., Nijhoff, editor, Information Processing in Medical Imaging, 106-121, 1986.

[7] BARBER, David. BROWN, Brian. FREESTON, Ian. United States Patent No. 4,617,939. Junho, 1985.

[8] BEVILACQUA, Joyce da Silva. YOSHIKAWA, Roberto Masaishi Santos. Interpolated Data in Condutivity Domain Reconstruction: Comparison between Fourier and Cubic Spline Techniques. 17th International Congress of Mechanical Engineerging, São Paulo, 2003. 
[9] CALDERÓN, A.P. On an inverse boundary value problem. Seminar on Numerical Analysis and its Applications to Continuum Physics. Sociedade Brasileira de Matemática, Rio de Janeiro, 1980.

[10] CHEREPENIN, V. KARPOV, A. KORJENEVSKY, A. KORNIENKO, V. KUSTIASOV, Y. MAZALETSKAYA A. MAZOUROV D. Preliminary static EIT images of the thorax in health and disease. Physiol. Meas. 23 (2002) 33-41.

[11] CORMACK, Allan M. Early Two-Diomensional Reconstruction and Recent Topics stemming from it. Nobel Lecture, 1979.

[12] FAES, T.J.C. MEIJ, H.A. van der. MUNCK, J.C. de. HEETHAAK, R.M. The electric resistivity of human tissues (100 $\mathrm{Hz}-10 \mathrm{MHz})$ : a meta analysis of review studies. Physiol. Meas. 20 (1999), R1-R10.

[13] GILIOLI, Antônio. Equações diferenciais parciais elíticas. 10o. Colóquio Brasileiro de Matemática.

[14] GREITZ, Torgny. Presentation Speech, Nobel Prize in Physiology or Medicine 1979. http://www.nobel.se/medicine/laureates/1979

[15] HERMAN, Gabor. Image Reconstruction from Projections. The Fundamentals of Computerized Tomography. Academic Press, New York, 1980.

[16] HOUNSFIELD, Godfrey N. Computed Medical Imaging. Nobel Lecture, 1979.

[17] JAIN, Anil K. Fundamentals of Digital Image Processing. Prentice-Hall, 1989.

[18] KELLOG, Oliver Dimon. Foundations of Potential Theory. Dover, New York, 1954.

[19] MOLINA, Nelson Antonio Vanegas. LIMA, Raul Gonzalez. Redução de Erro Numérico no Filtro Estendido de Kalman Aplicado à Tomografia por Impedância Elétrica. Dissertação de Mestrado, Departamento de Engenharia Mecânica, Escola Politécnica da Universidade de São Paulo, 2002.

[20] REITZ, John. MILFORD, Frederick. CHRISTY, Robert. Fundamentos da Teoria Eletromagnética. Ed. Campus, Rio de Janeiro, 1991.

[21] SANTOSA, Fadil. VOGELIUS, Michael. A Backprojection Algorithm for Electrical Impedance Imaging. SIAM Journal of Applied Mathematics. Vol. 50, no. 1, pp. 216-243. 
[22] SOBRINHO, João Batista Borges. AMATO, Marcelo Britto Passos. BARBAS, Carmen Silvia Valente. CARVALHO, Carlos Roberto Ribeiro de. PEEP e Recrutamento Pulmonar. Ventilação Mecânica, Vol. II, Série Clínicas Brasileiras de Medicina Intensiva, Ano 5, Volume 9, 2000, 79-105.

[23] SOMERSALO, Erkki. CHENEY, Margaret. ISAACSON, David. Existence and Uniqueness for Electrode Models for Electric Current Computed Tomography. SIAM Journal of Applied Mathematics. Vol. 52, no. 4, pp. 1023-1040. 


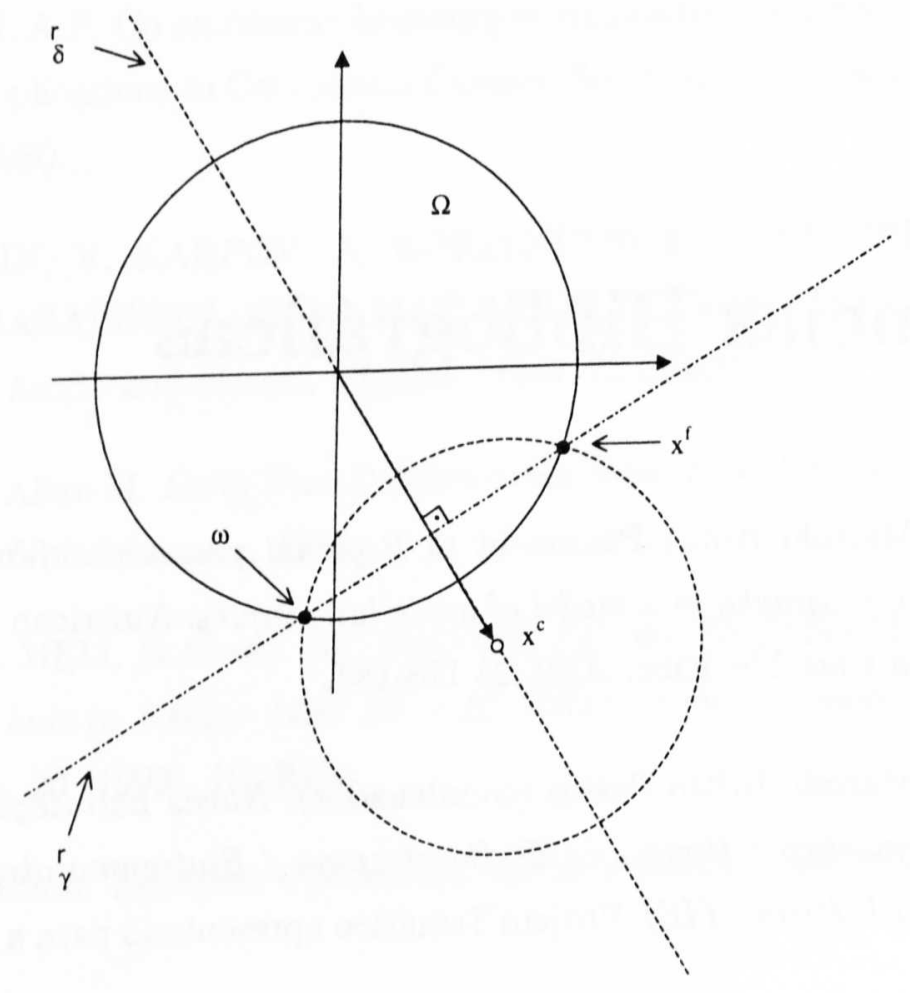

Figura A.3: Retas $r_{\gamma}$ e $r_{\delta}$

$$
\begin{gathered}
\Longrightarrow \delta\left\|\mathbf{x}^{c}\right\|^{2}=\omega \cdot \mathbf{x}^{c} \Longrightarrow \\
\Longrightarrow \delta=\frac{\omega \cdot \mathbf{x}^{c}}{\left\|\mathbf{x}^{c}\right\|^{2}}
\end{gathered}
$$

Substituindo A.13 em A.10, podemos encontrar o ponto médio e escrever:

$$
\frac{1}{2}\left(\omega+\mathbf{x}^{f}\right)=\frac{\omega \cdot \mathbf{x}^{c}}{\left\|\mathbf{x}^{c}\right\|^{2}} \mathbf{x}^{c}
$$

e, portanto,

$$
\mathbf{x}^{f}=2 \frac{\omega \cdot \mathbf{x}^{c}}{\left\|\mathbf{x}^{c}\right\|^{2}} \mathbf{x}^{c}-\omega
$$

Essa expressão será usada no algoritmo de BackProjection para determinarmos o ponto de fronteira de mesmo potencial do ponto $\mathrm{x}$ relativamente ao dipolo $\omega$. 